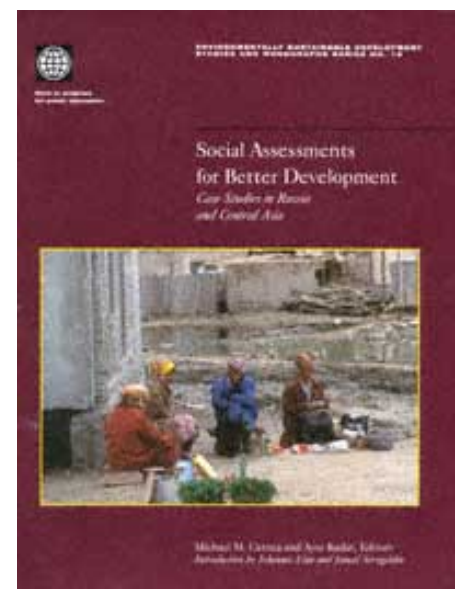

\title{
Social Assessments for Better Development
}




\section{Social Assessments for Better Development}

\section{ESD Proceedings Series}

1 Culture and Development in Africa: Proceedings of an International Conference (also in French)

2 Valuing the Environment: Proceedings of the First Annual International Conference on Environmentally Sustainable Development

3 Overcoming Global Hunger: Proceedings of a Conference on Actions to Reduce Hunger Worldwide

4 Traditional Knowledge and Sustainable Development: Proceedings of a Conference

5 The Human Face of the Urban Environment: A Report to the Development Community

6 The Human Face of the Urban Environment: Proceedings of the Second Annual World Bank Conference on Environmentally Sustainable Development

7 The Business of Sustainable Cities: Public-Private Partnerships for Creative Technical and Institutional Solutions

8 Enabling Sustainable Community Development

9 Sustainable Financing Mechanisms for Coral Reef Conservation: Proceedings of a Workshop

10 Effective Financing of Environmentally Sustainable Development: Proceedings of the Third Annual World Bank Conference on Environmentally Sustainable Development

11 Servicing Innovative Financing of Environmentally Sustainable Development

12 Ethics and Spiritual Values: Promoting Environmentally Sustainable Development

13 The Self and the Other: Sustainability and Self-Empowerment

14 Meeting the Challenges of Population, Environment, and Resources: The Costs of Inaction

15 Rural Well-being: From Vision to Action (forthcoming)

ESD Studies and Monographs (formerly Occasional Paper) Series

1 The Contribution of People's Participation: Evidence from 121 Rural Water Supply Projects

2 Making Development Sustainable: From Concepts to Action

3 Sociology, Anthropology, and Development: An Annotated Bibliography of World Bank Publications 19751993

4 The World Bank's Strategy for Reducing Poverty and Hunger: A Report to the Development Community

5 Sustainability and the Wealth of Nations: First Steps in an Ongoing Journey 


\section{Social Assessments for Better Development}

6 Social Organization and Development Anthropology: The 1995 Malinowski Award Lecture

7 Confronting Crisis: A Summary of Household Responses to Poverty and Vulnerability in Four Poor Urban Communities (also in French and Spanish)

8 Confronting Crisis: A Comparative Study of Household Responses to Poverty and Vulnerability in Four Poor Urban Communities

9 Guidelines for Integrated Coastal Zone Management

(continued on the inside back cover)

Social Assessments for Better Development

Case Studies in Russia and Central Asia

Environmentally Sustainable Development Studies and Monographs Series No. 16

Michael M. Cernea and Ayse Kudat, Editors

Introduction by Johannes Linn and Ismail Serageldin

The World Bank

Washington, D. C.

Copyright@ 1997

The International Bank for Reconstruction

and Development/THE WORLD BANK

1818 H Street, N.W.

Washington, D.C. 20433, U.S.A.

All rights reserved

Manufactured in the United States of America

First printing June 1997

This report has been prepared by the staff of the World Bank. The judgments expressed do not necessarily reflect the views of the Board of Executive Directors or of the governments they represent.

Cover photo by Curt Carnemark. Women street vendors in Uzbekistan.

\section{Library of Congress Cataloging-in-Publication Data}

Social assessments for better development : case studies in Russia and

Central Asia / Michael M. Cernea and Ayse Kudat, editors ; with an introduction by Johannes Linn and Ismail Serageldin.

p. cm.-(Environmentally sustainable development studies

and monographs series ; no. 16)

Includes bibliographical references.

ISBN 0-8213-3906-0

1. Asia, Central—Social conditions-Case studies. 2. Asia, 
Central-Economic conditions-Case studies. 3. Economic development projects—Asia, Central—Case studies. 4. Coal trade—Russia (Federation)—Case studies. I. Cernea, Michael M. II. Kudat, Ayse. III. Series.

HN670.22.A8S63 1997

306'.0958- $\mathrm{dc} 21$

97-18483

CIP

The text and the cover are printed on recycled paper, with a flood aqueous coating on the cover.

\section{CONTENTS}

A Word from the Editors

Acknowledgments

Contributors

Introduction

Johannes Linn and Ismail Serageldin

Part 1

Conceptual, Methodological, and Operational Issues

1

Social Analysis for Investment Projects: Rationale, Content, and Methods

Michael M. Cernea and Ayse Kudat

Recent Experiences with Social Assessments

A Bit of Not-So-Smooth History

The Rationale for Social Analysis in Projects

The Content of Social Analysis for Projects

Methodology of Social Assessments

Sharing Findings with Stakeholders

Costs of Social Analysis

Conclusion

Notes

References

2

The Direct Operational Relevance of Social Assessments

Jonathan C. Brown

Social Assessments and Policy Reform $\underline{\text { link }}$

$\underline{\text { link }}$

$\underline{\text { link }}$

$\underline{\text { link }}$

$\underline{\text { link }}$

$\underline{\text { link }}$

$\underline{\text { link }}$

$\underline{\text { link }}$

$\underline{\text { link }}$

link

$\underline{\text { link }}$

$\underline{\text { link }}$

link

$\underline{\text { link }}$

$\underline{\text { link }}$

$\underline{\text { link }}$

$\underline{\text { link }}$

$\underline{\text { link }}$ 
Social Assessments in Sector Work $\underline{\text { link }}$

Social Assessments and Investment Lending $\underline{\text { link }}$

Social Assessments and Emergency and Post-Conflict Lending $\underline{\text { link }}$

Social Assessments in the World Bank: The Current Situation $\underline{\text { link }}$

Part 2 link

Social Assessment Case Studies

3

Shaping the Future of Baku's Water Supply

$\underline{\text { link }}$

Ayse Kudat and Ahmed Musayev

Responding to a Water Supply Crisis $\underline{\text { link }}$

Initiating a Social Assessment $\underline{\text { link }}$

Conceptual Framework for the Social Assessment link

Incorporating Social Analysis and Participation into Project $\underline{\text { link }}$

Design

Key Findings of the Social Assessment $\underline{\text { link }}$

Implications for Project Design link

Notes $\underline{\text { link }}$

References $\underline{\text { link }}$

4 link

Restructuring Russia's Coal Sector

Ayse Kudat, Vadim Borisov, and Bulent Ozbilgin

Coal Industry Background $\underline{\text { link }}$

Social Assessment: Objectives and Methodology link

Social Assessment: Issues, Findings, and Recommendations $\underline{\text { link }}$

Annex $4.1 \quad \underline{\text { link }}$

Sampling Method

Notes $\underline{\text { link }}$

References $\underline{\text { link }}$

5 link

Responding to Needs in Uzbekistan's Aral Sea Region

Ayse Kudat, Arustan Zholdasov, Alisher Ilkhamov, and Janis

Bernstein

Country and Project Background $\underline{\text { link }}$

Conceptual Framework for Needs Assessments 쓰

Uzbekistan Needs Assessment $\underline{\text { link }}$ 
Needs Assessment Findings

$\underline{\text { link }}$

Project Implications

link

Annex 5.1

$\underline{\text { link }}$

Summary Findings of the Uzbekistan Water Supply and

Sanitation Social Assessments

Annex 5.2

link

Household Survey Data

Notes

$\underline{\text { link }}$

References

$\underline{\text { link }}$

6

$\underline{\text { link }}$

Improving Lives through Kazakstan's Water, Sanitation, and

Health Project

Stan Peabody, Janis Bernstein, Leonid Gurevich, Irina Malkova, S.I. Ospanov, Rita Cestti, and Ayse Kudat

Why a Social Assessment?

$\underline{\text { link }}$

Social Assessment Objectives and Methodology

$\underline{\text { link }}$

Key Findings

link

Project Implications

$\underline{\text { link }}$

Notes

$\underline{\text { link }}$

7

$\underline{\text { link }}$

Strengthening Ashgabat's Urban Transport System

Ayse Kudat, Stan Peabody, Ovezdurdy B. Muhammetberdiev, and Klaus Moeltner

Main Findings

$\underline{\text { link }}$

Project Implications

$\underline{\text { link }}$

Notes

$\underline{\text { link }}$

8

$\underline{\text { link }}$

Rehabilitating the Kyrgyz Republic's Power and District Heating

Services

Eugen Finkel and Helen Garcia

Patterns of Household Energy Use

$\underline{\text { link }}$

Implications for the Design of a Social Safety Net

$\underline{\text { link }}$

Targeting Subsidies

link

Notes

$\underline{\text { link }}$

9

$\underline{\text { link }}$

Overcoming the Ravages of Tajikistan's Civil War 
John S. Schoerberlein-Engel

Historical Background

$\underline{\text { link }}$

Political Context

$\underline{\text { link }}$

New Geopolitical Situation

$\underline{\text { link }}$

Social Mechanisms for Overcoming the Effects of Civil War $\underline{\text { link }}$

Conclusion

$\underline{\text { link }}$

Notes

$\underline{\text { link }}$

A SUMMARY OF THIS VOLUME IS AVAILABLE IN RUSSIAN. TO OBTAIN A COPY WRITE TO: AYSE KUDAT, THE WORLD BANK, 1818 H St., N.W., Rm. H8-015, WASHINGTON, D.C.20433, U.S.A. 


\section{Содиальный анализ}

\section{для улучшения проектов развития}

(на примере России и Средней Азии)

\section{Содержание}

Предисловие редакторов іх

Прнзнательности хі

Авторы $\quad$ xiii

Введение хvіi

Йоханнес Аинм и Исмаил Серагельдин

Часть 1 Конџептуальные, методологические и операџионные вопросы 1

1 Соџиальный анализ инвестиџионных проектов: обоснование, содержание и методы 3

Майкл Чернеа и Айше Кудат

Опьт социального анализа в просктах развития 4

Немного "шероховатой" истории 5

Обоснование соџиального анализа 7

Содержание соџиального анализа 8

Методология социального анализа 11

Обсужденис выводов с яаннтересованными сторонами 14

Затраты на проведение содиального анализа 16

Краткие выводы 17

Примсчания 17

Библиография 18

2 Прямая связь соџиального анализа и операџионной работы 21 Джонатан К. Браун

Соџиальный анализ и рефюрмирование политики 22

Соџиальный анализ при проведении отраслевых исследований 25

Социальный анализ и инвестиџионное кредитованис 26

Соџиальный анализ и крсдитование чрезвычайных и восстановительных работ

Соџиальный анализ в работе Всемирного банка: текущая ситуаџия 30 


\section{Social Assessments for Better Development}

Часть 2 Практические примеры проведения соџиального анализа.

3 Модернизаџия системы водоснабжения города Баку

35

Aйме Кудат, Ахмед Мусајев

Ответ на кризис водоснабжсния 35

Начальная фаза соџиального анализа 36

Конџептуальная схема социального аналияа

Включение социального анализа и участия заинтсресованных сторон в структуру проекта

Основные выводы соџиального анализа

43

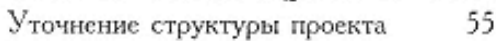

Примечания 59

Библиография 61

4 Структурная перестройка угольной отрасли России

Айше Кудат, Вадим Борисов и Булент Озбилгин

Состояние угольной отрасли 63

Содиальньй анализ: песли и методология 69

Соџиальный анализ: проблемы, выводы и рекомендаџии 71

Приложение 4.1 Метод выборки 102

Примечания 104

Библиография 107

5 Ответ на нужды населения Приаралья (Узбекистан) 109

Айме Кудат, Арустан Жолдасов, Алищер Ильхамов и Джанис Бернстайн

Общие сведения о стране и проекте 109

Кондептуальная схема анализа нужд насслсния

111

Анализ нужд насслсния Узбекистана

Выводы анализа нужд населения

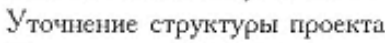

114

\section{Узбекистане 128}

Приложение 5.2 Данные обследования домашних хозяйств

Примечания 137

Библиография 138

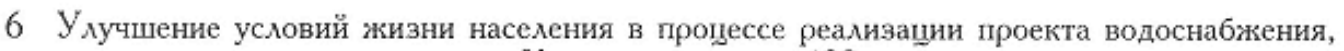
канализации и здравоохранения в Казахстане

Стэн Пибоди, Джанис Бернстайн, Леонид Гуревич, Ирина Малкова, С. И. Оспанов,

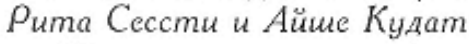

Почему соџиальный анализ?

Џели и методология соџиального аналнза

Основные выводы 142

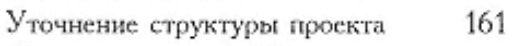

Примечания 162 
7 Укрепление системы городского транспорта Ашгабата

165

Айше Кудат, Стэн Пибоди, Овездурды Мухамметбердыев и Клаус Мёльтнер

Основные выводы 167

У точнение структуры проекта 182

Примечания 185

8 Восстановление системы теплоэнергоснабжения Кыргызской Республики

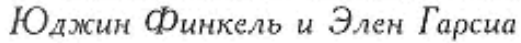

Параметры энергопотребления в жилиџно-коммунальном секторе

Уточнение требований к системе сопиальной защиты населения

187

Адресные субсидии 196

Примечания 197

9 Преодоление последствий гражданской войны в Таджикистане

Джон С. Шёрберлайн-Энгель

Исторические предпосьлки 199

Политический контекст 200

Новая геополитическая ситуация 202

Соџиальныс механизмы преодоления последствий гражданской войны

Заключение 207

Примечания 207

последствий гражданской войны

ДЛЯ РУССКОЯЗЫЧНЫХ ЧИТАТЕАЕЙ СПЕЦИАЛЬНО ПОДГОТОВЛЕНА БРОШЮРА С КРАТКИМ ИЗАОЖЕНИЕМ НАСТОЯЩЕЙ ПУБЛИКАЦИИ НА РУССКОМ ЯЗЫКЕ. ДЛЯ ПОЛУЧЕНИЯ УКАЗАННОЙ БРОШЮРЫ ПО

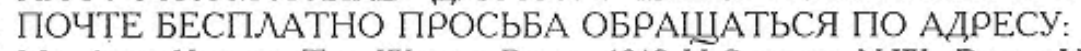
MS. AYSE KudAT, THE WORLD BANK, 1818 H STREeT, N.W., ROOM H8-015, WASHINGTON, DC 20433, U.S.A.

\section{A WORD FROM THE EDITORS}

With this volume we bring to public scrutiny and discussion one of several analytical tools, or research strategies, employed by sociologists and anthropologists to help shape the orientation, content, and ultimate impacts of development interventions financed by the World Bank. This strategy is commonly called social assessment-a term gradually gaining citizenship in the vocabulary of development.

The rise of sociology as a tool for inducing social change takes many forms; among these, action-oriented social analysis carried out on the ground is always essential. Such social analyses may employ different methods and techniques, serve different needs, and be completed at different junctures in the path and calendar of a development project. In this volume we present studies that were almost all carried out for the identification or preparation stage of the development projects in question. They respond, therefore, primarily to the kinds of initial data generation and beneficiary consultation and participation that are strongly needed at the outset of a program, which of course are different from data and analysis needs that arise at other project stages.

Part 1 of the volume is devoted to the general issues - those of a conceptual, methodological, and operational nature-that surface in carrying out social assessments. The first chapter is written by the book's editors, from the perspective of the specialist who conceives and actually does the social analysis. The chapter examines the relevance of social assessments to a development institution such as the World Bank. It argues that social analysis is an indispensable tool for guiding development investments and facilitating the participation of key social actors in project definition and execution. This realization, however, didn't come easy or smoothly to the Bank, and 


\section{Social Assessments for Better Development}

some elements of the checkered history of introducing social analysis are reviewed. Further, this chapter describes the methods applied, and the dilemmas that had to be resolved, while carrying out the assessment studies included in this book.

The second chapter of part 1 is written from a totally different perspective: the perspective of an institutional manager, by training not a sociologist, who commissioned these social assessments for a set of projects that his division manages. Significantly, he asked that the social assessments be carried out not only jointly with, but even slightly before, the habitual economic and technical analyses for the intended projects. He takes the perspective of the user. His chapter discusses whether or not the social assessments represented value added and whether they enhanced the quality at entry of the new projects. Since the value of social assessments is still doubted by some, and for philosophical or cost reasons they are still not generally practiced, the editors call this chapter in particular to the attention of those managers, government officials, and development practitioners who have not yet introduced social assessments as a routine part of preparing investment projects.

Part 2 of the book contains the actual social assessment studies, in a version summarized and adapted to the format of this book. The studies in Azerbaijan, Kazakstan, Kyrgyz Republic, Turkmenistan, and Uzbekistan were done for projects supporting social services-

water supply, transportation, heating, and the like-in cities or rural areas. The study on Russia was carried out for a different type of intervention - a major sectorwide restructuring program for Russia's coal industry —and required particularly intensive sociological work on the ground. The last study, on Tajikistan, differs from the more usual social assessment as it was constrained by circumstances of the civil war in that country, which precluded extensive, systematic empirical field work. The reader will find a contextual political-cultural analysis, but will also notice the absence of quantitative survey data. (The civil conflict did not, in fact, allow the full preparation and start of the project for which the social assessment study was initiated.)

The social assessments in this volume were the first stage of a research process that has since continued with topical, in-depth studies. These studies are ongoing as this volume is being published and will continue during project implementation. More details about this research process are contained in the first chapter.

In publishing this volume we would like to extend an invitation to all those interested in employing sociological tools for development programs to comment on the present studies and share their views and field experiences with us. This will intensify the intellectual exchange on the crafting of effective research strategies and will build further on the cumulative effort to sharpen the cognitive and operational value of social analysis in development.

\section{ACKNOWLEDGMENTS}

The authors and editors together dedicate this volume to the many people who helped us directly in the countries in which our field research was carried out, people whose knowledge, needs, pains, and practical proposals made relevant and urgent the social assessments in this volume. We see these social assessments as a way of giving voice to these people — both as individuals and as collectivities - and as an opportunity for making their presence felt in project preparation.

We also dedicate this book to James D. Wolfensohn, in recognition of his explicit support for the use of social assessments in the Bank's work. From the beginning of his tenure as president of the World Bank, he has encouraged the use of social assessments as a tool to enhance project quality and has demanded that the Bank's social specialists produce more of them, as part of the Bank's normal business practice. In presiding over the presentation of social assessments to the Bank's Board, he has regularly highlighted the social dimensions of the 


\section{Social Assessments for Better Development}

Bank's activities. His promotion of the social development agenda has made a big difference.

Many people have contributed to making this volume possible. In the World Bank our special thanks go to Johannes Linn and Ismail Serageldin, who mobilized their vice presidencies to work on these assessments and provided resources for publishing the book. We are grateful to Anand K. Seth and Anil Sood for their role in supporting the introduction of social assessments in the Europe and Central Asia region of the World Bank, especially early on, when social assessments were considered controversial.

The task managers responsible for the World Bank investment projects for which the social assessments discussed in this book were carried out have been true innovators and have encouraged the introduction of such assessments in their projects: the late Bob Wildeman (Azerbaijan), Tony Garvey, Lea Donaldson, and Piotr Krzyzanowski (Kazakstan), Salem Ouahes (Kyrgyz Republic), David Craig (Russia Sectoral Restructuring program), Jean-Charles Crochet (Tajikistan), Yusupha Crookes (Turkmenistan), and Roger Batstone (Uzbekistan). So did, very tenaciously, their division chief, Jonathan Brown, convincingly demonstrating in the process that resources can be found when there is a will to take a novel path. Further, each country study included in this volume acknowledges in a special note those who contributed to that chapter. Andrew Steer, director of the Environment Department, and in particular Gloria Davis and the Social Policy and Resettlement Division, have strongly advocated, sometimes in the face of entrenched reluctance, the introduction of social assessments in the Bank and have produced guidelines and dissemination notes on their objectives and experiences. Costas Michalopoulos made a major contribution to the Russia coal sector work, as did Marc Blanc in integrating social assessments into project work. Claude Blanchi chaired the participation Steering Committee for the Europe and Central Asia region, which helped institutionalize the social assessment work patterns. Thus this volume is the product of many people's collective efforts.

Funding to carry out the social assessments came from Jonathan Brown's division and from

the Bank's special Fund for Innovative Approaches in Human and Social Development, managed by Aubrey Williams with obvious sensitivity to priority needs. A generous grant from the Swiss government, facilitated by the Swiss Executive Director to the World Bank, Jean-Daniel Gerber, and adviser Pietro Veglio, provided needed financial and institutional support for the creation of an organized Network of Social Scientists in Azerbaijan and Central Asia, for work on development-related research.

Special thanks go to Alicia Hetzner and Virginia D. Hitchcock, who coordinated the editorial work and production of this volume, and to Mark Bock and Glenn McGrath of American Writing Corporation, who desktopped it. Thanks also go to Bulent Ozbilgin, Loral Patchen, Nezahat Özmen, Beaulah Noble, Clare Fleming, Gracie Ochieng, Eileen Monnin-Kirby, Anju Sachdeva, and several other colleagues, who did the numerous and unavoidable chores demanded by the publication of any such book.

\section{CONTRIBUTORS.}

Janis Bernstein is an environmental specialist with a master's degree in urban and regional planning and fifteen years of experience in environmental management and urban development. She has worked for the World Bank's central urban and environment departments on operational assignments, policy-related tasks, training in urban environmental planning and management, pollution control and waste management, national environmental action planning, and the preparation of social assessments for infrastructure projects in Central Asia. Her World Bank-published works include The Urban Challenge in National Environmental Strategies (1995); Land Use Considerations in Urban Environmental Management (1994); and Alternative Approaches to Pollution Control and Waste Management: Regulatory and Economic Instruments (1993). 


\section{Social Assessments for Better Development}

Vadim Borisov holds a Ph.D. in sociology from the Moscow Engineering Institute and has received further training in sociological research at the University of Surrey in the United Kingdom. He has coordinated British and Russian collaboration for quantitative studies of labor relations restructuring in Russian enterprises. At the time of the World Bank study reported on in this volume, Mr. Borisov was Director of the Institute for Comparative Labor Relations Research in Moscow, Russia. His writings include Workers' Movement in Russia (with Simon Clarke and Peter Fairbrother, Edward Elgar Publishers, 1995) and focus on worker movements, labor relations, trade unions, and employment problems.

Jonathan C. Brown is a graduate of Yale College, Harvard Business School, and the School of Communications at the University of Pennsylvania. He joined the Bank in 1973 and has since held operational and managerial positions in the Africa and Europe and Central Asia regions in a wide variety of sectors including agriculture, energy, environment, infrastructure, and human resources. He has pioneered the World Bank's work in social assessments and public participation, reorganization of state companies, reconstruction activities after civil strife and natural disasters, policy dialogue, donor coordination, relations with NGOs, and implementation of projects in new member countries. He has assisted governments, corporations, and NGOs in building up project implementation capacity. He is currently Division Chief of the Bank's unit providing policy advice and investment lending in infrastructure, energy, and environment to the Russian Federation, Azerbaijan, Kazakstan, Kyrgyz Republic, Tajikistan, Turkmenistan, and Uzbekistan.

Michael M. Cernea holds a Ph.D. in sociology and social philosophy. He joined the World Bank in 1974 as its first in-house sociologist, and for the past fifteen years (1981-96) has been the Bank's Senior Adviser for Sociology and Social Policy. He has been responsible for defining the social content of many World Bank policies, including those on population resettlement, indigenous people, NGOs, forestry, and water resources. He has also carried out field research and social analysis for numerous development projects in Algeria, China, India, Mexico,

Moldova, Pakistan, Senegal, Tanzania, Thailand, Togo, Ukraine, and Yemen. A visiting scholar at Harvard University in 1989-90 and member of the Romanian Academy of Sciences (elected in 1991), he also received the Solon T. Kimbal Prize of the American Anthropological Association (1988) and the Bronislaw Malinowski Award (1995) for his work on applying social sciences to development. Among his many books and studies on development theory, social change, resettlement, and the environment are Putting People First: Sociological Variables in Development (Oxford University Press, 1985 and 1991); Anthropological Approaches to Resettlement: Policy, Practice, Theory (edited with Scott E. Guggenheim, Westview, 1993); and Resettlement and Development Studies (NRCR, Nanjing, China, 1996).

Rita Cestti is a Ph.D. candidate in economics with a B.S. in civil engineering (Universidad Católica del Perú) and an M.S. in engineering administration (George Washington University). She is a consultant in the resources unit of the World Bank, dealing with water issues in countries of the Middle East and North Africa, and on related projects in Indonesia, Kazakstan, and Uzbekistan. She has worked for the International Irrigation Management Institute as an economist for a study in Egypt, and for the Organization of American States as a trainer.

Eugen Finkel holds a Ph.D. in Sociology (University of Heidelberg, Germany) and has been consultant to World Bank projects in Belize, Bolivia, Chile, Côte d'Ivoire, and Peru, working on issues of rural and urban poverty, decentralization and community participation, and indigenous people and refugees. As adviser to the Bolivian Ministry of Mining and Metallurgy during the Emergency Social Fund to Bolivia, he worked on reorganization and divestiture of state-owned mining enterprises and on employment generation for disemployed mining workers. Currently, he works on social assessment issues in the social unit of the World Bank for Central Asian and Middle East countries. His areas of expertise include energy, housing, and community services. 


\section{Social Assessments for Better Development}

Helen Garcia is a policy research specialist with extensive experience in household survey design analysis. She holds an M.S. in urban and regional planning (University of the Philippines) and a diploma in rural development studies (University of Sussex). She has ten years of experience in survey design, statistical database development and analysis, field staff training, and preparation of user handbooks and training manuals. She has been involved in World Bank-sponsored studies in China, Indonesia, Mexico, and Pakistan (Living Standards Measurement and Household Energy surveys).

Leonid Gurevich holds a doctor of sciences degree from the Kazak State University, where he studied history and sociology. He has served as Chair of the Sociology Department at the State Academy of Management in Kazakstan. At the time of the study, he was Director of the Giller Institute for Social Science Research in Almaty, which specializes in market research studies. He is currently General Director of Bilesim International of Kazakstan, a private social research firm.

Alisher Ilkhamov is a social researcher with a candidate of sciences degree in philosophy from Tashkent State University, where he has served as Senior Scientific Researcher in the Sociology Department. He has also served as Head of the Sociological Department at the Institute of Social and Political Problems. He is founder and Director of the social science research center, Expert, based in Tashkent. He has published numerous articles on political issues, ethnic relations, and economic challenges in Central Asia.

Ayse Kudat is Principal Environmental Sociologist and manages the social unit in the World Bank Regional Vice Presidencies for the Middle East and North Africa and for Europe and Central Asia. Previously she worked for several years in the Bank's Economic Development Institute (EDI). She holds a B.A. in economics, a graduate diploma in social anthropology (Oxford University), and a Ph.D. in social relations (Harvard University), with a major in political science (MIT). She has twelve years of experience in rural development, with a particular focus on

infrastructure. Her urban experience extends over sixteen years and includes work on water supply and sanitation, solid waste management, housing, transportation, and energy. Before joining the Bank in 1989, she served in many positions: Director of Berlin Science Center, Comparative Social Science Institute; Coordinator of the 1985 UN Conference on Women; Professor of Social Sciences at the Middle Eastern Technical University; and Senior Program Officer in the UN Center for Human Settlements. Her numerous published works include Fictive Kinship (Akyildiz, 1974); International Labor Migration (Berlin Science Center, 1976); Participatory Labor Management (Kent University Press, 1978); Women and Human Settlements Development (United Nations Center for Human Settlements, Nairobi, 1989); and Women's Presence in Arab Higher Education: Linking School, Labor Markets and Social Roles (EDI, 1990).

Johannes Linn studied law at the Free University, Berlin, Germany. He received his training as an economist at Oxford University, England (B.A.) and at Cornell University (Ph.D.). After joining the World Bank in 1973, he worked for nine years in the Bank's research wing on issues of urban development policy. In 1987-88 Mr. Linn was Staff Director of World Development Report 1988, which dealt principally with issues of public finance and development. He subsequently served as Senior Economic Adviser on the Bank's economic staff, as Director of the International Economics Department, and as Director of the Country Economics Department. In 1991 he was appointed the World Bank's Vice President for Financial Policy and Resource Mobilization. Since January 1996 he holds the position of World Bank Vice President for Europe and Central Asia. His published works include Cities in the Developing World: Policies for their Equitable and Efficient Growth (1983); (with Roy Bahl) Urban Public Finance in Developing Countries (1992); and (with Amarendra Bhattacharya) Trade and Industrial Policy in the Developing Countries of East Asia.

Irina Malkova studied sociology and history at the Kazak State University. She is Project Manager and Deputy Director of the Giller Institute in Almaty, Kazakstan. She has fifteen years of experience in applied sociology and 


\section{Social Assessments for Better Development}

analytical work, including focus group coordination for the Moscow-based firm Validata. She specializes in public opinion polling, focus groups, and market research. Her work has been published in Kazakstan and abroad.

Klaus Moeltner has worked at the World Bank as an Urban and Environmental Specialist. He holds an M.S. in environmental planning and engineering (University for Agriculture and Forestry, Vienna, Austria), an M.A. in international policy studies (Monterey Institute of International Studies, Monterey, California), and a diploma in business (French Chamber of Commerce, Paris). He is currently studying for a Ph.D. at the University of Washington, Seattle, Washington.

Ovezdurdy B. Muhammetberdiev is Professor of Sociology at the Turkmen State University and has been involved in many applied social research projects in Turkmenistan. In addition to the World Bank-assisted Urban Transport Project, he has worked on the social assessment of a water supply project in Turkmenistan. He is coordinator of the Turkmen Social Science Network and author of many books. He is also founder and Director of a nongovernmental organization focusing on female education.

Ahmed Musayev is Professor at the Institute of Social Management and Political Sciences at the University of Baku. He has participated in numerous social assessments in Azerbaijan, including poverty assessment and reconstruction studies. He specializes in urban development and is an expert on Georgia. He is the director of a unique applied social science center and manages large-scale survey research. He has been a leading figure in the establishment of the Azerbaijan Social Science Center. His articles have been published in several academic journals.

S.I. Ospanov is Professor of Sociology at the Kazak Academy of Sciences. He has extensive experience in both qualitative and quantitative analysis. In addition to the ethnographic studies he undertook for the social assessments reported in this volume, he recently worked on

farmer participation in an irrigation project and conducted a rural credit survey in Kazkstan. His writings cover a broad range of sociological and cultural issues.

Bulent Ozbilgin has a B.S. in textile engineering and an M.B.A. in corporate finance and international business finance. He has strong computer skills that include the use of several statistics and visual effects packages and programming languages. He is experienced in quantitative research and analysis, survey preparation, and management of manufacturing systems.

Stan Peabody is a Bank Social Scientist with a Ph.D. in sociology (Washington University, St. Louis) and an M.P.S. in international agricultural and rural development (Cornell University). An Applied Sociologist, he has twenty years of development experience working with bilateral and international agencies as an independent consultant and staff member. He specializes in natural resource management, particularly irrigation. He applies his interdisciplinary approach and multidisciplinary skills in various settings, articulating social and institutional issues and their operational implications, such as the interface between public sector agencies and clients, the private sector, and nongovernmental organizations. He currently manages the Aral Sea Program 6 on Land and Water Management in the Upper Watersheds, working with four multidisciplinary country teams. He has written many reports based on field studies, as well as social components of many projects and programs.

John S. Schoerberlein-Engel is Director of the Forum for Central Asian Studies at Harvard University, which he was instrumental in founding in 1993. He received his Ph.D. in anthropology from Harvard University. His research focuses on questions of identity and community organization among the Islamic peoples of Central Asia and neighboring regions. He has taught courses in the anthropology, history, and politics of the region as Lecturer on Central Asian Studies at Harvard University since 1993. His current projects include a study of the impact of national state formation on identity in Central Asia, investigation of the community-level institutions that effect 


\title{
Social Assessments for Better Development
}

violent intercommunal conflicts in the region, and research on means of promoting community-level participation in economic reform.

Ismail Serageldin is Vice President for Environmentally and Socially Sustainable Development at the World Bank, and Chairman of the Consultative Group on International Agricultural Research. Since joining the Bank in 1972, he has designed and managed a broad array of poverty-focused projects in developing countries. Educated at Cairo University and Harvard University, where he earned a Ph.D., he is an internationally published author on economic development, human resource issues, the environment, architecture, urbanism, the Arab world, Islam, and culture. His most recent books include Nurturing Development (World Bank, 1995); Making Development Sustainable: From Concepts to Action (edited, with Andrew Steer, World Bank, 1994); Culture and Development in Africa: Proceedings of an International Conference (edited, with June Taboroff, World Bank, 1994); and Development Partners: Aid and Cooperation in the 1990s (Swedish International Development Authority, 1993).

Arustan Zholdasov holds a diploma in trade union organization (Higher Trade Union School, Leningrad), a postgraduate diploma in sociology (Moscow State University), and is a candidate for a degree in history (Academy of Sciences, Karakalpakstan, Uzbekistan). Among his most recent works are studies of water supply and sanitation, poverty, and regional development. He works as a social research specialist at the Expert Sociological Center, based in Tashkent. He is also a leader of the Uzbek Social Science Network.

\section{INTRODUCTION}

\author{
Johannes Linn and Ismail Serageldin
}

Promoting socially and environmentally sustainable development to reduce poverty is the overarching objective of the World Bank's work. The present volume profoundly reflects this objective and lifts the curtain on a little-known part of the Bank's efforts to achieve it. Indeed, the book reveals to the interested reader the knowledge-generation process in which the Bank engages as a means to better understand and support the intended client populations.

This volume is a significant collective endeavor. It was prepared and edited by two leading social scientists at the Bank: Michael M. Cernea, who as Senior Adviser in the Bank's central Vice Presidency for Environmentally and Socially Sustainable Development has provided overall guidance for introducing social analysis in the Bank's policy and lending work, and Ayse Kudat, who as manager of the Social Unit in the Europe and Central Asia Region of the Bank led the work for producing the assessments included in this book and wrote several of them. Together with several other Bank analysts, many social scientists from the countries concerned were involved in the joint field investigations reported in this book. They have benefited from the cooperation of many Bank project managers and local people and officials.

As part of the Bank's process of gathering information and using knowledge, social analysis of newly proposed projects has in recent years become increasingly recognized, relevant, and employed. It harmoniously complements the Bank's traditional economic and technical analyses and its environmental assessments.

Since 1991 fifteen countries that were part of the Soviet Union have become independent states, and members of the World Bank. The Bank has been asked by all its member countries to provide substantial assistance to the socioeconomic transition and restructuring of these newly independent states. Doing so, however, is an extraordinarily complex endeavor. One of the main impediments the Bank confronts is scarce knowledge-about the populations of these countries; their social and institutional structures, cultures, and traditions; and the status of their physical infrastructure and social services. 


\section{Social Assessments for Better Development}

To overcome these obstacles, and in its role as a knowledge-based organization, the Bank is engaged in a vast effort of learning and generating knowledge-particularly social and economic knowledge-directly relevant to the projects and programs to be undertaken in these countries. This knowledge is indispensable for identifying priorities and designing the content, institutional structures, and delivery mechanisms of development interventions. We have learned that without proper analysis of social contexts and structures, and without involving local populations in defining short-term priorities and long-term goals, the services offered by a Bank-financed operation may not be ones that the intended users find beneficial or that they will help sustain. We also know well from past

Johannes Linn is the Vice President for Europe and Central Asia, and Ismail Serageldin is the Vice President for Environmentally and Socially Sustainable Development at the World Bank.

and painful experiences that failure to take into account how local institutions work, what communities need, and how their participation is incorporated has been a frequent cause of failure in many development projects.

This volume is a product of two parts of the Bank-the Vice Presidency for European and Central Asian Countries and the Vice Presidency for Environmentally and Socially Sustainable Development—and of our cooperation with research institutions from several transition countries-Azerbaijan, Kazakstan, Kyrgyz Republic, Russia, Tajikistan, Turkmenistan, and Uzbekistan-however, it still comprises only a small selection from a much larger Bank experience with social assessments.

The social assessments reported in this book have been essential in supporting major Bank activities in policy reform and investment lending in Central Asia, Azerbaijan, and Russia. They have been germane to the formulation of individual projects and also pivotal mechanisms in the process of consulting key stakeholders in these countries. They helped elaborate social mobilization strategies and, when needed, social mitigation strategies. Altogether, these social assessments have had a major impact, first on the design, and now on the implementation of the World Bank's activities in support of those societies whose economies are in transition. This theme is documented further in this volume. Not only the World Bank, but also governments and local specialists-for whom, in many cases, such studies were a novelty-have embraced the assessments' recommendations and are applying them.

We commend this book to the attention of development practitioners and researchers elsewhere who wish to undertake comparable studies. By assembling these assessments in one volume we hope that those engaged in the reform process will see the usefulness of social analysis in making both policy reform and investment lending more relevant to the people being helped and more efficient for the national and international financial institutions involved. Everywhere, development programs require the generation of both knowledge for understanding and knowledge for action. We are convinced that such social assessments are a flexible and effective instrument for acquiring both kinds of knowledge. For the Bank itself, this volume is a step on its determined way toward more systematic consideration of the social dimensions of development.

During the fifty years the World Bank has been in existence, the development paradigm has evolved from an almost exclusive focus on bricks-and-mortar and on physical capital to a more people-centered approach that recognizes human and social capital as critical factors in sustainable development. We hope that this new and powerful paradigm will be embraced, enriched, and applied by increasing numbers of countries, governments, institutions, and development practitioners. 


\title{
PART 1- \\ CONCEPTUAL, METHODOLOGICAL, AND OPERATIONAL ISSUES
}

\section{1 - \\ Social Analysis for Investment Projects: Rationale, Content, and Methods}

\author{
Michael M. Cernea and Ayse Kudat
}

Decades ago Robert K. Merton signaled a paradox adversely affecting the progress of sociological field investigations on communities. Merton called public attention to the strange situation created at that time, when the research procedures employed in the largescale collection of observational and interview data in communities were among the most widely practiced, but the least codified. Merton (1947) wrote that

a deep silence cloaks many of the concrete problems found in field work. Thus, social anthropologists have recently been indicted for the limited extent to which they have been articulate about their field techniques. 1 The experiences of field workers have not commonly been codified and set forth for all to read. As a consequence, these procedures have largely remained private skills, passed on through examples and word-of-mouth to a limited number of apprentices.

Since this observation was made, tens of volumes about community-focused research procedures have been written, effectively overcoming the discrepancy signaled by Merton. Yet today, history repeats itself. A comparable paradox is now detectable in the applied social research carried out in the service of development programs.

Much innovative applied research has been undertaken in recent years for the preparation, design, ex ante evaluation, or implementation of various types of development programs. The expansion and growing recognition of such applied sociological and anthropological research, particularly in developing countries, are in themselves major successes. Such research adds value to development programs and gains public credit for the noneconomic social sciences.

Even though academic social research has long since overcome the paradox signaled by Merton, the relatively new domain of applied, development-related sociological research still suffers-even in this decade!-from a comparable teething problem. Applied research methods and action-research procedures in the domain of development-related research-are insufficiently described, inspected, discussed, and codified. True, there are some remarkable examples to the contrary - some guidelines for social analysis in development projects-but they remain isolated (ADB 1991; ODA 1995; FAO 1992; RISN China 1995).

Some of the methods and procedures used in applied work are old and traditional; others are invented on the job, elaborated more by creative happenstance than by cold inference from textbooks on methodology. This creativity comes in response to the pressing demands raised by change programs. The drawback, however, is that such contributions of applied researchers risk being forgotten and unreplicated-if they are not discussed, codified, and retested. The happy accident of a development researcher's inspiration and innovation must be recorded and repeated if it is to become part of development's tool kit of systematized approaches. 


\section{Social Assessments for Better Development}

Codifying and disseminating these procedures further is indispensable for cumulative disciplinary endeavor.

The present volume contributes to this crucial discussion of significant recent experiences. It brings to the reader a set of rather unusual social studies - unusual both for the countries where they took place and for the World Bank, which initiated them. This chapter, therefore, will introduce the conceptual and methodological issues involved in conceiving and executing such social assessments.

First, we will briefly explore the background of social assessments in the World Bank and their utility for development work. Second, we will outline the rationale, content, and functions of social analysis in investment projects. Third, we will discuss some methodological questions that had to be confronted and solved in the cases described in this volume. And in conclusion, we will outline the perspectives of using social analysis increasingly in the future as a tool in social development work.

\section{Recent Experiences with Social Assessments}

When in the early 1990s the republics that had been part of the Soviet Union established themselves as independent states and applied for World Bank membership, the Bank was invited to assist their economic reforms and support the reorganization of their production sectors and social services. Yet the socioeconomic context in which the new programs had to be introduced was virtually unknown to the Bank. This was, and still is, a societal context unlike the one typical for most of the Bank's usual borrowing countries. The structure of these societies, their institutions, their cultures, the wishes of their populations-all were unknown elements.

Deciphering this unfamiliar social map quickly was, therefore critical. For this reason, the Bank's sociologists and social anthropologists were called upon to get involved and the initiative was taken to carry out social assessments. In a number of cases those segments of the reforming societies in which immediate project interventions were contemplated were placed under the magnifying lens of social analysis.

This volume includes some of the products of this effort: several social assessment studies carried out recently in Russia and the Central Asian republics, selected from a significantly larger number of such social assessments initiated by the World Bank.2 The studies themselves were done jointly by Bank and local social scientists. This compendium, including studies done in Azerbaijan, Kazakstan, the Kyrgyz Republic, Russia, Uzbekistan, Tajikistan, and Turkmenistan, will allow the public in general, and socioeconomic specialists in particular, to see significant examples of operationally oriented social analyses. The reader can also learn from this volume how such analyses had an impact on project design, as well as on policy dialogue between governments, the Bank, and various social actors with a stake in specific projects.

As these field studies got under way, it soon became obvious - both to Bank insiders and to the respective country governments - that their importance could be even greater than initially anticipated: their contribution was usable by the affected people themselves, not only by governments or the World Bank. These social studies plunged into little-known areas and social contexts as diverse as, for instance, Turkmenistan's urban transport and its beneficiaries, drinking water supply issues in Azerbaijan, coal miners and restructuring of the coal industry in Russia, and many other complex domains. These social analyses were conceived as action research, attempting not only to understand the problems but also to find feasible solutions.

Remarkably, it was the social research process itself, not only its specific findings, that added a healthy dose of realism to the institution's grasp of the contradictory situations in these new member countries. And for a number of individual projects under preparation, the social assessments became a functional complement to the traditional economic analyses and to the technical studies that are typical for Bank approaches anywhere.

This better grasp of a new and rapidly changing social reality, and the synergy derived from linking social and economic analyses, tangibly helped all those working at different levels on these projects-from the project task 


\section{Social Assessments for Better Development}

managers to the World Bank's president and vice presidents,

and to the Bank's board of executive directors, who had to approve the projects and the loans. In the countries themselves, these studies helped both local and central government officials. Most of these actors-including some initial skeptics and doubters-welcomed these social assessments.

Mentioning the skeptics or doubters of social analysis is directly relevant to the argument that not just this chapter, but the entire volume makes. The argument for doing social analysis can win only if social assessments can prove their value added. We have learned that these assessments must pay their own way in the coin of incremental bodies of knowledge and operational recommendations, clearly additional to the knowledge supplied by other analytical tools (for example, by economic or technical analysis).

Yet the necessity of social assessments is not recognized by many development practitioners. A brief look into recent history may therefore help clarify both how we arrived at the present stage and what the future holds for social analysis in projects.

\section{A Bit of Not-So-Smooth History.}

In introducing this volume, it is appropriate to note that social assessments are not a totally new element in World Bank activities, emerging only in the 1990s. In fact, social analysis has been not only advocated but also practiced in various forms, albeit insufficiently, for years (Cernea 1979, 1985a). The studies in this volume have benefited from, and build on, those prior experiences. But the road to the current stage has not been free of obstacles, resistance, and even direct opposition to social analysis.

During the 1960s and 1970s the Bank's internal guidelines for project preparation and appraisal contained mandatory requirements for doing economic, financial, technical, and even commercial preproject analyses. But social analysis was not required by those guidelines and was not even mentioned in them. Simply put, postwar development aid efforts had no tradition of employing social analysis; indeed, there was little, if any, institutional awareness about the need for-and likely benefits from—carrying out such analysis.

However, as poverty alleviation policies took hold in the mid- and late 1970s, and as lessons from failures caused by socially and culturally inadequate projects kept accumulating, the need for changed approaches was more readily recognized. Internal advocacy in the Bank in support of introducing normative guidelines for social analysis made significant progress. In 1980 the Bank adopted its first explicit guidelines, referring to social issues in projects causing involuntary population displacement and resettlement (World Bank 1980; Cernea 1988, 1995). Shortly thereafter, in 1982, guidelines for projects affecting indigenous populations were adopted (World Bank 1982). Each set of guidelines, however, was directed to only one or another (limited) class of projects-those entailing resettlement or those in areas with aboriginal groups-while the need for social analysis was general, present in virtually all projects, in one form or another.

After significant internal debate and advocacy, the view that internal guidelines have to be modified gained momentum in the Bank, and in 1984 the Bank's management approved new guidelines for the appraisal process. These guidelines were written jointly by Bank economists, sociologists, and technical experts (World Bank 1984). The 1984 guidelines required, for the first time in the Bank's history, that a sociological appraisal be carried out as part of the Bank's assessment of project feasibility, jointly with the economic, technical, and institutional analysis of projects at appraisal stage. $\underline{3}$

That was a major step forward. The new operational procedures defined sociological appraisal substantively and comprehensively. They made clear to staff that the social analysis of projects must explicitly focus on four sets of basic social variables and must use the knowledge so collected for adjusting project content and implementation 


\section{Social Assessments for Better Development}

strategy. The four sets of social dimensions to be considered in project preparation and appraisal were defined as follows (World Bank 1984):

The sociocultural and demographic characteristics of local populations in the project area, including the groups likely to be adversely affected

The social organization of productive activities and of social services in the project area

The cultural acceptability of the project design and its compatibility with the needs of the intended beneficiaries

The social strategy for project implementation and operation, involving beneficiaries' participation.

These four sets of dimensions are crucial to most development interventions and-even in hindsight thirteen years later-they appear to have been well identified as essential.

After the adoption of the new appraisal guidelines, social analysis was used in a gradually increasing number of projects. It helped improve their design and adequacy to local social contexts. Nonetheless, compliance with the new guidelines was far from general and the institutional mechanisms for absorbing them in practice were insufficient. Simply placing new rules on the Bank's internal guidebooks proved to be not enough for triggering the profound changes in staff work patterns that meeting the new demands implied. In retrospect, it appears that, at that time, the Bank at large wasn't yet equipped as an institution, in terms of either staffing or corporate culture, to absorb and consistently implement the sociological analysis methods as project-making and evaluation tools.

Enough experience, however, was gradually gained to answer the key questions: Does good social analysis lead to better projects? Has social analysis made a difference in general development outcomes and tangible economic benefits?

Most emphatically, yes. Substantiating evidence has been constantly accumulating. For instance, an independent study of fifty-seven Bank-financed projects (Kottak 1985) provided quantified proof that social analysis has been associated with higher rates of return from projects. The study hypothesized that if projects' sociocultural fit at appraisal is higher, they will be associated on average with a higher rate of return at completion. Conversely, initial sociocultural misfit will be associated on average with a lower rate of return. The study's findings showed that enhanced sociocultural fit was indeed associated with economic payoff: the average rate of return at audit time was 18.3 percent for projects found to be socioculturally compatible; in contrast, projects with weak or no social analysis at appraisal, which were incompatible socioculturally, had average returns of only 8.6 percent.

But it is also appropriate to note that, despite persuasive evidence about the benefits of social assessment, many projects that are assisted by the Bank or by bilateral European donors still do not use social assessment as a preparation or evaluation tool (Bierschenk, Elwert, Kohnert 1994; World Bank 1996).4 Unfortunately, this is even more often the case for the vast majority of programs financed domestically in developing countries, depriving those programs of a source of knowledge and strength.

What explains this?

Inertia and the influence of traditional technocratic or econocentric approaches, lack of awareness about the power of social investigation, traditional mind-sets or obsolete development paradigms-all have combined, in various proportions, to retard for a while the practical acceptance of social analysis as one of the basic instruments in the crafting of development programs. 


\section{Social Assessments for Better Development}

In fact, in 1994, when the Bank's 1984 appraisal guidelines were converted into a new format, the provisions for social and institutional appraisal were inadvertently left out from the new guideline format (World Bank 1994a, b, c), which was yet another procedural and practical setback.

To compensate for that, however, the Bank's central division for social policy took an important initiative: as part of its support to operations the division, in May 1994, issued informal guidelines for social assessment, to be carried out during project preparation and appraisal (Davis 1994). It also provided sustained support to a number of task managers for introducing such social assessments in their projects. This was the beginning of a revival of social analysis in Bank work, part of which is reflected in this volume.

Significant in this respect is the somehow surprised reaction of a senior Bank economist when he perceived what the contribution of these new social assessments is and can be (three of these are included in this volume: the studies on Azerbaijan, Russia, and Turkmenistan). In an internal memorandum, he wrote:

[These studies] very persuasively demonstrated that social assessments could be a powerful tool in resolving some of the real world problems faced by the Bank's borrowing countries. The examples of the social assessments carried out for the Askabad Urban Transport project, Baku Water Supply project and Russia Coal sector loan amply illustrate that involving the affected groups, asking them for their views and ideas, articulating these views in a systematic way to the authorities and dialoging with them for taking appropriate actions was a practical way of using the social assessments and participatory approaches. These assessments can complement the conventional market demand surveys and affordability studies carried out in the context of project preparation and provide insights that are not normally available through the existing tools — particularly for reaching the poor segments of the population and incorporating their own perspectives. In some cases these insights could provide more cost-effective solutions than are prescribed by the experts.

Thus, through demonstrations, advocacy, seminars, and the like, and through painful lessons from the failures of socially inadequate projects, the confidence in social assessments as a tool for project analysis and design has gradually increased, preparing the way for regular use of this instrument.

In light of this not-so-smooth history, it is important to distill some conceptual and methodological lessons from the successful experiences of the social assessments in this volume and that of similar social analyses. The next section will therefore discuss the conceptual rationale for social analysis in investment projects.

\section{The Rationale for Social Analysis in Projects}

Projects come in all forms, sites, and sectors: from health care systems in Asia to urban infrastructure in Latin America, from irrigation in the Maghreb to reforestation in Pakistan, from education in Africa to reducing environmental pollution in Thailand, to combating AIDS in Uganda, to structural adjustment reforms, and to projects for building hydropower dams, curing cataract blindness, or improving family planning and nutrition. More than 1,800 Bank-assisted projects are proceeding today, with Bank financing of $\$ 150$ billion and total investment costs of some $\$ 500$ billion. Despite this enormous diversity, some basic common features exist. Every project is a social process, not just a commercial investment, and brings into play an array of social actors. Yet for a long time the conventional approach was to treat projects as only economic or technical interventions. How to identify the social dimensions of projects and how to craft projects as interventions for purposive social change - these were not, and for the most part are still not part of any science taught in the academies. We had to invent and learn, in parallel with similar efforts of other colleagues elsewhere.

The need for good social analysis for development projects arises from the nature of the economic development process itself. Economic processes do not occur in a vacuum, but are always embedded in a social tapestry that affects their direction, face, shape, and outcomes (Barth 1996). In turn, people's economic behavior is generally 


\section{Social Assessments for Better Development}

determined not only by their economic rationality, profit-seeking, surrounding markets, or macroeconomic parameters, but also by a host of cultural variables. This is why adding social analysis to economic analysis can reveal both the potential for development in a specific context or locale and the means for realizing this potential in practice. In sum, the integration of economic, social, technical, and environmental analyses results in a consolidated knowledge that is distinctly more powerful in guiding project planning and execution than any of its separate parts used in isolation.

Another rationale for social analysis is that financially induced development interventions are planned programs for social development and social change, not just for economic growth. Social analysis, which brings to bear the conceptual and research techniques of noneconomic social science, is-and should be so employed-

the methodology for clarifying the social and behavioral mechanisms of development and change. These social and behavioral mechanisms are intrinsic to development and are commonly intertwined with the economic mechanisms of development. Therefore, these social mechanisms must be recognized and purposefully mobilized to achieve the objectives of development programs, similar to the ways in which the economic mechanisms are consciously harnessed, whenever feasible, to attain set development objectives.

To do this, the basic requirement for a project intervention is that the social fabric, the social context of the project, must be explained and understood. To accomplish this task, there is no substitute for social analysis.

The kind of developments we refer to in this book are induced, not spontaneous, and consist largely of deliberate restructuring and reorganization of major industries and public services. These restructuring developments are guided by a mix of knowledge and assumptions, labeled wholesale as policy, but a policy that is still insufficiently informed or tested. This is why additional knowledge through social analysis becomes essential and instrumental. While spontaneous development can only be observed and described by sociologists, an induced change is one that social scientists can influence, through knowledge and direct participation in the design of programs. Social scientists possess a body of professional knowledge - from sociology, anthropology, social psychology, political science-about social organization and cultural systems that is necessary and useful for designing and executing such programs effectively, with larger gains and fewer pains. $\underline{6}$

Further, social analysis must be employed to also help design the social goals and the social institutional scaffolding within which the project-financed physical technology is embedded and which support the project's economic goals. Paramount design goals are increased equity and poverty reduction through development. The design of social arrangements and of participatory implementation activities, including collective social action, is an indispensable proactive contribution to program design and program execution strategy. This contribution must be intrinsic to program generation and decisionmaking and integral to the development package itself.

In addition to designing for, and mobilizing, the constructive social mechanisms of development, social analysis must also confront the sometimes adverse social consequences of economic growth. When decisions are made to implement social policy reforms or programs, economic and financial analyses are clearly necessary to estimate costs and inform resource allocation. In turn, however, economic growth often has painful social costs. Therefore, when decisions are made to invest in economic growth, social risks and costs must be recognized in an equally unambiguous manner. This is yet another imperative for carrying out social analysis ex ante: to identify the social costs, risks, and benefits; define the social mitigations to be pursued; and factor in these elements in the program design.

For all these reasons social analysis is more than just instrumental: it is indispensable for increasing development effectiveness, including directly increasing the economic success of programs. Therefore, the sociological and anthropological knowledge required for and embodied in social research and analysis is not a luxury or a marginal add-on to inducing development, but is as necessary as economic analysis for designing and ascertaining the 


\section{Social Assessments for Better Development}

feasibility and adequate goal-directedness of development programs.

Based on this general knowledge, applied social research is called upon to answer specific practical questions. Obviously, the professional social analyst must also be ever aware of the limitations of the knowledge base, and must formulate recommendations with prudence and ethical responsibility.

\section{The Content of Social Analysis for Projects}

The content of social analysis is determined, in every case, by the variables relevant to a given project. But because there are many social variables that could influence project design and impact, social assessments must be selective and targeted. The extent and intensity of the assessments for different types of project interventions are determined at the initial review of the proposed operations.

Of course, in a normal course of events, carrying out a social assessment should be regarded primarily as the responsibility of the project owner, part and parcel of the feasibility studies and project preparation work. The Bank explains to project owners (the borrowing agencies) that social assessments are apt to help them primarily in such tasks as selection of the most appropriate project options, improvement in decisionmaking and in the quality of project design, and better understanding by ultimate beneficiaries of the proposed development initiatives. Yet quite often, when borrowing agencies are not equipped to do such assessments, the Bank provides advice and assistance for social assessments, as it provides assistance for other analytical and consultative procedures required for Bank-financed operations. In many situations, when local experience is limited, the Bank may take the initiative and start the social assessment jointly with local agencies, participating in the analysis of critical issues as necessary during the investment preparation process.

The social assessment is an indispensable part of the set of analyses (economic, $\underline{7}$ financial, $\underline{8}$ environmental, $\underline{9}$ technical) that the Bank requires for the projects it finances, and not a freestanding exercise or additional project report. Social assessments can enhance quality at entry, increase economic returns, and lay the groundwork for projects that have more impact and are more sustainable.

In project analysis and design the social assessments perform three specific functions:

To assess the social issues requiring project investments and identify the principal social actors (stakeholders) and their interaction

To design the social provisions needed in the project package to help achieve the project's economic, technical, and social goals and impacts

To formulate the social strategy for participatory implementation.

Together, these three elements support all stages of the project's cycle. Each is explained below.

\section{Assessment}

Development projects are interventions for social development, not only for economic growth. Therefore, the Bank supports early assessment of projects' distributional impacts in terms of differential access to income, productive assets, employment and services; promotes stakeholders' participation; pursues the strengthening of local institutional capacity for self-development; and aims at minimizing or mitigating, to the extent possible, adverse social impacts and risks. Social assessments, with the steps outlined below, are a means to these ends. 


\section{Social Assessments for Better Development}

A social assessment describes and explains the social fabric within which a project intervenes. The main content of the assessment at this initial stage is social mapping or diagnosis: defining the population involved by generating data on its key demographic characteristics, needs, and willingness to support the project. The social assessment elucidates the social issues that will have to be addressed by the proposed activity. Stakeholder analysis helps build on understanding of social diversity, reflects relevant gender and ethnic factors, recognizes indigenous groups or other vulnerable population segments, and identifies the structural reasons for their vulnerability. $\underline{10}$

Social analysis must be carried out in a participatory manner, with the researchers engaging the area population in the self-definition of needs, articulation of feasible solutions, and mobilization of locally available resources (for example, willingness to pay assessments).

\section{Design}

The findings of social analyses and public consultations are converted into social design provisions and incorporated in the project package, to complement its economic and technical provisions. This is essential for achieving the projects' goals and long-term social sustainability.

The social design of projects is that part of project formulation that explicitly translates general social policy concerns and locally identified needs into project-specific measures and sets out ways to accomplish them. Such measures include for instance, equitably distributing project benefits, reducing poverty, eliminating social exclusion, and increasing social cohesion. They may also include provisions for expansion of social services, human resource development,

and building of social capital. Social design also involves, when necessary, gender-specific provisions and the protection of indigenous and other vulnerable groups. Explicit social design is required, too, for strengthening local institutional capacity and in situations that require special social action plans, for example, assistance following a disaster or reconstruction in postwar societies.11 Mechanisms for feedback loops from area populations are also incorporated in project design.

Finally, the Bank requires that the social design of investment operations address the potential social risks of certain kinds of developments efforts. $\underline{12}$

Development projects and economic policies have social costs that must be recognized in a timely fashion in order to allocate counterbalancing resources and avoid cost externalization on affected populations. The forecasting of social costs, identification of at-risk groups, and determination of social mitigations to be pursued contribute equally to the social assessment, informing both project design and implementation. In addressing potential adverse impacts, the social analyst must favor preventive measures over mitigatory or compensatory measures, whenever feasible.

\section{Implementation.}

Implementing a development project must be seen as a social process, not as a sequence of administrative or technical decisions. For Bank-financed projects the borrower is expected to prepare an implementation plan that should include the participation of key stakeholders and spell out how the project's goals will be carried out. $\underline{13}$ Since government agencies alone cannot provide all that is required, it is crucial that the implementation strategy be formulated to encompass the roles of all principal stakeholders. The social strategy for implementation must therefore answer a fundamental question: How to mobilize and organize social action in order to translate project design into reality? Not all stakeholders can be expected to agree, and measures for building consensus and trust, resolving conflicts, and negotiating acceptable options are areas where social assessments can make substantive 


\section{Social Assessments for Better Development}

contributions to charting the social path for project execution. Finally, the implementation strategy must consider how to establish delivery mechanisms that people and institutions can manage effectively.

Social assessments can contribute to the design of implementation strategies by facilitating two-way information and communication between the project and its constituencies, developing awareness, determining what incentives maybe provided, and making recommendations for mobilizing nongovernmental organizations and local community organizations. The social assessment also can set the stage for beneficiaries' participation in monitoring early impacts during implementation, to help develop necessary adjustments while the project is being executed.

\section{Sectoral Social Assessments}

Beyond their value for project-specific planning and implementation, social assessments are a versatile analytical tool for certain nonlending activities that are part of a development agency's responsibilities, such as sector studies or the preparation of country assistance strategies. One such sectoral social assessment study is included in this volume - the assessment of social issues in the restructuring of Russia's coal mining industry. At the sectoral level social assessments are carried out to help understand the social context of sectoral priorities, the sector's social constraints and risks, and the social impacts of sectoral changes. We argue that social assessments are essential not only for discrete projects, but also in policy-based lending such as structural adjustment operations, economic reform in transition countries, or privatization operations, where the forecasting of short- and long-term impacts and the design of measures to mitigate adverse effects are indispensable. Of course, the methodologies and procedures for sectoral social assessments differ somewhat from those used in project-level assessments.

Of overriding importance in this discussion of the content and functions of social assessments is the role of the social scientist. Far from being engaged in such analyses as solely a data collector-supplier of static assessments- the

social scientist must actively help design the content of induced change and chart the action path for accomplishing it. It must be acknowledged, however, that social analysts are not infallible. In both our own and other development institutions errors in judgment have been made and misguided projects have been validated. Analysts have misassessed or mispredicted the behavior of populations involved. The analytical tools for social assessment — and the methods for translating the social knowledge that is gleaned into prescriptions for action-are still developing. Thus judgments must often be made with far-from-perfect social data, making errors sometimes unavoidable.

What is novel and noteworthy, despite such errors, is that as a result of social analysts' competence and work, new variables are now taken into account in project planning — variables anchored in social and cultural organization. These variables are factored in precisely because social specialists have started to inhabit the project-crafting process at its core, not just its periphery.

Applied and development sociologists must produce two categories of knowledge: knowledge for understanding and knowledge for action (Scott and Shore 1979), because they must help explain and help prescribe. Our experience confirms that knowledge for action is a relatively distinct, specific body of knowledge, but one that taken alone can be utterly pedestrian, narrow, and ultimately deceptive. Knowledge for action is effective only if it is based on, and incremental to, knowledge for understanding — precious though it may be, it is rarely self-standing over the long haul. These distinct categories of knowledge, both indispensable, result from different cognitive itineraries. It is part and parcel of the applied social scientist's job not just to apply established knowledge, but to create and recreate both kinds of knowledge in each assignment. The work of the applied sociologist is thus no less demanding than that of the teacher or academic researcher, since it is expected to meet at least these three explicit requirements: it must be based on a coherent analytical framework; must be predictive 


\section{Social Assessments for Better Development}

and be prescriptive as well (Serageldin 1994).

\section{Methodology of Social Assessments}

Social assessment of development projects should be seen not as a single, one-shot investigation technique, but as a process of research and consultations that employs a variety of methods and research procedures. These include: quantifiable sample surveys, focus groups, individual interviews, in-depth case studies, reanalysis of data from past research or of statistical/demographic information, participatory processes such as stakeholder workshops, needs assessments or poverty assessments, affordability assessments, family budgets, and so on. The choice of technique, or combination of techniques, depends on the given local circumstances of the study, the nature of the topic, financial resources, and time available, among other factors.

A variety of such methods was used for each social assessment in this volume - and in different combinations in almost every case. This will become apparent in a preview of the book's chapters. It is important first, however, to indicate here the basic, common methodological principles that guided our applied research and the preparation of these assessments. These were:

Analytical focus on the main social actors of each process (and project)

Linkage with the economic, technical, and environmental analyses

Action-research orientation, aiming at findings that can guide targeted activities, and making the research itself part of the improvement program

Integration of quantitative and qualitative research instruments, avoiding a reliance on sample surveys alone

Reliance on local knowledge with an effort to discover it

Use of participatory approaches in information collection and analysis

Strong postresearch communication effort for dissemination of research findings, to ensure that follow-up action is formulated with the participation of the local actors, findings define project content and boundaries of technical work and social assessment adequately informs the policy dialogue.

The Bank's work in Russia and Central Asia aims to support the fundamental transformation of the economies concerned. It thus has enormous social and political implications. But without the full support of the general public, and particularly of the key stakeholders, institutional and policy changes required to sustain either broad sectoral reforms or modest development projects such as local water supply could not have been put in place. The Bank wanted to learn, through social assessments, the real immediate needs of the local population, and what various groups of people stood to gain or lose from proposed projects and policy changes. It was therefore essential to find out the views of a range of stakeholders at an early stage in the dialogue between the Bank and the countries concerned.

The research teams that carried out systematic fact-finding efforts had the following common objectives:

Encourage intended beneficiaries to express their needs and preferences

Explore project measures designed to fit the needs of the beneficiary groups 


\section{Social Assessments for Better Development}

Identify in advance possible adverse social impacts that can be eliminated or mitigated with targeted countermeasures

Gauge people's perceptions concerning gains and losses and assess their implications

Propose measures to reduce resistance to changes required to sustain a reform program

Promote transparency and ensure that a broad range of civil society actors are involved in development efforts.

The emphasis on social actor analyses and on encouraging stakeholder participation in research interpretation is perhaps most critical. Involving a broad range of affected actors also distinguishes such social analysis in both breadth and depth, from what were called beneficiary assessments. For instance, the social assessments for the Baku Water Supply Project started with an analysis of a single group of potential beneficiaries of the project: households that are the major consumers of piped water. Earlier beneficiary analyses of the Bank water supply projects had also focused on this group, but rarely went beyond. The Baku social assessments, in contrast, attempted to analyze the behavior and expectations of other beneficiaries or users: industry, the private sector, and public institutions. And it also sought to capture the behaviors and expectations of the suppliers, both in the narrow sense of providing water-related services and in the broader sense of providing support to an overall economic reform agenda that would allow a sustainable institutional framework.

Some chapters in this volume present only an initial phase of a social assessment process for a project. This is done to draw attention to various aspects of the assessment process. In many cases the process is still continuing and thus a full description is not possible. That social assessments are part of a continuous process in project design and execution points to yet another difference between a typical beneficiary analysis and the social assessment approach. To illustrate the continuity in the social assessment process, let us focus on three of the social assessments presented in this volume.

The Baku Water Supply Project social assessment analyzes the stakes of a broad range of actors at the project design stage. During project implementation, however, a less rigorous but more project-focused social assessment is ongoing to facilitate the community education and public participation components of the project. During the project design stage, it was ascertained that unless the public gained a more realistic understanding of the value of water, sustainability of supply would not be enhanced, and cost recovery policies, leakage control and metering components of the project could not be implemented. Thus, during implementation a continuous social assessment is required to analyze how various stakeholders react to reform elements and how the public responds to education efforts launched by the media, the water agency, nongovernmental organizations, the academic community, the municipality, or the government.

The needs assessment presented for the Uzbekistan Water Supply, Sanitation, and Health Project started with an attempt to uncover community- and regional-specific needs, focusing primarily on rural areas and towns with a population of less than 20,000. Soon after its completion, a

new needs assessment was launched in large cities, through both quantitative surveys and focus group discussions with a broad range of stakeholders, such as users, suppliers, and policymakers. Subsequently, various detailed inquiries were made to learn more, for instance, about special issues relating to communities served by vendors. And, to address issues related to water standards, taste tolerance surveys were undertaken. In every instance surveys for the Uzbekistan project were initiated with focus group discussions, and after each systematic survey, results were discussed with a broad range of stakeholders. In particular, social assessment results were discussed extensively with the client water agency and follow-up research, consultation, and pilot implementation needs were jointly considered. The initial needs assessment was launched in November 1994, and the social assessment and consultation process is ongoing as of this writing, in early 1997. In the meantime, several pilot projects are 


\section{Social Assessments for Better Development}

being implemented and a social assessment is envisioned to assess their implications for the larger project.

The social assessment for the Russia Coal Sector Project was just one of several key inputs in a three-year process of multifaceted analysis, which included at least three components:

Economic analysis of the sector and its relationships with other sectors of Russia's economy

Technical analysis of current technological and productivity levels of coal production in Russia and, comparatively, in other coal producing countries

Environmental analysis of Russian coal enterprises on the physical environment (land, water, air) and of ways to soundly manage the various future impacts of the mining industry, as it emerges from the current restructuring process.

It is crucial to emphasize in this context how intimately intertwined social analysis can and must be with the other analytical tools, which have already won recognition as being indispensable for project preparation and appraisal. Social analysis is equally indispensable. Yet in current national and international practice it is still not recognized as essential, but is regarded rather as an innovation that remains optional. We hope that the examples provided in this volume - the real-life experience of effective social analysis that improves development interventions-will contribute to regularizing the social assessment, transforming it from a glamorous innovation into a routine tool.

Once a structured social assessment exercise was set in motion, the other analytical instruments (economic, technical, and environmental) reinforced the goals and the findings of the sociological analysis. Synergy between the various tools thus proved beneficial to each tool in itself, compounding the knowledge any one tool was able to send to the common effort of shaping the restructuring program. In the Russia coal project, for instance, the interrelated analyses became a significantly more systematic mechanism for incorporating the views of the various main stakeholders - not only the views of the affected communities and their residents (whether employed in the coal industry or not), but also of the wives, managers, economists, engineers, and other technical personnel-into the design of a sector program to reform the coal industry at large.

Given the critical importance of coal sector reform for Russia, it is now essential to sustain and continue the social assessment work throughout implementation of the reform. The Russian government has fully appreciated this and-perhaps a first occurrence in World Bank lending experience-has borrowed explicitly to fund continuous social assessment. A second baseline study for the social assessment has been completed recently and Russian social scientists, including some of the country's leading sociologists, are continuously assessing the unfolding impacts of the coal sector reform on affected communities.

Making, in turn, a self-assessment of our methods as presented in this volume, the editors and authors of this volume are keenly aware that the field assessments summarized here reflect only part of the arsenal of sociological research techniques available for doing social analysis in development programs. The options are always numerous, and the circumstances and resources that dictate which ones will be used vary from case to case. Choices must always be made realistically and tradeoffs must be accepted, however reluctantly. The

social assessments presented in these chapters are not meant as ultimate or rigid models to be followed: indeed, these very assessments might have been carried out more successfully with more experienced field investigators, for example, or with more time and resources. We want clearly to state our conviction that every specific situation demands sociological imagination, an original approach, a different combination of methods and procedures, tailored to the given issues and sets of actors. A fixed recipe is not being offered, but rather a demonstration which, we hope, will make evident that social assessments are feasible, entailing simple methods and lasting a relatively short time; and that such assessments can facilitate and enhance project quality, actor involvement, and 


\section{Social Assessments for Better Development}

implementation performance.

\section{Sharing Findings with Stakeholders}

A commitment to share social assessment results with the government, nongovernmental organizations, users, and suppliers of the services under consideration was an integral part of the assessment process. This poses various substantive and procedural questions concerning the assessments.

The social assessments presented in this volume were of a pioneering nature and had their limits, difficulties, and unanticipated turns. It was not always possible to estimate the full range of research requirements at the outset. The client governments were to give their blessing for an assessment process with which they were not fully familiar. In the Aral region of Kazakstan, for instance, what was started as a study of willingness to pay for a newly proposed water supply system, had to go into questions of potential large-scale population outmigration from the region.

The social assessments were undertaken in countries lacking a strong tradition of public consultation and participation. It was therefore questionable at the outset whether the client institutions would agree to set in motion a process with prior commitment to share results, at least with the most directly affected stakeholders. The social scientists working on the social assessments did not always have a full understanding of the range of stakeholders and the potential for consultation. Therefore, they were not always able to describe the consultative requirements. Each assessment basically served as a learning opportunity both for the social assessment experts and for the clients. In Uzbekistan, for instance, the assessment process started without a clear presentation to the client as to what might be expected from the results. However, as the first set of results became available and were shared, there was mutual enthusiasm to continue.

The extent to which nongovernmental organizations, the media, and the public can be informed or involved in the project is not always clear at the outset of the social assessment process. Therefore, close dialogue between the assessment team and the client is desirable. However, the assessment team did not always have a high profile within the Bank and was not assigned a key role in the project team. Although social development agenda has gained renewed importance in the Bank, partly because of the contributions of recent social assessments undertaken for Bank projects in many regions, putting people first in development practice still requires a concerted effort. In the meantime, the role assigned to social assessment in the Bank's work will continue to affect its acceptance among clients. However, pressures for democratization and transparency, along with an appreciation among policymakers of the need for public support, may well serve as the prime mover behind the conduct of social assessments. This was clearly evident, for example when the Turkmenistan government readily accepted the conduct of a social assessment, contributed substantially to preparation of their terms of reference; shared assessment results widely, including through the mass media; and acted upon the results, formulating policy and management reforms without waiting for Bank lending.

The commitment to share social assessment results publicly requires that the results be rigorous. More important, a quantitative and systematic social assessment depoliticizes its results and facilitates public debate.

The commitment to disseminate social assessment results requires that they be presented in a simple and practical manner with heavy reliance on visual modes of communications.

The practice in social assessments of relying heavily (ideally, exclusively) on local expertise and knowledge fits well with the process and participatory requirements of this kind of social analysis. It also grows out of the commitment to share and disseminate assessment results. Equally important, the need to produce social assessment results early in the project cycle - through the use of systematic, quantitative surveys as well as participatory tools such as focus group discussions-requires a local team fully familiar with the local social 


\section{Social Assessments for Better Development}

conditions and special issues of the sectors studied. Also, when social assessment is conducted by a country's own social science experts and nongovernmental organizations, it has greater credibility in the eyes of the public and avoids confrontation between the international agencies and local development institutions. The critical link between the success of projects and their demand-driven nature is increasingly appreciated. In this context, client ownership of the process of project preparation and implementation is as important as ownership of the project outputs. When social assessments are carried out locally, they can be sustained and replicated in the context of other development initiatives.

Several of the social assessments presented in this volume are carried out by local social science networks. These networks were established in late 1994 and were initially supported by the World Bank-financed fund aimed at facilitating innovative and participatory initiatives. By mid-1996 Swiss bilateral funding was made available to sustain the existing networks and to establish new ones. Currently, social science networks operate in Azerbaijan, Kazakstan, Turkmenistan, and Uzbekistan. Additional networks will be established in the Kyrgyz Republic and Tajikistan. Generally, each local network comprises representatives of the following types of institutions:

National academy of sciences (for example, the Uzbek Academy of Sciences)

Local academy of sciences (the Karakalpak Academy of Sciences)

Private social research firms

Nongovernmental organizations.

The president or vice president of each of these institutions is a member of the network. As the network moves from one task to another, researchers from these institutions are invited to participate and new institutions may be asked to join as members. The networks are voluntary associations; there are no fees for members. Once a network is established, an effort is made with the modest funds available to bring members together to discuss issues, approaches, and methodologies of common interest. The following examples illustrate how social science networks function.

In Uzbekistan a social science network was composed of the deputy president of the Uzbek Academy of Sciences; the president of the Karakalpak Academy of Sciences; Experts, a private research firm; and members of the Save the Aral Foundation (headquartered in Karakalpakstan). Its purpose was to support one of the Aral Sea projects, the Uzbekistan Water Supply, Sanitation and Health Project. After a short period of team work, the four institutions divided among themselves various parts of the social assessment. Experts undertook largescale community surveys; the Karakalpak Academy provided the historical background analysis and focused on ethnic issues; the Uzbek Academy analyzed the historical and current institutional framework for infrastructure development; and the nongovernmental organization put in place a hand pump monitoring system in two regions (Karakalpakstan and Khoresm) covering 500 hand pumps.

The results of the social assessment components were discussed among network members and finalized jointly. Subsequently, the network organized a series of focus group discussions aimed at ascertaining community responses to alternative solutions to problems identified through the systematic surveys; the discussions were guided by Experts, who, incidentally, also trained other networks in the use of this methodology. Two large-scale stakeholder meetings were organized, an initiative led by the Uzbek Academy of Sciences. Owing to invitations issued from the highest levels of scientific institutions, top-ranking central and local government officials attended, the media provided full coverage, and the nongovernmental community

actively participated. The Kazak and Turkmen social science networks resemble the Uzbekistan network in form and function. All the networks are doing many other types of social research beyond the scope of this discussion, 


\section{Social Assessments for Better Development}

and capacity-building seminars are being held in order to guide their work in these new directions.

In Azerbaijan the social science network was established originally with a single academic institution and the National Women's Association as its members. The network was formed to work on the Baku Water Supply Project. More recently, the network has been expanded to include all major academic institutions of the country and has shifted its focus to social science involvement in development project implementation and to social assessments for reconstruction. In November 1996 some thirty social scientists from eight institutions and nongovernmental organizations received training on social aspects of reconstruction. In addition, network members received training in quantitative data analysis and were involved in a large-scale survey assessing the needs of displaced populations.

\section{Costs of Social Analysis}

Cost-effectiveness is an important element in institutional decisions of whether a social assessment will be put in place. On the whole the greater the local capacity to carry out participatory social assessments, the lower the costs. Also, the less the intention or the need to disseminate social assessment results or to use assessments to enhance public participation in a project, the lower the costs. Again, several examples may provide a better understanding of the cost-related issues.

For the Baku Water Supply Project the initial survey of 400 households cost $\$ 850$ for data gathering, coding, and computer loading. The subsequent survey of 400 households, focusing on modes of water utilization; the survey of industries; focus groups discussions; and the community leakage studies-all cost a total of $\$ 6,000$, including preliminary analyses. A Bank social scientist coordinated the work, traveled twice to the country, and prepared all major reports. Another Bank social scientist was responsible for computer analysis and training of the local social scientists in quantitative data analysis. The efforts and international travel of the personnel cost $\$ 30,000$. Finally, a stakeholder seminar was organized with seventy-five participants from key governmental agencies, the local government, the water agency, the academic community, nongovernmental organizations, and the media. International consultants helped with local organization and provided the local institutions with hard and soft technology for seminar organization. Preparation and conduct of the seminar cost $\$ 11,000$. Thus the total cost of the social assessment was about $\$ 50,000$; but the local cost, including the seminar, was a small portion of this total.

In the Turkmenistan urban transport social assessment 600 household interviews, 1,200 user surveys, in-depth surveys with enterprises, and focus group meetings with bus drivers were conducted locally. Most of the data gathering, coding, and computer analysis was also done locally. These activities cost $\$ 11,000$. The stakeholder seminars and training cost another $\$ 5,000$. Coordination of the assessment by Bank social scientists and their related travel costs, detailed data analysis, and reporting, and preparation of tools for both communication and dissemination cost more than $\$ 30,000$.

The tools used to conduct social assessments had to fit conditions in the field. The intention was to use an appropriate mix of qualitative and quantitative tools in a series of interactive activities, with each effort contributing to the next. Thus qualitative research was undertaken to design quantitative methods. And once systematic surveys had been undertaken, a series of qualitative methods was introduced to reach a deeper understanding of the problems and to allow participatory identification of alternative solutions.

There were cases, however, where owing either to the limited knowledge of the social scientists involved or to time-resource restrictions, the qualitative or the quantitative work could not be done with sufficient rigor. There were other cases where the mobility of the social assessment team was hindered (for example, in Tajikistan). In the Kyrgyz Republic both the extent of quantitative coverage and the depth of the qualitative components had to be limited because of time and budgetary constraints. 


\section{Social Assessments for Better Development}

\section{Conclusion.}

The experiences described in this volume, experiences in other regions of the Bank, and analysis done in 1996 through the Bank's Task Force on Social Development (World Bank 1996) point to several important conclusions:

Experience in the World Bank has demonstrated the need, and value added, of social assessment for projects. This experience fully legitimizes efforts to link social analysis to the economic, technical, and environmental analyses that have become the staple of Bank project preparation and appraisal.

Social analysis should not be treated as if one size fits all. Although the careful consideration of relevant noneconomic variables (social, cultural, organizational, and so on) may be recognized as valuable generally, it is in the selection of specific techniques tailored to the case at hand that the real value of social analysis is achieved. There is no single best approach nor should one be prescribed as a standard.

Social analysis should be used as a complement to classic economic analysis to: help understand and explain the social fabric that is the immediate context of a project or development intervention; help formulate the social objectives underpinning the project's strategy and investments, particularly in terms of the equitable distribution of project benefits and the mitigation of local poverty; and help chart a participatory approach to the activities that will be carried out by project stakeholders.

Because the methodological options for social assessments are, in some respect, still less developed and quantified than other tools, a systematic effort should be made to improve and explain existing procedures, disseminate those that have been tested, codify newly emerging best practices, and train staff in using them. A sourcebook on methods and procedures for project social assessments, cataloguing the multiple experiences accumulated to date, will be a major step forward.

While it is our view that integrating economic and social analysis at the project level is bound to improve project quality and results, we believe that such integration would be valuable for a much wider range of Bank lending and nonlending activities, including sector and country reports, the elaboration of country assistance strategies, poverty assessments, project expenditure reviews, and national environmental action plans. Of course, the form, the scope, and specific content of any social analysis would vary from one to another of these instruments. It would be a mistake to make stereotypical prescriptions. What is important however, is to foster a culture of development work in which social analysis - as a key to understanding the mechanisms of development and maximizing its benefits-is viewed as beneficial and, indeed, indispensable.

\section{Notes}

1. The indictment to which Merton referred was contained in a study by Gottschalk, Kluckhohn, and Angel (1945), which compared the methods used at that time in historical, anthropological, and sociological research.

2. Numerous other social assessments were carried out for projects in other Bank regions, particularly in Latin America. They will be the focus of future publications. A number of recent social assessment studies in nontransition countries are also listed in the references and are now available as working papers or dissemination notes (see World Bank, Environment Department, 1995-96)

3. Interestingly enough, the requirement for environmental assessments was not yet introduced at that time in the formal operational guidelines for project preparation and appraisal. Some general guidelines regarding the environmental implications of projects existed as a separate internal Bank document, which was relatively weaker 


\section{Social Assessments for Better Development}

in operational terms.

4. Writing about the limited use of socio-anthropological studies in development in a region like West Africa, a group of German anthropologists (see Bierschenk 1996) deplore the fact that such studies

are virtually nonexistent in the German speaking world, and are still marginal even in the United Kingdom, Scandinavia, and the Netherlands. If at all, sociologists and anthropologists are usually consulted on development projects only if problems occur in their implementation, or if it is necessary to produce socio-cultural background papers based on temporary, three-week local research. The socio-cultural expert is then usually confront-

ed with a peculiar understanding of his role. It is more or less expected of him to come up with some trick or other, with which project management can successfully sell the project message to the target group. In this interpretation, sociology and anthropology are actually reduced to social technology. Instead, the function of a social scientist in a project should primarily be that of a mediator arguing for the target group and an interpreter of opinions which would otherwise not be brought in the discussion process.

5. Memorandum on Social Assessments from Ishrat Husain to Gloria Davis, June 26, 1996, on the Social Assessment seminar given by Ayse Kudat.

6. Merton (1949) has emphasized how powerful the theoretical frameworks for social research become when they rest on the

rewarding alliance between sociology and the related disciplines of social psychology and social anthropology. Despite their separate emphases, these three disciplines have taken up related problems, developed supplementary findings, and adopted something of a common language. This promises to result in a core of basic social science, in which the special interests of each discipline put previously obscure problems in a sharp focus.

7. See World Bank Operational Policy 10.04, Economic Evaluation of Investment Operations (April 1994, Washington, D.C.).

8. See World Bank Operational Policy/Bank Procedure 10.02, Financial Analysis and Management (1994, Washington, D.C.).

9. See World Bank Operational Policy 4.00, Environmental Assessment (Washington D.C.).

10. Detailed specifications regarding gender dimensions and women in development are contained in World Bank Operational Policy 4.20, The Gender Dimension of Development (April 1994, Washington D.C.). Detailed specifications for indigenous people inhabiting areas affected by Bank-assisted projects and for groups affected by involuntary resettlement are contained in World Bank Operational Directive 4.20 (Indigenous Peoples, September 1991, Washington, D.C.) and 4.30 (Involuntary Resettlement, June 1990, Washington, D.C.). Some regions have developed specific technical guidelines that help task managers-for example, Guidelines for 


\section{Social Assessments for Better Development}

Processing Investment Loans and Credits (April 1995, Latin America and Caribbean Region, World Bank).

11. See World Bank Operational Policy on Bank Assistance for Disaster Recovery (Washington, D.C.)

12. For special risks, such as in situations involving population displacement and resettlement, see World Bank Operational Directive 4.30, Involuntary Resettlement (June 1990, Washington D.C.). For indigenous groups inhabiting project areas, see Operational Directive 4.20 Indigenous Peoples (September 1991, Washington D.C.).

13. See World Bank Operational Manual Bank Procedure BP 10.00, Elements of a Project Implementation Plan (June 1994, Washington D.C.).

\section{References}

ADB (Asian Development Bank). 1991. Guidelines for Social Analysis of Development Projects. Operational Summary. Manila.

Barth, Fredrik. 1996. Economy, Agency and Ordinary Lives. Address presented to the European Association of Social Anthropologists, July, Barcelona.

Bierschenk, Thomas, George Elwert, and Dirk Kohnert. 1994. The Long-Term Effects of Development Aid: Empirical Studies in Rural West Africa. In Economics: A Biannual Collection of Recent German Contributions to the Field of Economic Science, volume 47. Tübingen, Germany:

Cernea, Michael M. 1979. Entry Points for Sociological Knowledge in the Bank's Project Cycle. World Bank, Agriculture and Natural Resources Department, Washington, D.C.

.1985a. Putting People First: Sociological Variables in Development. New York: Oxford University Press (see also second edition, 1991).

. 1985b. Social Science Knowledge for Development Intervention. In M. Cernea, ed; Putting People First:

Sociological Variables in Development. New York: Oxford University Press (see also second edition, 1991).

1988. Involuntary Resettlement in Development Project: Policy Guidelines in World Bank-Financed

Projects. World Bank Technical Paper no. 80. Washington, D.C.

1995. South Integration and Population Displacement: The Contribution of Social Science. International

Social Science Journal 43(1): 91112.

1996. Social Organization and Development Anthropology: The 1995 Malinowski Award Lecture.

Environmentally Sustainable Development Studies and Monographs Series no. 6. Washington, D.C.: World Bank.

Davis, Gloria. 1994. Social Assessments. Office memorandum, World Bank, Social Policy and Resettlement Division, Washington, D.C.

FAO (Food and Agriculture Organization of the United Nations). 1992. Sociological Analysis in Agricultural Investment Project Design. Rome: FAO Investment Center. 


\section{Social Assessments for Better Development}

Gottschalk, Louis, Clyde Kluckhohn, and Robert C. Angell. 1995. The Use of Personal Documents in History, Anthropology, and Sociology. Social Science Research Council Bulletin no. 53. New York.

Kottak, Conrad P. 1985. When People Don't Come First: Some Sociological Lessons from Completed Projects.

In Michael Cernea, ed., Putting People First: Sociological Variables in Development. New York: Oxford University Press (see also second edition, 1991).

Merton, Robert K. 1947. Selected Problems of Field Work in the Planned Community. Publication no. A-8.2. New York: Columbia University, Bureau of Applied Research.

1949. Foreword. In Logan Wilson and William L. Kolb, under the editorship of Robert K. Merton, Sociological Analysis: An Introductory Text and Case Book. New York: Harcourt, Brace and World, Inc.

ODA (Overseas Development Administration). 1995.A Guide to Social Analysis for Projects in Developing Countries. London: HMSO.

RISN (Research Institute for Standards and Norms). 1995. Operational Guidelines for the Social Assessment of Investment Projects in China (draft for field testing). RISN, Beijing; and Centre for Development Studies at Swansea, Wales.

Serageldin, Ismail. 1993. Foreword. In Michael M. Cernea and April Adams, Sociology, Anthropology, and Development. An Annotated Bibliography of World Bank Publications 19751993. Environmentally Sustainable Development Studies and Monographs Series no. 3. Washington, D.C.: World Bank.

Scott, Robert A., and A. R. Shore. 1979. Why Sociology Does Not Apply: Sociology in Public Policy. New York: Elsevier.

World Bank. 1980. Operational Manual Statement 2.33, Social Issues Associated with Involuntary Resettlement in Bank-Financed Projects. Washington, D.C.

1982. Operational Manual Statement 2.20, Indigenous People. Washington, D.C. ( see also Operational Directive 4.20, 1991).

1984. Operational Manual Statement 2.20, Project Appraisal. Washington, D.C. 1990. Operational Directive 4.30, Involuntary Resettlement. Washington, D.C. 1991. Operational Directive 4.20, Indigenous People. Washington, D.C.

D.C. 1994a. Operational Policy 10.00, Investment Lending: Identification to Board Presentation. Washington, 1994b. Operational Policy 10.04, Economic Evaluation of Investment Operations. Washington, D.C. 1994c. Operational Policy/Bank Procedure 10.02, Financial Analysis and Management. Washington,

D.C.

1995. Social Assessment Structured Learning Preliminary Findings. Environment Department Dissemination Note 37. World Bank, Environment Department, Washington, D.C. 
1996. Task Group Report: Social Development and Results on the Ground. Washington, D.C.

World Bank, Environment Department. 1995-96. Social Assessment Series no. 28, Social Assessment and the El Salvador Basic Education Modernization Project; no. 36, Social Assessment; no. 37, Social Assessment Structured Learning Preliminary Findings; no. 39, Involving Farmers: Social Assessment in the Estonia Agriculture Project; no. 41, Nigeria: Client Consultation and Institutional Analysis of Local-Level Poverty Reduction Programs; no. 42, India: Using Social Assessment to Foster Participation in Protected Areas; no. 43, Pakistan: Social Assessment Demonstrates Successes of Participatory Processes; no. 44, Mexico Resource Conservation and Forest Sector Review-Incorporating Social Assessment into Economic and Sector Work. Washington, D.C.

\title{
2-
}

\section{The Direct Operational Relevance of Social Assessments}

\author{
Jonathan C. Brown
}

Do international development agencies listen to the people they are trying to help? And if they listen, do they really hear? And if they hear, do they understand and follow up in ways that affect what we do?

In the mid-1990s development agencies are questioned by skeptics who contend that even if institutions like the World Bank want to listen to the people, they lack the means to do so, being trained in remote oases of learning in professions distant from what constitutes reality at the grassroots level of developing societies.

Indeed, development agencies face a major challenge in defining their roles and in mobilizing support at a time when the themes of the day are fiscal restraint (less money) and more discipline (fewer people doing more).

Some development agencies are responding to such criticisms by strengthening the quality of their technical, financial, economic, and environmental work. And they are reaching out to the people they are trying to help-the ultimate clients or main stakeholders - to work with, rather than for them.

In the private sector this is called marketing, demand assessment, or testing consumer preferences. No private company would operate or launch a product without demand assessment and marketing. And even then, the number of bankruptcies and failed products testifies to the difficulty of successful market gauging. Among international development agencies, stakeholder consultation at the grassroots level is still an innovation that is yet to be accepted and institutionalized. In the past, failure to consult adequately with stakeholders may have contributed to failure of project operations, but unlike private sector firms, the agencies themselves were not put at risk when their products failed. And to be fair, governments and their public servants were often as unwilling or as unprepared to consult with stakeholders as the international development agencies and their civil servants. While the private sector has spent much of the twentieth century expanding and deepening marketing, so that it has become an acceptable profession, stakeholder consultation in development agencies does not yet have the reputation of a profession - a status that economists, technicians, and financial analysts have achieved and for which environmentalists are still struggling. Rather, stakeholder consultation and social analysis (separate from economic or technical analysis) are mistakenly seen as something anyone can do.

This book illustrates the contribution of social assessment—one mechanism for stakeholder consultation-used by the World Bank. It has improved the substance and process of policy reform and investment projects in developing countries and economies in transition. The case studies presented result from the work of the social scientist group in the Europe and Central Asia region of the Bank and cover the period of three years when social assessments were introduced in that region. 


\section{Social Assessments for Better Development}

While it is accepted in principle that consulting the people-arguably the most important stakeholders in the development or transition process - should be systematically done by the World Bank, this consultation process is, in fact, rarely done. When it is done, it is often done superficially. And when it is done well, the

findings are not always followed up. This has happened in part because consultation is rarely the result of a structured process performed by specialized professionals trained in the social sciences. This situation has persisted because there have been too few examples of successful social analysis to serve as guides. Therefore, many World Bank staff have not been prepared to spend intellectual and monetary resources on social assessments and local consultation.

The consultation process can be narrow or broad. At its most narrow—as often occurred in the past—a World Bank staff member talks with officials in a country and on this basis alone policy dialogue or an investment project moves forward. At its broadest reach, the consultation process involves a wide range of stakeholders, including those people, groups, and institutions directly affected by the policy reform or investment project.

The narrow consultation is easier-not much more effort is required than looking in a mirror. The broad consultation requires more time and resources and a professional approach. The social assessment—a systematic, sociologically and methodologically guided process of learning about stakeholders-is an important mechanism for involving a full range of stakeholders. Social assessment is not the whole participation process but one input. For social assessments to gain credibility among World Bank staff and government officials-who are economists, financial analysts, technicians from many sectors, and even generalists-it is important to demonstrate that these strange products that result from the work of non-economic social scientists really do facilitate the process and improve the substance of the World Bank's basic products: policy reform and investment projects.

This chapter summarizes the relevance of social assessments to policy reform, investment projects, and lending for emergencies from the viewpoint of a division chief who is responsible for preparing, appraising, and supervising development projects and who is not a social scientist himself. It suggests reasons why social assessments have been more readily accepted in theory (by World Bank staff and governments) than in practice. Finally, the chapter will suggest institutional mechanisms to facilitate the acceptance of social assessments, either through persuasion - the basic thrust of this book—or through institutional norms within the domain of good management and leadership.

\section{Social Assessments and Policy Reform}

It is believed that improving the welfare of people in developing and transition economies requires institutions and policies that encourage economic growth and allow for the sustainable development of essential services. Part of the policy theology is that reform is usually unpleasant and has to be forced on people by governments, resulting in conflict. People are seen as part of the problem rather than as part of the solution.

Seeing people as the enemy of policy reform is nowhere more evident than in the debate over cost recovery, or who will pay for essential goods and services. The reform theology assumes that people will resist higher tariffs. But is it true that higher tariffs mean higher real costs for people in all cases? And even if this is true, will people object? Social assessments play a critical role in this debate. Their findings, as indicated in this book, have shown that higher tariffs can lead to lower real costs and that higher prices will be accepted by consumers if there is a credible expectation of improved services. Social assessments can give courage to governments facing the need for cost recovery measures by allowing the people to be supporters of reform.

During the preparation of the Baku (Azerbaijan) Water Supply Rehabilitation Project in 1994, water company officials and the World Bank team concluded that higher tariffs were essential to provide the financial resources 


\section{Social Assessments for Better Development}

necessary to put the Baku water company on a sound financial footing. However, discussions with the government over raising tariffs quickly became emotional. Government officials raised the specter of public riots, while the water company and World Bank team offered the gloomy vision of corporate bankruptcy.

The stalemate was broken as a result of the social assessment done as part of early project preparation. The social assessment found that

although the public water supply service was inadequate throughout Baku, the low-income segment of the city's population suffered the most from the water situation. On average, households spent about seventeen times more on alternative water supplies than on their monthly water bills. The poor spent 7 percent of their income on coping strategies while wealthier citizens spent only 2 percent. The social assessment also showed that householders would be willing to pay substantially more than their current monthly water charge for better public water service. The poorest elements of the population were prepared to pay 6 percent of their income, a slight decrease from their current payments for coping mechanisms.

The water company and World Bank team found that a tariff level of about 4 percent of income for the poorest population segments was sufficient for the company's financial objectives. The government could argue that while this was an increase in tariffs, it was actually a reduction from the 7 percent this group was currently paying for alternative water supply.

The social assessment was accepted in Azerbaijan because it was done by a team of World Bank and Azeri social scientists and was based on detailed surveys done professionally and presented in a user-friendly way, including public fora which were televised.

The role of social assessment in facilitating discussions of cost recovery was even more dramatic in Turkmenistan during the early preparation of the Urban Transport Project. Carried out in February 1995, before issues of cost recovery were even discussed with the government, the social assessment revealed a situation in Ashgabat of poor service in public transport and of tariffs so low that there was no coin small enough for a passenger to pay a single-ticket fare. The result was an unsustainable and deteriorating public transport system. The poorest quarter of households were compelled to spend 12.8 percent of their income on various mechanisms for coping with the lack of public transport or to make extra payments for using public transport when it was available.

The social assessment also revealed that 94 percent of public transport users would accept a 2,000 percent increase in tariffs if there would be real improvement in service. Tariff increases were immediately put into operation. The quick improvement in public transport service resulted in the poorest households paying higher fares but incurring lower real costs for transport when compared to the cost of their previous coping mechanisms. Raising tariffs lowered the real cost of transport and cost recovery was never an emotional issue during project preparation.

Turkmenistan's Urban Transport Project is the World Bank's first investment operation in this new member country. As part of project preparation the government has issued a Declaration on Urban Transport Policy, an Action Plan setting out the policy objectives to be implemented during the project's lifetime, and an Operations Improvement Plan to supplement the list of improvements already implemented. It is unusual for a policy reform package to be prepared by a government before World Bank financing has been negotiated, especially for a new member of the World Bank. There is no absolute proof, but one might suggest that the bank's social assessment turned urban transport consumers into allies of reform. It also emboldened the government, which was highly satisfied with the Bank's social assessment study, to take steps towards policy change.

Social assessments can be particularly helpful where cost recovery's impact on different population groups is more complicated. In the Kyrgyz Republic the World Bank provided a \$20 million International Development 


\section{Social Assessments for Better Development}

Association (IDA) credit in June 1996 to fund a Power and District Heating Rehabilitation Project. Cost recovery was a contentious issue for the government, since social considerations and its policy of promoting domestic power use were the main reasons for keeping power and heat tariffs artificially low and the structure biased towards household consumers. The result was an unsustainable deterioration in the financial situation of the energy utility, inefficient and uneconomic energy consumption, and inequitable prices. A social assessment of proposed tariff increases was carried out during project preparation. The findings of the assessment indicated that the proposed tariff increase for electricity was feasible, while the increase for district heating was feasi-

ble only if a social safety net was introduced to protect low-income households. Households without access to district heating, and therefore relying on natural gas and coal for heat, also needed protection. The impact of the tariff increase on electricity could be mitigated by maintaining a reduced subsistence tariff for residential consumers. The outcome was that higher tariffs were introduced where they were affordable, with a social safety net designed for those groups for which it had been demonstrated that the financial burden would be too great.

The important contribution of the social assessment was to provide a framework of facts, figures, and predictable outcomes that took the subjectivity and ideology out of the cost recovery debate.

The contribution of social assessments to policy reform can be broadened to encompass entire sectors engaging in major restructuring where the World Bank is supporting the reform program through a sector adjustment loan (SECAL), as the Russian coal case illustrates.

In June 1996 the World Bank approved a \$500 million loan for Coal Sector Adjustment in Russia in support of the government's program to reduce the adverse impact of the coal sector on the federal budget by making possible the decrease and eventual elimination of sector subsidies, which in 1993 amounted to 1 percent of GDP; promote the long-term sustainability of the coal sector through the establishment of a competitive, commercial industry; support a restructuring program to reduce the size of the industry while increasing its efficiency; and cushion the socioeconomic impacts of the restructuring on coal miners, their families, and affected communities. The SECAL was accompanied by a \$25 million loan for a Coal Sector Restructuring Implementation Assistance Project, which included:

Support for stakeholders' participatory activities at the national, regional, and local level for government, coal industry, and nongovernmental institutions

Social programs to be implemented by local governments, nongovernmental and community-based organizations with continuous social assessment, and social impact monitoring of the coal reform program

Improvement of the management of government subsidies to the coal sector to enhance transparency and financial accountability and to ensure that target groups received the level of subsidies for the purposes intended

Assistance for commercialization and demonopolization of coal companies, environmental management associated with the coal industry, development of procedures for closing unprofitable mines, and for operation of the government's coal reform agency in the Ministry of Economy.

The social assessment carried out as part of the SECAL's preparation had a profound impact on the coal reform program by:

Demonstrating (unexpectedly) that nonminers in coal regions were the largest group affected adversely by the coal reform program. In response, a major part of coal sector subsidies was reoriented to coal communities for the population at large rather than to coal companies for coal miners who had been a privileged economic group. In addition new mechanisms were devised to make the purpose, the beneficiaries, and the distribution channels for 


\section{Social Assessments for Better Development}

subsidies more transparent and able to be monitored.

Revealing that human settlements in the coal region have diverse characteristics with respect to demographic structure, income levels, and labor force. This would appear to be self-evident but much of the reform agenda treated the coal sector as a monolith. The social assessment persuaded the government to recognize the local nature of many of the problems and of possible solutions for the coal sector.

Demonstrating that the transfer of social assets from coal companies to local governments-an important objective of the coal reform program - was having adverse effects on local communities that were not previously anticipated. In response, coal subsidies for social assets were redirected from coal companies to coal communities.

Showing that miners and nonminers had low trust in the government, in the coal industry, and in outside agencies such as the World Bank, but would trust a new institution representing of a broad range of stakehold-

ers. The Interagency Coal Commission and the Association of Coal Mining Cities, new institutions with broad stakeholder representation, became the vehicles by which many decisions were made. In addition pilot programs were created to channel loan funds for the first time in Russia to nongovernmental and community-based organizations, as well as to labor unions.

Suggesting that measures to enhance workers' ability to move freely in search of alternative employment were seen by many coal miners facing job loss as more relevant than expensive job creation schemes whose funding and efficiency were questionable.

Difficult negotiations between the groups in Russia pushing for reform and those advocating the status quo-with control over nearly $\$ 2$ billion in annual subsidies at stake-were affected by what the social assessment revealed about the coal mining regions and peoples' concerns, especially about the subsidy system and the procedures for closing mines. At one point in the negotiations over the subsidy system, the supporters of the status quo produced an elaborate justification for keeping the existing system. The advocates of reform pointed to the results of the social assessment this way: those who were supposed to benefit from subsidies had no trust in the existing system. The findings showed that it was not the reformers alone or an outside institution like the World Bank proposing and supporting change, but the people themselves. The subsidy system was changed.

In addition, donor support, particularly from the World Bank, was facilitated because Russia could demonstrate that its coal sector reform program was cushioning the impact of reform on the most affected people, as the people themselves thought relevant and appropriate when they spoke through the social assessment-their vehicle for stakeholder consultation. Experience from around the world has shown that reform of coal sectors is difficult, costly, and takes many years, if not decades, to happen. The social assessment gave World Bank staff more confidence that Russia's coal sector reform program was based on realities in the coal mining areas and responded to the real needs of people. The Implementation Assistance Project's funding of social monitoring ensured that the process of social assessment and stakeholder participation would continue to be part of the future reform agenda for coal in Russia.

\section{Social Assessments in Sector Work.}

Sector work in the World Bank is designed to identify systematically the challenges, constraints, and options for a country in a specific sector, based on that country's own situation — such as population, resources, and needs—and considering relevant worldwide factors. Sector work sets the framework for the Bank's investment lending and policy dialogue in a sector as well as its identification of specific investment opportunities. 


\section{Social Assessments for Better Development}

Given the scope and importance of comprehensive sector studies, it would appear that social assessments should be key building blocks on which sector work is founded. Yet this has not been the case in the countries covered by this book, except perhaps for the Bank's poverty assessment studies. The explanation for this gap is the need for World Bank sector work to concentrate on macroeconomic analysis for new Bank members and on sector issues for which reform options have been explored in other parts of the world and are thought to be transferable to the countries of the former Soviet Union. Also, these countries' desire to borrow quickly for investment projects has meant that sector work and project preparation have in many cases been merged, rather than carried out in sequence. Still, sector reform is deeply country specific, and would benefit greatly from social assessment at the sector level.

The first draft of the Russia coal sector report, for instance, covered the coal industry as one national industry to be analyzed. The Russians requested the World Bank team to do a second draft, assessing the industry coal basin by coal basin. The final report was a much more relevant document that served as an important basis for preparing the Russia Coal Social Adjustment loan. Thus a social assessment at the sector level proved to be, in this case, very useful for designing a major, sectorwide restructuring intervention. It is likely that this is true for all or most Bank and borrower programs, and that the

use of social analysis in sectorwide studies and programs could be considerably expanded, both within the Bank and in other institutions.

When identifying constraints and reform options, sector work should investigate the social processes and factors that determine the current situation in the sector as well as the framework for realistic reform. As such, social assessment could have important contributions in:

Identifying key sector stakeholders and proposing a framework for their participation as actors in sector reform

Evaluating the impact of reform options on stakeholders, especially to gain their support where possible and to understand their opposition when it occurs

Designing measures to mitigate adverse effects of sector reform proposals

Identifying cost-effective interventions that could be undertaken immediately, the winwin actions that facilitate the implementation of sector reform in its early stage

Determining whether a sector is appropriate for Bank investment operations given the Bank's social development and poverty reduction objectives, including the most appropriate target groups and geographic areas where these objectives can best be achieved.

The social assessment in sector reviews is a more systematic process of stakeholder consultation, especially in countries of the former Soviet Union, where the traditional institutions of civil society such as nongovernmental organizations are not as representative of population viewpoints as they are in other parts of the world.

Utilizing of social assessment in sector reviews would go far in defining the social development agenda so that a social assessment would not have to be done in great depth for each investment operation in the sector.

\section{Social Assessments and Investment Lending}

The social assessments that our division has supported and used have had a profound effect on the focus and shape of our investment projects in countries of the former Soviet Union. As a result, these investment projects are more appropriate for the people being helped, more efficient and financially viable, involve the people in ways 


\section{Social Assessments for Better Development}

that reduce investment costs and improve operational performance, and are environmentally more sustainable. This may seem an ambitious contention, but if true, it implies that social assessments can make as great a contribution to World Bank investment lending as the traditional economic, financial, technical, and environmental tools for evaluating projects.

Consider, for instance, the Baku (Azerbaijan) Water Supply Rehabilitation Project for which a \$61 million IDA credit was approved in June 1995. This project was originally conceived as the provision of pumping stations and spare parts so that the traditional water company operations could be restarted. As a result of the social assessment, however, the focus of the project shifted substantially towards involving the consumers in the investment project.

The social assessment revealed the high level of water losses caused by leaks in households and in the distribution system. This resulted in the project's budgeting for a community-based repair and maintenance system for 180,000 households, as well as for a major network repair program. The social assessment also illustrated the need for a metering and billing program for households and industries as a means for improving the water company's finances and for promoting water conservation. A consumer outreach and awareness-raising program was designed to provide information on reducing water losses, to build public awareness about the scarcity of water and the need for conservation, to show the importance of community participation in leakage repair programs, and to explain the need to pay for water and the advantages of metering for improved cost recovery.

The social assessment also showed that the water company had little knowledge about the preferences of its customers. Therefore, the project included establishing a consumer relations unit within the water company to deal with consumers as partners.

In Kazakstan in 1995 the government and the World Bank initiated a detailed preparation for a Water Supply, Sanitation, and Health Project in the Aralsk and Kazalinsk regions, the parts of the

country most affected by the deterioration of living conditions resulting from the Aral Sea shrinkage. A social assessment was carried out that showed that people's concern about water was in fourth place, behind income to buy food, cooking fuel shortages, and unpaid wages. As a result, project preparation was stopped, redirected, and begun with a wider focus on peoples' concerns, especially the contribution of water to economic activities such as gardening and raising livestock. Rather than start with a full scale investment project, the government and the World Bank decided to fund a small pilot project to test project design and implementation capacity. Thus, the major contribution of the social assessment in Kazakstan was in reorienting project preparation before it had gone too far in a direction that did not respond to peoples' needs.

In Turkmenistan the initial orientation of the Urban Transport Project was toward the provision of new buses and spares to raise the level of service. The social assessment done during project identification revealed a system in chaos, with 90 percent of users dissatisfied with the service, which was practically nonexistent during the evening rush hour. The key problems were the behavior of drivers and the poor finances of the bus company. The social assessment identified a number of operational improvements and potential solutions, including:

Substantially raising bus drivers' salaries, thus reducing their incentive to exploit the public in order to supplement their incomes. At the same time transport supervisors were designated to ride on buses to monitor driver behavior, and fare collectors were added to buses. This carrot and stick approach to the key problem of driver behavior resulted in a marked improvement in driver performance and hence in better service to the public.

Increasing the nominal fare by 2,000 percent and making other improvements in ticket availability. This improved bus company finances enough to keep more buses in service. 


\section{Social Assessments for Better Development}

As a result of these reforms more buses were available for longer periods of time, allowing an improvement in bus scheduling, and satisfying a key complaint of consumers. Internal management and personnel policies were also improved.

In this way, the social assessment made possible real improvements in urban transport service more than eighteen months before World Bank investment funds were scheduled to become available.

The Turkmenistan social assessment revealed that the findings of social assessments cannot always be acted on automatically and that they, in turn, must be subject to the other usual analytical criteria for investment lending: economic, financial, technical, and environmental. That social assessment showed, for instance, that consumers expressed strong preference for having a seat in public transport vehicles during rush hour. If acted on uncritically, this priority would have resulted in overinvestment, since few urban transport systems can afford to satisfy this demand. Furthermore, the social assessment's survey by city zones reported the need to improve the road systems in parts of the city. Although also a legitimate concern this need was not within the financial possibilities of the Bankfunded project.

Perhaps the most extensive use of social assessment occurred during the preparation of the Uzbekistan Water Supply, Sanitation, and Health Project. As part of an extensive stakeholder consultation process on the project design, five distinct social assessments on different aspects of the project were carried out. Of these, the one covering Karakalpakstan and Khorezm - the two administrative territories most severely affected by Aral Sea Basin conditions-is included in this volume.

With regard to implementation arrangements, the social assessment and participation process helped convince people to change their view on some design options for the project. In initial meetings, people expressed strong preference for a self-managed water supply scheme because they believed that the local water company, Vodokanal, would provide poor service if it managed the plan. However, when the community received information on the advantages, disadvantages, and costs of the various schemes, they agreed with the experts' recommendation to link the community with the main supply pipeline operated by Vodokanal. This community consultation approach was a first experience for Vodokanal. While initially there was a

hostile reaction from the community and apprehension from Vodokanal's perspective, the end result has been beneficial for all stakeholders.

The social assessment also changed the technical parameters of a key project including the definition of what is acceptable water quality. The government suggested that a water supply project would have to use low-cost investments such as shallow wells and handpumps. But the social assessment found that 68 percent of households complained of the salty taste of their main water supply. It was then decided to complement the social assessment with a salinity taste-tolerance survey. This survey found that the local population would tolerate salinity up to 2,000 miligrams per liter, above the World Health Organization's recommended level of 1,500 miligrams per liter, and twice higher than Uzbekistan's own national standard of 1,000 miligrams per liter.

This finding had important cost-savings implications for the project: given resource scarcity, the project can make smaller investments in water quality to meet the 2,000 miligrams per liter tolerance level rather than the 1,000 miligrams per liter national standard. On the other hand, the survey demonstrated that shallow wells and handpumps, supplying water with salinity levels between 5,000 and 7,000 miligrams per liter might appear to allow an acceptable investment pattern. But this appearance is deceptive from the consumer's viewpoint, because the water produced would be undrinkable.

The social assessment and the local consultation process also suggested that it was possible to test a lower water consumption design standard, which would permit reducing investments and operating costs of water distribution 


\section{Social Assessments for Better Development}

networks. The current design norm of 350 liters per person per day has been reduced to 150 liters per person per day, a change made primarily for financial reasons. This change might well have been rejected as socially unconscionable had the information supplied by consultations and social assessment not been available.

Finally, the social assessment showed that people's highest priority was access to incomegenerating activities. This finding led to the introduction of several pilot schemes implemented by the government and financed by the donor community. The project design adopted a labor-intensive approach to water supply and sewerage investments in order to maximize local employment opportunities. Proponents of this approach, however, will still have to battle it out with the external commercial interests who are proposing capital-intensive approaches, but at least there is evidence of support from the affected people.

The social assessment for Uzbekistan provided me - and my colleagues on the project's operational and financial sides-with valuable information, otherwise unavailable, about how much water consumers in rural areas would be prepared to use at various price levels. We also decided that the project would include a pilot demonstration of a water metering system servicing small groups of households organized as water user associations. This will test the benefits of a system that charges consumers for the actual amount of water consumed.

\section{Social Assessments and Emergency and Post-Conflict Lending}

Since its establishment after the Second World War the World Bank has had the special role of assisting governments with programs to recover from natural and human-caused disasters and civil strife. Project preparation after floods and human-caused disasters (such as oil spills) often has to be telescoped and done under extreme time pressure as emergency interventions. There is a tendency to conclude that there is no time to consult with the affected people. In addition, it is suggested that the relief agencies, rather than the World Bank, are the ones that should consult with stakeholders, since choice of relief services will have an immediate effect on stakeholders, in contrast to longer-term reconstruction activities funded by the World Bank.

In reality, however, because of implementation constraints and lack of sufficient money from domestic resources and the donor community, it is common that the reconstruction efforts cannot rebuild completely what has been lost, at least not in the near and medium term. Consequently, consultation of stakeholders about what should be reconstructed, and in what order, is enormously relevant, especially

since commercial and political interests often claim that heavy infrastructure reconstruction is more important than social or light infrastructure reconstruction. We have learned that social assessments can be done quickly with results that facilitate decisionmaking and choices about what needs to be reconstructed and to what standards.

In 1994 the World Bank helped the government of Tajikistan prepare a preliminary program of reconstruction following severe floods and a pause in the civil strife. The mandate given to the Bank's team emphasized physical and commercial reconstruction, due to the desperate economic situation of the country, rather than other areas such as shelter, for which temporary measures were thought to be adequate. Yet the social assessment-in this case more traditionally ethnographic without detailed surveys-brought to our attention that shelter in Tajik society was more than housing - it was also the nucleus and location of various economic activities of the extended family. Therefore, the reconstruction program we eventually proposed gave more prominence to housing as the basic economic unit than it would have had we considered housing only as shelter.

In 1994 Tajikistan was a new member of the World Bank, and its local institutions, including community organizations, were unfamiliar to the international community. The social assessment raised the possibility of mobilizing community capital based on what already existed from the communist era or was embedded in traditional structures. When the civil strife lessened, and it became clear that there would be few external 


\section{Social Assessments for Better Development}

resources available for reconstruction, social assessments were continued in Tajikistan. These surveys revealed what people felt were the highest priorities to be delivered through efficient existing channels such as local and international nongovernmental organizations, in the face of an already overburdened public service.

Social assessments can be especially effective for involving stakeholders in selecting priorities when financial resources are limited. In 1996 the Azerbaijan government requested the World Bank and the United Nations Development Programme to help establish the Azerbaijan Resettlement and Reconstruction Agency to assist internally displaced people returning to demilitarized areas surrounding NagornoKarabakh. With lasting peace yet to be established in Nagorno-Karabakh and in view of the international community's preoccupation with reconstruction in Bosnia, it is unlikely that sufficient external resources will be available to Azerbaijan in the near term to restore to former levels the full range of infrastructure, and social and economic services. The government has instituted a process of social assessments, allowing internally displaced people to help decide how the limited financial resources should be used to improve their lives. It remains to be seen whether the social assessment results will have more impact than the central planning mentality of many people in this former Soviet Republic.

Emergency lending poses special demands on social assessments because of the need to move quickly. On January 24, 1994, the government of the Komi Republic, through the government of the Russian Federation, requested the World Bank and the European Bank for Reconstruction and Development to provide emergency assistance to deal with the oil spill from a major oil pipeline in the Komi Republic near Usinsk. If not contained, the oil spill threatened to flow into the Kolva, Usa, and Pechora Rivers, posing a massive threat to the fragile Arctic climate. The spill, estimated at three times that of the Exxon Valdez on the Pacific Coast of North America, had to be dealt with before the spring floods expected in May and June. Moreover, a spill recovery capacity had to be created in the river systems in the likely event that the oil could not be fully contained. The leaking pipeline had to be replaced over an 84 kilometer stretch under difficult construction conditions before further leaks developed and before the spring and summer floods made it impossible to work in the swampy tundra.

The project preparation effort which began the day after the government request and involved social scientists including representatives of a local nongovernmental organization-Save the Pechora Foundation. Using interviews and surveys they assessed the priorities perceived by the 7,000 people (10 percent of the

population) living in villages within a 200 kilometer radius of the affected area.

The social assessment revealed that the highest priorities were preventing the spill from reaching the river systems and protecting against future pipeline ruptures. A long list of local improvements followed, showing a lack of adequate investment in basic social services over many years. At the top of this list, the people placed funding for children's vacations and emergency food for livestock.

In its implementation the Oil Spill Recovery and Mitigation Project placed highest priority on preventing the spill from spreading. This was successful. Implementation of the social programs received lower priority and was completed at a slower pace than planned. As often happens the hardware got more attention than the software, but in this instance that emphasis reflected the views of the people most directly affected. Also, the social assessment exercise for the Komi Project did not delay project preparation or implementation, and it was done at low cost.

\section{Social Assessments in the World Bank: The Current Situation}

The question inevitably arises: If social assessments are as important for World Bank policy work and investment lending as our work has shown, why do we not carry them out systematically for all projects? And if they are not done very often, what needs to be done to change this? 


\section{Social Assessments for Better Development}

So far, the people in the World Bank who have championed social assessment—not all of whom are social scientists—have received insufficient support for their efforts.

Some people in the Bank, and in other development agencies, might contend that social assessments have always been done, have been an integral part of discussing Bank operations with client countries, and have been incorporated in the way Bank staff go about demonstrating the economic, financial, technical, and environmental justification for projects. This is an exaggeration, though there has been an improvement in stakeholder consultation in recent years. Many aspects of our social analyses have been done in an ad hoc manner rather than as a result of a systematic, professional approach, as a social assessment should be.

The Participation Sourcebook, published by the World Bank in 1996, states that social assessments must be carried out in a project context to do the following:

Identify key stakeholders and establish an appropriate framework for their participation in the project selection, design, and implementation

Ensure that project objectives and incentives for change are acceptable to the range of people intended to benefit, and that gender and other social differences are reflected in project design

Assess the social impact of investment projects and, where adverse impacts are identified, determine how they can be overcome or at least substantially mitigated

Develop ability at the appropriate level to enable participation, resolve conflict, permit service delivery, and carry out mitigation measures as required.

What this sourcebook recommends about social assessments is what we should have been doing all along — assessing and consulting with those we are trying to help about the best way to help them. It takes humility for the World Bank's management and staff to admit the need to organize differently in order to improve our performance on consultation. This is what many outside the Bank, and some inside the Bank, have been long saying, and what many more inside the Bank are now admitting.

Good quality, professionally administered social assessments require additional time and financial resources, just when of international donor agencies are being asked to do more with less money and fewer people. The contention that social assessments will save money by improving project performance is probably true. But it is seen by some as a long-term hope better left for tomorrow, especially as Bank staff see their budgets for project preparation being cut. Even fulfilling traditional economic, financial, and technical analysis is in doubt. If another unfunded mandate is given, yet allowed somehow to remain voluntary, it can hardly be welcomed by those responsible for project preparation in international development agencies.

If we add the uneven professional output of the social sciences in general, the sometimes weak professional qualifications of some social science staff, and the frequent lack of quality control over social scientists in development agencies, it will be possible to ignore social assessments and yet not feel as though we are contributing any less to solving problems in developing countries or countries in transition. I contend that the poor quality of some of the social science work in the World Bank has much to do with the prejudices of economists, financial analysts, and technicians toward noneconomic social science. When a staff member says surveys, meaning that thirty-nine people met on the street over several days about a major sector adjustment operation-it should not pass for social science. Client countries and agencies that have profited from decades of perfecting the way the Bank proceeds in doing economic, financial, and technical analysis, do not have far to look for evidence of the sloppiness of what we have often called spontaneous social assessments. This situation will not change until the international development institutions introduce a standard of professionalism for social assessments, 


\section{Social Assessments for Better Development}

and quality control by recognized social scientists and other professionals that results in acceptable quality.

The quality of social assessments can be enhanced and costs brought down by the use of local social scientists. The network of social scientists in Central Asian countries, which the World Bank has helped to establish and which has received generous funding from Switzerland, is an important step in this direction.

The World Bank has tried to stimulate the use of participatory approaches in general and social assessments in particular through a positive, voluntary series of measures. These measures have ranged from subsidizing the work of social scientists to helping budget-starved task managers through a special fund, to showing best practices, to issuing The Participation Sourcebook, and to publishing this volume. This reflects the Bank's early days of environmental work, when it was assumed that attention to environmental concerns would be sufficient to mainstream the environment in World Bank policy work and investment operations. Only when simple voluntary measures did not result in the mainstreaming of sound environmental criteria, and when environmental nongovernmental organizations publicized some of the more egregious environmental disasters accompanying some World Bank loans, did the Bank take a normative or mandatory approach. This change included issuing operational directives for all staff and the creation of environmental organizational units in all Bank regional vice presidencies, both for review and for direct environmental work.

Social assessments and participation seems to be going through the same experience as environmental concerns did earlier. As long as the instructions are only voluntary, and the work unfunded through regular budget allocation, social assessments will often receive the same lip-service that the environment received before structured attention was mandated. Few people will argue that the World Bank is not a better place today because of the seriousness with which it now treats the environment. The same would be said if we treated social assessments with equal seriousness.

The social assessment studies that our division has commissioned, svutome of which are included in this book, were not perfect. But they represent a constructive and useful attempt in some parts of the World Bank to move toward a more qualified and relevant process of doing hands-on social analysis and using local social scientists, thus improving the Bank's performance in new member countries. Social assessments are one of the better means of making the work of international development agencies more effective, more relevant, and genuinely appreciated by the people we are assisting.

\section{Part 2- Social Assessment Case Studies}

\section{3- \\ Shaping the Future of Baku's Water Supply.}

Ayse Kudat and Ahmed Musayev

Involving stakeholders and incorporating social goals in the design of water supply investments can ensure that project objectives and interventions are appropriately targeted, feasible, and acceptable to users, particularly the poor.* It also can improve project-related decisionmaking and strengthen public ownership of and commitment to the investment. The degree of stakeholder involvement needed is a key factor influencing the design of a social assessment. In some cases stakeholders simply provide information. But projects often are improved when issues are jointly assessed and agreed, or when beneficiaries are responsible for identifying problems and are empowered to find solutions. 


\section{Social Assessments for Better Development}

In Baku, the capital of Azerbaijan, a social assessment not only confirmed the acceptability of a water supply project, it also led project designers and other stakeholders to adjust the design of the project to meet local needs.

This chapter presents the methodology for carrying out the social assessment for the World Bank's Greater Baku Water Supply Rehabilitation Project and demonstrates how it helped shape the final design of the project. The first section summarizes water supply conditions in Baku and the project designed to improve them. Subsequent sections present the conceptual framework for the social assessment, the specific objectives and methods used in carrying out the assessment, key findings of the assessment, and implications for project design and future investments.

\section{Responding to a Water Supply Crisis}

In 1994 the government of Azerbaijan asked the World Bank for assistance in providing essential public services to its population as it made the transition to a market economy. Water supply is the most important of these services. And in Baku, where a third of the country's population resides, residents are facing an acute water crisis (box 3.1). Supplies are intermittent and unreliable, water quality is poor, system losses are high, and cost recovery is grossly inadequate. Moreover, the inefficiencies of the existing system not only waste large quantities of scarce water and financial resources, they also result in losses in productivity and opportunities for poverty reduction.

The enormous quantity of water wasted is evident in the discrepancy between the volume potentially available and the actual quantity received by users. Based on per capita consumption of 250 liters per capita per day (lcd), Baku theoretically has enough production capacity to satisfy the needs of a city of 3.5 million people -1 million more than its current population. But per capita water consumption in Baku is high, averaging 400600 lcd (compared with 250300 lcd in most Western European cities). High consumption levels do not mean that households are wasteful, however. Indeed, many households are restricted to six hours or less of piped water a day for fourteen days of the month. Rough calculations suggest that 4060 percent of all water production is

\section{Box 3.1 Perennial water shortages in Baku}

If there's one thing on everybody's mind these days in Baku, it's water. You hear it all the time. Some will tell you they haven't had water for two days. The next person will say it's been five days or two weeks or even a month. Access to water is so unreliable lately that it's hard to meet a person who hasn't been directly affected-even at the best hotels where foreign dignitaries stay or the apartments of top government officials. What complicates the issue is that there is never any warning-no television or radio announcements - to help people feel more in control and more able to anticipate when the water will be cut or when it will eventually be restored. People have simply learned not to rely on water at all. They've stopped asking why there is none.

It's impossible to understand how severe the problem is by seeing how well-dressed and well-groomed people look on the streets. Appearances are deceiving. It's a cultural value to always appear attractive no matter how difficult. How do they manage? Not without an incredible expenditure of time and effort, especially on the part of women. They cope the best they can. There's always a friend or relative in some other part of the city who has water where they can wash and shower. Life goes on but it's a consuming headache for everybody. Everything suffers. Work almost comes to a halt. Hospitals and clinics, day care centers, and 


\section{Social Assessments for Better Development}

schools struggle incredibly to maintain hygienic conditions. More often than not, it's impossible.

It's not that there have never been problems before. Some people in Baku can't remember a time when there weren't difficulties. It's just that now the shortages are much more prevalent and severe. Water pressure has always posed difficulties, especially for those living in apartments on the top floors. Many families have built storage tanks in the ceilings of their bathrooms so that if, and when, the water flows in the middle of the night, the tanks can refill for the next day's usage. Some people use their bathtubs as storage tanks. Apart from the problem of accessibility, there's the perpetual problem of clean water. In most apartments, the tap water is quite murky and cloudy; an amazing amount of particles float around in suspension in a glass of water, for example. Most people don't realize what causes this turbidity.

Source: Excerpted from Blair 1994.

who has water where they can wash and shower. Life goes on but it's a consuming headache for everybody. Everything suffers. Work almost comes to a halt. Hospitals and clinics, day care centers, and schools struggle incredibly to maintain hygienic conditions. More often than not, it's impossible.

It's not that there have never been problems before. Some people in Baku can't remember a time when there weren't difficulties. It's just that now the shortages are much more prevalent and severe. Water pressure has always posed difficulties, especially for those living in apartments on the top floors. Many families have built storage tanks in the ceilings of their bathrooms so that if, and when, the water flows in the middle of the night, the tanks can refill for the next day's usage. Some people use their bathtubs as storage tanks. Apart from the problem of accessibility, there's the perpetual problem of clean water. In most apartments, the tap water is quite murky and cloudy; an amazing amount of particles float around in suspension in a glass of water, for example. Most people don't realize what causes this turbidity.

wasted, and leaks in the distribution network appear to be the main cause. Moreover, leaks lead to large financial losses because a substantial portion of the cost of supply is not recovered.

Sewerage service levels are even lower than those for water. In large urban areas one-third of the population is not connected to a municipal sewerage system. In the adjacent towns and villages outside of Greater Baku but within the Apsheron Peninsula, all the urban centers have inadequate sewerage and lack treatment facilities. Sewage is usually discharged directly into the nearest lake or into a ground soakaway (septic pit). Sewerage systems are in poor condition, leading to groundwater contamination and imminent risk of polluting the water supply systems through pipes built too closely together. The situation is even more precarious in small urban and rural areas. Moreover, water pollution resulting from organic nitrogen and phosphorous loads from point and nonpoint sources has emerged as a serious problem, particularly in the Apsheron Peninsula.

In response to the government's request for assistance, the World Bank initiated its first lending operation in Azerbaijan to address the critical water supply problems in Baku. The principal objectives of the Greater Baku Water Supply Rehabilitation Project are to make emergency improvements to bring the system as a whole to order, to provide the basis for longerterm planning, and to restore water supply to Baku, particularly to the poor segments of the population. To achieve these objectives, the project supports water demand management, operations and maintenance, improvements in supply, institutional capacity building, and the preparation of a regional water supply and sewerage master plan and a second-phase water supply and sanitation project. The project is intended to be the first in a series of investments to address Azerbaijan's water supply and sanitation needs. 


\section{Social Assessments for Better Development}

\section{Initiating a Social Assessment}

In preparing a water supply project in Baku, the project designers wanted to ensure that the project would place priority on the poor without adversely affecting other social groups and that the resulting development impacts would be sustainable.

To respond to these concerns, the International Development Association (IDA) initiated a social assessment based on rapid user surveys and supporting consultations. These efforts were the first

step toward generating informed public participation in the design of the project. In addition to confirming the need for and acceptability of the proposed project — which included measures to improve water pressure and quality as well as institutional reform - the findings of the social assessment led to the following positive consequences:

Strengthened policy dialogue. The social assessment made significant contributions to the policy dialogue concerning several key issues: the need for full cost recovery and more equitable pricing to encourage water conservation, the need for an adequate policy framework to ensure effective monitoring of the private wells supplying drinking water and the operations of private water vendors, and the need to design water supply improvements that take into account the specific needs of the multiple water users in Baku.

Capacity building. The project includes several measures to strengthen local institutions and ensure effective user participation in project implementation and monitoring as well as in designing follow-up projects to sustain development impacts. The social assessment provided empirical evidence, and made operational recommendations, that enabled the investment project to: (a) provide support to establish a project implementation unit with sufficient capacity to coordinate the implementation of components involving community mobilization and participation; (b) establish a public information and consumer outreach unit within the local water agency to facilitate the flow of information among consumers, suppliers, water agency, and municipality; (c) implement a consumer outreach program to raise awareness about the need to conserve water, participate in leak repair, pay for water, ensure effective metering for improved cost recovery, and carry out necessary repairs and metering; and (d) equip the Baku water agency to ensure effective cost recovery through improved metering and billing as well as to establish the necessary regulatory framework to monitor pipe connections and water vending.

Metering and billing program. The social assessment revealed a willingness to pay for improved water supply and a need to improve citywide water metering and billing to conserve water and improve cost recovery. Thus the project includes a metering program to be implemented in conjunction with improved billing procedures. Additional social assessment findings led to the delineation of guidelines on selecting the types of households and enterprises to be metered during the first phase of investment.

Community-based water leak prevention program. This program would improve water supply conditions for about 40,000 households. The social assessment revealed the potential for community participation in the implementation of the program and led to the identification of key criteria for selecting the first group of beneficiary communities.

Although begun after the initial design of the project, the social assessment generated key information that ordinarily is not available at such an early stage of project preparation. The insights gained from this assessment allowed the project designers to shape the project to meet specific local needs and identify priority measures. The next section discusses the conceptual basis for carrying out the assessment that led to these important conclusions. 
Social Assessments for Better Development

\section{Conceptual Framework for the Social Assessment}

Traditional analyses of water supply systems define water supply conditions in terms of the percentage of population served by a safe water supply. But in Baku - as in many other major cities in developing countries and transition economies - this indicator is useful but insufficient for accurately characterizing the water supply situation or for designing and ensuring the effective implementation of water supply interventions. This indicator is insufficient because:

Defining access to water in terms of the percentage of population served does not reflect the true nature of the service. In Baku, for example, almost 100 percent of the

population officially has access to the public water supply, but the supply is intermittent and of poor quality. Indeed, the Baku water system is so unreliable with respect to quantity and quality as to render the phrase access to water almost meaningless.

Demand studies often fail to recognize that when an essential public service is inadequate, users undertake self-provisioning, thus becoming both suppliers and users. When that happens, the factors that affect user demand for infrastructure are different from those in a situation where users are consumers only.

Water supply studies typically do not take into account the complex water supply situation that emerges when users must adopt various strategies for coping with an unreliable water system. There is a need to understand the behavior of all users in the system, particularly with respect to how each one deals with an unreliable water supply.

Traditional water supply studies fail to take into account that water is used for different purposes and that consumers are willing to pay different prices for different uses of water. Similarly, a user's response to an unreliable water supply is determined by numerous factors, including household and community characteristics.h

In contrast to the traditional approach to defining the water supply situation, a more comprehensive social analysis of the complex interactions within a water supply system is needed to identify appropriate remedial measures.

Such an analysis requires an understanding of the functioning of the formal public water supply system as well as the social factors affecting the entire water demand and supply situation. The conceptual framework used is based on recent World Bank experiences and methodological studies. 1 In this case, such holistic analysis involves identifying the nature of demand and supply to determine the adequacy of the public water supply system and the areas where user demand is not being adequately met, and to identify the nature and costs of the strategies adopted to cope with the situation (figure 3.1).

\section{User Demand}

Three factors define the demand for water: type of water user, specific attributes (in terms of quality and quantity) of the water demanded by each user, and specific activities for which each user needs alternative types of water services.

Water users. A principal element of water demand is the type of user (for example, residential, industrial, or agricultural) demanding water. In Baku, for example, the main types of users are household, industrial, commercial, governmental, and peripheral agricultural, as well as residential and institutional users located outside the city who are served by the Baku water supply network through piped connections, irrigation canals, or vendor services. 


\section{Social Assessments for Better Development}

Demand specification. Water users have different requirements in terms of water attributes, that is, quality and quantity. Measures of quality include taste, odor, appearance (visible solids, color), safety from acute health risks and chronic health risks, and general public confidence that the water is safe to drink. Measures of quantity relate to pressure, which involves both the delivery of water (for example, adequate pressure in

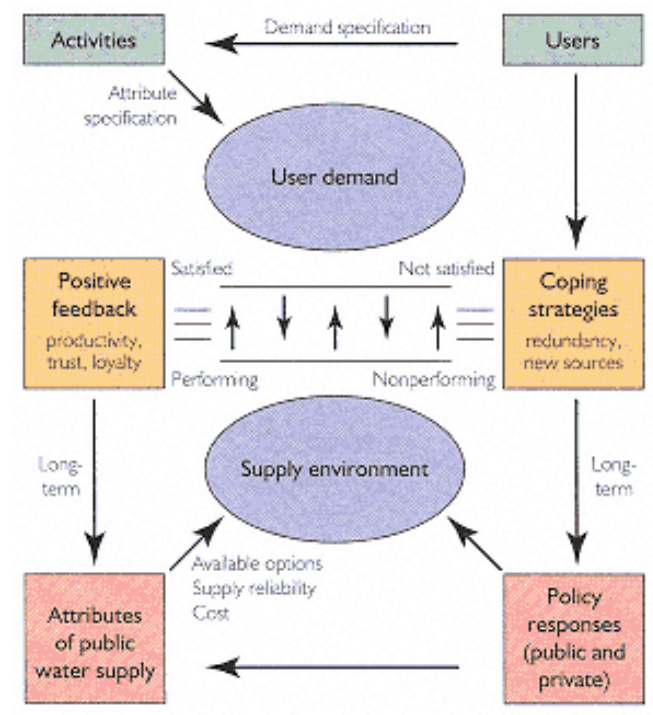

Figure 3.1

Conceptual framework for water use

Source: Humplick, Kudat, and Madanat 1993.

the pipe) and its intermittency (for example, adequate pressure throughout the day).

Attribute specification. The demand for water by various user groups is determined by the nature and level of their activities. For example, Baku households demonstrate a clear preference for more pressure. Although quality is also important to these households - especially the availability of water without visible particulates-the perception that boiling compensates for pollution makes quality considerations secondary to pressure. Industries, by contrast, prefer lower-quality technical water (untreated or recycled public water) or sea water as an input to production. In fact, sea water accounts for 80 percent of industrial water consumption in Baku.

Water Supply.

The main elements determining water supply are the available sources of water, the various physical attributes and uses of water, and the prevailing policy and institutional framework affecting water use and availability. In addition, water supply is closely linked to other infrastructure services, particularly electricity and telecommunications. In Baku this is a key link because the irregular delivery and reliability of the water service is closely related to unreliable power and telecommunications systems. Any attempt to improve the reliability of the water service will have to acknowledge the system's dependence on these two other infrastructure elements.

Water sources. The source of water is a key element of the supply environment. In Baku the main sources are the formal piped water supply system (fed by four different sources), direct access to ground water through private wells, and private vendors who supply water to institutions and households.

Water attributes As mentioned above, water has two major attributes: quantity and quality, as determined by pressure and purity. Water attributes also vary by source of supply (for example, ground water, surface water, 


\section{Social Assessments for Better Development}

piped water).

Policy and institutional aspects. Another important aspect in analyzing user responses to an unsatisfactory water situation is the extent to which consumers communicate with the responsible authorities. The ability of users to interact with public suppliers is an essential component of service delivery. This is one of the main reasons for the growing emphasis on the commercialization of infrastructure services. Thus promoting consumer feedback options and consumer orientation should be an integral part of an overall institutional development process.

Finally, the reliability of the public water supply is defined in terms of the probability that its service characteristics are adequate for the intended purpose. When the supply does not have all of the attributes necessary to satisfy a given user's demand for water, the supply is considered unreliable and the user pursues alternative supply options. Thus households, industries, and other users find ways of coping with inadequate public services and adopt strategies to meet their needs.

\section{Coping Strategies}

Inadequacy in the quality or quantity of water creates different coping responses. In Baku, for example, households make clear distinctions between various types of water (box 3.2). Unsafe water may be boiled and filtered for drinking. But if larger quantities of water are needed for gardening, a well may have to be drilled, and well water will be used regardless of

\section{Box 3.2 There is water and water: some real-life distinctions}

One of the households visited had an elaborate multiple supply system. One pump moved well water into two large storage tanks for use in garden watering. Another pump stored well water in an overhead tank. The house also had two piped water connections. Extremely low pressure in the original pipe connected to the house led to the creation of a second connection to the underground water main. This second connection was linked to a pump that stored water in yet another overhead tank. The household used well water for drinking (without boiling or filtering) and the tap water pumped to the overhead tank for bathing. Apparently, the well water was considered good for drinking but caused itching when used for bathing.

its safety. Industries and other users adopt similar coping strategies. Analyzing these strategies requires attention to the types of strategies adopted, the factors influencing their selection, and the range of costs imposed by the inadequate public water supply.

Types of coping strategies. Enhancement strategies and accommodation strategies are the two main types of coping strategies. Enhancement strategies increase the level and quality of the water supply by supplementing the water available through the public system. Approaches include developing alternative supplies, filtering water for drinking and cooking, and buying water from vendors.

Accommodation strategies, by contrast, adjust behavior to accommodate an unreliable piped water supply. Accommodation strategies might include shifting the hours of doing laundry or bathing to times that correspond to the availability of water. In extreme situations accommodation might mean consuming less water, bathing less frequently, and sacrificing general hygienic standards. 


\section{Social Assessments for Better Development}

Selection factors. Generally, the type of coping strategy adopted by a household is determined by a number of factors (figure 3.2). These factors apply to three different levels:

Household/user. Specific household characteristics (that is, socioeconomic characteristics, cultural background, housing characteristics, gender, age structure) influence the type of coping strategy adopted. For example, high-income households with higher education profiles tend to be more active in searching for safe solutions to their water supply problems. Female-headed households expend more labor than capital in finding alternative water supplies. And, depending on the income generated, some households with garden plots drill wells when it is affordable. For industries and enterprises the nature of production is the principal factor determining the coping strategy adopted.

Settlement. District or neighborhood location is another important factor influencing the choice of coping strategies. Although Baku's water supply is inadequate in all neighborhoods, there are clear community differences in water supply problems and the behaviors adopted to deal with them. Centrality, especially in the western core city, implies universal piped water coverage. In the eastern areas of the city, where there is rapid urban expansion and growing informal settlements, there is a higher willingness to pay for piped water supply. To reflect these differences and to facilitate the analysis and presentation of data on water availability and coping strategies, the study team grouped household data into four distinct zones:

Zone 1. Central city - population densities are high and most residents live in highrise developments. This is the area where national organizations as well as tourism and commercial activities are located.

Zone 2. Western peripheral zone-population densities are high, and most of the residents live in high-rise buildings. Informal housing is widespread, and settlement development is constrained by the hills.

Zone 3. Central eastern zone - contains large industrial plants as well as the informal communities that have encroached

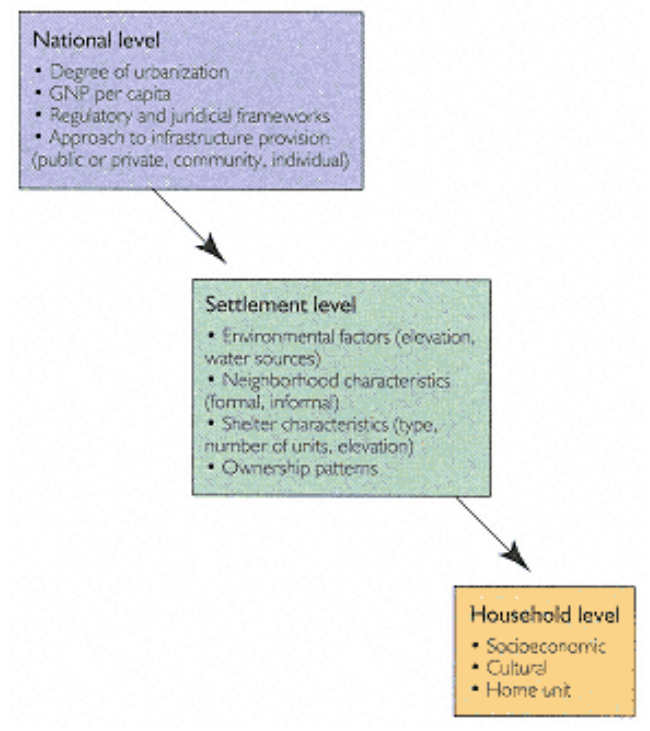

Figure 3.2

Factors affecting user choices of coping strategies

Source: Author.

around them. The periphery of this zone contains new high-rise development. 


\section{Social Assessments for Better Development}

Zone 4. Eastern peripheral zone—-settlements are expanding further into the peninsula.

In characterizing water consumption and household leakage, the study team classified the data by administrative district to reflect the prevailing jurisdictional boundaries established by water supply authorities.

National. Other factors determined at the national level influence the choice and feasibility of alternative coping strategies. These factors include level of urbanization, stringency of the regulatory environment, institutional and policy frameworks, and degree of privatization in the water supply sector.

There are many different ways to classify the behavior of users as they adapt to or change situations that do not fit their needs. Every coping strategy is functional for a specific purpose. Thus it is important to analyze these behaviors to see whether they represent ways of dealing with the system or ways of opting out (that is, exit options). If large numbers of consumers simply give up on the public water supply and pursue self-provisioning, serious damage to water resources could occur. This outcome is especially likely if the industrial or service sectors attempt large-scale extraction.

Policy responses to address the costs of unreliability. A comprehensive analysis of water supply conditions should uncover important information about the social and environmental costs of an unreliable water supply system. Effective policies and interventions to improve the water supply system cannot be designed or implemented without the following information:

Extent to which the cost of coping with an unreliable water supply is higher for the poor and the threat that inadequate performance of water supply institutions poses to poverty alleviation programs.

Extent of labor productivity losses (for example, time and effort spent locating, transporting, storing, boiling, and filtering water that could otherwise be spent on more productive activities, as well as income lost as a result of water-related illnesses) imposed by inadequate water supplies. These losses are difficult to measure.

Private activities adopted to respond to the failure of the public system to function efficiently (for example, buying water from private vendors, erecting permanent storage facilities, selling water storage products, digging or drilling wells, carrying water from public fountains, water pipes, or neighbor's taps).

Extent to which an irregular water supply creates conditions conducive to major outbreaks of infectious disease, especially during the summer. For example, intermittent supply causes negative pressure in the water mains, allowing raw sewage and highly contaminated ground water to enter the system.

\section{Incorporating Social Analysis and Participation into Project Design}

To gain a better idea of the effects water service levels have on Baku residents, in July 1994 the World Bank designed and initiated a social assessment with local collaboration. To carry out this assessment, the Bank called for the support of the local academic community, nongovernmental organizations (NGOs), and the Baku Regional Water Supply Department. The objectives and key elements of the social assessment were designed according to the particular needs of the Baku water situation, the phase of the project cycle, and the resources available to carry out the assessment.

\section{Objectives}

The overall objective of the social assessment was to identify socioeconomic conditions that would affect project design and implementation as well as the potential impact of the project on city residents, particularly the poor. The assessment was also intended as a first step toward initiating a dialogue between the water supply agency and water users. The specific objectives of the social assessment were to: 


\section{Social Assessments for Better Development}

Identify key stakeholders and propose an appropriate framework for their participation in project design and implementation

Evaluate the social impact of the proposed interventions on households and investigate whether certain social groups would be adversely affected

Design social mitigation measures for those who would experience negative impacts, if necessary

Help identify the most critical interventions to be undertaken immediately to improve the water supply situation in Baku

Ensure that project objectives and incentives for change-including cost recovery measures-were appropriate and acceptable to all beneficiaries.

\section{Key Elements}

The social assessment consisted of three basic components: rapid user surveys, consultations, and a stakeholder workshop held at the start of project appraisal. (It is important to note that the social assessment preceded project appraisal.) The cumulative findings of these activities were discussed with key stakeholders and ultimately influenced the final design of the project.

Rapid user surveys. The social assessment included three rapid user surveys - two household surveys and one industrial survey. The first household survey was initiated on July 14, 1994, and completed in fourteen days. A social scientist from the World Bank worked with three faculty members from two of Azerbaijan's higher education institutions to design and pretest a household questionnaire focusing on water availability, water quality, and strategies to cope with an inadequate public water supply. About 150 interviews were conducted directly by this core team. In addition, ten local interviewers were trained to conduct an additional 400 interviews. 2 Most of the coding was carried out by the core team to gain greater familiarity with the data, understand their shortcomings, and help design and lead community discussions that would clarify special issues. This interactive system gave the survey team a better understanding of user behavior.

The first survey focused on household water availability and strategies to cope with an unreliable supply. A key finding of the survey was the discrepancy between the apparent abundance of water resources, the seemingly economical use of water in households, and the inability of the local water agency to satisfy local demand.

Consequently, a second household survey involving another 400 households was conducted to examine the number, location, and size of leaks within individual households; assess the costs of leak repair and households' ability to invest in leak repair; calculate the amount of water used by households for various purposes; compare the amounts of water used and lost; and, based on the results of this survey, formulate policy recommendations for future improvements in the water supply situation in Baku.

Early results of the first social assessment were shared with the borrower, and a commitment was made to adopt a participatory approach in project design and implementation. To be effective, however, it was recognized that such an approach must be based on an understanding of the behavior of all stakeholders-households and other water users (for example, industry and agriculture) — all of whom should be given an active role in project design and implementation.

This led to a rapid industrial survey of a rather difficult nature. It involved macroeconomic studies on industrial output and water use (carried out by local academics), analysis of reports provided by the Baku water agency, and a survey of fifty-one enterprises focusing on water consumption, recycling, metering, and cost recovery. 


\section{Social Assessments for Better Development}

Consultations and case studies. To complement the rapid surveys of households and enterprises, the social assessment involved various consultative activities and limited, in-depth case studies. These included:

Institutional analyses and reviews of socioeconomic and demographic data.

Community-based discussions conducted through informal household visits and group interviews in the temporary shelters of displaced populations.

Participatory assessment discussions held with NGOs such as the Women's Committee

and the Committee for Refugees and Displaced Populations. These groups' weekly regional meetings were used as a forum for needs assessment, agreement on tactics, and implementation strategy development.

Discussions held with representatives of the European Bank for Reconstruction and Development (EBRD), United Nations Development Program (UNDP), United Nations High Commissioner for Refugees (UNHCR), and the International Monetary Fund (IMF).

Meetings with representatives of local and national governments, including the deputy prime minister, mayor of Baku, deputy prime minister for refugees and displaced population affairs, deputy director of the State Statistical Office, and director and staff of the Ministry of Housing and Communal Property.

Visits to informal and private sector agencies—-such as water vendors and water storage tank producers and installers-serving households.

Case studies of a small subset of households, including those with garden plots, to identify the coping strategies used to deal with shrinking incomes and acute economic difficulties.

Stakeholder workshop. The results of the social assessment were presented at a stakeholder workshop at the start of project appraisal. The workshops involved seventy-two participants, including representatives from all sectors of society, user groups, government ministries, local NGOs, the academic community, the media, and donors. $\underline{3}$ The meeting generated substantive participation and a high level of consensus on each component and policy aspect of the project. In addition, wide coverage of the stakeholder workshop by the media generated extensive interest and support for the project by many segments of the country's population.

With respect to the findings of the social assessment, the participants strongly endorsed the establishment of an autonomous water agency to ensure full cost recovery, a leak prevention and community repair program, a public information campaign to encourage water conservation and ground water monitoring, and a capacity-building component to improve governance, ensure public participation, and improve consumer relations. The workshop also encouraged sustainable future investments to improve Baku's water supply and sanitation services, and stressed the need to invest in sewerage facilities and industrial waste water management in subsequent projects.

\section{Key Findings of the Social Assessment.}

The social assessment revealed trends relating to water availability, consumption behavior patterns, and cost recovery that substantially influenced the design of the water supply project (figure 3.3 and table 3.1-3.4). This section presents the empirical findings from the three user surveys. The next section discusses their implications for the design and implementation of the project and future investments. 


\section{Household Water Availability and Consumption}

Although most residents are connected to water, most believe piped water is unsafe to drink.

Water availability. Although nearly 100 percent of Baku's households are officially connected to the public water network, almost all households lack an adequate water supply. Throughout the city water supply is intermittent; Baku households receive water for an average of about eleven hours a day for twenty-two days of the month. In different parts of the city, however, daily and hourly availability of water vary substantially, with availability closely related to geographic zones, socioeconomic factors, and housing characteristics (see table 3.1, figure 3.3). For example, although every neighborhood and income group contains households that suffer from inadequate water supply, low-income groups bear the greater burden of the shortage (see table 3.2). The average number of hours of water available per day is higher for occupants of single-story houses (see table 3.3). And residents living on the higher floors of buildings receive less piped water than those living on the lower floors (see table 3.4).

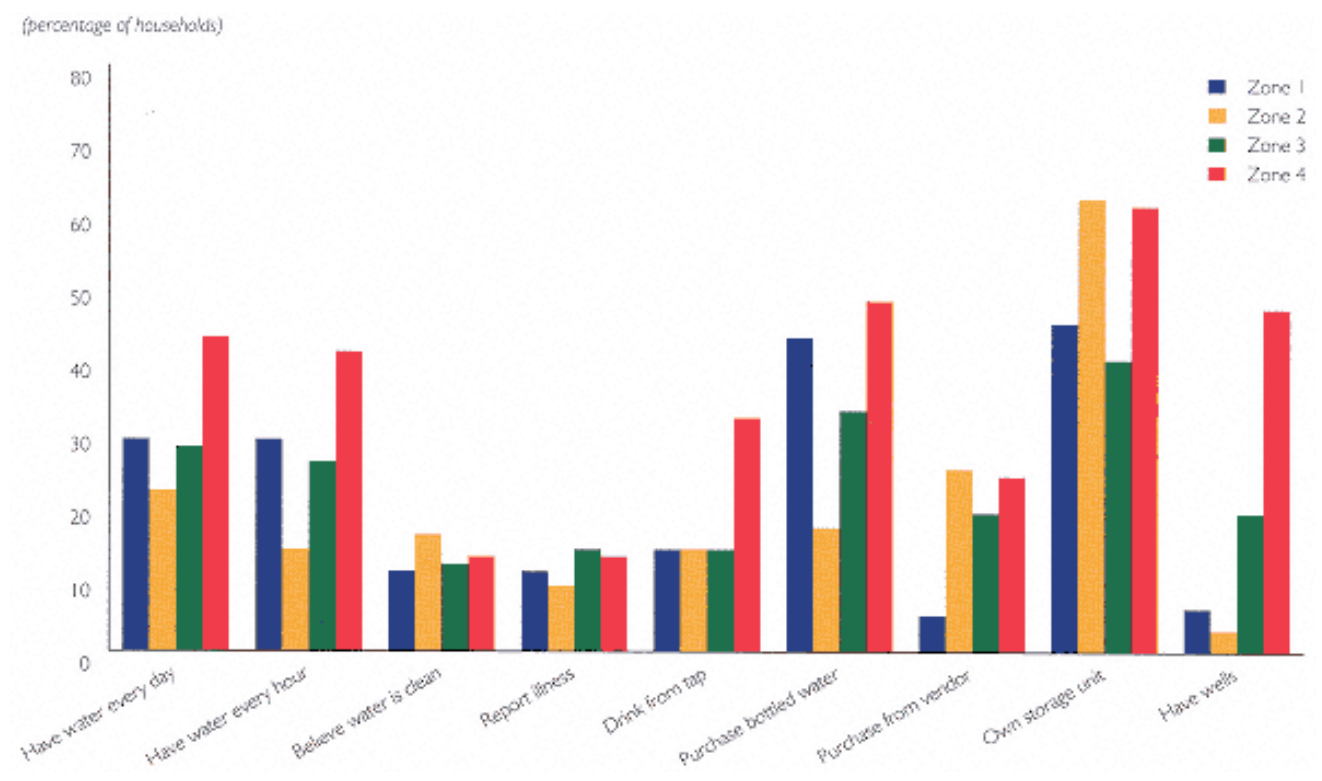

Figure 3.3

Water availability and related statistics, by residential area

Note: Zone I is the central city, zone 2 is the western peripheries,

zone 3 is the central eastern areas, and zone 4 is the eastern peripheries.

Source: User surveys.

Most households that receive water every day of the month (one-third of the population) have backup systems or tap into other sources of water.4 Indeed, a third of these households - which have only slightly higher levels of income and home ownership than the rest of the city-attribute their good supply to investments in private wells. In other cases households obtain daily running water because they pipe into the waste steam of a nearby oil refinery and convert it to hot water. More than half the households have water storage facilities with electrical pumps.

Water quality. Among Baku residents 87 percent perceive piped water as being unsafe for drinking; only 21 percent of the households reported that they drink water directly from the tap. $\underline{5}$ These residents had many reasons for believing that tap water is unsafe (figure 3.4). Authorities do not deny this sad reality, and this was why the government asked for Bank financial assistence. The perception that water is unsafe is supported by a high 


\section{Social Assessments for Better Development}

incidence of water-related diseases (figure 3.5). Because storing worsens the quality of water, households that have access to water on a daily basis also have a lower reported incidence of water-related illness.

Insufficient water pressure is the most important cause of the unreliable and intermittent water supply as well as of its poor quality. Low pressure is caused by leaks, illegal connections, and poorly functioning pumping stations. Low pressure in the water mains makes it easier for sewage, contaminated ground water, and other pollutants to enter the distribution system.

Household water consumption. Per capita water consumption (not including losses) in almost all districts of the city ranges from 60 to 80 liters a day, well below the Western average of 250300 liters a day per capita.

According to the survey, most water is used for bathing (90.2 liters a day per household) and for washing clothes (69.4 liters a day per household). The third largest share of water (54.4 liters a day per household) is used for a Baku-specific purpose: water storage. As discussed below, water is stored in bathtubs, tanks, and other containers to provide water when public water is unavailable. Household interviews found that storage containers are emptied and refilled as soon as there is fresh water.

Table 3.1 Water availability: characteristics by zone (percent, unless otherwise noted)

\section{Characteristic}

Have water available every day of the month

Number of days water availability per month

Have twenty-four hour water availability 29 (when water comes)

Number of hours of water availability per 11.8 day

Own private home

Number of people in household

Number of working people in household

Average cost of rent (manats)

Average cost of electricity (manats)

Average cost of water bill (manats)

Stated monthly income (manats)

Estimated monthly income (manats)

Are willing to pay 200 manats for water

Are willing to pay 500 manats for water

Are willing to pay 1,000 manats for water 61

\section{Zone 1 (central city)

\begin{abstract}
Zone 2
peripheries)
\end{abstract}

29

24

21

4

2

134

156

90

55,463

105,695

91

85

1

22

20.4

14

8.2

45

5

2

86

179

84

43,714

79,285

91

79

55

31
Zone 3

(central eastern

areas)

28

19.6

26

10.6

45

5

2

124

172

95

38,020

57,938

95

86

70

53
Zone 4

(eastern

peripheries)

43

24

41

14

49

4

2

140

204

109

39,128

77,574

98

90

66

58 
Are willing to pay 2,000 or more manats for water

Believe the water is clean

Report illnesses due to the water

$11 \quad 16$

12

13

Purchase bottled drinking water

119

14

13

Monthly cost of bottled drinking water

43

17

33

48

(manats)a

1,793

1,733

1,626

1,447

Buy water from vendors

5

25

19

24

Monthly cost of water vendors (manats)a

500

1,525

1,639

2,209

Own water storage units

45

62

40

61

Fixed cost of storage units (manats)

69,166

89,857

84,000

108,687

Drink water directly from the tap

14

14

14

32

Have wells

6

Cost of wells (manats)

50,000

3

19

47

Transport water

68

150,000

52,917

98,704

Total cost of coping (manats)

1,347

70

65

45

Percentage of Baku residents living in 26

1,125

1,450

2,616

each location

24

21

Note: 1,000 manats $=$ US $\$ 1$.

a. Average for those with a positive response.

Source: Household surveys.

Table 3.2 Water availability: characteristics by income group

(Percentage, unless otherwise noted)

\section{Characteristic}

Have water available every day of the month

Have twenty-four hour water availability

Average number of hours of water availability per 11.5 day

Own private home

Number of people in household

Monthly cost of rent (manats)

Monthly cost of electricity (manats)

Estimated monthly income (manats)

Are willing to pay 1,000 manats for water

Are willing to pay 2,000 or more manats for water
Less than

100,000 manats

31

26

27

4

154

173

44,871

66

56
100,000 manats

and more

43

34

14

49

5

145

221

156,524

91

90 
Report illnesses due to the water

Buy water from vendors

Monthly cost of water vendors (manats)

575

Own water storage units

Fixed cost of storage units (manats)

91,024

Drink water directly from the tap

Have wells

Fixed cost of wells (manats)

Note: 1,000 manats $=\mathrm{US} \$ 1$.

Source: Household surveys.

Table 3.3 Water availability: characteristics by type of residence (percent, unless otherwise noted)

Characteristic

Have water available every day 26

of the month

Have twenty-four hour water $\quad 22$

availability (when water comes)

Average number of hours of $\quad 10.5$ water availability per day

Own private home 22

Number of people in household

Average cost of rent (manats)

Average cost of electricity (manats)

Average cost of water bill (manats)

Stated monthly income (manats)

Estimated monthly income (manats)

Are willing to pay 1,000 manats 62

for water

Are willing to pay 2,000 or more 48 manats for water

Believe the water is clean

Report illnesses due to the water 13

Purchase bottled drinking water 36
Single-story

house

40

39

12.6

78

5

81

219

82

44,300

82,309

64

46

25

9

34 


$\begin{array}{lll}\text { Buy water from vendors } & 7 & 41 \\ \text { Own water storage units (manats) } & 43 & 69 \\ \begin{array}{l}\text { Fixed cost of storage units } \\ \text { (manats) }\end{array} & 41,254 & 81,189 \\ \text { Drink water directly from the tap } & 14 & 31 \\ \text { Have wells } & 12 & 51 \\ \text { Cost of wells (manats) } & 91,600 & 108,333 \\ \text { Transport water } & 69 & 46 \\ \text { Distribution } & 68 & 32 \\ (\mathrm{n}=405) & (\mathrm{n}=275) & (\mathrm{n}=130)\end{array}$

Note: 1,000 manats $=$ US $\$ 1$.

Source: Household surveys.

Table 3.4 Water availability: characteristics by floor level (percent, unless otherwise noted)

\begin{tabular}{llll} 
Characteristic & First floor & $\begin{array}{l}\text { Second } \\
\text { and third floors }\end{array}$ & $\begin{array}{l}\text { Fourth floor } \\
\text { and higher }\end{array}$ \\
$\begin{array}{l}\text { Receive water every day } \\
\begin{array}{l}\text { Number of days of water per } \\
\text { month }\end{array}\end{array}$ & 51 & 27 & 19 \\
$\begin{array}{l}\text { Receive water for twenty-four } \\
\text { hours }\end{array}$ & 45 & 23 & 21 \\
$\begin{array}{l}\text { Number of hours of water per day } \\
\text { Fetch water }\end{array}$ & 14.4 & 31 & 9 \\
Time spent fetching water & 57 & 12.7 & 7.6 \\
\hline
\end{tabular}

(minutes)

Source: Household surveys.

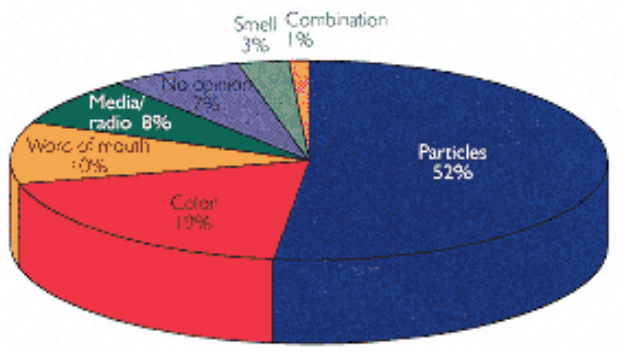

Figure 3.4

Reasons for thinking tap water is unsafe Source: User surveys.

This pattern is not followed in two administrative districts: Binagadi, where water use is significantly higher than the city average (125 liters a day), and Azizbekov, where residents consume significantly less (45 liters a day; 


\section{Social Assessments for Better Development}

figure 3.6). These disparities are caused by the distance between these two areas and the nearest water pump or distributor. In Binagadi, where a main distributer pump is located, there is enough water pressure to provide more water to the area's population. People in Azizbekov consume less water because the area is located at the

far end of a network branch, where there is substantially less pressure.

Additional findings of the social assessment reveal how consumption changes according to floor level and household size. $\underline{6}$

Floor level. According to the social assessment, per capita water consumption is highest on low floor levels (first to third floors, 82.5 liters a day), considerably lower on middle levels (fourth to sixth, 75.6 liters), and lowest on high levels (above the sixth floor, 71 liters). This pattern of consumption correlates with better water pressure and supply on the lower levels. To consume even small amounts of water, however, residents on the higher floors must store more water than their neighbors below. The level of water stored is also a function of floor level. On the first through sixth floors about 15 liters per capita are stored each day. On higher floors this amount increases to 20 liters per capita per day (figure 3.7a).

Household size. Larger households use more water than smaller families, but per capita consumption is lower in larger households (figure 3.7b). Large households (more than six people) have a much lower real per capita water consumption (47 liters a day) than medium-size (four to six people; 64 liters a day) and small households (one to three people; 106 liters a day), with high statistical significance. Given the current water tariff system, which is based on household size ( $\$ 0.07$ per household member per month), the larger the family, the higher the tariff per liter of public water consumed.

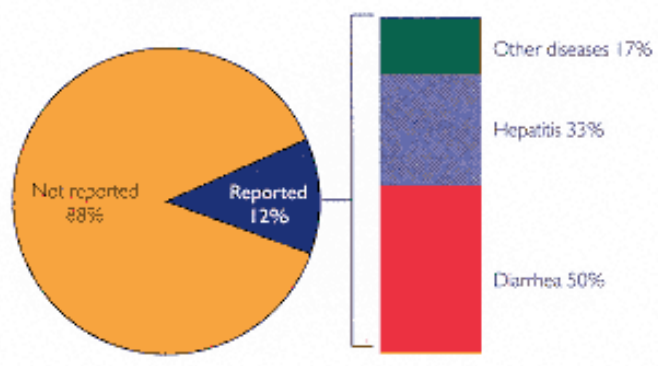

Figure 3.5

Water-related illness

Source: User surveys.

(This clearly suggests that the water agency should base its tariffs on water quantity consumed. Of course, such a system would require water metering, which currently exists only for public institutions and industries.)

\section{Household Coping Strategies}

The expectation that Baku's water supply will be intermittent and of low quality is universal. Practically everyone is prepared to cope with the unreliable supply in one way or another. As discussed earlier, households react either by adjusting their behavior (accommodation) or by adopting coping strategies designed to improve the level and quality of water consumed (enhancement). The tendency to adopt a coping strategy for water used for drinking and cooking, however, is considerably higher than for water used for other purposes.

Most households adopt one or more of the following strategies: installing overhead storage tanks, reducing water use, digging or drilling wells, participating in community action to create joint options, increasing the time and 


\section{Social Assessments for Better Development}

effort spent transporting water, and purchasing water from vendors or buying bottled water (table 3.5).

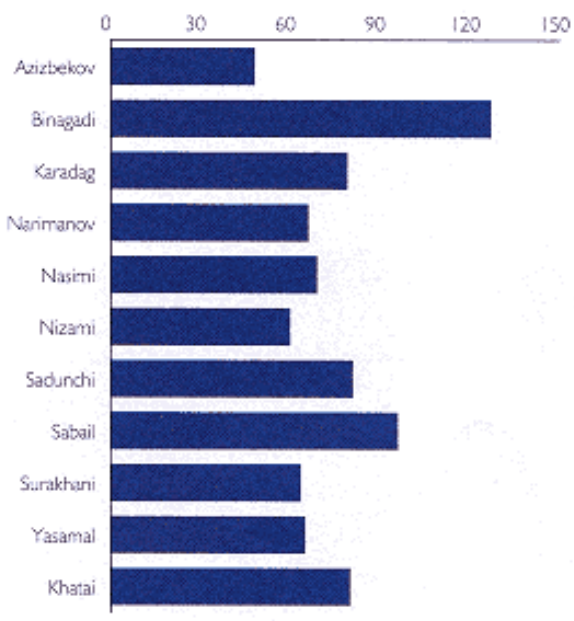

Figure 3.6

Daily per capita water consumption, by district

Source: User surveys.

Households at different income levels experience different levels of unreliability and respond in different ways. For example, households with high incomes and high levels of education are more active in searching for safe solutions to their water supply problems than households with low levels of income and education.

Female-headed households have more trouble coping and appear to expend more labor than capital. In areas where small-scale agricultural activities supplement incomes, households with garden plots dig or drill wells when it is affordable. Again, depending on the income generated from their gardens, these households also install large overhead tanks with storage capacities of up to five tons. By contrast, households living in apartments store water either in small buckets or in 400500 liter storage tanks installed in bathroom ceilings.

Among the various coping strategies, storing water is a universal response to supply intermittency. The survey found that 53 percent of households already have invested in built-in or overhead storage tanks and that all homes have pots, kettles, buckets, or barrels explicitly set aside for this purpose. Of those with fixed storage facilities, 71 percent are able to have running water for twenty-fours hours a day if the supply is not interrupted for many consecutive days.

Storage tanks in apartments are usually installed in the bathroom ceiling and linked directly to the piped water system. Because the system is decentralized, inadequate water pressure in a particular apartment can cause storage tanks to remain empty for a long time. Thus whenever there is water in the pipes, all households first fill small pots, kettles, and buckets before running water from their pipes. People living in single-story homes have more elaborate systems of connecting storage units to piped water or wells and use pumps. And people living in large buildings may have huge storage facilities in their basements. On average, households with fixed storage units have the capacity to store 948 cubic centimeters of water. The average cost of these facilities was $\$ 92$ at the time of the survey (July 1994). 7

Households adopt a range of coping strategies in response to the poor quality of water. Boiling is the most popular approach, and is used by 75 percent of households. Other households (12 percent) use a container with large stones, known to be an effective filtering device, some (9 percent) have their own filter machines, and the rest (4 percent) use a combination of methods, some of which are quite elaborate (box 3.3). 
The four city zones clearly differ from one another in terms of their access to water and in the strategies they adopt to cope with shortages. In addition, the type of housing (that is, whether households reside in single-story homes or highrise apartments) and the floors that households occupy influence the nature and extent of their
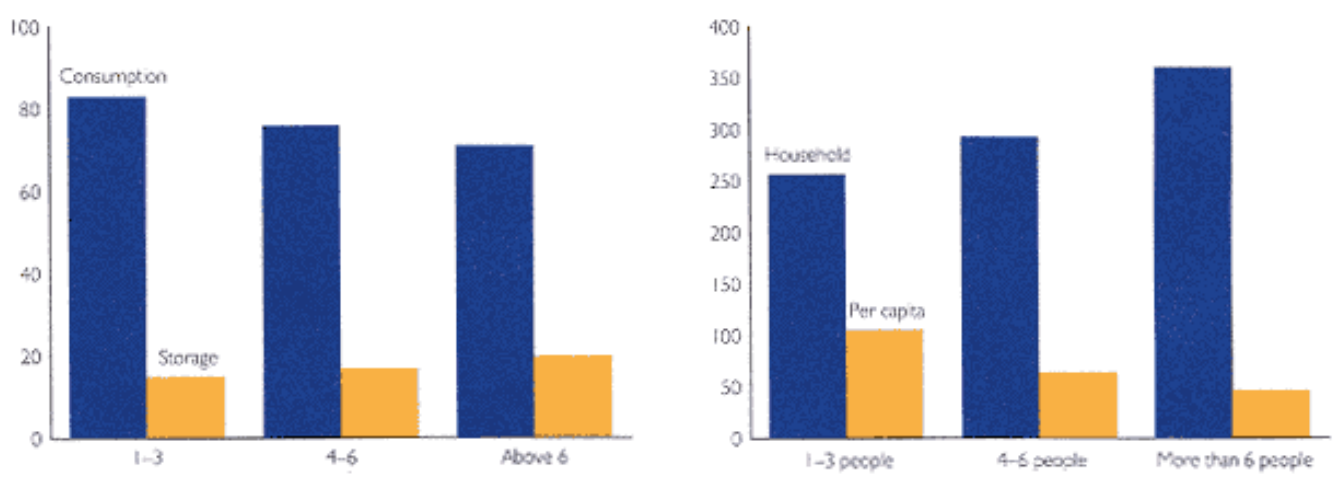

Figure 3.7

Household water consumption and storage Source: User surveys.

water problems as well as their solutions (see tables 3.3 and 3.4).

Costs of unreliability. Households in Baku face substantial net costs from the unreliable water supply. These costs come in three forms:

Opportunity costs. These are the costs of forgone opportunities in areas where the water supply is unsuitable for household purposes and coping strategies cannot adequately compensate. These costs are most evident in households with a yard for vegetable or flower production but no access to a well or a sufficient supply of tap water. Another example is when a contaminated water supply leads to illness that causes household members to miss work and spend time and resources on medical treatment. In some parts of the city as many as 12 percent of households report illnesses directly attributable to poor water quality. Another opportunity cost is the substantial amount of time spent trans-

\section{Table 3.5 Responses to water supply unreliability and average costs of water}

Response

\section{Strategies at the community level}

Use of steam from nearby oil refineries

Pumping water from nearby industries

Sharing vendor services with nearby enterprises

Investing in community fountains or making public main pipes serving in-kind a community

\section{Strategies at the household level}

Long-term fixed investments

Investments in new source generation
Indicative cost

(US\$)

100200/fixed

100200/fixed

13/monthly 
- Motorized wells

- Hand-dug wells

- Connections to water mains and installing pumping systems

Investments in storage facilities

- Overhead storage tanks with pumps connected to piped water

Concrete or fiber glass

Metal

Recycled material

— Overhead storage tanks with connections to wells

Concrete

Metal

Recycled material

- Storage tanks installed in kitchens or bathrooms connected to the city $3050 /$ fixed water

— Large water heating units with storage capacity

Investments in additional space

- Closure of balconies for storage

Short-term fixed investments

Purchase of metal barrels and buckets

Pots and kettles

Plastic containers

Purchase of filter machines

Acquiring traditional filter stones

Maintenance activities

Repair of pumps and pipes

Change of filters

Recurrent expenditures

Energy costs of water boiling

Purchase of bottled water

Purchase of water from vendors

Water transport arrangements

Collection from public facilities

Collection from neighbors

Savings 200500/fixed

100200/fixed

5070/fixed

50100/fixed

20300/fixed

10100/fixed

2001000/fixed

20300/fixed

10100/fixed

5060/fixed

50/fixed

520/56 years

510/56 years

$210 / 3$ years

$30 / 10$ years

10/fixed

12/annual

1/annual

12/annual

1520/annual

13/monthly 


\section{Social Assessments for Better Development}

Recycling of water for different uses

Reduced home cleaning

Reduced personal hygiene

Behavioral modifications

Excessive tea drinking as water substitute

Reduced consumption of fresh food

Source: Household surveys.

\section{Box 3.3 Boiling, filtering, flowering: the family way to clean water}

During one household visit the study personnel were offered water in a decanter covered with a hand-crocheted cloth. They were told that the water was first boiled, then filtered through a handkerchief. It was then left to settle for some hours. The top of the water was then transferred to another pot for reboiling with carnation and other flavors, and filtered once more before refrigeration. After all this, members of the household reported that the water tasted very good.

porting or fetching water. Women and children often must bear these burdens. If long distances are involved, it is not unusual for women to spend hours trying to locate a source of running water and then carry the water home (box 3.4). The average household opportunity cost for fetching water (in terms of forgone income) varies from 4 percent (high-income group) to 16 percent (low-income group) of household income.

Financial costs. These are the out-of-pocket costs of coping strategies (for example, a drilled well with facilities for pumping water to large overhead tanks can cost up to \$600). On average these costs range from $\$ 1.50$ to $\$ 2.00$ (July 1994 prices), $\underline{8}$ although the payments made to vendors and the costs of installing overhead storage tanks, drilling wells, installing pumps to link city water or well water to storage systems, and purchasing

\section{Box 3.4 Social vulnerability also means dirty water}

One poor household that was visited exemplified how social vulnerability decreased the chances for coping with inadequate water. The household was composed of an elderly mother and two daughters in their early twenties. The mother worked as a cleaner and received a \$6 monthly salary plus some food. One of the daughters was handicapped and received $\$ 6$ a month in state support, while the other daughter took care of the house. There was no piped water connection to the neighborhood, and many neighbors had private wells. The handicapped daughter dug a well with her hands. During the rainy season the house was flooded and water surfaced from the well. Although muddy, this water was used for poultry and laundry. For other purposes, there were several oil barrels in the garden that a vendor filled once a month for $\$ 0.30$. When the barrels ran out of water or when the family had no money to secure the services of a vendor, the mother carried a small bottle of water home from work.

bottled water add up to many times the monthly bill paid to the water agency. $\underline{q}$ The highest costs are borne by the poorest segment of the population, who live where water is most unreliable and who cannot afford an alternative 
supply. Because low-income households have fewer resources, they are more likely to pursue an accommodation strategy, such as reducing the amount of water consumed, than an enhancement strategy, such as building a storage tank or purchasing bottled water. Consequently, the welfare loss associated with an unreliable water supply falls disproportionately on low-income households.

Social costs. The expectation that the public water supply will be unreliable induces some households and enterprises to drill a well to provide an alternative source of water. Well drilling may gain greater popularity as the reliability of piped water decreases and incomes increase. Because ground water is of questionable quality, however, private wells may pose health risks. Similarly, there are health risks associated with purchasing water from unregulated vendors. $\underline{10}$

Households in Baku face substantial costs in responding to an unreliable water supply. An examination of the impact of these costs on different income groups reveals that they are regressive. Low-income households spend a significantly higher percentage of their income on coping strategies than high-income families (figure 3.8). 11

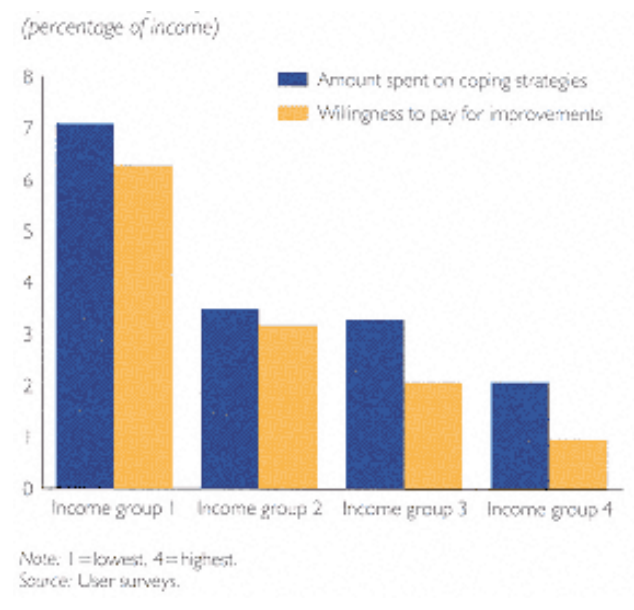

Figure 3.8

Coping expenditures and willingness to pay, by income group

Note: $1=$ lowest, $4=$ highest.

Source: User surveys.

This is especially true in the eastern parts of the city, where people live in small apartment units in high-rise buildings, and in the eastern peripheries (zone 4), where shanty towns are mushrooming, water problems are acute, and incomes are lower than elsewhere in the city. In addition, outside the city boundaries, where displaced populations have been settled temporarily, there is a severe shortage of water. Many of these areas are not linked to the piped system and receive water transported by truck. These trucks are frequently diverted from their main routes to provide water to households that can afford to pay cash. 12

Finally, an examination of the components of total coping costs (vendors, bottled water, tanks, wells, and opportunity costs) revealed that some income groups spend more on a particular strategy than others (figure 3.9).13 In the low-income group, for example, the largest share of coping costs goes to vendors, followed by bottled water and fetching opportunity costs. In all other groups the largest percentage of coping costs is spent on bottled water, followed closely by vendors (income groups 2 and 3) and tanks (group 


\section{Social Assessments for Better Development}
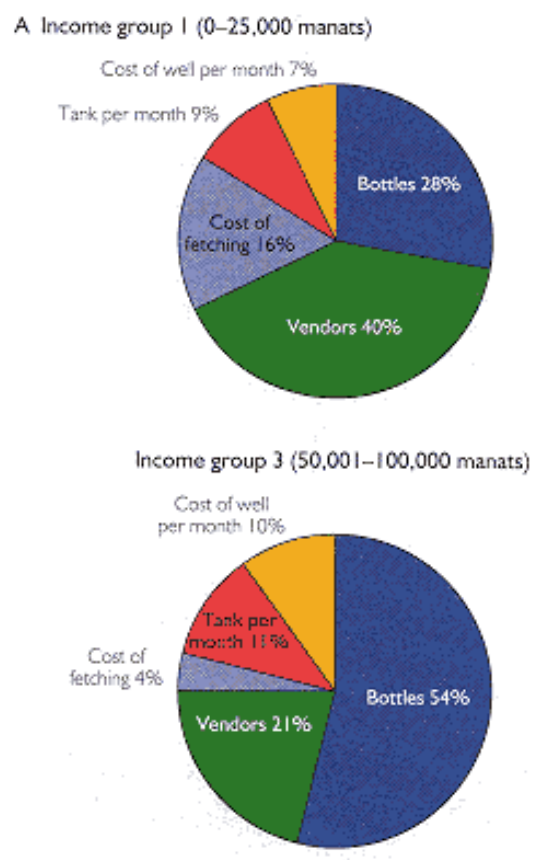
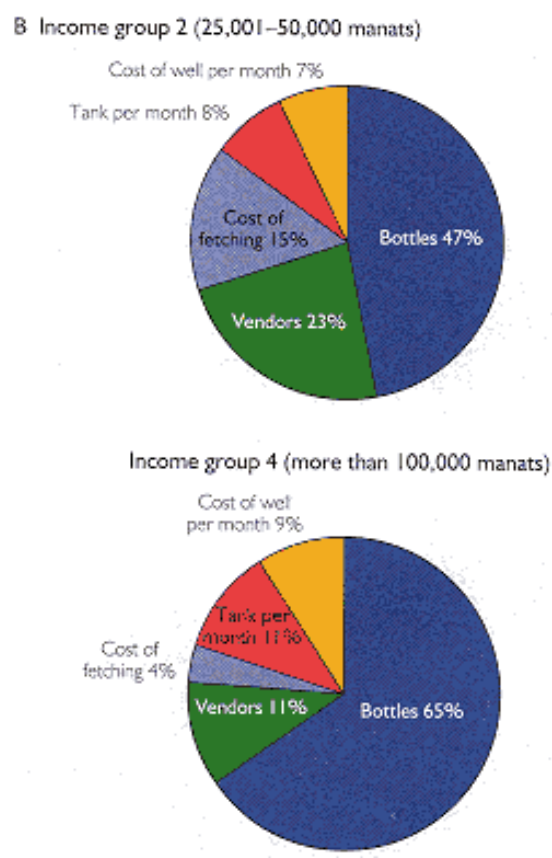

Figure 3.9

Coping costs, by income group

Source: User surveys.

4). In addition, storage devices have become an important coping tool in the higher-income groups, and the lower-income groups face higher opportunity costs for fetching.

Willingness to pay. At the time of the survey (July 1994) an average monthly water bill (\$0.10) cost about the same as a loaf of bread, and many households were paying large sums to enhance their access to safe water. Most households, therefore, are willing to pay more for water, generally without conditions (that is, without asking for conditions to make payments for an improved water supply in the form of subsidies from the government). Almost all households (94 percent) are willing to pay twice as much as they were paying at the time of the household survey, and 85 percent are willing to pay about five times more. Nearly two-thirds would pay ten times more if substantial improvements were made in the water supply system. And more than a third of the households (47 percent) reported that they would pay more than twenty times more if they could get

water regularly (figure 3.10).14 Moreover, the social assessment found that there is a clear relationship between income level and willingness to pay. Poor households are willing to spend a substantially larger share of their income on improved water services than better-off families (see figure 3.8).

A closer look at the correlation between willingness to pay and other household-related variables reveals that families that have invested in a well are significantly less willing to pay more for water than others (with willingness to pay measured as the percentage of income a household would agree to spend for better public water service). Further, the larger the household and the higher the current availability of public water, the less willing Baku residents are to pay more for a better system.

Finally, a comparison of willingness-to-pay figures with total water expenditures reveals a very different picture from the one described above. Although it is significant that households are willing to pay many times their current formal water payments, this reflects only a part of the actual water situation. The payments these households are willing to make for improved water service have to be compared with the total costs of their 
coping strategies. When all costs to

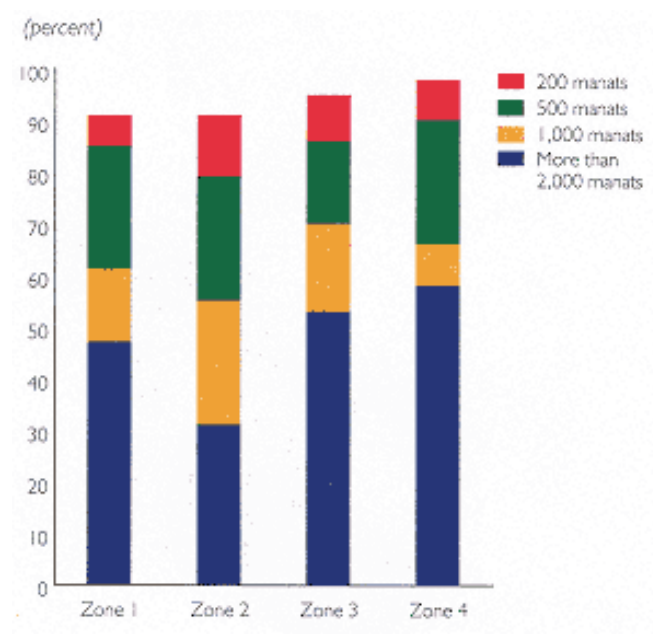

Figure 3.10

Willingness to pay more for water supply, by residential area

Note: Zone I is the central city, zone 2 is the western peripheries, zone 3 is the central eastern areas, and zone 4

is the eastern peripheries.

Source: User surveys.

secure a water supply are added together - the cost for vendors and bottled water, the opportunity cost of fetching, and the depreciated capital cost of fixed investments (excluding operating costs 15 ) — households pay an average of 1,680 manats (\$1.68) a month for additional, nonpublic water. Consequently, their willingness to pay up to 2,000 manats (\$2) a month would be only a minor increase in their actual payments.

\section{Household Water Leakage}

Water leakage is one of the main reasons Baku's water is intermittent and of poor quality. Indeed, the city's water supply crisis can be fully appreciated only when the quantities of water consumed by households are compared with the quantities lost. For every 300 liters of public water used per day by an average family in Baku, 400 liters are lost. On a per capita basis these figures are 80 liters and 100 liters, respectively.

Household leakage is a principal source of water loss in Baku. On average there are 2.1 water leaks in the home of a Baku family, regardless of income. This figure is substantially higher for the districts of Azizbekov, Binagadi, Karadag, Sadunchi, and Surakhani (figure 3.11). These leaks occur throughout the household, as well as in the yard and garden plots, and cause considerable damage. Most water is lost from toilet leaks (26.08 liters an hour) and bathroom leaks (19.95 liters an hour). Kitchen leaks and leaks directly from public pipes contribute slightly smaller amounts (14.52 and 13.49 liters, respectively). Moreover, a substantial amount of water (15.70 liters an hour) is lost through leaks in storage units.

Across income groups households say leak repair costs range from $\$ 12.5$ to $\$ 17.5$. Most households, however, do not even have half of this amount to repair leaks. Only families in the highest-income category (22.7 percent of the population) can afford to repair all the leaks in their homes (figure 3.12). Almost all respondents, however, pursue a monthly leak control strategy rather than spend a large lump sum on complete repairs. These monthly expenses average about $\$ 1$, or 3 percent of average household income. Residents claim that they continuously 


\section{Social Assessments for Better Development}

have to invest small sums in leak repair to avoid damage to water installations and apartments. They do not have time to save enough for thorough repairs and major replacement parts.

Baku residents perceive leaks in the water distribution network as one of the main reasons for the current water supply crisis. When asked to identify possible causes for the unsatisfactory water situation, most respondents (359 of 410) cited damaged pipes, followed by lack of repair and maintenance (285) and serious breaks (280). To residents these factors seem more important than consumption-related causes such as excess consumption (264) or nonpayment of water bills (147). When asked for priority improvement measures, 88 percent of respondents mentioned network repair, followed by water conservation (306) and a public awareness/media campaign for water conservation (278).

Another important factor influencing the incidence of leaks in buildings is the agency responsible for repairing leaks in specific buildings. The number of leaks per household is substantially smaller in buildings where a house maintenance office (1.78 leaks) or the water agency (2.19 leaks) is responsible for dealing with leaks than in buildings where residents (2.88 leaks) or private repair persons (4.0 leaks) have to take care of leaks.

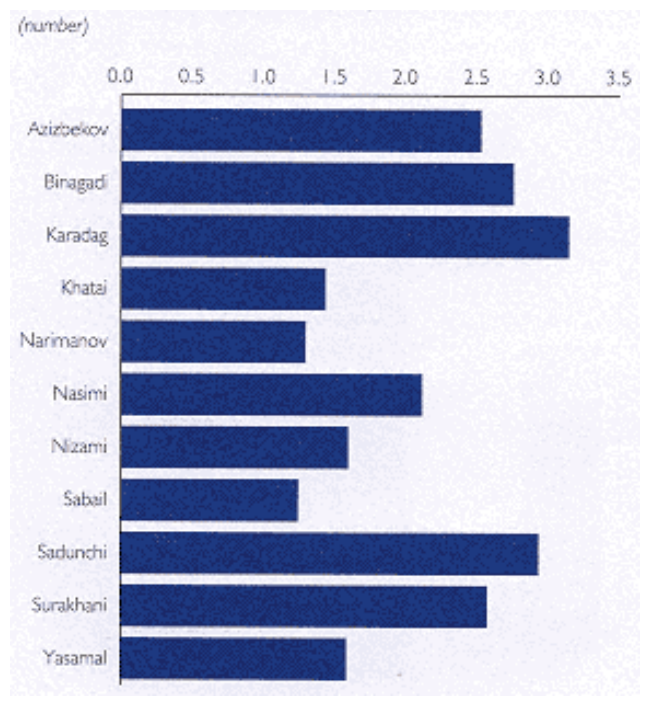

Figure

3.11 Household leaks, by district

Source: User surveys.

As the amount of water supplied by the public agency has increased, so too has the amount of water that is lost. For example, assuming that water is supplied by the water agency for an average of four hours a day throughout the city, the water loss is about 100 liters per capita per day. If water is supplied for six hours a day, the water loss is 150 liters per capita per day. And if water is supplied for eleven hours a day, the water loss is 275 liters per capita per day. Any improvement in the quantity of water supplied per day, therefore, will need to be accompanied by measures to repair household leaks and to deal with the other causes of intermittent supply and poor water quality (that is, illegal pipe connections and dysfunctional pumping stations) that require improvements in the main water supply network.

\section{Industrial Water Consumption and Coping Strategies}

At the time of the industrial survey (November 1994) 270 industrial enterprises were located in the eleven districts of Baku. Karadag, Narimanov, Nasimi, and Sabunchi contain the most enterprises, but production capacity is highest in Nizami, Khatai, and Narimanov (table 3.6). 
Since the late 1980s industrial output has decreased substantially, mainly because of the

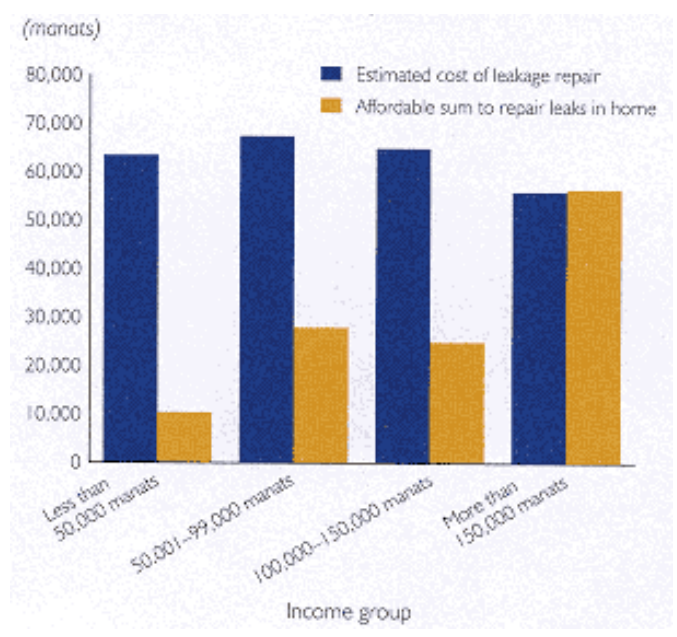

Figure

3.12 Estimated costs and available funds to repair leaks, by income group

Source: User surveys.

Table 3.6 Enterprises and industrial output, by district (percent)

District

Baku, Total

Binagadi

Karadagh

Azizbekov

Narimanov

Nasimi

Nizami

Sabunchi

Sabail

Surakhani

Khatai

Yasamal
Share of industrial enterprises

100

8.3

10.6

7.9

14.5

10.3

9.4

10.3

5.2

6.3

9.9

7.3
Share of industrial output

100

4

6

13

17

6

21

5

3

5

17

3

Source: Industrial surveys. 


\section{Social Assessments for Better Development}

disruption of economic links with Russia and other former Soviet states after the breakup of the Soviet Union. Other reasons include the general economic hardships caused by privatization and the move toward a market economy, and the ongoing strife with Armenia. Between 1989 and 1994 industrial output dropped by as much as 35 percent. The drop in output was especially dramatic for electric power, machine building and metal processing, and food industries (table 3.7). According to local experts, since 1989 industrial output has stayed at less than 50 percent of full capacity.

Despite the current discouraging situation for Baku's industries, the city hopes to bring output back to 1989 levels and beyond as soon as security improves in surrounding areas. This optimistic outlook is based mainly on high expectations of foreign investment connected to the exploration of new oil fields in the Caspian Sea in the near future. In addition to growth of the oil industry, a revival of chemical and petrochemical, metallurgical, and machine-building industries is expected. For consumer goods the goal is annual growth of at

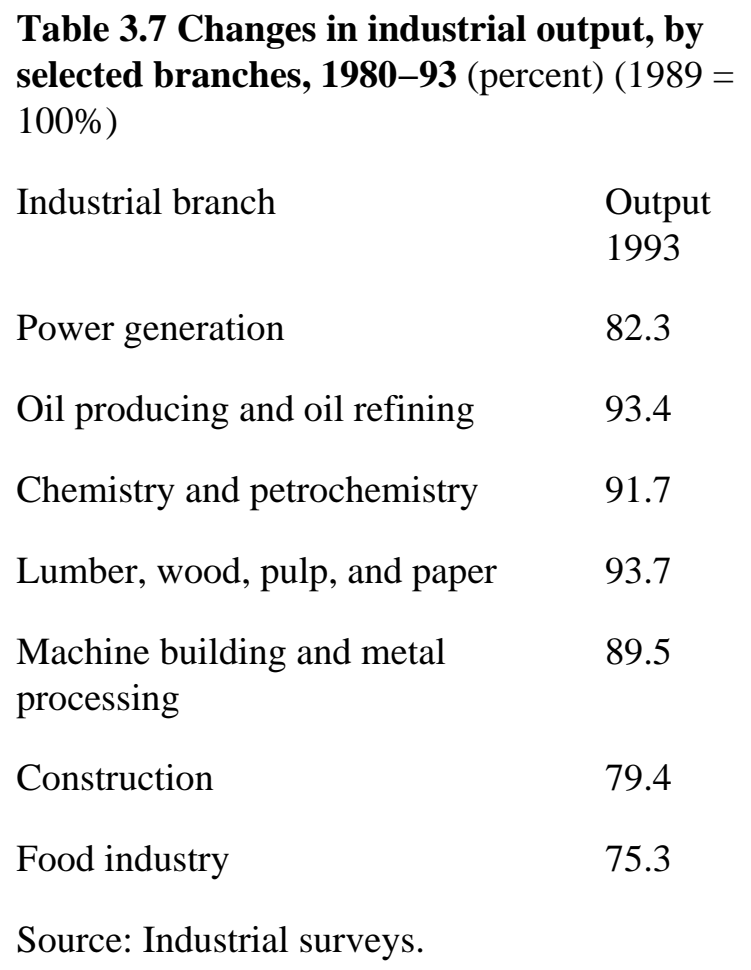

least 20 percent once supply routes are reopened.

Consumption. The amount of water consumed for household and communal needs reached its peak of 477.7 million cubic meters in 1993 (an 18 percent increase over 1989) and fell back to 391.7 million cubic meters in 1994.16 Industrial water use declined steadily over the same period, from 146 million cubic meters (26 percent of total consumption) in 1989 to 45 million cubic meters in 1994 (11 percent of total consumption; figure 3.13). Because the ratio of drinking water to technical water used by industries (roughly 4:6) did not change over this period, it can be concluded that industrial consumption of technical and potable water in 1994 was only about one-third the level observed in 1989. 


\section{Social Assessments for Better Development}

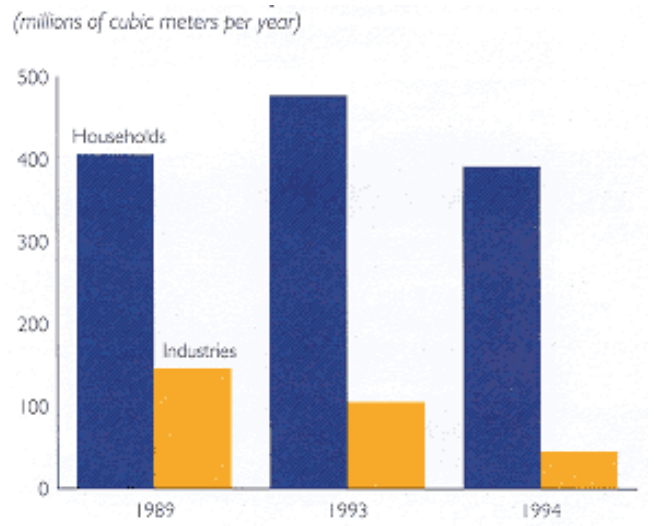

Figure

3.13 Potable water consumption, by households and industries, various years

Source: User surveys.

Baku industries use three different types of water: sea water, technical water, and potable public water. When industries are working at full capacity, sea water accounts for 80 percent of total water consumption, 17 followed by technical water (12 percent) and potable water ( 8 percent). The most water-intensive industries are heat and power generation (49 percent of total water consumption, including sea water), chemical and petrochemical industries ( 22 percent), and oil producing and oil refining (20 percent). All other enterprises consume less than 2 percent of industrial water in Baku.

Industries that use large amounts of sea water in their production cycles are heat and power generation (97.4 percent of water used), gas production (89.3 percent), and chemical and petrochemical industries (82.9 percent). Technical water accounts for the largest share of water consumption in electric engineering (57.4 percent of water used), transportation (33.9 percent), and construction (34.0 percent). Potable water plays an important role in instrument making (100 percent); lumber, wood, pulp, and paper (100 percent); and metallurgy (79.2 percent).

At full production capacity in 1989 Baku industries consumed 146 million cubic meters of potable water a year. By far the highest share was used by the oil-producing and oil-refining industry ( 40 percent), followed by light industry (14 percent), the food industry (11 percent), and machine building ( 9 percent). Considering the important role the oil sector plays in the consumption of potable water, overall industrial demand for potable water will be closely linked to the development of this industry in the near future.

The dramatic decline in industrial water consumption is a direct consequence of lower output. During December 1994-March 1995 about 9 percent of Baku's enterprises asked the water agency to stop supplying water to their facilities because production had come to a complete halt. Of the enterprises that are still operating, however, only about 15 percent are paying their water bills (figure 3.14).

Coping strategies. During the peak period of industrial water consumption some enterprises had to dig private wells or recycle water at the end of the production process to cope with an inadequate public water supply. $\underline{18}$ Recycling was used much more often than wells. In 1992 only about 6 percent of Baku enterprises facing water limits had a private well or were planning to dig one. Of this group 44 percent had abandoned well construction or the retrieval of water from wells, either because of insufficient quantities or, more frequently, because of the high salinity of the ground water. According to the water authorities, moreover, well digging activities have stagnated; thus the 1992 figures are still valid. In 1989 about 48 percent of Baku industrial units facing water limits had installed water recycling facilities. This figure also has remained basically unchanged over the past few years. $\underline{19}$ 
Metering. To control water consumption by industries, a municipal law passed in 1989 made the installation of water meters obligatory for all enterprises with consumption limits (about 80 percent of enterprises). Although the law helped to monitor water consumption, the metering of all enterprises with consumption limits was never achieved. At the end of 1989, 56 percent of enterprises had functioning meters, 10 percent had some meters that were functioning, 32 percent had nonfunctioning meters, and 3 percent had no meters. During the past five years, moreover, the situation has not improved. Indeed, the number of industrial units with properly working meters has fallen (figure 3.15$). \underline{20}$

\section{Implications for Project Design.}

The social assessment revealed large demand for water supply improvements and confirmed that the project's objectives and interventions would be acceptable to its intended beneficiaries,

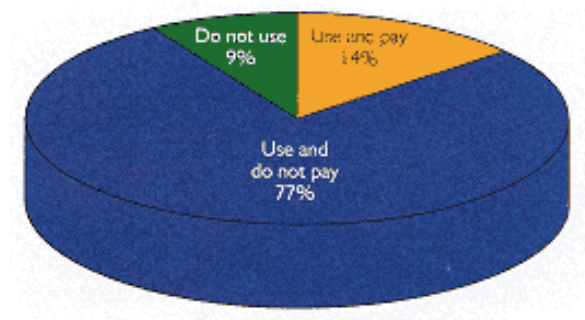

Figure

3.14 Water bill payment

Source: Industrial surveys.

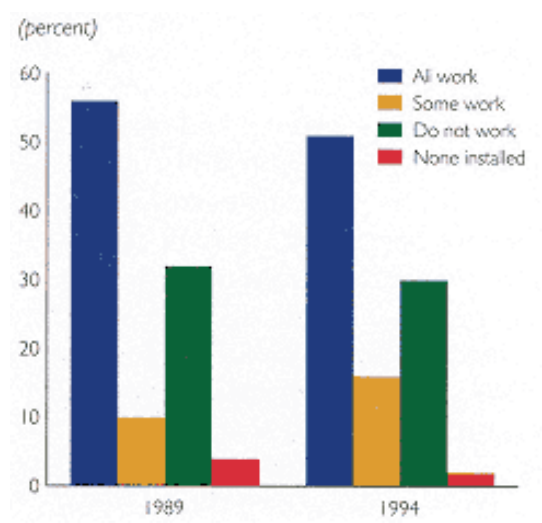

Figure

3.15 Meter performance in limited enterprises, 1989 and 1994

Source: Industrial survey.

particularly the poor. It also confirmed that the benefits of the project would include water conservation; savings in time and energy spent fetching, transporting, storing, boiling, and filtering water; savings in gas and electricity used for boiling water and for pumping from individual wells and pipes to overhead storage units; and reduced medical expenses and productivity losses associated with water-related illnesses. These benefits not only justified the components of the proposed project, they also suggested an even higher loan amount than was initially planned. 


\section{Social Assessments for Better Development}

The social assessment's three most important contributions were that it expanded the policy dialogue on key issues confronting Baku's water supply, endorsed the technical components of the project proposed in the Initial Executive Project Summary, and helped define additional project interventions to address the urgent needs of Baku's water users.

\section{Policy Dialogue}

The social assessment made significant contributions to the policy dialogue on several key issues. Specific attention focused on:

Improved governance and privatization. The project will not only result is a more reliable water supply, it will also generate support for the government's privatization agenda. Participants at the stakeholder workshop strongly endorsed this aspect of the project because it will allow project beneficiaries and other stakeholders to influence the management of the water agency.

Pricing policies. Although actual water use may be comparatively low at present, it is likely to increase substantially once the technical and institutional improvements are initiated. Water conservation, therefore, can only be achieved through a pricing strategy that is economically viable and socially equitable. The current system of per capita charges is not only unfair to large households and families that receive lower than average amounts of public water, it also fails to encourage water conservation. Moreover, large household expenditures for alternative water supplies reflect a high willingness to pay for an improved water supply. The strongly perceived need for the project and the high cost of coping strategies confirm household preferences for a reliable water supply that could justify tariff increases to at least five times the July 1994 levels for households.

Environmental monitoring. The social assessment revealed that several coping strategies adopted by households and enterprises-drilling wells, storing large quantities of water, purchasing water from private vendors-may have adverse environmental and health impacts. For example, preliminary results of aquifer studies indicate high levels of oil infiltration and sewage contamination. Current deficiencies in environmental monitoring and regulation of private wells and water vendors need to be addressed to avoid the potential risks to Baku's water users. Future policy interventions will need to focus on establishing an effective regulatory framework and monitoring private wells and the operations of private water vendors.

Community specificity. The social assessment demonstrated that there are important geographic and socioeconomic variations in water supply conditions in Baku and in the way users in different neighborhoods are affected by an inadequate public water supply. For example, communities located on hilly parts of the city peripheries suffer primarily from inadequate water pressure. Communities in the peripheral areas that rely totally or partly on wells are exposed to the potential hazards of

polluted water.21 In the western parts of the city, where incomes are low, households pay disproportionately high costs to cope with inadequate public services and suffer a relatively high incidence of water-related diseases. Interventions, therefore, should be designed to meet the specialized and potential needs of various users and their geographic locations. To facilitate the design of community-specific action, future planning for water supply and other infrastructure improvements should incorporate adequate community participation and consultation.

\section{Confirmation of Technical Components}

The social assessment confirmed the project's emphasis on improving pressure in the Baku water supply system. Inadequate water pressure is the main reason the public water supply is unreliable and intermittent. And low pressure is caused primarily by malfunctioning pumping stations, illegal pipe connections, and extensive leaks. Thus the project allocates substantial resources to the repair and rehabilitation of pumping stations. It also devotes 


\section{Social Assessments for Better Development}

resources to the purchase of vehicles and equipment for improved repair of burst pipelines. In addition, the social assessment found that household leaks are an important cause of water loss in Baku. On average there are 2.1 leaks per household, and most families do not have even half of the money needed to repair them. Nonetheless, if improvements are made in the quantity of water supplied without the necessary leak repairs and other measures at the level of the main supply network, the improvements will result in ever greater amounts of water losses. Consequently, the project addresses this issue at the technical and institutional levels.

The social assessment also confirmed the need to improve water quality. According to the assessment, about 87 percent of the population thinks that tap water is unsafe. This perception is supported by the finding that the group of households with access to water from other sources has the lowest reported incidence of water-related illness. To respond to this issue the project includes support for the rehabilitation of two water treatment facilities in the project area.

\section{Additional Project and Investment Components}

The insights gained from the social assessment and supporting participation allowed project designers and other stakeholders to refine the project to meet local needs and identify priority measures. As a result of the social assessment the following interventions, among others, are now included in the project.

Capacity building. The success of the Greater Baku Water Supply Rehabilitation Project will depend on the capacity of both the water agency and water users to carry out the community mobilization and participatory aspects of the project. Key elements of the project's capacity building interventions are:

Project implementation unit. The project will support the establishment of a project implementation unit to coordinate implementation of the project. Within this unit, staff will be recruited to oversee the components involving community mobilization and participation.

Consumer outreach and awareness raising program. This program is designed to provide information and advice on reducing water losses and to build public awareness of the scarcity of water and need for conservation, the importance of community participation in leak repair programs, the need to pay for water, and the advantages of metering for improved cost recovery. The program will involve two types of activities: first, community-based activities to help mobilize communities to complete the repair and metering work, to be implemented primarily with the support of local social scientists and NGOs and involving community-based meetings and dissemination of fliers and posters; and second, national activities directed at sustaining longer-term public support for the project and future investments. An underlying principle of these activities is that there are multiple users of water. Households, as well as powerful government institutions and industries, should be encouraged to influence the management of the water supply.

Public relations unit. Establishing this unit within the water agency will help ensure that there is effective collaboration among local

social scientists and billing and metering specialists in selecting communities for the metering and leak prevention program on an annual basis and will help identify other opportunities for community participation. Staff of this unit will also design the community-based and national communications and public education campaigns.

Institutional strengthening for cost recovery. Organizing and strengthening the Baku water agency's billing and metering department will set the stage for greater cost recovery as the water supply increases and displaced populations start returning home. Before any large-scale metering is initiated, however, it will be necessary to establish a legal framework addressing illegal connections, illegal water vending, damage to meters, and defaults. 


\section{Social Assessments for Better Development}

Metering and billing program. The social assessment indicated that many families are willing to pay for water supply improvements. However, it would be unfair to charge for water that is not consumed. As a first step toward optimizing water use, therefore, a metering program will be implemented and billing practices will be revised. About 15,000 domestic water meters will be installed. At the same time the billing system will be gradually changed from flat rate to metered billing. This program will be designed to improve cost recovery and encourage water conservation. Based on the recommendations of the social assessment, the program will be implemented first in new homes and households where water supply is continuous (about six hours a day), per capita water availability is high, the housing stock is well maintained and there are few leaks per household, and average incomes are high. Moreover, the metering program will be complemented by strong community mobilization and public education and outreach programs to support the metering program and the closely related community household leak repair program (see below).

Community-based household leak prevention program. The social assessment indicated that members of the communities affected by the project have the potential for participating in community-based leak protection. The criteria for including communities in this program are high per capita consumption, high levels of leakage, and average or higher than average incomes. Key elements of this program are:

Household repairs. For single-story homes the program would consist of repairs in the house, in home gardens, in links to minor pipes in the street, and in the community pipe system. For multiple story buildings the program would involve repairs in the buildings, in pipes linking the ground storage unit to the individual apartments, and in the storage unit itself.

Community mobilization. Ensuring effective participation in this program will require a carefully designed community mobilization program to identify potential communities for the program and to ensure program implementation and continuation in subsequent phases of the project.

Regional water and sewerage plan. Meeting the demand for an improved water supply in the Greater Baku area has direct implications for upgrading the sewerage system. The project therefore includes support for the preparation of a regional water and sewerage master plan for the Apsheron Peninsula addressing all current sector issues by taking into account possible future developments and options during the next twenty years. Among other elements the master plan is based on an estimate of water and sewerage demand, taking into account demographic changes, residential and industrial location options, and agricultural needs; evaluation of existing abstraction, treatment, and distribution facilities; evaluation of various sewerage schemes; and assessment of water and sewerage tariffs and consumer ability to pay for such services, leading to a proposal for the development of a revenue stream that will enable repayment of capital and interest as well as a self-financing operation for the maintenance of the water and sewerage network.

\section{Future Investment}

The Greater Baku Water Supply Rehabilitation Project will not address all of Baku's water sup-

ply and sanitation needs. Continued, long-term investments will be needed to solve Baku's extensive water and sanitation problems. The Baku water supply project, therefore, should be seen as a crucial first step. Future investments will focus on improving household water supply and sanitation as well as industrial water supply and waste water management (that is, improved supply of technical water, increased water recycling, improved metering and cost recovery, reduced water leakage, and reduced industrial discharges into ground water and the Caspian Sea).

Ideally, the success of this first project in improving the reliability of water delivery will generate community trust in the service and ultimately increase public support for other components of the government's reform 


\section{Social Assessments for Better Development}

agenda. By meeting the basic need for water through measures that focus on institutional strengthening and stakeholder participation, the project can help set the stage for similar reforms in the delivery of other infrastructure services.

\section{Notes.}

+ The task manager of the social assessment and main author of this chapter is Ayse Kudat. The field work for the assessment was carried out by Ahmed Musayev from the Institute of Social Management and Political Sciences of the University of Baku, with support from Abdullayev Alikram, also from the University of Baku. Janis Bernstein, Klaus Moeltner, and Nezahat Ozmen carried out analysis and prepared major sections of the final report.

Robert Wildeman, task manager of the Greater Baku Water Supply Rehabilitation Project, supported the social assessment throughout the project preparation process. This chapter is dedicated to his memory.

Financial assistance to carry out the assessment was provided by the Fund for Innovative Approaches in Human and Social Development.

Helpful comments were provided by Eugen Finkel, Yvonne Jones, Piotr Krzyzanowski, Costas Michaolopoulos, Stan Peabody, Junho Pena, V.N. Rajagopalan, and Peter Whitford. The paper also benefited from the comments of John Briscoe, Michael Cernea, Gloria Davis, and Shelton Davis.

1. See Kudat (1992); Humplick, Kudat, and Madanat (1993); Bell, Boland, and Kudat (1993); Cernea (1991); and World Bank Operational Manual Statement 2.20, Project Appraisal.

2. The pretest and the formal interviews were conducted in the first language of the respondents. The questionnaire was designed in both Azeri and Russian.

3. For a list of participants at the seminar on the Greater Baku Water Supply Rehabilitation Project held at the Government House in Baku, Azerbaijan, on February 16, 1995, see the original May 1995 report, Azerbaijan: Baku Water Supply Rehabilitation Project, World Bank, Europe and Central Asia, Country Department III, Infrastructure, Energy, Environment Division, and Europe and Central Asia and Middle East and North Africa Regional Offices, Technical Department, Environment Division, Washington, D.C.

4. Many households have illegal direct connections to water mains and self-fabricated hookups to the electricity system to run private pumps. This is one reason metering water household use - a prerequisite to cost recovery in the sector-is such a challenge. An environmental communications campaign is being prepared to inform the public about the negative economic and environmental consequences of such practices and ultimately to change people's behavior.

5. Although piped water is generally perceived as unsafe, households with wells are more confident about the quality of well water. Well water is often pumped to an overhead tank and provided to the household through a

Notes. 


\section{Social Assessments for Better Development}

tap.

6. Although the social assessment investigated water consumption across different income groups, consumption was not correlated with income. Most water is used by the lowest and highest of the four income groups (90 liters and 88 liters a day, respectively). This paradoxical finding is explained by the more statistically significant correlation between income and household size. The social assessment found that the average household size increases with income (from 3.5 to 4.4 members). Because only a small amount of water is available to families of any income group, higher-income groups generally have to share public water among more members. This explains the decline in per capita water use from the first to the second and third income groups. But households in the highestincome category have more money to install storage tanks and devise other coping strategies to capture public water. As a result real per capita water consumption increases.

7. In older neighborhoods storage tanks were installed many years ago, and residents do not remember the costs involved. Because the government sought cost recovery in the installation of these units, some units in apartment buildings have storage tanks while others do not. In some new housing developments outside the city, centralized storage facilities, connected to pumps, are being constructed on the roof of apartment buildings.

8. This includes $\$ 0.50$ to account for the opportunity costs of fetching water.

9. In July 1994 households paid about $\$ 0.10$ a month to the water agency.

10. There is a much wider range of possible interventions to improve the reliability of the water supply

than simply focusing on investment in the local water utility. In fact, the private sector, despite its currently informal nature, plays a major role in providing options for mitigating the impacts of an unreliable water supply by promoting both enhancement and accommodation coping strategies. For example, vendors provide bulk water to a large number of households. Other persons or institutions build overhead storage facilities, drill or dig wells, or sell buckets, barrels, and other types of containers for water storage. Still others produce or sell bottled water. And imported table water is becoming increasingly popular. These are just some of the many private responses to the unreliable water service-many of which the poor cannot afford.

11. The four income groups used for this analysis are group $1(025,000$ manats a month), group $2(25,00150,000)$, group 3 (50,001100,000), and group 4 (more than 100,000). Not surprisingly, wealthier households spend significantly more (in absolute terms) on coping strategies than poorer ones (3,582 manats for group 4, compared with 1,195 manats for group 1). When focusing on relative figures (coping costs as a share of income), however, the opposite is true. Richer households spend only about 2.1 percent of their income on coping strategies; poorer families invest up to 7 percent of their monthly income on additional nonpublic water.

12. The water agency provides water in trucks to institutions based on their demand. Some institutions are not connected to the public water service, while others may have long-lasting interruptions in the supply and be forced to buy water from public vendors. Enterprises and public or private institutions that need water submit a written petition to purchase water from the agency. Most demand is met in this way. Water is usually supplied only to institutions, not to individual households. The current tariff applied to institutions requesting water

Notes. 


\section{Social Assessments for Better Development}

transported in this manner is about twice that applied to households through regular service connections. However, it has become common for operators of trucks transporting water to sell water to households that have an inadequate supply. These types of informal arrangements are among the many symptoms of weakening state control and workers' efforts to cope with severe reductions in formal incomes.

13. Total cost of coping was calculated by discounting the investment costs of wells and tanks over ten years. The resulting monthly figure was then added to monthly expenditures for vendors and bottled water. Finally, an opportunity cost for fetching water was added. This cost was calculated by translating the data on minutes each day spent fetching water into an hours per day figure and multiplying the result by four if fetching frequency was occasional and by thirty if fetching frequency was high. In both cases a ceiling of fifty hours a month was established. The monthly results were multiplied by eighty, the current standard hourly wage in Baku. Finally, a ceiling of 500 manats $(\$ .50)$ was established for the fetching opportunity cost.

14. The group willing to pay more than twenty times their current bill if supply was regular was examined further. Data revealed that the majority of this group lives in the city in high rises and pays higher than average rents. Their incomes were also substantially higher than average. As opposed to a studywide average of 17 percent believing that tap water was safe for drinking, only 5 percent of this group drinks tap water. In contrast with 26 percent of the studywide sample, 55 percent of this group buys bottled water. In addition, this group has incurred large fixed and recurrent costs for other reliability measures that they have adopted, and they did so far more frequently than other groups. Their average payment to vendors was $\$ 4.50$. Thus this group is already paying a large amount to enhance the reliability of their water supply, and it is not surprising that they would be willing to pay more than $\$ 2$ a month for improved services.

15. A simple approach was used to calculate total water payments: the monthly water bill was calculated on the basis of the household population alone. This approach gave a much lower than actual figure for households that live in single-story homes with garden plots because these households are charged an additional amount based on the size of their yard. Monthly payments to vendors were added to this figure, but the cost of bottled water was excluded because for many households this cost may represent behavior and choices broader than a response to a shortage of drinking water. For instance, some respondents drink bottled water only when they are at work or outside their homes as a precaution; others drink it as a luxury. The capital costs of fixed investments were depreciated over ten years without regard to interest rates. The estimated current cost of wells, filter machines, storage tanks, and systems built to pump and distribute water were simply divided equally into monthly amounts over a ten-year period. The costs of small storage facilities and the energy costs of pumping water were considered negligible. Thus a lower than actual average water expense was calculated for purposes of comparison with willingness-to-pay figures.

16. This rapid drop in water consumption was mainly the result of strongly reduced communal water consumption in 1994. Communal needs include water used for fire control, central heating systems, public laundries, hair salons, restaurants, and other institutions of public life. Between 1993 and 1994 communal water consumption dropped more than 56 percent, from 157 million cubic meters to 89 million cubic meters. This drop can be seen as a consequence of reduced spending on public activities by the population and reduced performance by public institutions-yet another symptom of the country's current economic crisis.

17. This figure includes cooling water and water used or stored to extinguish fires. Because large

Notes. 


\section{Social Assessments for Better Development}

amounts of sea water are used for both purposes—especially in power generation and chemical industries—sea water contributes a high share to total water use.

18. The term recycling is used here to describe the process of recirculating used water back into the production cycle. This does not necessarily imply that water is cleaned or otherwise treated before the second usage.

19. On average, about 1,200 cubic meters an hour of supplied water can be recirculated into the production cycle by these plants at full output capacity. But there is potential for increased recycling capacity.

20. Only 3540 percent of enterprises have functioning meters. According to the local water authority's department for metering and water sales, one reason for the low percentage of enterprises with working meters may be inadequate meter quality and durability. Because the country lacks supplies of appropriate raw metals, the national water meter production plant is forced to use plastic for various meter parts. Depending on water quality and intensity of meter use, the lifespan of these instruments may be as short as a few months-even with the best maintenance. Because of the current economic crisis, moreover, most firms cannot afford to purchase meters and pay for installation and regular maintenance. Indeed, most firms do not have the financial capacity to pay their monthly water bills.

21. Little is known about the distribution network. Thus it is unknown whether communities with acute problems due to low pressure can be targeted. Similarly, a lot of well drilling is done informally and not reported; thus the monitoring of wells and examination of the impacts of well water used for agricultural and household purposes are difficult. Consequently, outreach programs targeting households with wells ought to be carefully designed, with inputs from social scientists.

\section{References}

Bell, Michael, John Boland, and Ayse Kudat. 1993. Reliability of Urban Supply in Developing Countries: The Emperor Has No Clothes. World Bank, Transportation, Water, and Urban Development, Washington, D.C.

Blair, Betty. 1994. Perennial Water Shortages in Baku. Azerbaijan International (Summer).

Cernea, Michael M. 1991. Knowledge from Social Science for Development Policies and Projects. In Michael M. Cernea, ed., Putting People First: Sociological Variables in Development Projects. New York: Oxford University Press.

Davis, Gloria. 1994. Social Assessment: Incorporating Participation and Social Analysis into the Bank's Operational Work. World Bank, Environment Department, Social Policy and Resettlement Division, Washington, D.C.

Humplick, Frannie, Ayse Kudat, and Samer Madanat. 1993. Modeling Household Responses to Water Supply: A Service Quality Approach. World Bank, Transportation, Water, and Urban Development, Washington, D.C.

Kudat, Ayse. 1992. Women's Constant Struggle against Unreliable Public Services. World Bank, Transportation, Water, and Urban Development, Washington, D.C. 


\title{
4- \\ Restructuring Russia's Coal Sector
}

\author{
Ayse Kudat, Vadim Borisov, and Bulent Ozbilgin
}

Russia's transition from central planning to a market economy has increased opportunities for many of its workers. $*^{*}+$ In the coal sector, however, where restructuring will cause unemployment to rise and real incomes to fall, economic reform has worsened the already difficult lives of many coal industry employees, their families, and communities. As a result the coal sector, one of the country's most heavily subsidized industries, is the focus of intense attention. The closing of unproductive mines will affect more than 800,000 people indirectly and about 250,000 miners and their families directly. In considering support for the restructuring of Russia's coal sector, the World Bank hopes to help foster a process that reduces hardships to affected workers and communities and ensures the establishment of an appropriate social safety net.

This report presents the findings of a social assessment designed to help the government and the World Bank prepare an assistance program that responds to the concerns, reactions, and expectations of miners, their families, and communities affected by restructuring. The first section presents an overview of the coal mining situation in Russia, covering the status of the coal industry, the social effects of coal industry restructuring, and the various stakeholders affected by this process. The second section discusses the objectives and activities of the social assessment, and its key findings and implications are summarized in the third section.

\section{Coal Industry Background}

Russia has some of the world's largest coal reserves and one of the world's largest coal production industries. The industry currently employs about 800,000 people working at 260 mines and associated coal processing and servicing enterprises. As in other industrial countries, where the past twenty to thirty years have brought painful periods of change to coal sectors, the coal industry in Russia is restructuring. Unlike in most other countries, where coal sectors have declined drastically, the coal sector in Russia will remain large even after restructuring. The eighteen coal regions throughout Russia include more than seventy cities and settlements. In addition, twenty-eight coal associations operate about 261 deep and surface mines. There are vast differences among large and small cities and settlements, northern and southern coal regions, and areas where alternative energy is available.

The situation in Russia's coal sector is very serious (World Bank 1994a). Over the past several years demand for coal has fallen, and inefficient sector management has remained unchanged. Coal prices are no longer controlled, but federal subsidies to the coal industry are second only to those in agriculture. The difficulties of adjusting to market conditions are exacerbated by excessive hiring, low productivity, and poor economic conditions in the mines.

The adjustment required to achieve an economically viable coal industry, operating

without a large-scale subsidy, cannot be made through changes in productivity and wages alone. By the year 2000 the demand for coal is expected to be 50 percent lower than 1990 levels. Most projections of the demand for coal anticipate a need for major reductions in mining employment over the next ten to fifteen years.

The coal industry receives a large amount of state subsidies; Rosugol, the national coal company, controls the distribution of these funds. Several problems have emerged in the administration of these subsidies, however. For example, subsidies have been used to build new mines and to rehabilitate old ones when funds might be put to better use cushioning the impact on those who lose their jobs in loss-making mines. In addition, workers 


\section{Social Assessments for Better Development}

generally get inadequate, unreliable, and inconsistent information on compensation rights, and compensation payments are irregular. The management of almost all local coal associations seems unprepared to deal with restructuring. Regional managers and local coal association managers seem unaware of the fragile economic outlook for coal in the medium to long term and do not appreciate the need to reduce employment if the industry is to provide stable levels of employment in the future. Some state funds have been used to expand non-coal activities to create jobs for laidoff miners. These jobs have not materialized, however.

One of the main problems facing coal industry workers is inadequate information. 1 The various actors in the sector-including national and regional mining associations, unions, and the media—provide inconsistent information. Moreover, complicated legal instruments and tariff agreements and diverse practices are applied to wage payments, downsizings, closures, and the allocation of benefits. Coal workers, for example, often do not know which presidential decrees related to worker rights apply to their area, or what legal recourse (if any) they have.2 In many cases workers strike because they are not paid for months at a time. Even more confusing than information on individual entitlements are issues concerning social assets, such as who owns and manages mines; current practices have led many workers to believe that many social services will no longer be provided. The uncertain nature of coal sector operations also contributes to the growing social and political tension throughout Russia's coal communities.

A key factor contributing to information problems is the repeated shifting of responsibility in the coal sector. When the Ministry of Coal disbanded in 1992, authority for the sector shifted to the Ministry of Fuel and Energy's Coal Department and the Russian Coal Corporation. Since then the Ministry of Fuel and Energy has lost much of its influence, which is now centered in Rosugol.

\section{Key Players and Their Interests}

Although state subsidies to the coal industry fund some of the social services managed by coal enterprises, they do not appear to be reaching the people in coal communities who are affected by the declining demand for coal. Further, many of the coal industry's problems can be attributed to centralized control over the state's shareholding in the industry. Household surveys, community-based consultations, and informal discussions with miners indicate mine closures and job reductions are arbitrary. Such beliefs are reinforced because the legal requirements for information disclosure to affected populations are not implemented.

Many groups of stakeholders are affected by coal industry restructuring, each with concerns and interests that often conflict with those of the others. Principal stakeholders are:

Beneficiaries. Coal sector restructuring generates no direct and immediate beneficiaries. Russians all over the country who have indirectly paid for large subsidies to inefficiently managed, loss-making mines will eventually see their financial burden reduced as the sector becomes more self-sustaining. In addition, the employees of efficient mines will benefit from a smaller, viable, and profitable mining sector. People in the coal regions, whether miners or not, will likely be adversely affected when subsidies are reduced, jobs are cut, and mines are closed. Nonetheless, their suffering could be eased with better policies and full payment of entitlements under the law. The losses accruing to miners and their communities from rapid

deterioration of social services, housing, and infrastructure can be partially and gradually compensated by strengthening local governments to take over the management and maintenance of social assets and by encouraging new investment in other sectors. The problems people in coal basins experience are mainly the result of countrywide economic and sector restructuring. Mitigating the short-term adverse effects of restructuring is difficult, to say the least. It is hoped, however, that these effects could be cushioned with international assistance. Such aid can be secured through a dialogue on the targeting of reduced subsidies to meet the needs of affected populations. 


\section{Social Assessments for Better Development}

Affected populations. Affected populations include miners and their families as well as communities that rely on mine operations. These groups will inevitably be the major losers in the short term. Their concerns include compensation for those who lose their jobs and continued access to social and community services. In other countries the populations directly affected by coal sector restructuring often have received additional compensation; the social problems associated with Russia's transition to a market economy will make it difficult to finance special packages for coal workers solely with internal resources. Moreover, many coal communities have mixed employment structures. Consequently, even if benefit packages for miners could be expanded, it may be socially problematic to exclude nonminers.

Local stakeholders and new actors. Local stakeholders and new actors include local governments and other local or regional institutions that will have to assume the management and operation of the social assets of mines after restructuring. Local governments will be unable to manage the mines' social assets unless they are given financial support to perform this new role. If this support is available, however, local governments would have much to gain.

Coal sector managers. Coal sector managers include mine managers and managers of regional and national mining associations. The associations seem to be redefining their positions in the sector to maintain their control over subsidies and restructured enterprises. Because restructuring will affect the balance of control in the sector, performance expectations will begin to focus on individual mines. For the regional associations the best way to maintain the status quo is through the transfer of power from the national to regional level. The national associations, however, have certain reservations about decentralization. The continued hold of national associations on the sector, especially in managing subsidies, poses a challenge in directing subsidies to appropriate objectives.

Trade unions. Trade unions are defining their position to either gain or regain power. Traditional trade unions have lost some power since independent trade unions were established. $\underline{3}$ What the future will hold for both types of unions will largely depend on the extent to which they can represent the workers and their communities and resist taking sides in the power struggle between national and regional coal associations.

Regulators and policymakers. This group includes policymakers (Duma), the InterAgency Coal Committee, the Ministry of Economy, the Ministry of Fuel and Energy, the Ministry of Finance, the Ministry of Labor, and the Federal Employment Service. The Inter-Agency Coal Commission has made the coal sector restructuring process more participatory and has substantially enhanced its visibility and positive role in the system.

Nongovernmental organizations (NGOs). While limited in number and regional scope, NGOs are important and are receiving increasing government attention and support. 4 NGOs have emerged largely in response to the growing unmet social assistance needs of the disadvantaged. The presence of foreign NGOs also has increased interest in Russian NGOs. The lack of NGO history, financing, and trained personnel in Russia has been addressed by many successful foreign NGOs, some of which have worked in Russia's coal regions. Although some of the foreign NGOs had operated successfully in other countries,

many NGO activities are unique to either Russia or the former Soviet Union. Some NGOs receive government subsidies in the form of staff salaries, office space, and tax relief. NGOs working with the disabled have tended to form around specific disability concerns or the need to raise awareness among policymakers of the problems this group encounters. Women's groups also have been active; the Federal Employment Service has been cooperating with and contracting out service delivery to women's NGOs. Other NGOs in coal sectors operate in areas as diverse as small business associations, sports associations, pensioners groups, veterans groups, chambers of commerce, environmental groups, and health and safety structures. $\underline{5}$ Yet nongovernmental activity faces serious constraints, including difficult economic conditions, a restrictive regulatory environment, and the taxable status of income-generating activities. 


\section{Social Assessments for Better Development}

Constituency for reform. This group includes public interest groups and some of the media. Given the visibility of the coal sector, the views of the media and the public are extremely important for developing a constituency for economic reform. Similarly, the management of coal sector reform is one of the issues directly influencing political stability or instability in Russia.

\section{Social Effects of Coal Industry Restructuring.}

Coal settlements in Russia have diverse characteristics in terms of demographic structure, income levels, and labor force. Consequently, the effects of coal restructuring and each community's response to them are not uniform. Notwithstanding the community-specific effects, there are three general negative social effects of restructuring:

Loss of employment. Unemployment can arise in three ways: jobs lost at closing mines, employment downsizing at mines that continue their operations, and employment reduction in enterprises that support mining operations (for example, equipment manufacturing) and in services that support mine settlements (for example, medical facilities and kindergartens). Thus mine restructuring through closure or downsizing not only causes unemployment directly within the sector, but results in the reduction of overall job opportunities.

Inadequate compensation. Miners are uncertain of their entitlements, and there are significant differences between entitlements and what miners actually receive. Severance benefits are restricted to three months of wages. If unemployment extends beyond three months, laid-off workers are entitled to additional compensation equivalent to a portion of their base salary. Further, the rules and regulations governing the term or duration of employment and the size of severance packages are unclear. In addition, those who are least likely to be reemployed (that is, older workers near retirement age) have little protection. And while regulations theoretically allow workers to receive compensation and pension payments with the regional coefficient - therefore allowing increases above the base salary for residents of harsh climactic zones-entitlements are usually nullified by the ceilings imposed on them by the entities administering them. Moreover, although the severance package agreements between individual mines and unions have been generous, they often have not been observed during closures. Additional complications arise from the lack of information on entitlements and the confusion surrounding the multiplicity of legal instruments introduced.

Deterioration of social services. Mine associations traditionally have provided a range of services (including housing, education, health care, transport, and energy) to miners and to the settlements that support mines. In addition, miners, including pensioners and disabled miners, obtained goods (such as coal for heating and cooking) that tended to be better than the average for the general population. By January 1996 the stock of social assets remaining attached to Rosugol had dropped by about 70 percent, while in Kuzbass this decline was 80 percent. Non-core social facilities account for a large share of the assets that are still with Rosugol, while housing is either divested or will be completely divested in

1996. The housing subsidies available during the past three years are not considered sufficient for keeping the housing stock in proper shape. $\underline{6}$ In some smaller coal towns municipal governments became responsible for a housing stock that was thirty times larger than what they had managed in the past. 7 The transfer of services such as housing, health, and education to financially pressed local governments has meant either that these services are no longer available or that the quality of the service has deteriorated. $\underline{8}$ According to the chairman of the trade union in the Shevyakova mine (Kuzbass), after monthly social service payments to miners were transferred to local administrations payments fell from 300,000 rubles to 60,000 rubles per child. Miners, who were owed three to four months of back pay, could not afford to pay for such services. Although this problem is not unique to the coal basins, it affects residents at a time when their ability to cope with the inadequacy of these services is particularly limited due to large-scale disguised unemployment in both coal and non-coal sectors, as well as to an insufficiently diversified economic base that cannot offer alternative employment. 


\section{Social Assessments for Better Development}

Any restructuring involves significant social costs. In Russia, however, coal restructuring has had particularly adverse impacts because workers often have not received the advance notice required by Russian labor legislation; coal labor unions have failed to defend effectively the interests of the workers affected by mine closures; social services transferred from coal companies to municipalities have been allowed to deteriorate; the social safety net does not adequately protect nonminers from the impact of mine closures; institutional arrangements do not ensure an equitable allocation or reliable distribution of subsidies; coal company management is diverting coal subsidies from wages and other social obligations to operating losses and investment; coal subsidies could have been used to provide better social protection for miners who have lost their jobs; and miners are poorly informed about their rights and about the restructuring program and have little trust in the current system, particularly for allocating and distributing subsidies.

The response of Russian coal miners and their communities to the adverse effects of restructuring is not well documented. Elsewhere in the world, responses at the individual and community levels have been diverse (box 4.1). In Russia, too, responses appear to range from active opposition (through strikes) to adjustment (through new job search and other mechanisms) to resignation or withdrawal. Miners' expectations of government benefits also vary. It is increasingly recognized, however, that financial constraints are too severe even to allow benefits packages to be defined and delivered.

Given the current level of knowledge, the resolution of several key issues will increase the social sustainability of coal sector restructuring:reducing uncertainty among miners and their

\section{Box 4.1 Trends in behavioral responses to mine closures-the global experience}

The international literature on individual responses to mine closures identifies three basic patterns of behavior:

1. The individual remains passive. This absence of reaction can continue for an indefinite period of time during which the displaced worker does not lower aspirations to make ends meet, but will be forced to adjust when money becomes completely unavailable.

2. The individual becomes active in an adequate way. This involves the development of income-creation strategies such as working longer hours, switching jobs, using assets (such as garden plots) more effectively, taking on debt, and changing consumption patterns to reduce spending.

3. The individual becomes active in an inadequate way. In this case the individual's needs and expectations are transformed and must be met with the acceptance of a lower degree of satisfaction. Transformation of needs in this manner may lead to negative effects such as alcohol abuse or stress-related health problems.

Responses to mine closures also include behavior such as denial, migration, and self-employment. Displaced workers often exhibit a high level of alienation from and distrust of other groups and institutions that make up the social fabric of the community and the nation. Although expressions of alienation are not necessarily influenced by workers' age or gender, older workers and women tend to be more pessimistic about future employment prospects.

Little research has been done on family responses to mine closures; employment as such is often discussed in terms of the individual. A 


\title{
Social Assessments for Better Development
}

\author{
decline in family cohesion and an increase in tension are common. \\ Studies also show that nearly one-third of respondents' relationships with \\ their spouse had worsened because of economic hardship after mine \\ closures.
}

families by establishing a schedule that identifies where mines will be closed and where employment will be reduced over the near term; clarifying the legal framework and establishing more equitable policies (for example, allowing the transfer of coal pensions to other regions and providing flexibility in the residential registration system for those leaving coal regions); strengthening the institutional capacity of local governments to prepare and implement social mitigation programs, covering both miners and nonminers; directing reduced subsidies to cushion the impact of restructuring and to ensure that equitable treatment is given to adversely affected populations engaged in nonmining activities; increasing the participatory structure of local governments in coal basins to ensure transparency and accountability in the regional and local distribution of government support; and establishing a permanent social assessment program to expand knowledge of the situation, especially with respect to access to social services, to provide for stakeholder involvement and feedback, and monitor and evaluate the effectiveness of social impact mitigation efforts.

\section{World Bank Involvement}

The World Bank has been working with Russia's coal industry since mid-1993. By late 1993 the Bank had published a draft sector report, Restructuring the Coal Industry: Putting People First. (The report was published with annexes in 1994.) The draft aimed to share global experience with Russian policymakers and coal managers. It attempted to show the relevance of international experience for Russia and to demonstrate the importance of putting people first instead of allowing economic hardships and bankruptcies to affect miners and their communities in an ad hoc manner. It argued that employment reduction and mine closures should be carried out only when there is an appropriate and funded social safety net in place. The report also suggested that the social safety net be determined at the local level, and that the government's restructuring strategy include decentralization. Appropriate policies to promote labor mobility also were shown to be important.

The report noted that in 1993 only 5 percent of coal industry subsidies were used for social services and, based on international experience, drew attention to several key elements of the social safety net: provision to coal miners of the social security system and unemployment benefits available throughout Russia; continuation of social services in mining communities and special financing in areas where mines were closed or severely downsized; continuation of coal industry pensions; consideration of a new and temporary system of lump sum payments to encourage voluntary departures; and a new and temporary system of special employment programs in affected regions.

The report was discussed with major sector stakeholders. As a result of these discussions the focus of the report shifted from the coal industry as a whole to a more detailed analysis of the impact of restructuring in the main coal basins. Between October 1993 and April 1994 the first set of supporting annexes was prepared and supplemented by a series of studies. In May 1994 a seventeen-person delegation from the InterAgency Coal Commission visited Washington, D.C., to discuss the findings presented in the annexes. In August 1994 the World Bank presented the second version of the main report and the annexes to the government as discussion drafts. The government then convened a meeting of the Inter-Agency Coal Commission in September to review the report. As part of the preparations for the September 23 meeting-which included World Bank representatives-about twenty-five agencies submitted written comments. A number of the Russian stakeholders agreed with the report's findings but believed that the pace of adjustment it proposed was too fast.

After the Bank's report was published, the Russian government produced a coal sector reform program in 


\section{Social Assessments for Better Development}

mid-1995 titled Basic Trends that adopted some of the Bank report's key recommendations-especially those relating to the need to reduce subsidies - and requested a $\$ 500$ million loan to support its implementation. In response to the government's request for assistance in implementing a coal sector reform program, the World Bank is considering providing support through two

operations, the Coal Sector Adjustment Loan and the Coal Sector Implementation Assistance Project. The objectives of these two operations are to reduce the coal sector's impact on the federal budget by supporting the reduction and eventual elimination of subsidies, promote the long-term sustainability of the coal sector by establishing a competitive, commercial industry, support a restructuring program that reduces the size of the industry to increase efficiency, and cushion the impact of restructuring on miners, their families, and affected communities by reordering government priorities to focus on maintenance of social assets and creation of new jobs at the local level.

After the 1994 study one of the World Bank's first activities in preparing a support program was to conduct a social assessment to find out how the people in affected coal communities wanted to see coal restructuring proceed and to provide important input on the attitudes of a wide range of stakeholders. The Russian government created a project preparation unit in the Ministry of Economy with substantial bilateral funding. The unit is staffed mainly by Russians and is using primarily Russian consultants to prepare the loan. The unit has been instrumental in expanding communications to stakeholders and is implementing the participation recommendations of the social assessment.

\section{Social Assessment: Objectives and Methodology}

A social assessment is the systematic investigation of the social processes and factors that affect development impacts and results. An assessment supports participation and is a tool for incorporating social analysis into World Bank-assisted investments and analytical work. Social assessments are carried out to identify key stakeholders and to establish an appropriate framework for their participation in project selection, design, and implementation; to ensure that project objectives and incentives for change are acceptable to the range of beneficiaries; to assess the social impact of investment projects; and to develop the capacity at the appropriate level to facilitate participation, resolve conflicts, permit service delivery, and carry out social mitigation measures. A social assessment is but one input into the process by which a World Bank project is prepared. It reports what people experience and believe and draws conclusions from these to form a basis for a dialogue with clients. Further, a social assessment should be viewed as a process because continual assessment and monitoring are needed during project preparation and implementation to learn more about key issues and to ensure that the project's intended benefits reach the people.

This section describes the specific objectives of the social assessment of Russia's coal sector restructuring, the means by which it has been carried out, and the two mining towns where the household surveys were undertaken.

The main objectives of the Russia coal social assessment are to:

Identify key stakeholders and establish an appropriate framework for their participation in the restructuring

Assess the socioeconomic characteristics of households in mine basins

Determine how miners and employees of other sectors are affected by coal sector restructuring, as well as understand the labor market and workers' expectations with respect to social protection and compensation

Characterize attitudes toward government sponsored relocation programs that promise free housing to residents of northern regions affected by the restructuring 


\section{Social Assessments for Better Development}

Assess the level of trust toward various social institutions

Determine how people affected by mine closures would like to see the restructuring proceed.

The social assessment is also intended to help identify steps necessary to mitigate the negative social effects of the coal restrubturing program.

\section{Methodology}

To achieve its objectives, the social assessment involved consultations with a broad range of stakeholders, focusing primarily on miners, their families, and mining communities. In particular, the social assessment team carried out several thousand formal and informal interviews and

group discussions in four major coal basins: Kemerovo, Rostov, Tula, and Vorkuta. The team also surveyed 800 households in Komi Republic-Vorkuta and Kemerovo-Kiselovsk and prepared case studies based on several hundred interviews in each of four towns: Cherkasovskaya, Dimitrova, Halmer-Yu, and Promyshlennaya. Several hundred informal interviews in coal communities in Rostov and Tula also took place. In addition, World Bank staff and consultants working on social safety net issues have held consultations with local stakeholder groups.

In all of the communities visited, the social assessment team consulted local trade union members, coal associations, local government representatives, and, where present, NGOs. Their observations are incorporated here, as well as information received between October 1995 and May 1996 by the project preparation unit in the Ministry of Economy from a broad range of stakeholders and secondary data sources. In addition, a first draft of the social assessment report, prepared in March 1996, has been discussed with the Ministry of Economy and the Ministry of Labor, key stakeholder groups (including members of the Duma), and executive officers of trade unions. The social assessment team also consulted with academics and with two NGOs focusing on vulnerable groups within the coal sector (the Fund for Social Guarantees and the Veterans of the North).

Specifically, the assessment involved:

Household surveys. A local team of social scientists conducted a comprehensive survey of 800 households that will be directly or indirectly affected by the restructuring of the coal industry (see annex 4.1). Coal settlements in Kiselovsk and Vorkuta and populations of the two coal cities were included. This sample, however, is not representative of miners and mining communities throughout the country. Rather, it includes the populations of two sub-regions that are already downsizing and closing mines. Notwithstanding the differences in the socioeconomic conditions of these sub-regions, the trends observed in them are important and call for an immediate launching of a more comprehensive social assessment process.

Community visits and group discussions. World Bank staff visited a large number of communities and held extensive discussions with community members, often in groups of five to seven persons. In addition, the Russian social science team that led the social assessment has been working with many communities over the past five years. Local branches of the Institute of Comparative Labor Relations that are located in the coal basins, particularly Kemerovo, also provide daily research support to the unions.

Case studies. As part of the assessment, the team of social scientists explored lessons learned from three mine closures in Vorkuta that were then compared with the experiences of five mine closures in Kiselovsk. In the course of case study preparation, several hundred interviews were conducted with workers, unions, and mine and city managers. The social assessment team also conducted less systematic case studies in Rostov and Tula. 


\section{Social Assessments for Better Development}

Assessment of voluntary relocation. The social assessment team also initiated consultations with experts, held community discussions, reviewed proposals by various institutions, and conducted interviews with residents of coal communities to assess the effects of mine closures and the issue of voluntary relocation.

The social assessment methodology combined quantitative and qualitative methods. This approach allowed the researchers to uncover phenomena that influence people's behavior in the current social and economic climate but that cannot be measured by statistical methods alone.

In May 1996 a number of additional issue-focused social assessments were launched for four regions: Kuzbass, Rostov, Tula, and Vorkuta. 9 The objectives of these assessments, completed in draft in September 1996, were to:

Broaden the regional coverage of the systematic social assessment activities carried out through March 1996

Deepen understanding of several key issues, including information and communication patterns of miners and communities, access to and use of social assets and services, interactions with local and federal institutions, household assets (acquisition and loss of, changes in composition of), coping strate-

gies, changes in levels and sources of income, and attitudes on reform

Define the role of coal sector activities in a broader socioeconomic context at the household, community or settlement, and regional levels

Develop a better understanding of the dynamics of change and patterns of adaptation to transition.

These additional social assessment activities will focus on:

Expanding the social assessment database to Rostov and Tula through 800 additional household surveys undertaken in four settlements. Two of these settlements will be associated with mines slated for closure starting in 1996; the other two will be near mines that will experience significant labor force downsizing over the next few years, starting in 1996.

Understanding the regional context in which coal reform takes place by focusing on two microregions in Kuzbass and Rostov, defining the role of coal sector operations (including the management of social assets) in the lives of the people in a dynamic context through the use of secondary data (for the past five to ten years) and convening focus group discussions in the regions.

Analyzing patterns of adjustment to reform through longitudinal studies, comparing coal and non-coal employees who have left their jobs voluntarily with those who have been laid off and focusing on institutional constraints to their adjustment.

Analyzing changes in family budgets, comparing coal communities with others by using existing Goskomstat family budget studies and by adding a special target sample to the existing sample base.

Carrying out thematic studies on patterns of geographical mobility, impacts of restructuring on the disabled, and impacts of lump sum payments on redundant worker families.

\section{Survey Areas}

The areas surveyed in the social assessment were Vorkuta and two surrounding mining towns (Oktyabrski and Sovetski) in the Arctic Circle and settlements in Kiselovsk close to two mines that are closing (Surtaikha and 


\section{Social Assessments for Better Development}

Cherkasovskaya) and in other districts of the city. The sampling procedures used are described in annex 4.1. Vorkuta, a gulag, was settled in the mid-1950s as a result of a general organized recruitment of workers from different regions of the former Soviet Union (box 4.2). Since then Vorkuta has experienced a constant migration of people into the region because of its high wages and the deteriorating economic situation in the rest of the country. Located in western Siberia, Kiselovsk was developed during the early Soviet period in an area where two villages, Afonino and Cherkasovo, had been located. In 1936 Kiselovsk was officially declared a city. Unlike Vorkuta, Kiselovsk has a stable population, and a substantial portion of its population is of Siberian heritage.

\section{Social Assessment: Issues, Findings, and Recommendations.}

The results of the social assessment confirm that miners, their families, and mining communities in both Vorkuta and Kiselovsk are not faring well in the current economic environment. Their difficult living conditions, desire to leave their homes, feelings of vulnerability, and lack of trust in the government and other institutions highlight the need to carefully manage the social dimensions of the coal industry restructuring process. This section summarizes the main findings and key issues emerging from the social assessment as well as the implications of these findings for the proposed restructuring program. It should be remembered, however, that the social assessment was limited in its scope and geographic coverage. Consequently, its conclusions may not be valid for the entire coal sector. Still, its results point to the need for launching a continuous social assessment process to guide social safety net interventions and to ensure that all remaining subsidies reach miners and their communities.

\section{Develop Community-Specific Responses}

Coal settlements have different characteristics in terms of demographic structure, income levels, and labor force.10 As a result their responses to and expectations from coal sector restructuring are not uniform. Some communities have a well-

integrated social fabric and their members support one another in coping with the adverse social effects of restructuring. Other communities, such as Vorkuta, are more heterogeneous, with many immigrants from other regions of the former Soviet Union, and have weaker community support systems. Thus community-specific assessments are needed to define the effects of sector restructuring and the necessary measures for mitigating these effects.

The economic base is an important source of settlement variability. In coal cities and settlements people employed in the coal sector constitute only one segment of the population, and sometimes account for a small percentage of total employment. Generally, the larger and more geographically integrated a settlement is, the greater is the economic mixture. And as each economic sector goes through its process of restructuring and market adjustment, different parts of the labor market will experience negative impacts. How people are affected by changes in each economic sector, and how they respond to them, will depend on the transition in the economic base as well as on the patterns of social organization that characterize their communities.

\section{Box 4.2 Vorkuta's history}

Vorkuta is entering its annual sleepiness, which never quite succumbs to

a total hibernation. Stemming from a gulag history, stories of which dominate each family's history, a mentality of captivity remains.

Approximately 2,500 people now live in Vorkuta. Many were once held

as prisoners in the various gulags that dotted the 42-kilometer circle

around this northern Arctic city of 250,000. Generally, prisoners were taken to the gulag capitol of Vorkuta to mine coal and live in exile. Both 
men and women received one to two pounds of bread daily, soup, and, if the individual was a productive worker, barley porridge and a kilogram of sugar per month. Many of the women were part of the forced-labor of the Vorkuta Brick Factory, which remains in operation today. Political prisoners were given longer sentences and treated more harshly than were criminal prisoners.

Following the closing of the last gulag in the 1950s, the prisoners were released with passports that prohibited them from ever leaving Vorkuta. In effect, the city became a conglomerate; its gulag subsidiaries had been merged. Prisoners used to work in the deep mines surrounding the 42 kilometers encircling the cold city; many of the current miners are relatives of those prisoners. Due to the state-controlled coefficient payment system, many of the present workers had moved to Vorkuta for the highest pay available (because of the ten-month winter and 115 annual snowstorms) and have simply never left. The sun sets here these days a little after noon. Thirty degrees below zero is considered normal, and thick black clouds of coal exhaust leave the brittle tundra snow gray. We have twelve straight months of winter here, everyone says repeating an old labor camp adage, but the rest is summer.

Yuri Mikhail Yakolev is one of few who has not left Vorkuta. Where would I go? he asked. He is unfamiliar with everything; he recently has had to learn how to tie a tie. He is almost eighty years old, but has no friends whom he has known for more than twenty years. Although he says that he cannot imagine life being any different, he knows that, somehow, it is supposed to be different. His passport indicates that he was a political prisoner, and that he is now rehabilitated. He carries it everywhere; all Russians carry their passport and accompanying papers at all times. Yuri had been sent to the gulag at age fifteen as an opponent living in the occupied territories. Although he never saw his family again, he heard that his father spent eight years at the Yur-Shor Mine.

Following twenty-five years in the gulag, he was further sentenced to a lifetime in Vorkuta until 1990 when he was rehabilitated.

\section{Source: Kudat 1996}

For example, it is more difficult to cushion the impacts of unemployment, long delays in salary payments, and severe reductions in purchasing power when both the reliance on a single-sector activity and the incidence of single-parent households are high. Similarly, in coal communities such as those surrounding Kiselovsk, where the proportion of households that relies solely on pension payments is large, the effects of restructuring are difficult to mitigate. Pensioners, for example, report that they lose access to many of their entitlements (such as free medicine) and encounter difficulties in coping with sharp reductions in the purchasing power of their pensions.

The following sections highlight community differences with respect to economic base, labor market characteristics, and household responses to coal restructuring, primarily by comparing Vorkuta and its mining settlements with mining settlements in Kiselovsk. Although little is known about the key features of social organization and about how the social fabric protects individuals against the effects of transition, the information on demographic structure and the role of social relations in obtaining access to information, jobs, and other resources helps to 


\section{Social Assessments for Better Development}

Vorkuta for the highest pay available (because of the ten-month winter and 115 annual snowstorms) and have simply never left. The sun sets here these days a little after noon. Thirty degrees below zero is considered normal, and thick black clouds of coal exhaust leave the brittle tundra snow gray. We have twelve straight months of winter here, everyone says repeating an old labor camp adage, but the rest is summer.

Yuri Mikhail Yakolev is one of few who has not left Vorkuta. Where would I go? he asked. He is unfamiliar with everything;

he recently has had to learn how to tie a tie. He is almost eighty years old, but has no friends whom he has known for more than twenty years. Although he says that he cannot imagine life being any different, he knows that, somehow, it is supposed to be different. His passport indicates that he was a political prisoner, and that he is now rehabilitated. He carries it everywhere; all Russians carry their passport and accompanying papers at all times. Yuri had been sent to the gulag at age fifteen as an opponent living in the occupied territories. Although he never saw his family again, he heard that his father spent eight years at the Yur-Shor Mine. Following twenty-five years in the gulag, he was further sentenced to a lifetime in Vorkuta until 1990 when he was rehabilitated.

define social issues and the mechanisms for dealing with them (box 4.3).

Demographic structure. Coal communities differ substantially from each other in almost every aspect of their demographic profiles. For example, Vorkuta has a much younger and more ethnically heterogeneous population than Kiselovsk, with higher monthly incomes and a more active labor force (figure 4.1). Moreover, many families immigrate to Vorkuta seeking higher wages (the number migrating has increased since 1989). This is in contrast to the image of the city as a coal prison, a place where no one wants to live and everyone wants to escape. Based on their experience, many families who migrated recently express a desire to remain in Vorkuta because the conditions of their former homes are so bad. A few people have roots in Vorkuta and are committed to making it a better place in which to live. Communities in Kiselovsk, on the other hand, are more homogeneous and have roots in the region; most people have no intention of leaving.

Dependency ratios are low and family size is small in many mining communities. In Vorkuta, for example, 54 percent of households are families with children. In Kiselovsk, by contrast, 29 percent of households are families with children. In both regions, however, a high percentage of households are headed by a single parent; female-headed households account for a signifi-

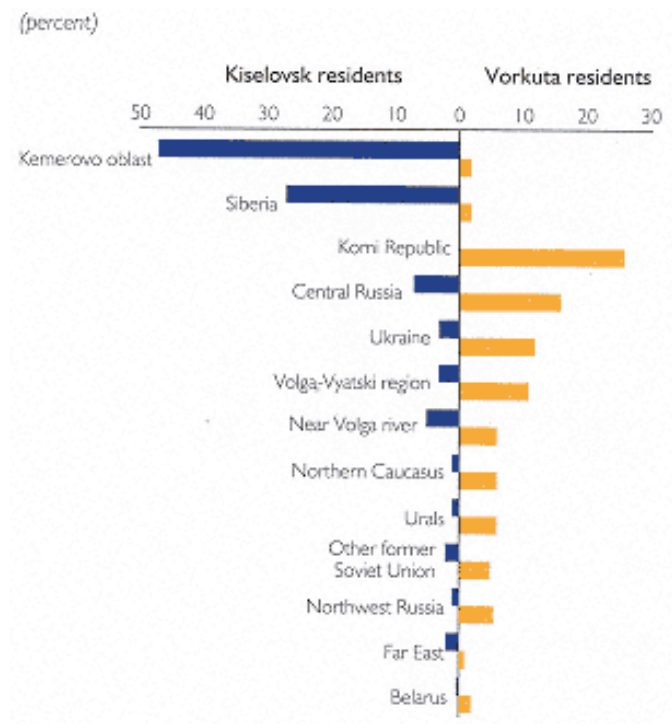




\section{Social Assessments for Better Development}

Figure 4.1

Place of birth

Source: Household surveys.

cant percentage of the total in coal towns (figures 4.2a and 4.2b). Indeed, more than a third of all households are headed by a single person, with or without children. In Vorkuta there is an almost equal percentage of female-headed households, with and without children (13 and 12 percent, respectively). In Kiselovsk, by contrast, about 20 percent of women do not have their children with them; these are elderly women living alone.

\section{Box 4.3 Coping with uncertainty: responses to a mine closing}

A range of responses was observed during the closing of the Promyshlennaya mine. The responses are summarized:

Get a job and get lost. Some people left when they heard of the imminent mine closing. This group generally included the youngest and most active employees who had not worked at Promyshlennaya long and had not identified with it.

Seek restitution. Some workers were laid off before the imminent mine closing. The miners consider this to be an illegal and voluntary attack on their rights. Workers now believe that anyone can be laid off at any mine - even one that could close in a hundred years. Because an order on the mine closing does not exist and employees' destinies are unclear, they plan to pursue court action and sue the administration for production halt and moral damage and demand compensation.

Get protection. Some employees were transferred to other mines. For example, one development section was transferred to the Komsomolskaya and Yur-Shor mines.

Take political action. Forty-one workers went on strike underground and later, thirty-seven more miners joined them. Yur-Shor mine (the second of four mines to be closed in the area), where many of the Promyshlennaya miners had been transferred, was the first to support the strike. While striking at the Yur-Shor mine, former Promyshlennaya employees defended their benefits. Transferring workers from one closing enterprise to others spread the conflicts and increased resistance to restructuring.

Keep working. Pension-age workers actively opposed retirement and transfer to other enterprises. It was easier for them to fight to keep their positions than to change work or retrain. They promised to fight to the end, seeing no prospects for themselves at other enterprises. Employees who receive payments for disability remained at the mine. They feared that they would lose their payments if the mine closed and demanded that restructuring be slowed down. 


\section{Social Assessments for Better Development}
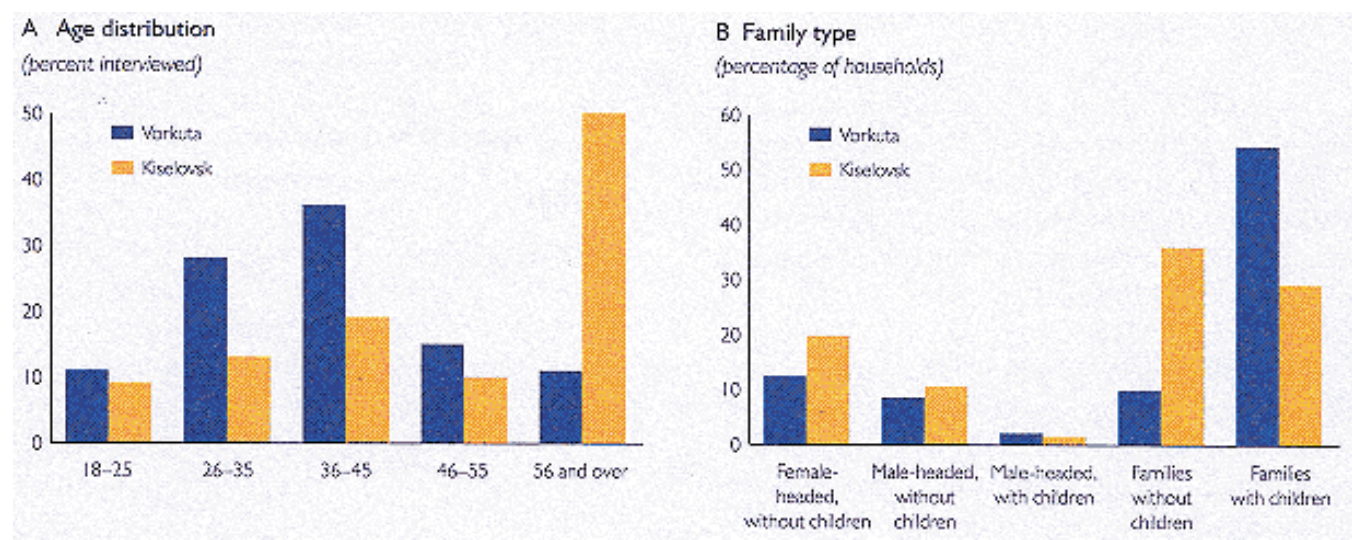

Figure 4.2

Household characteristics in Vorkuta and Kiselovsk

Source: Household surveys.

Regardless of whether they care for their children on their own and are left alone at old age, female-headed households in the communities visited are particularly vulnerable because they have low incomes and little family support.

Income. Although coal miners generally enjoy higher incomes than workers in other sectors, long delays in wage payments and increases in the prices of goods and services previously controlled by the state have created general poverty among miners. While there are no recent income data, the social assessment survey found substantial variability in household incomes. Average monthly household incomes are \$92 in Vorkuta11 and \$55 in Kiselovsk. $\underline{12}$ But prices, especially food prices, are also said to be higher in Vorkuta, according to its residents. $\underline{13}$ In Kiselovsk almost 70 percent of households have monthly per capita incomes of less than $\$ 60$, with 17 percent earning less than \$30. In Vorkuta more than half (52 percent) of households report incomes of more than $\$ 80$ a month. Also in Kiselovsk, respondents 36 years and older have average monthly incomes that are about 20 percent less than the incomes of younger age groups. In both areas about two-thirds of randomly selected households had no members working in coal mines as managers or skilled or unskilled workers. When different parts of the regions are compared, the data show that income levels in the mining settlements, where there is a larger proportion of mine workers, are significantly higher than in Vorkuta City (table 4.1). Not surprisingly, the residents of these settlements also have higher demands for compensation if they are affected by coal sector restructuring.

Labor market characteristics. Perhaps the most important finding of the social assessment is that a variable portion of the working population in coal communities actually works in the coal sector. Coal sector employment as a share of total employment is less than 6 percent in most coal regions (figure 4.3). Other enter-

Table 4.1 Average monthly per capita household income (percentage of respondents; U.S. dollars )

$\begin{array}{lllll}\text { Household income } & \text { Vorkuta Center } & \text { Sovetski } & \text { Oktyabrski } & \text { Kiselovsk } \\ \text { Less than } \$ 40 & 8.9 & 10.0 & 14.8 & 34.2 \\ \$ 40 \$ 60 & 15.8 & 15.3 & 21.5 & 34.7 \\ \$ 61 \$ 80 & 22.8 & 20.0 & 17.6 & 20.4\end{array}$


$\$ 81 \$ 100$

$\$ 101 \$ 150$

More than $\$ 150$

Number of respondents

Source: Household surveys.
15.8

16.8

20.0

101
24.0

18.7

12.0

150
12.7

16.8

16.8

149
5.0

3.1

2.6

383

(all mining workers as a percentage of totd employment)

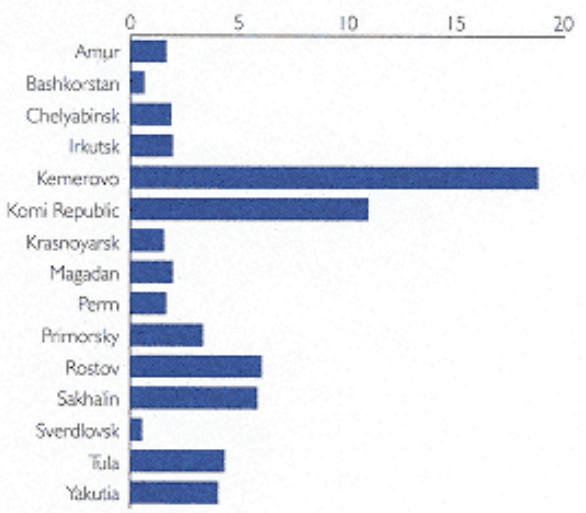

Figure 4.3

Mining as a share of total employment, 1992

Source: World Bank 1994a.

prises—including milk factories, refrigerator and mechanical plants, construction materials plants, agricultural enterprises, and chemical and textile enterprises-are important sources of employment. Moreover, in the past five years the mines have shed functions. Consequently, social service workers who once were categorized as coal sector employees are now considered government sector employees. These findings are confirmed by official data indicating that only 7 percent of the population in Vorkuta works in the coal mines (including pensioners; table 4.2).14 In other regions this figure ranges from less than 1 percent (Shekino in Tulskaya oblast) to 26 percent (Vanek). The social assessment results also confirms this finding: only 6.9 percent of the active population in

Table 4.2 Labor structure in coal basins

\begin{tabular}{|c|c|c|c|c|}
\hline City & $\begin{array}{l}\text { Total } \\
\text { population }\end{array}$ & $\begin{array}{l}\text { Number of } \\
\text { coal sector } \\
\text { employees }\end{array}$ & $\begin{array}{l}\text { Coal sector } \\
\text { employees } \\
\text { among total } \\
\text { population } \\
\text { (percent) }\end{array}$ & $\begin{array}{l}\text { Other significant enterprises or } \\
\text { industries in the city }\end{array}$ \\
\hline \multicolumn{5}{|c|}{ Komi Republic } \\
\hline Vorkuta & 192,600 & 13,545 & 7.03 & $\begin{array}{l}\text { Milk factory, machinery, construction, } \\
\text { refrigeration facilities }\end{array}$ \\
\hline Inta & 65,300 & 2,681 & 4.11 & Construction, power station, boiler \\
\hline
\end{tabular}

\section{Rostov Oblast}




\begin{tabular}{|c|c|c|c|c|}
\hline Shahti & 229,900 & 22,453 & 9.77 & \\
\hline Novoshahtinsk & 106,800 & 11,812 & 11.06 & Textile industry, hydropower plant \\
\hline Sinegorskiyin & 10,000 & 2,278 & 22.78 & Agricultural enterprises \\
\hline Sholohovskiyi & 13,600 & 3,010 & 22.13 & Agricultural enterprises \\
\hline Belaya Kalitva & 49,600 & 4,333 & 8.74 & Agricultural enterprises \\
\hline \multicolumn{5}{|l|}{ Tulskaya Oblast } \\
\hline Shekino & 79,500 & 541 & 0.68 & $\begin{array}{l}\text { Agricultural enterprises, machinery } \\
\text { plant }\end{array}$ \\
\hline Uzlovaya & 85,300 & 1,541 & 1.81 & Chemicals \\
\hline Kimovsk & 37,100 & 251 & 0.68 & Machinery \\
\hline Donskoyi & 73,600 & 583 & 0.79 & Machinery \\
\hline Venev & 15,500 & 4,055 & 26.16 & \\
\hline Aleksin & 72,100 & 764 & 1.06 & Agricultural enterprises \\
\hline Kireevsk & 29,400 & 1,536 & 5.22 & Construction and machinery \\
\hline Lipki & 10,500 & 3,141 & 29.91 & Agricultural enterprises \\
\hline \multicolumn{5}{|l|}{$\begin{array}{l}\text { Smolenskaya } \\
\text { Oblast }\end{array}$} \\
\hline Safonovo & 56,100 & 1,129 & 2.01 & $\begin{array}{l}\text { Agricultural enterprises, hydropwer } \\
\text { station }\end{array}$ \\
\hline \multicolumn{5}{|l|}{ Tverskaya Oblast } \\
\hline Nelidovo & 30,100 & 863 & 2.87 & $\begin{array}{l}\text { Chemicals, agricultural enterprises, } \\
\text { machinery plant }\end{array}$ \\
\hline \multicolumn{5}{|l|}{$\begin{array}{l}\text { Kemerovskaya } \\
\text { Oblast }\end{array}$} \\
\hline Kemerovo & 502,500 & & 17.50 & $\begin{array}{l}\text { Chemicals, agricultural enterprises, } \\
\text { machinery plant }\end{array}$ \\
\hline Anjoro-Sudgensk & 107,500 & & 3.50 & $\begin{array}{l}\text { Chemicals, machinery, construction, } \\
\text { textiles industries }\end{array}$ \\
\hline Berezovskiyi & 57,400 & & 1.80 & $\begin{array}{l}\text { Chemicals, machinery, textiles, truck } \\
\text { depot, forestry }\end{array}$ \\
\hline Belovo & 170,700 & & 5.60 & $\begin{array}{l}\text { Coal power station, hydropower } \\
\text { station, textiles }\end{array}$ \\
\hline Leninsk-Kuzneskiyi & 161,000 & & 5.40 & $\begin{array}{l}\text { Textiles, mining equipment } \\
\text { maintenance }\end{array}$ \\
\hline Kiselevsk & 121,900 & & 4.10 & Machinery, truck depot, shoe factory \\
\hline Prokopevsk & 253,300 & & 8.40 & Textiles, machinery, truck depot \\
\hline Novokuznetsk & 586,000 & & 19.40 & $\begin{array}{l}\text { Poultry incubator, food industry, } \\
\text { machinery, furniture factory, forestry }\end{array}$ \\
\hline
\end{tabular}


metallurgical plant, construction industry

Osinniki

80,900

3.40

Source: Data on Zapadnaya mine, January 1, 1996, and Vorkutaugol, Tulaugol, Rostovugol, January 7, 1996, from the results of a statistical survey of project preparation unit; Social and Economic Cost of Coal Restructuring, Kemerovo Administration, Rosugol and Kuzbassinvestugol, 199-4; and Population of the Russian Federation, Moscow Statistics Service, 1995.

Table 4.3 Employees in different sectors (percentage of respondents )

$\begin{array}{llllll}\text { Sector } & \text { Vorkuta City } & \text { Sovetski } & \text { Oktyabrski } & \begin{array}{l}\text { Vorkuta } \\ \text { overall }\end{array} & \begin{array}{l}\text { Kiselovsk } \\ \text { overall }\end{array} \\ \text { Active population a } & 67.4 & 80.7 & 73.2 & 74.6 & 43.0 \\ \text { Mine workers } & 6.9 & 28.7 & 28.9 & 23.3 & 16.2 \\ \text { Vorkutaugol } & 4.0 & 6.0 & 15.4 & 9.0 & 0.0 \\ \text { Government } & 31.7 & 26.7 & 16.8 & 24.3 & 11.4 \\ \text { employees } & & & & & \\ \text { Other } & 24.8 & 19.3 & 12.1 & 18.0 & 15.4 \\ \text { Inactive population } & 32.7 & 19.3 & 26.8 & 25.4 & 57.0 \\ \text { Pensioners } & 11.9 & 6.0 & 6.7 & 7.6 & 44.3 \\ \text { Unemployed } & 20.8 & 13.3 & 20.1 & 17.8 & 12.7\end{array}$

a. Includes pension-age individuals who are active in he workforce.

Source: Household surveys.

Vorkuta City works in mines (excluding Vorkutaugol workers, table 4.3); 13 percent of the households in the city contain people who are either retired from or working in the coal sector (table 4.4). In settlements that support specific mines, however, nearly half of the households have either a person working in, or a pensioner related to, the coal industry. In Tula the communities that support mines are often large (30,00040,000 people), and in many major coal settlements employment in the coal sector accounts for 810 percent of total employment. Other industries such as soap, shoes, textiles, and manufacturing also contribute substantially to employment. More recently, informal sector jobs and urban agriculture have been introduced to these communities.

Education levels in coal communities are high, especially among younger workers. For example, although a large segment of the labor force in Vorkuta and Kiselovsk has not received formal training in a particular field and works as generalists in mining and nonmining sectors, about a third of the labor force has received degrees from a specialized higher-level institution, and more than a third are high-school graduates (figure 4.4). Less than a tenth of the labor force has a university education. Most workers with only a primary-school education are older and are more prevalent in Kiselovsk because of the older age structure of the communities in this region. The female labor force does not appear disadvantaged with respect to education. Thus community differences in labor force characteristics are closely related to the age structure of the population but point to important differences in the ability of Vorkuta and Kiselovsk residents to cope with the impacts of enterprise restructuring. 


\section{Social Assessments for Better Development}

Recommendations for the coal sector restructuring program. As illustrated above, the social and economic structures of coal regions are not uniform. And because there are large differences between coal communities in their populations' involvement in the coal sector and in the potential for development of other sectors (including the informal sector), policymakers should take into account differences in responses to coal sector restructuring.15 In assessing the community-specific effects of sector restructuring and designing relevant actions, therefore, it is particularly important to pay attention to coal settlements where the share of coal employment in total employment is high (for example, Sinegorskiy and Sholohovskiyi in Rostov, Lipki, Kemerovo) and to focus on specific settlements associated with individual mines, whether or not the share of coal employment is high.

Table 4.3 Employees in different sectors (percentage of respondents )

$\begin{array}{llllll}\text { Sector } & \text { Vorkuta City } & \text { Sovetski } & \text { Oktyabrski } & \begin{array}{l}\text { Vorkuta } \\ \text { overall }\end{array} & \begin{array}{l}\text { Kiselovsk } \\ \text { overall }\end{array} \\ \text { Active population a } & 67.4 & 80.7 & 73.2 & 74.6 & 43.0 \\ \text { Mine workers } & 6.9 & 28.7 & 28.9 & 23.3 & 16.2 \\ \text { Vorkutaugol } & 4.0 & 6.0 & 15.4 & 9.0 & 0.0 \\ \begin{array}{l}\text { Government } \\ \text { employees }\end{array} & 31.7 & 26.7 & 16.8 & 24.3 & 11.4 \\ \text { Other } & 24.8 & 19.3 & 12.1 & 18.0 & 15.4 \\ \text { Inactive population } & 32.7 & 19.3 & 26.8 & 25.4 & 57.0 \\ \text { Pensioners } & 11.9 & 6.0 & 6.7 & 7.6 & 44.3 \\ \text { Unemployed } & 20.8 & 13.3 & 20.1 & 17.8 & 12.7\end{array}$

a. Includes pension-age individuals who are active in he workforce.

Source: Household surveys.

In Vorkuta there are substantial, statistically significant differences between households located in the center city (where fewer households have members working in the mines, incomes are higher, living standards are better, and more families are headed by single parents) and those in coal settlements (tables 4.5 and 4.6). The concerns of each type of community, as well as those of the broader coal region, will need to be addressed.

The following measures should be taken into account in assessing community-specific effects and designing locally relevant actions to respond to coal sector restructuring:

Supporting the development of community-specific responses. The bulk of coal production and coal sector employment is in eighteen regions, four of which account for more than 90 percent of coal output and 70 percent of employment (1992 figures). For that reason, efforts should be focused on these four regions to ensure maximum impact. Within each region, however, there is substantial variability among communities in terms of their reliance on coal production for their livelihood. Those with heavier reliance should receive greater support.

Allowing communities to help define the response. It will be important to help establish or promote local committees that bring together the interests of various stakeholders. These committees can help assess coal sector-specific impacts and discuss the extent to which mitigation measures should be coal sector-based. Given 
the results of the social assessment and field discussions held in Vorkuta, solutions should address families involved in both mining and nonmining sectors. A comprehensive social response to restructuring should be formulated and implemented by agencies that are not limited to the coal sector.

Supporting regional interagency commissions and local governments to facilitate participatory priority setting in the regional distribution of
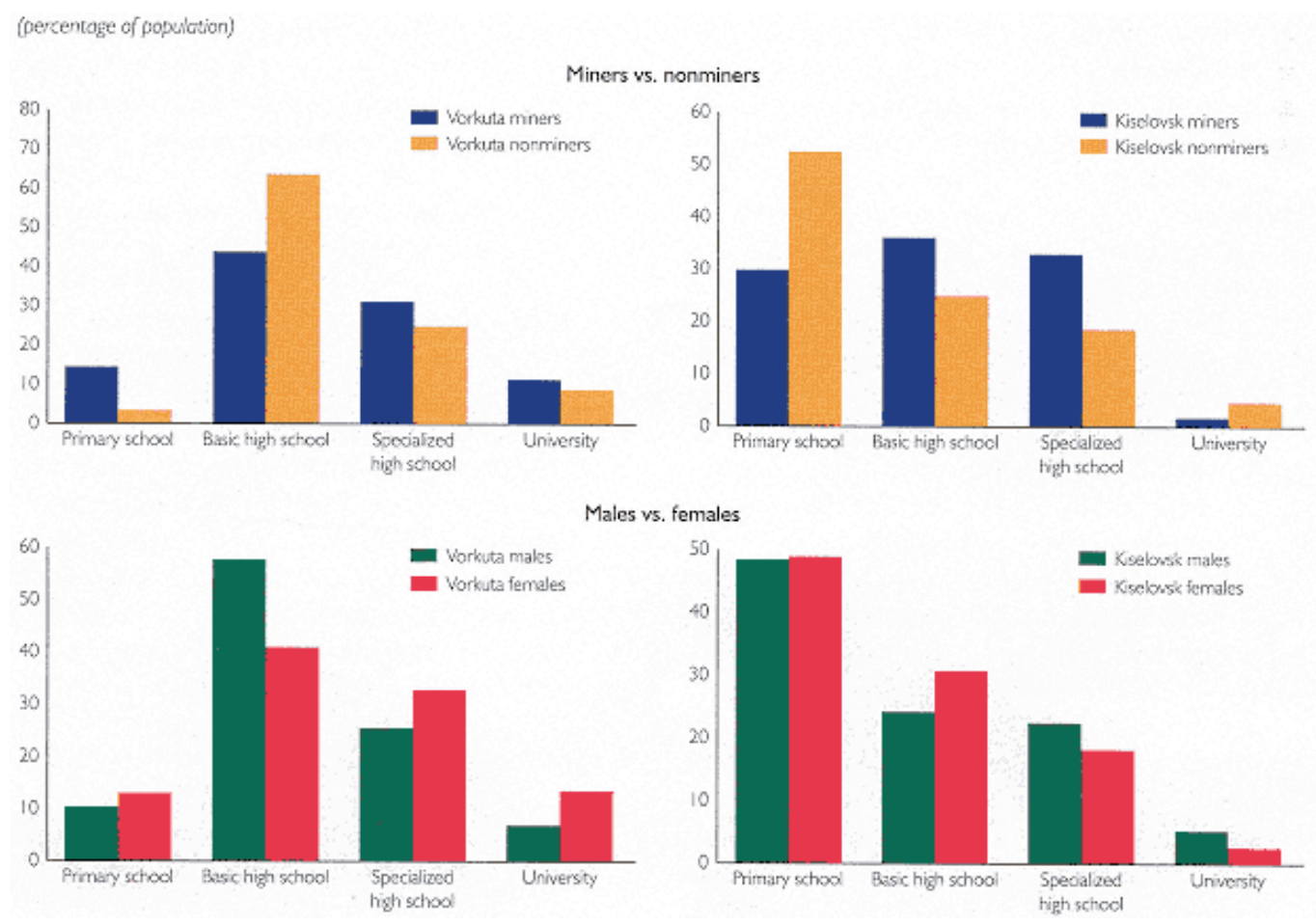

Figure 4.4

Education levels

Source: Household survey.

Table 4.5 Housing conditions in Vorkuta

\section{settlements}

(percentage of households)

$\begin{array}{llll}\text { Condition } & \text { Center } & \text { Sovetski } & \text { Oktyabrski } \\ \text { Good } & 31.0 & 25.0 & 2.0 \\ \text { Average } & 40.0 & 60.1 & 37.6 \\ \text { Bad } & 19.0 & 12.8 & 31.5 \\ \text { Very bad } & 10.0 & 2.0 & 28.9 \\ \begin{array}{l}\text { Number of } \\ \text { respondents }\end{array} & 100 & 148 & 149\end{array}$

Source: Household surveys. 


\section{Social Assessments for Better Development}

benefits. One of the most important findings of the social assessment was the need for local multistakeholder structures to administer the subsidies and severance packages associated with coal sector restructuring. The social assessment also revealed variability in the social, demographic, and economic structures of the coal basins and thus points to the need to set local priorities for interventions aimed at cushioning coal sector restructuring. In defining community-specific actions, it may be useful to incorporate a participatory structure that brings together the views of local communities (for example, a multistakeholder committee). Such a structure could guide the process of adjustment to coal sector restructuring. In this relation it is important to support regional branches of the Inter-Agency Coal Commission and mechanisms such as the recently established (February 1996) Network of Mayors of Mining Cities. The activities of such a network could include bringing together the proposals and views of communities affected by sector restructuring, helping to develop an assistance program, and helping to set priorities for community assistance in a transparent manner. It could also help monitor impacts and evaluate the effectiveness of alternative assistance programs.

Helping set up an independent social impact monitoring mechanism. The emphasis on putting people first, the social assessment findings, and the information gaps in the sector-particularly with respect to the transfer of social assets from enterprises to local governments-all point to the need for a continuous social assessment process. Research institutions currently perform important civil functions in Russia, as well as in the coal sector. Thus it is appropriate that a local university

\begin{tabular}{|c|c|c|c|}
\hline Availability & Center & Sovetski & Oktyabrski \\
\hline $\begin{array}{l}\text { All modern } \\
\text { conveniences }\end{array}$ & 76.2 & 99.3 & 0.0 \\
\hline $\begin{array}{l}\text { Some modern } \\
\text { conveniences }\end{array}$ & 23.8 & 0.7 & 67.1 \\
\hline $\begin{array}{l}\text { No modern } \\
\text { conveniences }\end{array}$ & 0.0 & 0.0 & 32.9 \\
\hline $\begin{array}{l}\text { Number of } \\
\text { respondents }\end{array}$ & 101 & 149 & 149 \\
\hline
\end{tabular}

Source: Household surveys.

or research institute provide independent assistance to the government in conducting community-specific social assessments. A schedule of closures and planned downsizing will be needed in advance for social impact monitoring. Such a procedure also would respond to the right of people to know about events that affect their lives. The objectives of social impact monitoring are to:

Help determine the extent to which redundant mine workers receive benefits, the extent to which the entitlements of coal sector employees specified by various legal instruments (including the tariff agreements reached by the trade unions) are respected, the extent to which workers are informed of their entitlements and given notice on laws and regulations, the extent to which there are mechanisms and opportunities for recourse, and the extent to which the local, regional, and federal institutions mandated to help workers actually provide such services. If intended benefits and services do not reach the miners, an examination of the constraints and identification of mechanisms to remove these will be necessary. 


\section{Social Assessments for Better Development}

Help determine whether voluntary departures are based on adequate information and on workers' decisions. If the evidence suggests otherwise, the social impact monitoring will focus on factors that distort workers' ability to make their own decisions. Monitoring will also be used to propose corrective measures.

Help determine whether geographical, job, and housing mobility is hindered and whether the measures envisioned under the reform program and the capacity-building activities of the sector adjustment loan and the Implementation Assistance

Project are in place. If mobility is hindered, social impact monitoring data will be used to propose specific measures to enhance such mobility.

Help determine whether special groups—-such as migrant workers, the disabled, and women — shoulder a disproportionate burden of restructuring. Where practices are discriminatory, social impact monitoring will identify contributing factors and provide a basis for proposing mitigation measures.

Help determine whether household and community access to and quality of social services are adversely affected by restructuring. Where adverse impacts are observed, social impact monitoring will be used to identify contributing factors, including coal sector reform, and provide a basis for proposing mitigation measures.

Create an appreciation of the overall hardships of a transition environment and evaluate the relative social impacts of coal sector reform, in addition to the absolute impacts listed above.

Help determine whether trust in the institutions, which is so important in the implementation of reforms, is weakened and whether the public has a negative perception of reform.

Social impact monitoring is also intended to help determine whether:

Relative to baseline conditions, miners, their families, and communities are better cushioned with the sector adjustment loan and the Implementation Assistance Project than without.

The social safety measures in the government's program that are supported by the sector adjustment loan and the Implementation Assistance Project are implemented and reach the intended beneficiaries to minimize or mitigate adverse impacts.

The restructuring program takes place in a dynamic transition environment in which the adverse effects of coal sector restructuring weigh less heavily in the lives of the people it affects than planned or spontaneous restructuring in other sector activities.

Particular regions, settlements, or social groups (women, the elderly, the disabled, migrants) are systematically disadvantaged.

Restructuring at the level of communities and individual enterprises or mines takes place when social safety measures are fully in place in a planned, open, and transparent fashion.

Institutions mandated to implement reforms, make severance payments, provide training and job placement services, manage social assets, and have the capacity and commitment to perform their roles.

Decisions at all levels are made with the participation of relevant stakeholders and whether mechanisms are in place to ensure such participation. 


\section{Social Assessments for Better Development}

The public, especially in the coal regions, is informed of developments and whether trust in the reform agenda is weakened.

Specific monitoring indicators include: $\underline{16}$

Access to severance pay based on existing laws

Access to support for legal recourse

Ability to restore income to levels prevailing before sector restructuring, including effective use of severance compensation

Ability to identify alternative sources of income

Flexibility in changing household patterns of labor force participation

Job mobility and accessibility of alternative employment opportunities

Availability and accessibility of training, retraining, and job placement services

Access to social services during sector restructuring (particularly health care and education)

Ability to maintain living standards prevailing prior to restructuring, including access to heating and cooking energy, housing maintenance, and utilities

Access to and availability of information on social safety measures prior to departures from the sector (voluntary or not)

Adequacy of support from local, regional, and federal agencies

Adequacy of participation and representation in relevant decisions.

Social impact monitoring will have to be selective in its emphasis in order to produce timely results in a cost-effective manner. This selectivity will be exercised in several ways:

Regional focus. Surveys, case studies, and a major portion of the field work will focus on four regions: Kuzbass, Rostov, Vorkuta, and Tula. Among these, Kuzbass and Rostov account for more than 55 percent of employment in coal mines and thus deserve particular attention.

Focus on closures and substantial reductions. Because the main objective of social impact monitoring is to minimize the adverse effects of restructuring, monitoring will focus on mines scheduled for closure and large-scale downsizing.

Reliance on coal. The social assessment has already established that some coal communities rely more on the coal sector for employment than others. Social impact monitoring will focus more heavily on cases of exclusive reliance. Still, social assessment studies will attempt to put overall effects in a more representative perspective by showing the relationship between patterns of community reliance on the coal sector and the patterns of adjustment to post-reform conditions. 


\section{Social Assessments for Better Development}

Social impact monitoring cannot seek representativeness in its results. First, many regions have a handful of mines (for example, Vorkuta has fifteen), and a search for a representative mine settlement would not be statistically fruitful. Second, social impact monitoring will proceed based on the nonviability of mines. 17 As mines are announced for closure and downsizing, a major part of the social impact monitoring will focus on communities themselves to determine whether they are typical of the coal regions.

Social impact monitoring will use several sources of primary and secondary data. It also will involve longitudinal, cross-sectional, and thematic studies that complement one another with respect to their coverage of regions and issues. The following provides a general description of social impact monitoring activities:

Monitoring with secondary data. Monitoring with secondary data will involve analyzing total redundancies, unemployment registration, training provided, and placement. The data will be collected in all regions, and sources of discrepancy between intended and achieved targets with respect to redundancies, unemployment registration, and placement will be analyzed.

Cross-sectional surveys. These surveys will focus on mine closures and large-scale downsizing. Brief surveys will be undertaken in a selected number of mines in the four identified regions. Committees will be selected based on the closure lists obtained from coal associations. About 1,000 interviews will be conducted with employees who are made redundant (with a control group of those who have left voluntarily) to ensure that severance packages are received, social assets are transferred, maintenance arrangements are made, unemployment registration is made without delay and unemployment payments are received, adequate notice was given prior to closures, information is available to make the necessary adjustments, and the institutions mandated to support different groups of workers (including vulnerable groups such as the disabled) provide the required services.

Longitudinal monitoring. This effort will focus on a small group of miners who have left the industry voluntarily and on those who were made redundant. It will compare and contrast patterns of adjustment, job search, and mobility. A control group of employees made redundant from nonmining sectors will also be traced over the same period of time (about eighteen months) to identify the relative impacts of coal sector restructuring. Both groups of workers will be selected from the communities included in the first round of cross-sectional studies and will consist of about 400 miners and 200 nonminers.

Regional comparisons. A modest effort is proposed for social impact monitoring purposes. As described in the social assessment

baseline studies, this activity will compare two microregions: one with heavy reliance on coal and another with a more diverse economic base (for example, Prokopyevsk in Kuzbass and Borodinskaya in Tula) to assess differences in coping strategies and their implications for restructuring beyond the period of social impact monitoring.

Monitoring of vulnerable groups. Small-scale studies are proposed to monitor the responses of vulnerable groups (particularly the disabled and migrants) to sector restructuring.

Thematic studies may be required as new issues emerge during the social impact monitoring period. Thus contingency funds have been set aside to provide flexibility in carrying out social impact monitoring.

\section{Focus on Vulnerable Groups}

Social assessment. The social assessments in the two communities reveal that pensioners (55 years or older) and workers approaching retirement are particularly vulnerable because they are less educated than other workers (even less than the unemployed; figure 4.5), lack specialized expertise, and have low geographic mobility and a 


\section{Social Assessments for Better Development}

weak social support base for changing locations and jobs. As in other communities, older age groups are overrepresented among those with lower levels of education and training. For example, more than half of Vorkuta's pensioners and more than 80 percent of Kiselovsk's pensioners have only a primary education. The unemployed (that is, those who have voluntarily or involuntarily lost their jobs or who were unable to get a first job), by contrast, have substantially higher levels of education.

Some pensioners continue to work, and many others are potentially available for work. A 1995 World Bank poverty assessment found that average pensions have been maintained at reasonable levels, although the minimum pension frequently has fallen significantly below the subsistence level. Moreover, about 3 percent of pensioners receive a social pension that is as low as two-thirds of the minimum pension. Pension payments to coal miners have a ceiling that is determined by the average pension levels for all sectors. Compared with miners' pre-retirement salaries, their pensions are severely depressed. The national ceiling imposed on coal pensions makes it difficult for coal pensioners to sustain their families in environments where prices of food and other consumer items are high. Consequently, the perceived need to continue employment after retirement is extremely high among miners. This perception is strengthened by the fact that the coal sector has a low retirement age. Pensioners are particularly vulnerable to mine closures not only because mines provide opportunities for post-retirement employment but also because pension benefits are often distributed by the mines. 18 As in the case of the Promyshlennaya mine closing, pension-age miners usually oppose retirement and do not want to transfer to other enterprises. In addition, there is
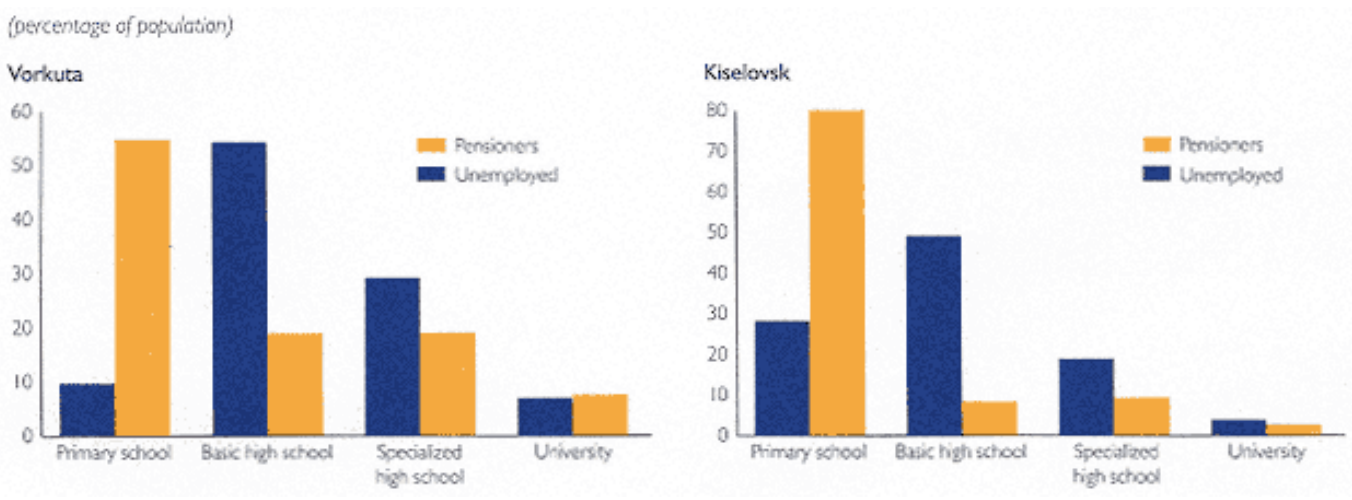

Figure 4.5

Education levels: pensioners and the unemployed

Source: Household surveys.

a clear gender distribution among the elderly with respect to poverty levels. $\underline{19}$

The status of migrant workers is not well-documented, but under the current system, migrant miners from Azerbaijan, Kazakstan, Ukraine, and other republics of the former Soviet Union receive half the salary and far fewer privileges than Russian miners. The effects of restructuring on migrants is unknown, but one of the labor unions is launching a study to document their problems.

The vulnerability of women and female-headed households is less obvious from the social assessment survey data, but women appear to have lower incomes. Also, a higher proportion of women claim that they lack adequate specialized skills for the work they perform (table 4.7).20 Because female participation in the coal sector is low, the threat to female employment comes from the nonmining sectors. In Vorkuta, for example, about one-fifth of women are employed in mine-related activities (table 4.8). Unemployment among the men surveyed is 13 percent, but among women it is 17 percent. 
Most miners are men, with the largest portion of miners belonging to the middle- to higher-income groups. Among the employed respondents in the survey, men account for the largest proportion of miners in both Vorkuta and Kiselovsk. In Vorkuta, moreover, men account for the largest percentage of the group having specialized skills. Women, by contrast, are mostly nonminers, with most women in Vorkuta working for the government. In Kiselovsk, however, a larger percentage of women works in mines.

The composition of the unemployed has shifted since 1991 (World Bank 1995). Job losses have been concentrated on early retirees and women. During the early stages of the transition, most of the unemployed were women-more than 80 percent in some oblasts. This was attributed to firms' desires to retain core production workers and their preference for laying off clerical and auxiliary workers first, the vast majority of whom are women. The Bank's poverty assessment also found that households headed by an unemployed person are more than twice as likely to be poor-63 percent of households headed by an unemployed person were poor in summer 1993. More than 40 percent of households with an unemployed member were poor, and almost half of these were very poor.

Table 4.7 Professional specialization, by gender (percentage of respondents)

$\begin{array}{lllll} & \text { Vorkuta } & & \text { Kiselovsk } \\ \text { Specialization } & \text { Male } & \text { Female } & \text { Male } & \text { Female } \\ \text { Training in mining activities } & 0.6 & 9.0 & 20.0 & 2.2 \\ \text { Generalists } & 46.3 & 43.9 & 51.3 & 43.2 \\ \text { Technical training } & 26.6 & 17.0 & 1.9 & 11.2 \\ \text { No specialty } & 26.6 & 30.0 & 26.9 & 42.7 \\ \text { Number of respondents } & 177 & 223 & 160 & 232 \\ \text { Source: Household surveys. } & & & & \end{array}$

Table 4.8 Employment structure, by gender (percent)

\begin{tabular}{|c|c|c|c|c|}
\hline & Vorkuta & & Kiselovsk & \\
\hline Source of employment & Male & Female & Male & Female \\
\hline Mines & 41.8 & 8.5 & 25.0 & 10.2 \\
\hline Vorkutaugol & 4.5 & 12.6 & n.a. & n.a. \\
\hline Government organizations & 16.4 & 30.5 & 9.4 & 12.8 \\
\hline Other & 20.9 & 15.7 & 18.1 & 13.6 \\
\hline Pensioners & 3.9 & 10.8 & 35.6 & 52.3 \\
\hline Unemployed & 12.4 & 22.0 & 11.9 & 11.1 \\
\hline
\end{tabular}




\section{Social Assessments for Better Development}

Number of respondents

n.a. Not applicable.

Source: Household surveys.
177

223

84

86

The more vulnerable position of female--headed households is also demonstrated by case studies in the coal sector.21 For example, between early 1994 and July 1995 the number of employees at the Dimitrova mine was reduced by 45 percent, from 1,909 to 1,043. While waiting for the mine to close, less mobile and less socially protected groups remained at the mine-including more than 200 women, often older women or single mothers responsible for the care of their children, more than 200 men of pension and pre-pension age, and elderly workers with low education and professional levels. Unemployment benefits and pension and severance payments were insufficient to make a living. Nonetheless, workers from the settlement claimed that mine management had attempted to lay off single mothers (which appears to violate the provisions of the Labor Law). The social assessment survey also found a higher incidence of unemployment among female heads of households.

Activity rates are especially low among female-headed households relative to male-headed households. For instance, 29 percent of the female-headed households in Kiselovsk are unemployed, and 43 percent are pensioners. In Vorkuta these figures are 19 percent and 16 percent, respectively.22 Unemployment among male-headed households is slightly higher than among other groups in Kiselovsk (32 percent), but pensioners account for a relatively small portion of this group (20 percent). Male-headed households are clustered in the older and younger age groups; the high unemployment rates are due in part to the difficulties of entering the labor market in an extremely constrained transition environment. Unemployment rates are consistently lower in jointly headed households in both Kiselovsk and Vorkuta. Understandably, the presence of two adult members helps to cushion a family against economic crisis. Single male-headed households, therefore, also manifest vulnerability in Kiselovsk.

Workers in the nonmining sectors are also vulnerable because they have lower incomes, higher rates of unemployment, worse living quarters, and lower levels of skills than miners. In other words, when measured in terms of vulnerability to unemployment and ability to cope with the shocks of restructuring, nonmining employees are also disadvantaged. As mentioned earlier, there has been a dramatic change in the classification of workers by sector; many workers who were on the payroll of a coal enterprise some three years ago now appear on the local government payroll. In designing assistance programs, therefore, it is more useful to think in terms of communities than in terms of individuals.

The disabled, very numerous within the coal sector because of the lack of adequate safety measures, face uncertainty regarding disability benefits in cases where it is not clear who will be the legal beneficiary of a closing mine (legal beneficiaries are responsible for paying disability benefits). In Halmer-Yu this was one of the reasons many disabled miners remained in the settlement at the end. Moreover, there are several categories of disability, and employers had an obligation to provide surface jobs to those with lower levels of disability. Mine closures and serious downsizing are particularly threatening to the disabled because they risk losing the social benefits they and their families have received from the coal associations.

When Vorkuta's indicators are compared with those of Kiselovsk (for example, income, human resources, quality of housing, satisfaction with living conditions), there is little evidence that Vorkuta is more vulnerable than other communities, and its residents do not claim to be more vulnerable than those of other coal communities. But activity rates are much higher in Vorkuta, as are unemployment rates (figures 4.6 and 4.7). More than half of the respondents in Kiselovsk are pensioners or unemployed; pensioners alone account for 53 percent of those interviewed, and about a sixth of them are working while receiving pension payments. Informal interviews 
indicate a strong preference among pensioners to continue working because pensions are low.

Unemployed workers below the pension age account for a considerable percentage of the population in both regions; but unemployment is especially high (21 percent) in Vorkuta.23 Moreover, about 10 percent of respondents in Vorkuta and 5 percent in Kiselovsk have been laid off. Still, voluntary departures for such rea-

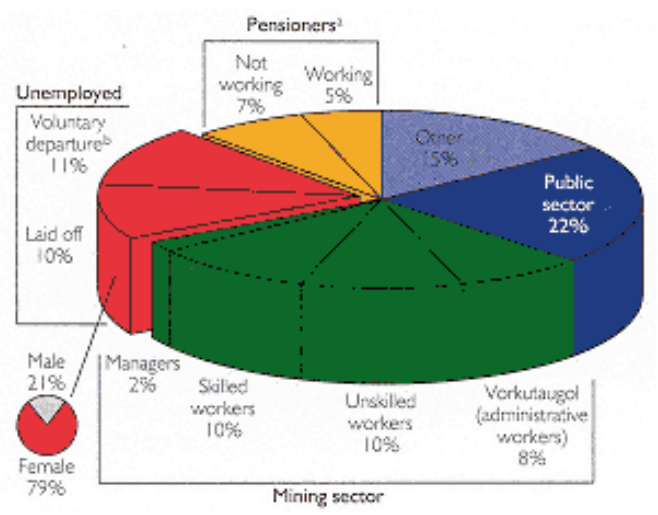

Figure 4.6

Employment structure, Vorkuta

a. Includes individuals older than age 55.

b. Includes departure because of health reasons, own desire, and other reasons.

Source: Household surveys,

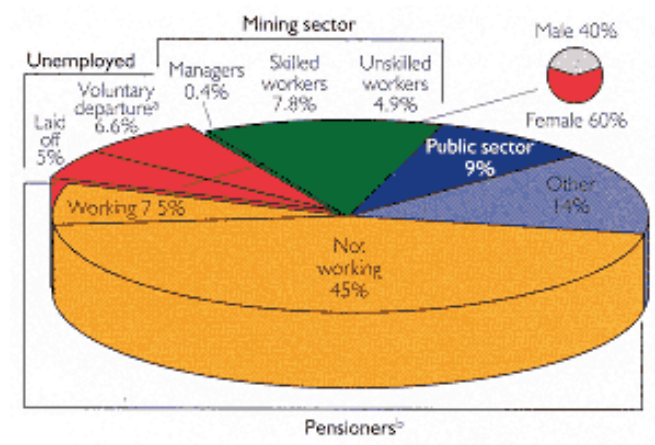

Figure 4.7

Employment structure, Kiselovsk

Note: Figures add up to more than $100 \%$ because of rounding.

a Includes departure because of health

reasons, own desire, and other reasons.

b. Includes individuals older

than age 55. Source: Household surveys.

sons as health, dissatisfaction with work, and migration account for a larger portion of unemployment than layoffs. Among those who have been laid off, miners account for 4 percent of the total in Vorkuta and 16 percent 


\section{Social Assessments for Better Development}

in Kiselovsk.24 In many coal cities or coal basins, therefore, unemployment that has its origins directly in the coal sector varies considerably, and vulnerability to unemployment is communitywide and as common among nonminers as among miners. 25 In numerous communities visited in Tula, for example, many factories had shed workers or closed their doors long before the coal sector restructuring. During these visits people frequently reported their perception that no one has a guarantee of a job for the next day and, regardless of what employment they have, they explore other opportunities.

With respect to the professional characteristics of working-age populations in Vorkuta and Kiselovsk, the social assessment findings are consistent with earlier observations and reveal experience and training in areas other than the coal sector. Indeed, only 5 percent of the respondents in Vorkuta and 9 percent in Kiselovsk have specialized training in mine-related operations; the rest are trained in diverse fields. As such, there is potential for workers to make adjustments through work in other sectors. Indeed, about 6 percent of households in Vorkuta and 8 percent in Kiselovsk report receiving income from activities other than their main employment.

In summary, vulnerability in the coal basins results not only from coal sector activities but also from the adverse effects of transition in other sector activities. This is especially pronounced for women, whose participation in the coal sector is substantially lower than that of men. Similarly, the vulnerability of the elderly, the uneducated, the unskilled, and those without social support systems can be traced to various sources - an important one being coal sector restructuring. Although coal sector institutions can help ensure that affected coal miners and their families receive their legal entitlements, the government should focus on affected communities at large and help establish communitywide protection measures.

Recommendations for the coal sector restructuring program. Given the above findings of the social assessment, the issue is whether targeting vulnerable groups for assistance through a coal sector restructuring program is justifiable and practicable. With respect to this issue, the following recommendations may be considered:

Giving special but not exclusive attention to the needs of vulnerable groups. The transition to market is causing unemployment and hardship throughout Russia. Social assessments cannot establish whether such hardship is higher or lower in coal basins, and thus does not call for special treatment of coal areas. Nor does it call for exclusive new benefits to vulnerable

groups. Although it is necessary to focus attention on vulnerable groups in the coal basins, singling out those who have been engaged directly in the coal sector is insufficient. For example, female-headed households are vulnerable, but the source of their vulnerability is not directly linked to their participation in the coal sector. Thus focusing only on those involved in the coal sector would not address the needs of most female-headed households. Broader, communitywide and regionwide interventions can provide as much support to vulnerable groups as they do to the communities at large. Avoiding discrimination is also important and implies that people should not be deprived of their entitlements because of their vulnerability or political weakness. Case studies of mine closures provide evidence of such discrimination, which must be discontinued. Case studies also show that people have been deprived of their regular entitlements, including wage payments. Possible broader social interventions that would benefit the vulnerable groups as well as others are outlined below.

Ensuring that entitlements to vulnerable groups are provided and avoiding promises for new protection mechanisms unless they can be fulfilled. In this regard it is important to note that targeting specially designed assistance to vulnerable groups may be administratively burdensome. It would also be difficult to monitor such assistance in a restructuring environment.

Addressing both miners and nonminers that are adversely affected by coal industry restructuring. Implementing such a recommendation, however, would require making a policy decision entitling all workers in the coal basins, regardless of their employer, to fair notice and severance compensation. 


\section{Social Assessments for Better Development}

Assisting in the development of social infrastructure maintenance programs to ensure that all community members are protected and that some will be employed. The social assessment showed high demand for support in the maintenance and management of housing and community infrastructure. The housing stock and infrastructure in some of the coal settlements have deteriorated severely, and communities are particularly articulate in their demand for support to repair it. Maintaining housing stocks and infrastructure would not only help improve living conditions, it would also generate employment. Although the employment effects of these programs would necessarily fall on the younger, better-trained, and more dynamic parts of the labor force, their development effects would be shared by the more vulnerable groups. Public works programs focusing on housing and infrastructure maintenance would help establish support for local communities, rather than just miners, in coping with the adverse effects of restructuring. This support should be targeted. In many mining settlements infrastructure services such as central heating were specifically established to support individual mines. Case studies show that these services were owned and managed by the mine associations. When mines were closed, these services were not maintained and eventually broke down. Transportation services to neighboring towns also were provided by mines, and they too collapsed when mines were closed. Consequently, there is a need to identify the specific infrastructure requirements of the affected communities and establish mechanisms for providing these services.

Helping to create employment opportunities through community-based development initiatives such as microenterprise development. Providing financial and technical assistance to local governments through existing support programs is important to help create employment alternatives to mining. Such alternatives are also important given that numerous other nonviable economic enterprises in the coal regions have already closed down because, unlike with coal, there were no large subsidies to support them. In addition, there is a need to support innovative initiatives such as microenterprise development. These types of community programs would help in planning long-term strategies aimed at creating new employment opportunities and ensuring diversification of the coal basins. 26 According to the social assessment findings, a segment of the coal communities is somewhat skeptical of private initiatives, based on what they per-

ceive to be the motivations of private operators. Nonetheless, there is large support for and interest in microenterprises. Many workers feel that they could work for such enterprises and would be willing to receive training to acquire the skills these enterprises need.

This type of community-oriented development effort would provide opportunities for both miners and nonminers and thus would provide social protection for the communities. The need for community-based action is also supported by the findings of the social assessment. Further, such programs would also help develop civil society in coal basins and strengthen community-based organizations and NGOs. 27 Microenterprises should be free to recruit their own labor without regard to social vulnerabilities. Once established, however, these enterprises would recruit from within the coal communities and thus would provide employment opportunities for their members. Women who have experience in non-coal sectors would be particularly good candidates for these enterprises.

Enhancing transparency in the closing of mines. The necessary institutional arrangements for closing mines more humanely are not in place and should be defined. As demonstrated by the Dimitrova mine, some mines have been closed without a beneficiary, cutting off pensioners from their entitlements and shutting down local services (for example, heating). Further, there has been insufficient consideration of the takeover arrangements and the capacity of municipalities to manage postclosure functions.

Encouraging government to establish policies that enhance labor mobility. The social assessment found numerous policies and practices that hinder the ability of workers to move out of the coal basins in their search for employment. Such policies and practices also make it difficult for retired populations to move to other parts of the country. Reviewing and, when appropriate, changing regulations that require residential registration, that prevent workers from getting their full pension compensation (including those with a northern coefficient), and that do not 


\section{Social Assessments for Better Development}

allow collection of pensions and unemployment benefits in different parts of the country are important actions. Moreover, changing these regulations may have institutional and financial implications that should be given adequate consideration.

\section{Improve Living Conditions and Housing}

Social assessments. Living conditions are difficult in the coal basins, especially in the northern regions. In the past regional coefficients and highly subsidized wages compensated for these conditions. Miners were able to save, and many in Vorkuta, having no inflation to deal with, were able to leave these savings in a bank until retirement.

Housing subsidies over the past three years are insufficient for keeping the housing stock in good shape. Besides, under the current institutional setting (monopolistic position of service providers in the housing sector, poor corporate governance, and supervision by municipalities) even available funding is used inefficiently. Historically, the housing stock in the coal regions was relatively underdeveloped in terms of both its volume and quality. During 1993-95, when there were substantial cuts in real social spending, the condition of the housing stock deteriorated further. The social assessment results confirm this observation.

The apparent hardship and enormous burden of transition are reflected in people's perceptions about their living conditions. Very few-about 1 percent of the sample—feel well off. This contrasts dramatically with the results of several national polls showing that some 10 percent of the population feel good about their lives during this reform and transition period. About a third of the population are able to get along but can afford only basic necessities. A large group (more than 40 percent) can afford only food. More than 20 percent of the sample reports that they are barely able to survive.

According to the social assessment findings, living standards in Vorkuta compare favorably with those in the coal settlements of Kiselovsk as perceived by the respective populations. Far more visible are the differences between those in the coal sector and those employed in other sectors. In both Kiselovsk and Vorkuta miners have a more positive perception of their living standards, and this perception is matched by

their higher incomes. There are no consistent differences among male-, female-, and jointly headed households.

Housing conditions also show significant regional variation. In Vorkuta 98 percent of the population lives in flats, often in two-story apartment buildings. Unlike in other parts of Russia, living in communal apartments is not widespread. In Kiselovsk three-quarters of the households have individual, single-story homes. These dramatic differences are particularly important with respect to the ownership and maintenance of the housing stock.

Perhaps as a result of the differences in the type of housing stock, Kiselovsk families are also deprived of modern conveniences, including adequate water and sanitation services (figure 4.8). In general, housing and housing services are better in Vorkuta than in Kiselovsk. While only 12 percent of Vorkuta households are deprived of amenities, some two-thirds of households in Kiselovsk are. Nonetheless, 


\section{Social Assessments for Better Development}
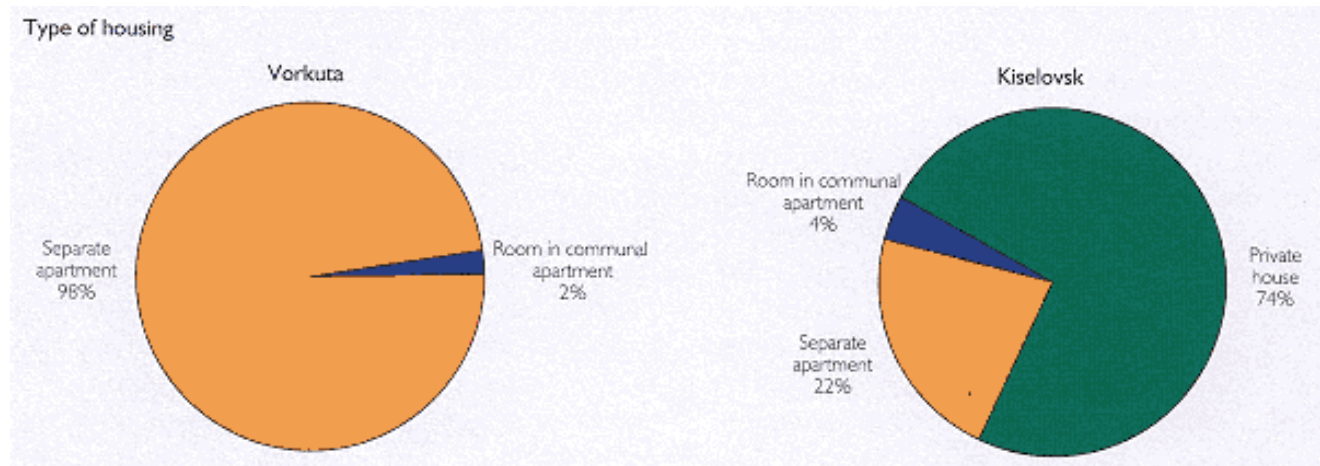

Availability of modern conveniences
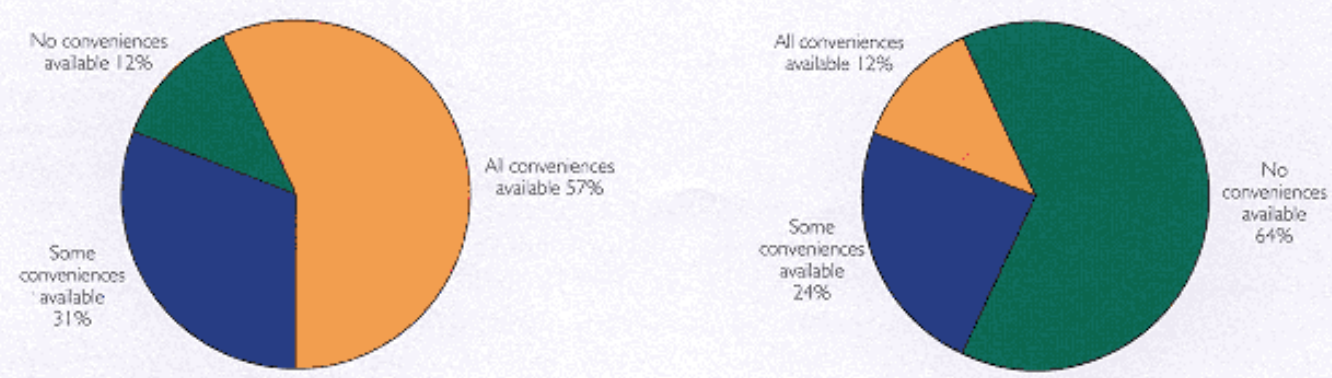

Housing conditions
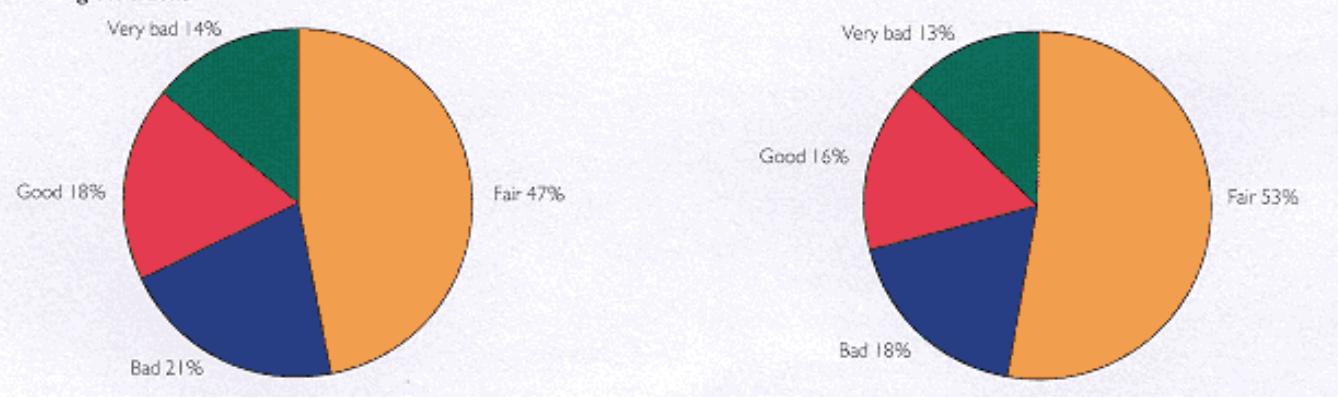

Figure 4.8

Living conditions in Vorkuta and Kiselovsk Source: Household surveys.

community-specific differences are far more pronounced than regional differences. For example, the conditions in the city of Vorkuta are very different from those in the two coal settlement areas. In Vorkuta City, for instance, 76 percent of the homes have modern conveniences. In Sovetski settlement every household has these conveniences, but Oktyabrski is largely deprived. This situation is consistent with income differences.

People's perceptions of the adequacy of their housing situation is generally positive, with two-thirds finding housing conditions good or fair. Perceptions are somewhat more positive in Kiselovsk, despite the reported lack of moden conveniences. In both cities there are no differences between miners and nonminers, among different income or age groups, and between male- and female-headed households with respect to housing conditions. The only predictor of housing quality is location. Again, community-specific differences are large: in Vorkuta City 31 percent of households find their housing conditions to be good and another 40 percent find them to be satisfactory. The coal settlement Sovetski also reports high levels of satisfaction. In Oktyabrski, however, the conditions are considered extremely poor.

In both Kiselovsk and Vorkuta a substantial number of households were waiting for a new housing assignment: 21 percent in Vorkuta and about 9 percent in Kiselovsk. In both regions twice as many miners as nonminers 


\section{Social Assessments for Better Development}

expect a housing allocation. Income, gender, and age are not determinants of those registered for new housing. In addition, a long list of families has signed up for relocation homes. Interestingly, families who are living in the worst-quality housing are significantly less likely to appear on these lists than families with good housing. This is a difficult finding to explain given the lack of correlation between perceived conditions of housing and socioeconomic variables such as income, age, and employment status. Given the political realities of Vorkuta, it appears that those whose living conditions are already good aim to improve their living standards further and use various opportunities, including queuing for relocation homes, to maximize their options.

Some families already own second homes outside the coal basins. More than 6 percent of Vorkuta households and 1.3 percent of Kiselovsk families are in this situation. Further, a certain level of underreporting is expected given the high demand for relocation from Vorkuta. Families who expect to be relocated may well be quiet about home ownership in other areas. It also is important to recall that the percentage of pensioners in Vorkuta is substantially lower than in Kiselovsk and in comparison with national averages. In addition, many pensioners had homes outside the area and moved after retirement. During field visits to Vorkuta, moreover, it frequently was reported that this practice was common until the 1990s.

Recommendations for the coal sector restructuring program. These findings on housing and living conditions have three main implications for coal sector restructuring. First, there is a need to provide support to municipalities to maintain the social assets that have been transferred to them. The recent divestiture of the bulk of social assets was not fiscally coordinated, creating problems in housing and other social assets. At the moment this problem is at least as important as more traditional social problems deriving from rising unemployment and inadequate social protection. Second, the means by which municipalities and households will take over the maintenance of the housing stock and infrastructure from enterprises requires further study. Third, alternative approaches should be developed to facilitate rapid privatization of housing in areas where there is a high incidence of single-story detached houses; this too will require additional social assessment and consultation.

\section{Recognize Diversity in Compensation Expectations}

Social assessments. Households directly or indirectly affected by coal sector restructuring expect cash compensation, housing, continuation of social benefits, and continued access to social assets. Remarkably, few persons expect government assistance in finding employment. By contrast, Vorkutans would like a house elsewhere, want their moving expenses covered,

and expect cash compensation as well. Those from Kiselovsk, on the other hand, would rather have cash and guarantees that their social services will continue. The demand for direct cash compensation is particularly pronounced in Kiselovsk (about 55 percent), where there is little expectation of relocating. According to the survey results, there are high expectations for government support to mitigate the adverse effects of restructuring, and the types of assistance being sought are those best delivered by central and local government agencies.

It is clear that relocation expectations are high in Vorkuta. The demand for housing is particularly pronounced: 90 percent of respondents expect assistance in either housing or housing plus housing-related costs (that is, relocation and travel costs, additional costs, additional compensation). About 25 percent of households in Vorkuta are concerned exclusively with the housing issue, while another 65 percent require housing as well as relocation support, additional costs, or additional compensation.

A large percentage of those demanding housing (70 percent) also specified the amount of money they expected to receive for this purpose. Excluding extreme figures, the data reveal an average figure of 162 million rubles, or about $\$ 36,000$ (1996 prices). Interestingly, the data show little relationship between the socioeconomic characteristics of the individual respondents or households and the housing compensation expectations. One exception is the relationship between income and expected compensation. The largest percentage of high-income 


\section{Social Assessments for Better Development}

respondents in Kiselovsk expect compensation in the form of cash, whereas the largest proportion of high-income respondents in Vorkuta expect housing assistance.

Survey respondents appear to have a fixed figure in mind for housing costs on the mainland (southern Russia). Far more realistic expectations were articulated during the informal pilot studies. In a large number of individual and group discussions held during a pilot study carried out in August 1995, respondents said that they would be prepared to accept cash compensation equivalent to the average square meter price of an apartment in southern Russia multiplied by 12 square meters for each member of the household. This calculation yielded a cost of about $\$ 10,000$ for a three-room apartment.28 In addition, many respondents claimed that it was possible to get housing through informal channels for as little as $\$ 6,000 \$ 8,000$ in cities and less in rural areas. Nonetheless, nobody believed that anyone would actually provide them with such compensation, despite their knowledge of the recent relocating of many of the affected workers following a mine closure. In addition, there is widespread disbelief that any relocation assistance would be forthcoming, despite numerous decrees.

Some people also expect support through local enterprise development. Only 4 percent of households in Kiselovsk and 2 percent in Vorkuta are involved in informal sector activities. When the respondents were asked whether they would be interested in having their own business, younger populations (mostly in Vorkuta) responded with enthusiasm. About half of Vorkuta households were interested; among those, 24.8 percent would be interested if they received supportive training (table 4.9). Thus this should be considered an important area of training that needs to be tailored to geographic and economic possibilities.

More important, the proposed microenterprise component is meant to generate employment possibilities for the coal communities. As mentioned earlier, households are willing to adapt to changing work situations, but they do not have much faith in private business initiatives. About one-fifth of the sample claims that such initiatives are for people seeking easy money. Still, many respondents, especially those in the active employment age group, are willing to get involved in employment within this sector. Another fifth would work in such jobs if there was no better alternative.

\begin{tabular}{|c|c|c|}
\hline Opinion & Vorkuta & Kiselovsk \\
\hline Never & 44.5 & 73.6 \\
\hline Yes, with support & 24.8 & 11.9 \\
\hline $\begin{array}{l}\text { Yes, if there is no other } \\
\text { way }\end{array}$ & 24.3 & 10.9 \\
\hline Yes, if I wish & 5.0 & 2.6 \\
\hline Already have & 1.5 & 1.0 \\
\hline Number of respondents & 400 & 386 \\
\hline
\end{tabular}

Few people expect state support in finding new employment, mainly because miners can still find jobs in other mines. Nonetheless, the labor reduction process has recently started in most mines, and the situation in the coal 


\section{Social Assessments for Better Development}

sector labor market is expected to change rapidly in the near future. In addition, there is a need for alternative employment, especially in settlements lacking a diverse economic base and potential for informal sector development.29 These findings suggest that if trust can be established, and if there is transparency in the development and operation of microenterprises on a pilot basis, they can be introduced to the coal regions.

Recommendations for the coal sector restructuring program. The findings on compensation expectations suggest that the restructuring program should give high priority to ensuring that workers receive all cash that is owed to them under the law. $\underline{30}$ Specific recommendations are:

\section{Box 4.4 Unemployment benefits}

Russia has extensive legal protection for unemployed workers. The extent of the law's application and funding varies greatly, however. All back pay and wages must be paid to workers on the day they are laid off. All workers are guaranteed their basic salary during the job search period for a maximum of two months if they were laid off due to staff reductions and three months if the layoff resulted from the closing of an enterprise (five months for those in the far north and similar regions), provided they register with the local employment service within two weeks of the layoff.

If workers have not found a job within three months of being laid off, they will receive unemployment benefits equal to or higher than the minimum national salary. If applicable, regional coefficients are added to benefits. Benefits are increased by 10 percent for each of a worker's dependents. The amount cannot exceed the worker's basic salary at his or her last place of employment. These benefits include:

Workers laid off in connection with the closure or reorganization of an enterprise who have worked for that enterprise for more than twelve weeks in the year before official unemployment receive 75 percent of their base salary for the first three months, 60 percent of their base salary for the next four months, and 40 percent of their base salary for the next five months, provided that this amount is more than the minimum national salary. Benefits may not last for more than twelve consecutive months in an eighteen-month period.

Workers who worked in closed or reorganized enterprises for less than twelve weeks are paid benefits equal to the minimum salary.

Provide adequate information on compensation. Workers should be given due notice under the law, have a clear picture of their unemployment benefits as stipulated by various laws, decrees, regulations, and tariffs (box 4.4), and receive all their cash entitlements regardless of their decision to stay in the affected communities or leave in search of new opportunities.

Ensure that the government pays severance in a timely manner. This is a priority that would enhance workers' ability to move freely in search of alternative employment opportunities. Case studies on mine closures indicate mixed experience in workers' ability to receive full severance payments under the Labor Law and only partial compensation as per tariff agreements. It is recommended, therefore, that a substantial portion of the subsidies remaining in the sector be allocated to social protection expenditures and disabil-

Workers who have lost their jobs for any other reason receive benefits equal to the minimum national salary.

All laid-off workers are reimbursed 100 percent of all costs associated with voluntary or forced relocation. They may also be given the right to receive their old-age pension two years before the legal retirement age (55 for women; 60 for men). Miners can retire at an earlier age. For example, underground workers with at least twenty years of work experience can retire an any age. 


\section{Social Assessments for Better Development}

Workers who are still unemployed after a year of unemployment benefits may qualify for material assistance, which is equal to the minimum salary. This assistance cannot last longer than six months. Nonetheless, after the limit on material assistance benefits has expired, it is unclear whether workers may begin a second round off unemployment benefits.

The benefit period is extended by two weeks for each year worked beyond pension age.

Workers under 18, pregnant women, women with children under 3, and single mothers with children under 14 can only be laid off with the permission of the local employment service or the Regional Commission for Minors; the employer must find new jobs for these workers.

All women receive benefits equal to the minimum salary until their youngest child is $11 / 2$ years old. Women laid-off in closed enterprises receive additional benefits until their youngest child is 3 years old. Women also may receive onetime benefits equal to ten times the national minimum salary if they are pregnant.

ity compensation. Given the high levels of uncertainty and low trust in the system documented by the social assessment, promises for additional compensation should be made only when they are financially and economically feasible. Similarly, it may be appropriate to review the financial feasibility of the promises made over the past several years, including those concerning free relocation homes for a portion of the affected populations, and to revise them to increase transparency in the implementation of the coal sector restructuring program (box 4.5). 31

Do not raise false hopes. It is important not to raise expectations that cannot be fully met, whether they relate to relocation or other types of compensation. Tariff agreements made in the past were not followed, and few relocation

\section{Box 4.5 Social assistance benefits in Russia}

Cash benefit packages consist primarily of pension benefits, family allowances, and unemployment benefits. Sick pay, maternity benefits, and family allowance to working mothers with children under eighteen months are paid from the Social Insurance Fund. The latter are administered by enterprises. All these benefits, except the birth grant, are related to actual wages. The birth grant is equal to five months of minimum wages. Because most social benefits are financed at the regional level, the profitability of enterprises and the size of the wage bill are important for the financing of social assistance benefits. Given that 23.5 percent of coal industry enterprises are unprofitable, both the amount of the profit tax and payroll controls are questionable, and the practical ability to pay social assistance is in doubt.

Underground miners are eligible for old-age pension benefits at age 50 for men and 45 for women if they have had at least 10 years ( 7.5 years for women) of underground service after 20 years ( 15 for women) of total service. These pensions are paid by the Pension Fund. Surface coal workers are eligible for pensions at age 55 (men) and 50 (women) if their service period at the mine was at least 12.5(10)years and they have a total service period of 25 (20) years. The pension benefit is 55 percent of wages and is raised by 1 percent for every year of service beyond the required service period. Pensions for workers in the northern regions are subject to the northern coefficient increase. Inflation and the increasing costs of all the normal benefits that continued for pensioners have led many miners to continue working to draw their pensions and salary. Rosugol estimates that about 27 percent of all coal employees are eligible for pensions.

Source: World Bank 1995. 


\section{Social Assessments for Better Development}

promises were kept. These failures to meet obligations reduced trust in the system and substantially contributed to the uncertainty felt by mine communities (box 4.6).

Ensure that local governments continue social programs and services. Case studies and survey results show high demand for continuing the social services once provided by the coal associations. A substantial portion of these services and relevant assets already have been transferred to local governments. $\underline{32}$ The recent divestiture of social assets was not fiscally coordinated, creating problems in housing and other social assets. Given the economic realities experienced throughout Russia, it would be unrealistic to expect federal or local governments to continue to provide health, education, and other social services at levels previously available to the citizens. With no further support from the mines in the provision of medical services, heating and cooking energy, scholarships, and so on, many households are adversely affected even when workers remain employed. This problem is at least as important as more traditional social problems deriving from rising unemployment and inadequate social protection. For non-housing social assets, regional authorities implemented various types of cost-saving measures that were conducted on a uncoordinated, case-by-case basis. The government, therefore, should explore the feasibility of continuing key social services to communities. This could be done by ensuring that a substantial portion of the remaining subsidies to the sector is allocated to support the management of transferred social assets. An additional problem that needs to be addressed in this context is enforcing budgetary arrangements ensuring that support to communities is not divested at the regional level or to less important objectives at the local level.

\section{Discourage Government-Funded Voluntary Relocation.}

Social assessments. The propensity for and expectation of receiving state support for free housing and relocation is strong in Vorkuta but not in

Box 4.6 Miners' benefits in Dimitrova mine

Two unions have been active at the Dimitrova mine: the Independent Miners Union (NPG) and the Union of Coal Industry Workers (PRUP). In compliance with the collective agreement with NPG, mine management had to pay 15 percent of the average monthly wage for each year of work at the mine when an employee reaches pension age; pay compensation to the children of perished miners while they are in school (until twenty-three years of age); provide housing subsidies for pensioners in compliance with Articles 1,3, and 9, of the tariff agreement; provide free coal delivery for invalids, World War 11 veterans, recipients of the Mining Glory badge, and families of perished miners; provide payments to pregnant women and women with children under three years of age; pay public transportation fare for employees living outside the city; pay two months of pension for the funeral of pensioners, and provide free coffins, transportation, and tombs; pay housing rent for old apartments; provide guarantees to banks for loan to construct dachas; provide free telephone communication for dachas and free transportation to dachas on weekends; provide skis at the ski resort and in the health center; organize mass festivals and sport competitions; provide gymnasiums, swimming pools, skating rinks, stadiums, and a ski resort; pay benefits to the best athletes; allocate at least 0.15 percent of the wage funds of the mine for sports and festivals; supply free coal or its cash equivalent; and pay half of World War 11 veterans' central heating costs.

The NPG agreement was signed in 1993. When the mine was still in operation, all requirements of the agreement except one were fulfilled. But mine workers lost all their benefits after the mine was closed. The technical and economic confirmation for mine closure was given by the Inter-Branch Committee in July 1995, and production stopped in the fourth quarter of 1995. 


\section{Social Assessments for Better Development}

According to mine management and Kuznetsugol, support for social programs includes compensation to invalids (those with injuries or diseases caused by working in mines), free coal for pensioners and other eligible miners, free funerals for invalids and pensioners, old house repair and maintenance, and housing construction to replace old houses. By mid-1995 less than 10 percent of the financial resources needed for these purposes was actually being allocated.

Kemerovo, Rostov, and Tula. These expectations have arisen mainly as a result of four presidential decrees that promised homes to miners affected by mine closures. These promises also contribute to continued immigration to Vorkuta from other parts of Russia as well as from Central Asia and Ukraine. Even settlements created to serve a mine that is now being closed contain a large number of recent immigrant households. 33 For example, the social assessment found that about 5 percent of the households in Vorkuta have immigrated in the past five years. Expectations of state support for relocation were fueled by the relocation homes provided to many miners from Halmer-Yu (box 4.7). A survey of household attitudes toward voluntary relocation-defined as a free home elsewhere-found that 62 percent of the households in Vorkuta and 12 percent in Kiselovsk were ready to move to another area if the opportunity arose (figure 4.9). In terms of the respondents' reasons for wanting to relocate, family and health concerns were as important as housing problems and expectations that a move would bring monetary benefits. $\underline{34}$ The desire to move is most intense in Sovetski settlement in Vorkuta, where housing conditions are very bad. Only a fifth of the population in Vorkuta

and no one in Kiselovsk had registered to relocate (that is, to demand free housing elsewhere in Russia). More important, nonminers were more eager to relocate than miners (table 4.10). And the number of nonminers registered to move was almost equal to the number of miners who registered.

As a result of the active struggle of the Fund for Social Guarantees - together with the Disabled Miners Fund and Veterans of the North — the government has approved small funds for relocation for Vorkuta households. Accordingly, the disabled and their families, pensioners who have worked for more than twenty years in the mines and have been on the waiting list for relocation, and former gulag prisoners may benefit from this program over the next five years. The scope of these activities is limited, however, and broadly based financing of voluntary relocation is not affordable.

Recommendations for the restructuring program for the coal sector. In light of these findings, the following recommendations largely discourage large-scale assistance for government-financed relocation.

Avoid government-funded voluntary relocation. Government-provided voluntary relocation

Box 4.7 Halmer-Yu mine closure and relocation

Halmer-Yu mine is located two hours north (by train) of the Arctic city of Vorkuta. Because of the region's harsh climate, all of the housing structures are in serious disrepair. There was talk of closing the mines as early as the late 1980s. By 1993 it had become the target of Rosugol and others to serve as the model for closing. The mine had 1,573 workers; the settlement of 4,100 people was associated almost exclusively with the mine.

In considering relocation, Vorkutaugol and the Halmer-Yu Mine Administration directed the Fund of Social Guarantees to survey Halmer-Yu residents about their location preferences. The survey found that 270 families (499 people) wanted to leave the Vorkuta region. The list for priority relocation consisted of the most vulnerable groups: single mothers, pensioners, and laid-off workers. By 1994, 600 families were on this list. As part of the relocation process residents were given an opportunity to fly south and review two to three apartments before being moved. Rosugol, Vorkutaugol, and the Vorkuta City Administration were responsible for financing the new housing and for transporting residents to evaluate the new housing sites.

Discourage Government-Funded Voluntary Relocation. 
The experience at Halmer-Yu was not successful, however. It demonstrated that relocation was extremely costly (more than 140 billionrubles so far), followed a unique course not necessarily connected to the legal requirements for a closing, and created false expectations for workers at other mines that may or will close. In addition, many Halmer-Yu residents were not relocated. Rosugol had planned for all workers to relocate by July 1995, but this plan did not materialize. At the end of 1995, 360 families were still registered as residents of the settlement. Of these, 76 families were providing support services to the settlement, 156 had received apartments in central Russia and could leave but were in court trying to secure disability payments, and 128 remained because their housing had not been completed.

Former Halmer-Yu residents are now located in several regions of Russia, although many now say that they would have preferred to relocate to their family home-generally located in other countries. For example, a large number of Ukrainian nationals resides in the Arctic, but a lack of housing coupled with the fact that Russia will not transfer pensions or pay costs outside the country has held back workers from taking this course. The impact of the Halmer-Yu experience on other workers in northern Russia is important. In March 1995 the InterBranch Coal Committee visited Vorkuta and, following a participatory process, agreed that only people who worked in mines to be closed for ten years or more had the right to be relocated.

Do you want to move?
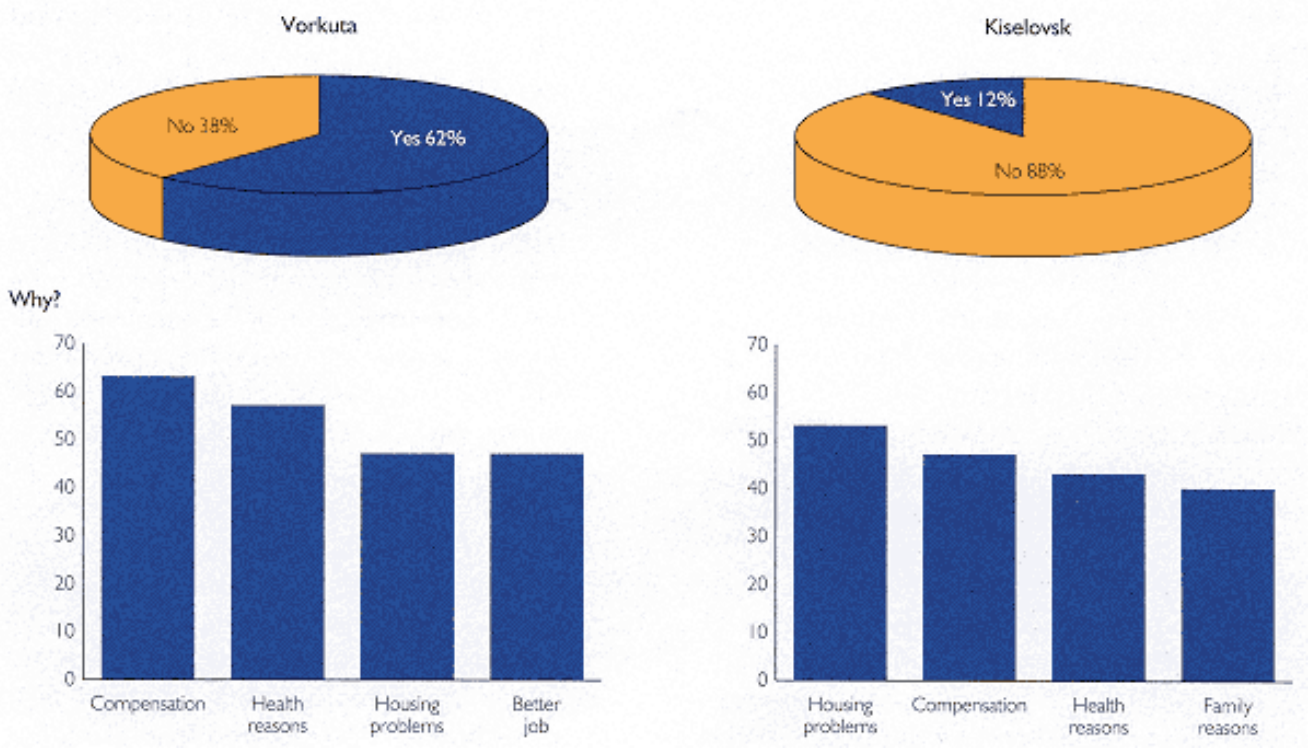

Figure 4.9

Household views on relocation

Source: Household surveys.

Table 4.10 Readiness to move among miners and nonminers (Percentage of respondents)

\begin{tabular}{llllc} 
& Vorkuta & \multicolumn{3}{c}{ Kiselovsk } \\
Readiness & Miners & Nonminers & Miners & Nonminers \\
Ready & 68.8 & 58.0 & 12.5 & 10.3 \\
Not ready & 29.0 & 38.1 & 82.8 & 87.6
\end{tabular}


Social Assessments for Better Development

$\begin{array}{lllll}\text { Unsure } & 2.2 & 3.9 & 4.7 & 2.1 \\ \text { Number of respondents } & 93 & 307 & 64 & 330\end{array}$

Source: Household surveys.

homes should not be provided to those who have lost their jobs, to special categories of miners, $\underline{35}$ or to nonminers for several reasons: the overall demand for relocation is not high and is location specific; demand for voluntary relocation is not limited to miners, especially in Vorkuta, where nonmining families demand social justice and expect the same treatment that is extended to miners; institutional and financial arrangements for largescale relocation would pose large problems and would be difficult to sustain; and even limited applications would create false wage and compensation expectations among laborers and reduce the future economic viability of coal production. Nonetheless, there are provisions for relocation travel support under the existing Labor Law. Workers who are laid off would receive cash compensation for the transportation of up to five tons of their household effects if they choose to resettle. These entitlements should continue to be provided to affected workers and their families.

Several proposals regarding relocation programs that would provide free housing to groups of affected populations were developed for Vorkuta and shared with the Bank missions. One of these proposals was designed by the mining association; the other was put forward by the Fund for Social Guarantees. $\underline{36}$ These were intended to cover pensioners who have worked in the mining sector for at least twenty years or workers who are particularly vulnerable (for example, the disabled). Even at this limited scale, however, publicly financed provisioning of relocation homes poses several problems:

It is not equitable to confine relocation homes to coal sector employees when many other workers, often with lower pay,

support the coal sector by providing health, education, and other services.

The number of households meeting the criteria for relocation housing entitlement (disabled and those with twenty years' work experience) would increase every year. Attempts to deny them similar support would not be equitable.

Supporters of the relocation program argue that good housing is in short supply and that relocating 11,000 families from Vorkuta would free housing for miners who are on the waiting list for a new housing allocation. Nonetheless, allocating the resources to be used for relocation homes to a comprehensive housing maintenance program in Vorkuta could create employment and benefit many more families.

Construction of relocation homes, especially when undertaken by the public sector or by mining associations, is costly. For example, official estimates put the cost of relocating 11,00012,000 families in Vorkuta at $\$ 300500$ million. According to the social assessment results and the expectations articulated by workers, relocating this number would mean that the households requiring relocation homes would increase by 1,200 a year as additional households meet the criteria for relocation. A relocation housing program of that magnitude would be very hard to sustain.

Family members of those who qualify for a limited relocation program would not necessarily benefit from relocation, especially because the relocation program would be designed for populations who are no longer active in the job market. In fact, some families that received free relocation homes recently as a result of mine closures

returned to Vorkuta when the legalities concerning their ownership of these homes were clarified. 


\section{Social Assessments for Better Development}

There is a lack of management capacity to handle a major relocation housing program, as demonstrated by the Halmer-Yu relocation process. In the past people have used their own initiative to relocate, and they could continue to do so at relocation costs far below those of the public sector.

\section{Consider government support to voluntary relocation programs when there are environmental hazards} associated with mine operations or closings. Field visits during the social assessment found housing made unsafe as a result of mining operations. This finding suggests the need to relocate affected households for reasons of physical safety - whether or not their members have lost their jobs because of mine closures or significant downsizing. Further, such support should be available to families whether their members are employed in mines or in other activities. In addition, the relocation of households subject to environmental hazards associated with coal operations should be a precondition for closing any mine. The promises made to residents of northern regions and to Vorkutans for free relocation housing should be reviewed from the perspective of financial feasibility and social equity, as well as in terms of the implications for coal sector restructuring objectives. Rather than financing free relocation homes for a limited number of miners, the restructuring program might focus on designing policies and regulations that enhance free movement of workers and their families and promote geographical mobility in and out of the coal basins. As indicated by the World Bank report, Vorkuta-A Town in the Far North, there is nowhere in the world which provides workers with a free house virtually anywhere in the country when economic conditions force job-shedding, and it is difficult to see why Russia should be an exception. 37 Relocation costs should be estimated for each mine and included in the overall costs of mine closures. If hazards are present in mines not subject to closure, affected households also should be relocated. It should be possible for the restructuring program to support such relocation regardless of the status of the mine. Municipalities that are asked to assume maintenance responsibility for the housing stock of enterprises can put forward proposals for environmentally induced relocation. Moreover, financing this type of relocation activity within the coal basins would help create employment.

\section{Recognize High Levels of Perceived Vulnerability}

Notwithstanding the findings of vulnerable groups above, perceived vulnerability in the two regions is high. Nearly a third of the households expect to lose their jobs within a year (figure 4.10). Feelings of vulnerability are higher in Kiselovsk, where most of the interviews were conducted in mine settlements near mines that were closed. When asked whether mine closures in their communities would affect them and their families, nearly 60 percent of Vorkuta respondents and 72 percent of Kiselovsk respondents said yes. A more important aspect of the findings, however, is that more than a quarter of the residents in coal regions do not feel threatened, and these more confident people are miners. In both Vorkuta and Kiselovsk some 67 percent of miners feel such a personal threat. One in three or four employees working in other sectors, on the other hand, feel that they are in immediate danger. Similarly, younger working women and female heads of households perceive the threat of restructuring to be large and immediate.

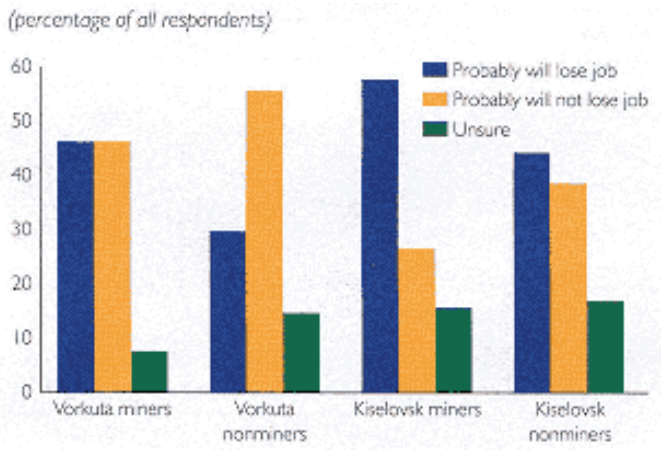

Figure 4.10

Worker vulnerability 


\section{Social Assessments for Better Development}

Source: Household surveys.

Despite their perceived vulnerability, many respondents support coal sector restructuring provided that procedures are followed (box 4.8). About half the respondents disagree with coal sector restructuring regardless of the manner in which it is done, but 54 percent of Vorkuta residents and a third of Kiselovsk respondents support what they understand of the government's restructuring efforts. When asked whether they believe that mines should be closed, 91 percent of Vorkuta respondents and 92 percent of Kiselovsk respondents said that nonviable mines should close only when workers are offered equivalent work (table 4.11). Slightly less (83 percent and 81 percent, respectively) said that unprofitable mines should be closed provided that workers are offered material compensation. In Vorkuta, where unemployment is higher than in Kiselovsk, respondents indicated greater support to reform. Still, two-thirds of the Kiselovsk respondents did not want mines to close under any circumstances, perhaps as a result of their recent negative experience with mine closures. Female-headed households had greater uncertainty about the conditions under which the reform program was being implemented than any other group.

When asked whether they would support mine closures if the program included protection for the workers, respondents indicated considerably more support for reform. For example, more than 90 percent agreed that unprofitable

Box 4.8 Procedures for mine closures

According to the Basic Trends document (Russian Federation 1995), a mine closure should proceed as follows. First, the technical-economic confirmation of the closure should be available and approved by both labor unions. Then the confirmation should be discussed by the Rosugol Expert Commission, resulting in a protocol signed by representatives of Rosugol, the association, the closing mine, and both labor unions. The confirmation and a program of closure should be submitted to the Inter-Agency Coal Commission for approval before the actual closure takes place. The commission also should decide on sources of financing for the closure, and on this basis Rosugol should submit to the government a request to start financing. Rosugol then issues an order about closing and allocates appropriate financing for it. After that the government should issue a decree on mine closure and the related financing procedures. Finally, a legal successor of the mine should be defined to provide payments according to the disability claims.

mines should be closed provided there was compensation to workers and irregularities - such as those seen in some of the closed mines-were not allowed (box 4.9). Most respondents (90.8 percent) in Vorkuta think that unprofitable mines should be closed only if workers receive another job of equal value in another place; 44.5 percent, however, think that unprofitable mines should probably close. Also in Vorkuta, 5 percent of the respondents think that unprofitable mines should close even when workers receive minimal compensation

Table 4.11 Workers' views on mine closures (percentage of respondents )

\begin{tabular}{lllllll} 
& Vorkuta & \multicolumn{3}{c}{ Kiselovsk } \\
Opinion & Agree & Disagree & Unsure & Agree & Disagree & Unsure \\
$\begin{array}{l}\text { Mines should not close under } \\
\text { any circumstances }\end{array}$ & 44 & 34 & 22 & 67 & 18 & 15
\end{tabular}


Social Assessments for Better Development

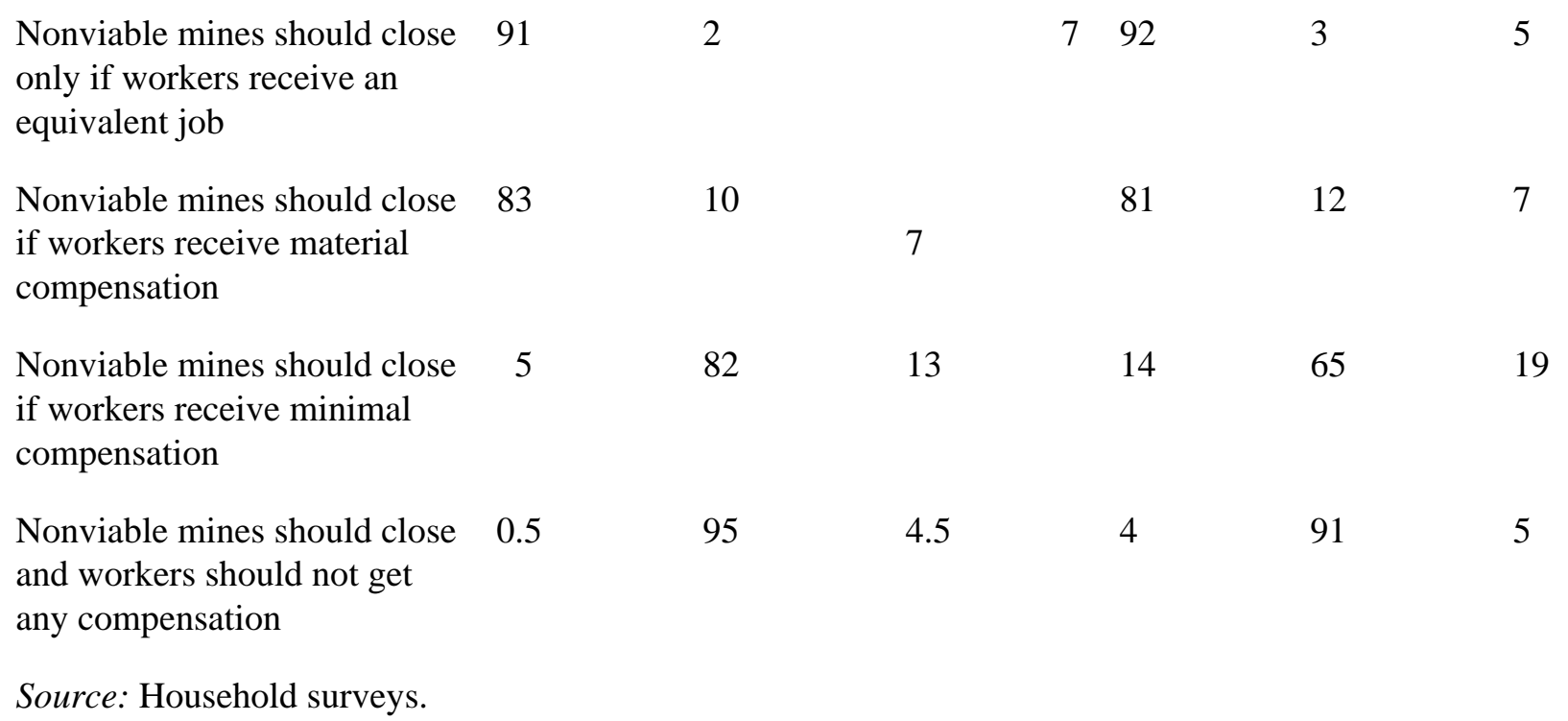

Box 4.9 Promyshlennaya mine closing

According to interviews with the Promyshlennaya mine management and workers, no order was issued for the mine's closing. The decision to close the mine without a governmental decree was met with negative reactions. Uncertainty among workers about their future and the lack of work and information about the fate of the mine led to an outburst of social discontent on September 25, 1995, when the workers went on strike. On September 27, 1995, a governmental decree was signed about the mine closing, but the miners remained on strike for many months.

Around the beginning of October 1995 a delegation including representatives from Promyshlennaya and Vorkuta mines visited Moscow to discuss the strike with the government. The workers had gone on strike because of the continuing uncertainty about compensation and other social guarantees. Seeing few prospects, people were desperate and tensions were high. The uncertainty also has generated an antigovernment sentiment among miners and opposition to the idea of coal industry restructuring. As a result of the increased pressure from the delegation, Rogugol agreed to finance mine closures and provide free relocation for miners of Promyshlennaya mine.

In Kiselovsk, by contrast, a much higher percentage (67 percent) think that mines should not close under any circumstances. Nonetheless, 92 percent of respondents agreed that mines should be closed if workers receive another job of equal value. Eighty-one percent of the respondents in Kiselovsk think that unprofitable mines should close if workers receive material compensation.

A large percentage of households (85.5 percent in Vorkuta and 71.0 percent in Kiselovsk) stated that there is a need for government support (figure 4.11). The residents of Kiselovsk have lower expectations of their government. This may be based on their recent experience with mine closures, where little assistance was provided. It also may be attributed to the lower political profile of Kiselovsk.

Increase Trust in the System

Social assessments. Mine communities do not trust coal sector institutions, and there is little 


\section{Social Assessments for Better Development}
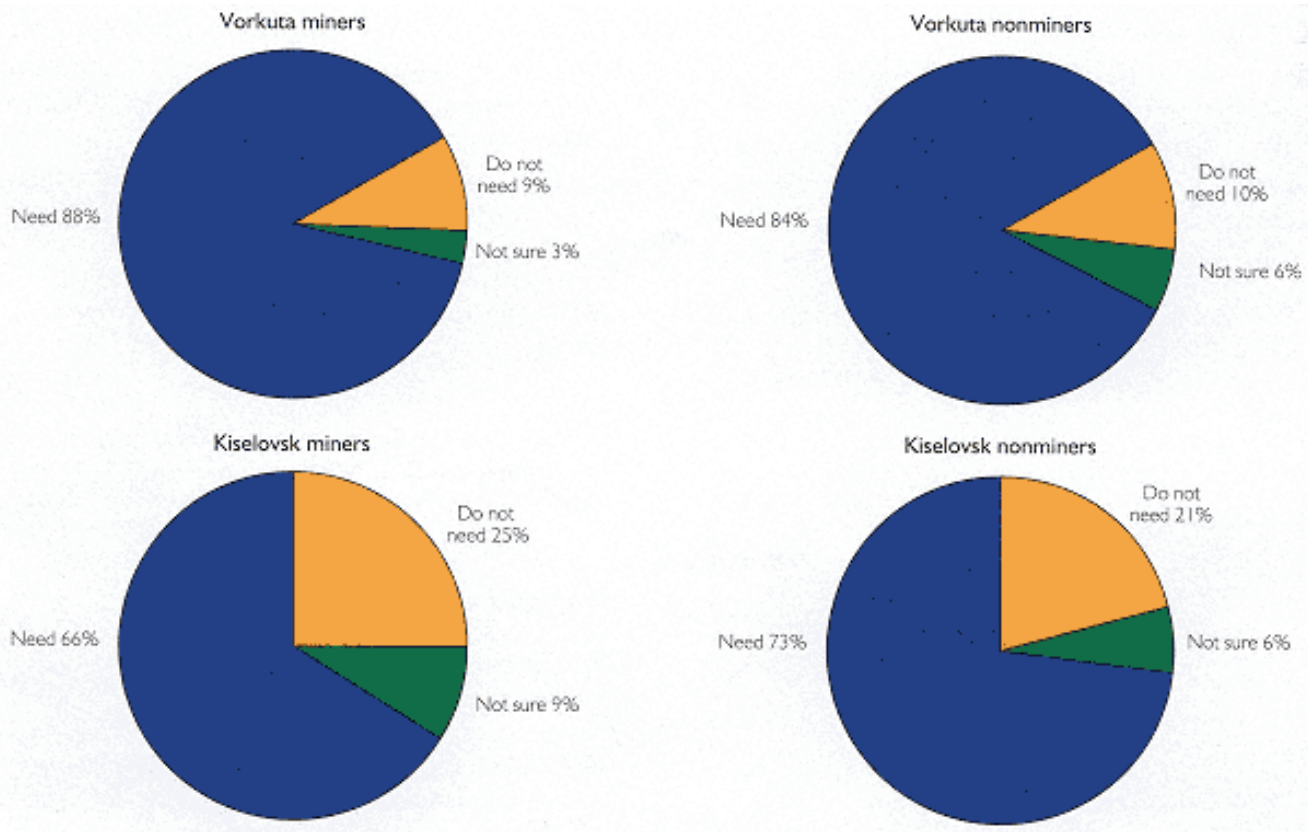

Figure 4.11

Need for government social assistance, Vorkuta and Kiselovsk

Source: Household surveys.

trust in the system at large (figure 4.12). $\underline{38}$ About a fifth of the households surveyed do not trust anyone, and another quarter are uncertain about who can be trusted. Most respondents do not think that any organization is worthy of trust. Only 5 percent trust Rosugol, less than 3 percent trust the regional coal companies, 3 percent trust the regional government, less than 8 percent trust unions, and less than 2 percent trust the employment service. $\underline{39}$ The results of systematic surveys are supported by case studies. Part of the lack of trust can be traced to the many mine closings that are occurring without notice (box 4.10).

Awareness of international organizations and the World Bank also is low in Kiselovsk and Vorkuta. Few people know about the role of international assistance in transition and sector reforms, and those who are informed have negative views and little trust that assistance from such organizations will benefit them. Although the project preparation unit's efforts 

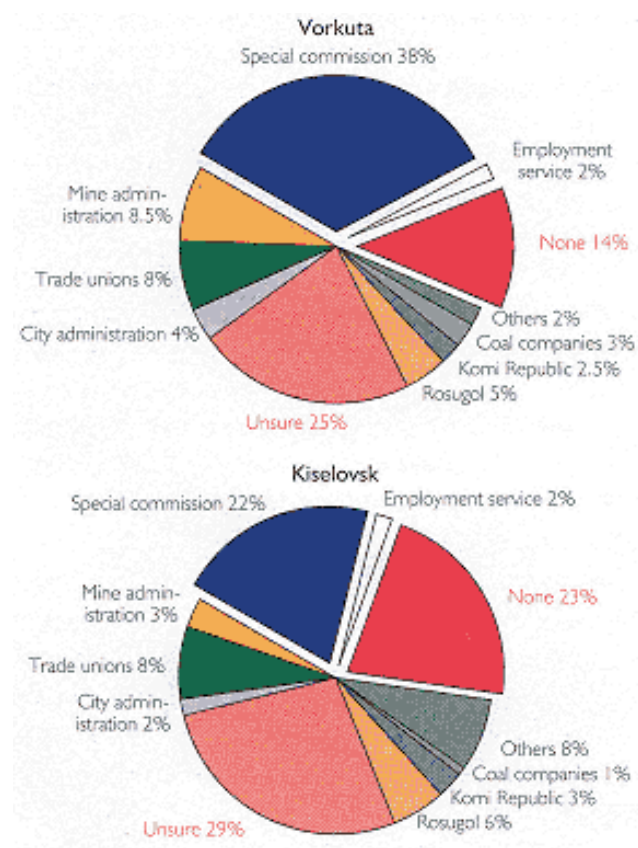

Figure 4.12

Organizations trusted to distribute money and benefits

Note: Figures add up to more than $100 \%$

because people could give more than one answer.

Source: Household surveys.

during the past several months — especially the participation specialists' efforts—might have changed these perceptions to some extent, continuous efforts in this regard are needed.

Notwithstanding the general lack of trust in institutions, 38 percent of households in Vorkuta and 22 percent in Kiselovsk would trust a multistakeholder commission. 40 If such a commission gains the people's trust, those who are skeptical or uncertain will change their views.

Recommendations for the coal sector restructuring program. Given the pervasive lack of trust, restructuring should be used to establish mechanisms that allow the public's voices to be heard in the course of designing, implementing, and monitoring the social impacts of the program.

Use a participatory structure such as the Coal Commission to meet expectations and broaden trust in the system. A detailed description of how such a fund could be established and operated already has been developed by the project preparation unit.

Work with the Union of Coal City Mayors to ensure that local committees are composed of multiple stakeholders. As proposed in the social assessment undertaken in August 1995, carrying out this recommendation will generate trust along the lines proposed by the affected populations.

Box 4.10 Workers and the Cherkasovskaya mine closing

According to discussions with management and workers in Kuzbass, no notice was given for the closing of the Cherkasovskaya mine. Technical and economic confirmation for the mine closure was given by the 


\section{Social Assessments for Better Development}

Inter-Branch Committee more than a year after the process started. In July 1994 the director of Rosugol issued a letter authorizing the liquidation of the mine's assets. Before this letter was received, workers were given assignments over a weekend period to bring up major mine equipment from underground. Workers were told to go on vacation, that they were being transferred to another mine, or nothing at all. The workers said that the process was like being shot with a bullet and not knowing it until minutes later. The sudden manner in which the closure occurred has alarmed neighboring mining communities.

Ensure that continuous social impact monitoring is put in place. This effort should be carried out by an independent group of experts and scholars.

Develop a participatory framework for the coal restructuring process. Such a framework should consider the conflicts among stakeholders and empower affected populations with sufficient information on their rights and entitlements. This framework also should be designed to ensure transparency in reform implementation so that all stakeholders can adjust their responses to reform. Funds need to be made available to support public information, public relations, and other forms of public participation.

\section{Foster a Participatory Approach}

The proposed participation activities are based on the results of the social assessment. Their objectives are to:

Provide miners, their families, and communities with adequate and timely information about the coal sector reform program and reform implementation arrangements; and maintain and strengthen support for reform in both the affected regions and in the country at large.

Provide miners with adequate information about their entitlements under the restructuring arrangements and mechanisms for legal recourse; ensure transparency in implementation arrangements, help avoid discriminatory practices, and support equitable treatment of all affected social groups (particularly vulnerable groups, such as the disabled).

Clarify the roles and responsibilities of local, regional, and federal institutions in the implementation of reforms, in the delivery of social safety packages defined by the government restructuring program, and in the provision of services envisioned under the Implementation Assistance Project; help create trust in these institutions; and clarify the roles of the international agencies supporting the government restructuring program and contributing to the financing of the Implementation Assistance Project.

Facilitate the participation of key stakeholders in decisions concerning the design and implementation of sector reform; and help strengthen the capacity of labor organizations, NGOs, and local institutions to ensure that the interests of miners, their families, and communities are adequately voiced and taken into account.

Support interagency commissions at the federal and local levels to ensure that miners and communities are cushioned from the adverse effects of reform.

Support regional and local governments in managing assets transferred from coal sector associations to municipalities and in responding to reform effects.

The basic elements of the participation strategy include:

Information and communication support, focusing on empowerment through information for miners, their families, and communities; support to institutions responsible for the provision of such information; assistance in 


\section{Social Assessments for Better Development}

clarifying their roles and responsibilities; and assistance in enhancing transparency in reform implementation.

Public relations support to create and sustain a constituency for reform and to help broaden ownership of reform objectives, and public and government relations support for legislative changes that may be put in place to enhance geographical and job mobility.

Support to consultative local institutions representing the interests of key stakeholders, particularly miners and their communities.

Continuous social assessment and social impact monitoring to have feedback from the most directly affected populations.

Specific actions to support these objectives and the general participation strategy are presented below in terms of institutional arrangements and include support to the Inter-Agency Coal Commission, local governments, trade unions, NGOs, and private coal companies. NGOs and unions need seed money to facilitate their organizational growth and to support their programs. Thus formal requests should be made to unions, municipalities, NGOs, and private coal companies to submit formal requests for the use of funds allocated for their support. Because

the Ministry of Economy is the Secretariat for the Inter-Agency Coal Commission, the project preparation unit could prepare its proposal.

Public relations activities. The information and communication requirements of each group of stakeholders are different. Consequently, the messages, use of the media, medium of communication, and feedback mechanisms to be set in place differ substantially from one group to the other, as summarized below. They should be designed in detail by the participation and information specialists in the project preparation unit during project preparation. The primary objective of the public relations functions should be to establish a constituency for coal sector reform and to ensure that the proposed donor support to the government's program is consistent with the Basic Trends document (Russian Federation 1995). The main target groups for public relations activities (including political lobbying) are the public (through the national, regional, and local media), senior policymakers (Duma and other federal ministries through the Inter-Agency Coal Commission), and unions. Implementing these functions through the media will be costly. The establishment of a Coal Sector Media Network during the project preparation stage (through the communications specialist recruited by the project preparation unit) is advisable so that public relations functions can be sustained and expanded during program implementation. Specific public relations activities could include:

Familiarizing the public with the Basic Trends document (Russian Federation 1995) after it has been clarified, explaining the government's coal sector restructuring program, and showing how people will be protected once the restructuring program, is launched.

Familiarizing the public with the costs of no restructuring or delayed restructuring.

Publicizing the mechanism for restructuring subsidies and showing how these subsidies will reduce practices that leave workers, their families, and communities unprotected.

Defining the role of donors in supporting the restructuring program as well as documenting and making clear that external support to the program-including that from the World Bank-emphasizes support for the social safety net. (Such donor roles could include facilitating transfer of social assets in a manner consistent with the interests of the affected families, supporting community-based programs to enhance employment and generate development within the coal basins, establishing policies to remove constraints to labor mobility, and ensuring that the reduced subsidies to the sector are used for worker protection.) 


\section{Social Assessments for Better Development}

Providing information on international experience in responding to coal sector restructuring.

Preparing fact sheets and press releases on a regular basis.

Identifying and undertaking high-level lobbying to support the proposed modalities for coal sector restructuring.

Evaluating the positions of both unions and formulating a public relations approach to respond to their concerns (especially those pertaining to subsidy restructuring, Rosugol, regional mining associations, and local participatory schemes).

Relationships with trade unions should not be confined to public relations activities because, as outlined below, close collaboration with the unions will be needed to launch the reform and ensure that miners, their families, and members of affected communities are protected. Consultation requirements for loan preparation could consist of bilateral discussions and a workshop with ample media coverage to clarify arrangements for the restructuring program and proposed modalities for donor support to the program.

Participation requirements for restructuring cannot be confined to public relations functions that consist of one-way flows of information from policymakers to generate public support for the restructuring program. Other, potentially more important functions of participation as well as information and communications activities to support project preparation and implementation are ensuring that the voiceless are empowered and have a clear understanding of their entitlements and prospects for readjustment, and clarifying stakeholder responsibilities to facilitate worker and community access to restructuring programs. This integrated approach to participation will allow efficient functioning of the scheme for restructuring subsidies, ensure con-

tinuous support to the government's coal sector reform program, and enhance governance during restructuring.

Stakeholders. An appropriate participation framework should be formulated for each group of stakeholders. The framework should ensure that the interests of each group are taken into consideration in project design and implementation. The following forms of participation are recommended for the following main groups of stakeholders:

Although miners and their families are the group most directly affected by the coal sector reform program, they have very little information about the reform agenda and its potential effects on them. The immediate measure to be taken is to establish feedback mechanisms so that sector managers know whether the resources intended to compensate workers actually reach them. Several types of information are needed by miners:

Full list of entitlements under the law and various decrees and tariff agreements, including pension levels and lump sum arrangements. Workers should also be informed about their entitlements concerning legal notice requirements for mine closures.

Status of the policy debate about key issues of concern, including whether miners from northern areas can receive their pension payments with the coefficient should they live elsewhere.

Clarification of status of relocation promises.

Progress of restructuring in the sector, and emerging problems and proposed measures to deal with them.

New opportunities offered by the restructured subsidies (such as job placement, counseling, microenterprise development) and by other agencies designed to create alternative job opportunities, including possibilities of placement in operating mines. 


\section{Social Assessments for Better Development}

Rights and responsibilities of institutions involved in the execution of the government restructuring program, including the Ministry of Economy, the Inter-Agency Coal Commission, Rosugol, regional mining associations, and unions and managers of individual mining enterprises.

Recourse mechanisms if social assistance mechanisms fail.

Although the restructuring agenda should focus on active miners, the problems of vulnerable groups (such as the disabled) cannot be ignored. It is therefore critical to undertake a comprehensive review of issues of concern to these groups and identify and communicate solutions.

Several elements of the restructuring process are of specific concern to communities. These affect considerations of the social safety net for miners and constituency formation for the reform program, and are directly relevant for labor productivity in viable mines. The issues include:

Management and operation of social assets, especially in isolated communities with heavy reliance on mining enterprises that are being closed.

Effects on workers and families that are not employed in mines, but that support mining operations.

Entitlements of vulnerable groups who rely on mines.

New infrastructure, including transport, that needs to be provided to some of the isolated mining communities so that their workers can maintain access to their homes when they take up employment in other mines or in sectors outside their communities. There are no estimates for these social costs, nor is there sufficient dialogue on these issues. Consequently, there is a need for public debate on these issues. Such debate could be fostered by inviting proposals from local communities on dealing with asset transfers and infrastructure requirements.

Trade union participation in all aspects of the coal sector restructuring program is critical. The unions must have a good understanding of the goals, responsibilities, and limitations of the restructuring program, and receive timely and regular information on its implementation. Equally important is close collaboration with the unions with respect to the social and environmental monitoring of restructuring activities. Collaboration is also desirable in the empowerment of the workers on the issues outlined above and in setting up feedback mechanisms to respond to emerging issues. The Inter-Agency Coal Commission may also wish to consider direct collaboration with unions on specific information and communication areas, includ-

ing the joint preparation and dissemination of information relevant to miners. For effective implementation and for a successful restructuring program, full ownership by the unions of the principles is important.

Involvement by local and regional governments and other local institutions is important for two reasons. First, municipalities and regional governments are expected to assume housing, infrastructure, and other productive assets belonging to coal companies, but institutional and financial capacity for these new responsibilities is restricted. Local institutions may need information support in their new roles; this need should be assessed during loan preparation. Second, community-based social problems that arise as a result of the restructuring program require local and participatory solutions. Although information from these local agencies is needed, it is important to build capacity at the local level to ensure that proposals are technically, socially, and financially sound before submission to the Inter-Agency Coal Commission.

Mine managers should be clearly informed of the procedures to be set in place for restructuring implementation. Principles concerning payments to workers, legal notification requirements, mine closure procedures, and liquidation of social assets should be clear and transparent. 


\section{Social Assessments for Better Development}

The role of regional mining associations and Rosugol are being redefined. In addition, some mines are redefining their relationship with the regional organizations. It is important that mechanisms for information exchange, cooperation, and collaboration with these parties be developed.

The Inter-Agency Coal Commission is using a participatory framework to define the agenda and pace of the coal sector reform. Several key issues identified in this early social assessment require review and call for the preparation of concrete proposals that can be supported by the commission. These include:

Regional variations in legal entitlements of mine workers and the political and financial difficulties involved in the application of differential treatment to workers affected by the restructuring program in different coal basins

Legal difficulties in the transfer of entitlements recognized under the law from one region to the other

Lack of adequate knowledge and policies to deal with the communitywide impacts of restructuring

Sharp differences in stakeholder interests and lack of clarity in institutional arrangements

Lack of legal mechanisms to honor pensioner rights, whether they stay in their original communities or move out of the coal regions

Legal rigidities that hinder labor market and housing mobility.

\section{Annex 4.1}

\section{Sampling Method}

The sampling criteria require a survey pool in Vorkuta and surrounding towns of about 400 respondents, 300 of which should reside in mining towns and 100 of which should be city residents. Participants should be adult residents of Vorkuta and surrounding mining towns who fall under the city's administration. Vorkuta's total population as of September 1, 1995, (according to the city administration's most recent data) was 192,100; 137,400 residents are over eighteen years old.

\section{Data on Preselected Participants.}

A three-step systematic sampling process was used. The first step was to select the towns in which the survey would be conducted. Because the suggested survey size was not too large, it was determined that the pilot survey would be conducted in two mining towns. The program directives required the inclusion of Vorkuta in the study as well. Among the mining towns, Oktyabrski and Sovetski were selected as the most typical in terms of distance from the city, population, and proximity to closing mines. There are some key differences between the towns, however. Oktyabrski is not seen as viable, the relocation process has already begun, and hopes of improving living conditions have been abandoned. Sovetski is better equipped and will not be subject to closing, according to the city administration.

To obtain comparable data, the same number of people were surveyed in each mining town, 150 residents in each. In Vorkuta 100 people were interviewed. Typical towns were selected at the first stage of sampling.

The second stage of sampling was based on voting districts (because each of the selected settlements is a voting district). Vorkuta contains thirty-one voting districts.

Each interview covered twenty people in a selected voting district to avoid cross-surveying. The number of respondents in each district was the same because the number of registered voters in these districts is about the 


\section{Social Assessments for Better Development}

same $(2,0002,500$ people). Thus five voting districts were selected in Vorkuta to survey 100 respondents.

All voting districts are numbered. The numbers increase depending on location (from the railway station to new districts of the city). Every sixth district was selected. Thus, at the second stage of sampling, a systematic sampling with even distribution was applied. The sampling based on voting districts provides for even distribution of respondents since these districts were formed according to population density.

For the third stage, a systematic sampling was applied (selection of respondents within voting lists). The list of registered voters over eighteen years old containing names, addresses, and dates of birth was used. The full names and addresses of respondents were put in data sheets for preselected participants (date of birth was not put on the data sheet for preselected participants; the interviewer had to find it out so that the supervisor could check to see if the participants were interviewed). For systematic sampling, the total number of registered voters was divided by the number of people to be surveyed.

For example, the number of voters in Oktyabrski settlement (excluding military regiments and hospitals) is 1,355. To prepare a list of 150 respondents, every ninth person was selected. The lists that were used for sampling were based on the results of the January 22,1995, election. Every sixth adult resident of the Oktyabrski settlement was selected from the list of respondents.

There are 4,046 voters in the Sovetski settlement. To make a list of 150 respondents, every twenty-sixth person was selected. In Vorkuta the sampling was based on the same principles: thirty people from each voting district (plus a list of extra names); in different voting districts every eighty-ninth, eighty-fifth, seventy-third, and seventy-fourth registered voter was selected. All selected voters are evenly distributed throughout the voting district.

All data sheets for preselected participants contained full names and addresses. The names on the main list were substituted for extra names in a number of cases (for example, refusal to answer, sickness, death, long-term absence). Using the three stages of systematic sampling resulted in a good representativeness of the Vorkuta population and the population of the settlements. Assuming that the suggested sampling is equal to random sampling (which is possible considering the method), the planned average/standard deviation is 2.5 percent. The maximum deviation is 4.9 percent for the level of significance 0.05 .

Sampling in Kiselovsk was carried out in the same manner; a systematic sampling using voters lists was applied. Initially, the settlements close to the closing mines (Surtaikha and Cherkasovskaya) were selected. These lists did not reflect the current situation, however, because they were compiled during the 1993 elections. Nonetheless, no other lists were more precise. In the selected settlements 150 people were to be surveyed, in addition to 100 people in other districts of the city. This reflected the structure of the population of the selected districts. The results, however, require some explanation. First, there was a correlation among age groups; half of the population is over fifty-six years old because these settlements are the oldest in the city. Moreover, housing in these settlements is of a low standard. Young families have moved to new districts of the city; only those who settled long ago remain in the settlements.

\section{Sampling Restrictions}

Voter lists from January 1995 were used to sample participants. Subsequently (within eight months), some people reached voting age, and some registered voters died. Most of the selected participants were middle aged.

Closed districts (military zones, hospitals) were not included in the lists for two reasons. First, military officers are not permanent city residents, and hospital patients do not represent a 


\section{Social Assessments for Better Development}

constant category. Second, comprehensive lists of these segments of the population are not available, and those that are available do not contain addresses. Lists of prisoners also were not available. Others who are not included in the lists are mentally retarded individuals and people without a permanent address.

Even considering the existing survey restrictions, however, the results received will be true for all families in Vorkuta within the representativeness deviation mentioned above.

\section{Regional Specifics for Vorkuta}

The representativeness of the survey reveals some social and demographic aspects of the selected groups that are typical for Vorkuta as a whole. The settlements selected are typical; the data received are from the miner settlements surrounding Vorkuta, which will be greatly influenced by coal sector restructuring.

Vorkuta has other industrial enterprises, administrative organizations, several higher education institutions, and vocational schools. The experts visiting the region noticed that people born in Komi or Vorkuta are more settled than people who moved to Vorkuta for high salaries.

Interviews with local experts showed that there were certain differences between the selected settlements. In some of the settlements (for example, Sovetski) housing is of a relatively high standard-new buildings with all conveniences, and a developed social and cultural infrastructure. By contrast, Oktyabrski settlement is an example of a settlement with poor housing conditions. Most families live in barrack-type housing where there is no sewerage.

Vorkuta is noted for its negative population growth. People of working age have a higher tendency to move to other parts of Russia where the climate is better. The population of the settlement near Vorkuta differs from that of Vorkuta City. The main differences are determined by the employment structure. The survey found that the settlements rely heavily on the mines. The number of miners' families in the settlements is three times higher than in the city.

\section{Notes}

Ayse Kudat, Principal Environmental Sociologist, was the task manager for the Russia coal sector restructuring social assessment and the main author of this chapter. The field work for the assessment and initial analysis of the data were carried out by Vadim Borisov from the Institute for Comparative Labor Relations, with support from Peter Bizyukov and Konstantin Burnyshev. The data analysis as reflected in the social assessment was completed by Bulent Ozbilgin, who, together with Nezahat Ozmen, prepared figures and tables. Janis Bernstein drafted sections of the report.

The authors wish to acknowledge the strong support of Constantine Michalopoulos, Senior Adviser to the Director (Europe and Central Asia, Country Department III); David Craig, task manager for the World Bank Russia Coal Sector Adjustment Loan (SECAL); Selina Shum, task manager for the Coal Sector Restructuring Implementation Assistance Project; and Division Chiefs Jonathan Brown (Europe and Central Asia, Country Department III, Infrastructure, Energy, and Environment Division) and Anand K. Seth (Europe and Central Asia, Regional Office, Technical Department, Environment Division).

1. Coal workers' rights and benefits in cases of lay-offs are regulated by more than twenty federal decrees, resolutions, laws, and orders. In addition, two national tariff agreements provide benefits to coal workers. Many government bodies regulate the social safety net for laid-off workers: the Supreme Council of the Russian 


\section{Social Assessments for Better Development}

Federation, president of the Russian Federation, government of the Russian Federation, Ministry of Labor, and the Federal Employment Service. Moreover, regional and local governments can pass legislation regulating the social safety net within their jurisdiction. In addition, tariff agreements have been signed between the two unions (the Union of Coal Industry Workers and the Independent Miners' Union) and the Ministry of Fuel and Energy, as well as the Ministry of Labor.

2. This assessment found no examples of workers successfully taking legal action against a coal company.

3. Shortly after independence the Independent Miners' Union (NPG) moved into the coal sector as an active independent union representing only the coal workers. The competition presented by NPG led the Union of Coal Industry Workers (PRUP) to take a somewhat new stand, and the situation has changed since 1993. NPRUP has increased its influence on coal sector workers through a series of successful strikes and other national actions. During the same period NPG's role gradually diminished as a major player in the coal sector. Currently, more than 90 percent of the coal sector workers are members of Rosugleprof (former NPRUP).

4. The Fund for Social Guarantees, working with the Veterans of the North and the Disabled Miners

Fund, recently received Inter-Agency Coal Commission support for a five-year proposal to relocate a group of particularly vulnerable mine workers.

5. In addition, a number of NGOs have emerged in the coal communities of Komi Republic, Rostov, Kuzbass, Tula, Chelyabinsk, and the Far East. These organizations cover a large variety of activities, ranging from private sector involvement to social issues; they are funded through either the state or foreign partnerships.

6. The national program for transferring social assets is a long process that involves many players. For example, when a mine or mining association reaches an agreement with a local municipality or city, the transfer application is forwarded to the oblast administration, where the requests are consolidated with other applications. The oblast conducts individual negotiations with each ministry and agency that finance social assets operations. Such negotiations may include an exchange of liabilities for the oblast to talk over the financing of the social sphere. Oblast demands vary from case to case. For example, the coal industry Rosugol is committed to financing several projects, such as water purification system installations and the building of a new hospital wing in Rostov (financed from investment subsidies). In addition, commitment to reconstruction of old housing is always demanded by the oblast administration before social assets are transferred.

7. An April 1996 World Bank mission to various coal regions found that housing and utility costs were the largest burden, amounting to 58 percent of social spending. Kindergartens were 27 percent and entertainment facilities were 11 percent. For housing costs, those associated with providing heat and hot water amounted to 60 percent; the rest is spent on maintenance and capital repair. In 1993 the Russian government began divesting social assets from enterprises to municipalities. Only during the last months of 1995, however, did coal enterprises divest a significant amount of their social assets.

8. Household visits in Vorkuta found a miner and four of his neighbors who had been living in their flat since 1958; during that time no one had ever come to do repair work. The wooden structure of the flat was covered with 


\section{Social Assessments for Better Development}

plastic to protect the residents from the cold, and the roof had collapsed.

9. These regions account for most of the employment and production in the coal sector.

10. Field visits made as part of a March 1996 World Bank preappraisal mission of a sector adjustment loan and Implementation Assistance Project found the economic and employment structure and prospects of the coal regions to be varied. For example, some coal localities have opportunities for economic diversification and adjustment. Others-mostly remote, single-industry coal towns-have few alternative employment opportunities. Consequently, the approaches used in dealing with coal redundancies will need to respond to the special circumstances of the area. Thus employment adjustment strategies must be regionally or locally based, and efforts must include not only the coal sector but the entire local economy as well.

11. The exchange rate used in this calculation is US $\$ 1=4,500$ rubles.

12. Most of this difference is attributable to regional wage coefficients. In northern regions, such as Vorkuta, wages are paid at a multiple of 1.6.

13. According to a miner, the miners in Vorkuta earn more than the average wage in the rest of Russia, but a loaf of bread costs more than $\$ 1$, a bottle of vodka costs more than twice as much as in Moscow, and a warm mink hat costs $\$ 300$. In other parts of Russia, some poor people have at least a plot of land to grow potatoes, tomatoes, and cabbage. But nothing grows here. Miners in search of the long ruble used to save tens of thousands of rubles in about a decade, saving for their eventual move south to Russia, which is how they refer to the rest of the country. Inflation has made a joke of those savings. Ten years ago, 100,000 rubles was a life's dream. These days it is not even enough to pay for dinner at one of Vorkuta's two restaurants, both of which are bad. A man who has spent eighteen years working at the Vargashovska mine told a journalist, I came here because it was the one place in Soviet times that would ensure my freedom. Now it's one of the few places where there is no freedom at all. I can't afford to leave. And even if I could, where would I get a job? I blame myself. I can't blame a politician. I put my faith in a new ideology. If we have learned anything on this land, you would think it was that no ideology will ever help a common man (New York Times, December 11, 1995, p. A1).

14. Coal settlements around Vorkuta have much higher percentages of coal employment.

15. The World Bank already supports projects that deal with community infrastructure development, enterprise housing divestiture, employment services, and social protection in Russia. Lessons from these projects should be taken into account in the government's restructuring program and in any other activities that the Bank might support in the coal sector.

16. Appropriate indexes of measurement will have to be defined at the level of individual workers, households, communities, and microregions.

17. It is expected that communities that are facing mine closures have been experiencing some of the social consequences of these inefficiencies for some time. 


\section{Social Assessments for Better Development}

18. A substantial portion of the housing in coal communities, especially in settlements outside the cities, rely on oven heating. According to the tariff agreement between trade union PRUP and the Russian government, miners must be provided with coal to sustain them through long winters. When these services are withdrawn because of mine closures, pensioners particularly suffer because they do not have an alternative employer providing these services or because they cannot afford to pay for coal to be delivered to their homes.

19. The summer 1992 Russian Longitudinal Monitoring Survey found similar poverty rates for prime working-age males and females (1854). For elderly females (55 and over) the poverty rate was 44 percent higher than for elderly males (22.5 percent).

20. The employment characteristics of coal cities and settlements are highly variable and have changed dramatically over the past four to five years. Previously, in many coal settlements, if spouses did not jointly work in the mines, women worked in jobs that supported the mines (for example, farms, repair shops, preparation plants). In addition, there were textile factories where hundreds of miners' wives could work sewing miner and oil worker uniforms and underwear. Since market reforms began, these factories have quickly closed because material is expensive and the quality of the imported products is higher than domestic ones. Other workplaces for women included bread factories, beer factories, and schools. These also have been transformed into tighter, more market-oriented structures, leaving many women unemployed.

21. According to World Bank (1995), women in Russia are particularly susceptible to poverty. Despite higher education levels and high labor force participation rates, women have traditionally been concentrated in low wage occupational groups, and paid less than men. They also figure disproportionately among the unemployed.

22. Differences in distribution were statistically significant based on chi square analysis.

23. Although 21 percent of respondents in Vorkuta and 12 percent in Kiselovsk are reported to be unemployed, few have registered themselves as such. A better understanding of voluntary and forced unemployment is needed.

24. This information is imprecise. The survey did not ask about the sector of employment before layoffs. Rather, information on professional background was provided for those who were laid off. Thus the data reflect professional background instead of sector of last employment.

25. According to World Bank (1995), unemployment benefits average only 15 percent of the subsistence minimum.

26. According to World Bank studies, the Russian Federation's overall economic and employment situation creates great difficulties for coal sector redundancy efforts and limits the effectiveness of standard ameliorative measures such as job placement and retraining. Thus another priority should be to promote economic diversification through a local economic development program aimed at creating jobs in new and expanded enterprises. Possible programs include a community employment program to integrate existing and new resources to meet both immediate needs and to plan long-term strategies, a local economic development program aimed at creating permanent new jobs through the development of new enterprises, and a transitional employment program to provide interim employment for displaced workers. 


\section{Social Assessments for Better Development}

27. Nonetheless, there is need to base decisions on microenterprises on an analysis of economic feasibility. These enterprises should be viable for the regions proposed and not be established merely to provide social assistance.

28. According to another estimate for small apartments, the cost of 1 square meter was about the equivalent of $\$ 350$ in summer 1995 . Thus a 5060 square meter, three-bedroom apartment would cost $\$ 17,500 \$ 21,000$.

29. Not only miners and their families but also representatives of the Duma, Ministry of Economy, Ministry of Labor, and scientific community stress the need to demonstrate innovative approaches that would help generate alternative employment opportunities in coal basins.

30. An extensive legal social safety net that can assist laid-off coal sector and other workers already exists. Worker rights and benefits in the case of layoffs are regulated by more than twenty federal decrees, resolutions, laws, and orders. In addition, two national tariff agreements provide benefits for coal sector workers. Several government bodies are involved in delivering the various programs and benefits. The safety net provides for a full range of support-severance pay, unemployment benefits, retraining, job finding or creation, relocation, and so on. The major problem, however, is not the profusion of safety net provisions but their availability because of funding constraints. Another problem, particularly for coal sector workers, is the level of income maintenance benefits and their relatively limited duration. As a result coal pensioners continue to work because they cannot live on their pensions.

31. Clearly, a financial framework is necessary and people's priorities need to be better understood with respect to alternative cushioning mechanisms such as support to social programs. The next phase of the social assessment aims at a better understanding of these priorities.

32. By January 1, 1994, all kindergartens in Dimitrova were transferred to the municipality. It was agreed, however, that kindergarten 31 would continue to be supported by the mine. The decision to transfer kindergartens was based on Presidential Decree N1702 (December 30, 1992) and was not discussed with mine employees or unions.

33. This is not surprising because, except for those living in Vorkuta-most of whom expect to receive housing through voluntary relocation-few people intend to leave, even if they lose their jobs. People in Tula say they would move only if they had to, and many workers commute to Moscow while keeping their families in Tula. Residents of the private housing stock in Tula are interested in renting part of their accommodations to immigrants in the region. The potential for private home ownership and the scarcity

of housing elsewhere account for the generally low demand for relocation.

34. The lack of alternative employment opportunities in Vorkuta and downward multiplier effects of downsizing in the coal sector mean that people may have to move to other parts of Russia in search of work. Regional labor mobility is not a new concept to the residents of Vorkuta, most of whom were not born in the area. But large-scale movement in a depressed national economy with bleak employment prospects and critical housing shortages is a daunting prospect. 


\section{Social Assessments for Better Development}

35. One proposal is to provide relocation assistance only to miners with ten years or more of mining experience in Vorkuta. Another proposal is to relocate pensioners and disabled people who had worked twenty years.

36. Relocation programs will be important for the remote nonviable coal areas. Relocation is difficult given the shortage of housing and the costs involved. Previous efforts have run into difficulties, including some abuses. A relocation program involving Vorkuta and Tula has yet to be implemented. The proposal by the Fund for Social Guarantees for relocation in Vorkuta also appears to have merit and should be given careful consideration. The Inter-Agency Coal Commission has instructed the Federal Employment Service and other concerned agencies to address the relocation issue, particularly its financing.

37. This is not to deny that living conditions in the far north are exceptionally severe, or that workers' former expectations that their high wages would enable them to save enough to buy or build a house elsewhere at retirement can no longer be satisfied. The erosion of past savings resulting from inflation and the unavailability of financial assets for savers have adversely affected people throughout Russia. In any case a relocation package cannot be fulfilled for more than a handful of workers. Even if Vorkutaugol were willing to pay for such relocation, large additional subsidies from the central government would be needed-an unlikely possibility.

38. There are also concerns about the adequacy of the delivery systems that provide benefits and social services. An in-depth review of the Federal Employment Service's operational capacity in the coal areas is needed. In addition, there are financial constraints on the employment service. Future financial pressures on the employment fund will come not just from pending coal industry layoffs but also from a projected increase in unemployment throughout the economy. Registered unemployment in 1997 is expected to rise to 3.7 million, a 1.3 million (60 percent) increase from the end of 1995. The funding situation of the employment fund is crucial to the coal sector. Even if tax collections are strengthened, the fund would barely be able to pay the unemployment benefits, let alone provide proactive labor market services to the redundant coal sector workers.

39. Most laid-off employees look for jobs independently and do not apply to federal employment centers. Theoretically, it is better to look for a job through the employment service because the service pays unemployment benefits. Nonetheless, it is hard to actually receive that benefit. For example, a mechanic/operator was offered a job as a tractor driver on the surface; the wage is five to six times less than what he received underground. He rejected the job and received no benefits because his refusal was considered unreasonable.

40. Employment services and local and regional organizations would not be the only members of the multistakeholder committees. Since these organizations' independent support would also be needed for restructuring, the next phases of social assessment will attempt to gain a better understanding of the sources of mistrust and how trust can be enhanced. Focus group meetings and other participatory social assessment instruments would be used for this purpose.

\section{References}

Russian Federation, Government of the. 1995. Basic Trends. Moscow, Russia.

World Bank. 1994a. Russian Federation—Restructuring the Coal Industry: Putting People First. Report 13187-RU. Europe and Central Asia, Country Department III, Infrastructure, Energy, and Environment Division, Washington, D.C. 
Social Assessments for Better Development

1994b. Russian Federation-Social Protection During Transition and Beyond. Report 11748. Europe and Central Asia, Country Department III, Human Resources Development Division, Washington, D.C.

1995. Russian Federation-Poverty in Russia: An Assessment. Report 14110. Europe and Central Asia, Country Department III, Human Resources Development Division, Washington, D.C.

1996. Preappraisal Mission for Coal Sector Adjustment Loan. Europe and Central Asia Country Department III, MarchApril. Washington, D.C.

5-

Responding to Needs in Uzbekistan's Aral Sea Region.

Ayse Kudat, Arustan Zholdasov, Alisher Ilkhamov, and Janis Bernstein

In 1994 the government of the Republic of Uzbekistan requested World Bank assistance in improving water supply, sanitation, and health in the two regions of the country most adversely affected by the Aral Sea crisis: the Republic of Karakalpakstan and Khorezm Oblast (province).* During the early stages of project preparation the Bank, working with local groups, carried out a needs assessment as part of a broader social assessment. This chapter presents the findings of the needs assessment and discusses their implications for the design and implementation of the proposed Uzbekistan Water Supply and Sanitation Project.

\section{Country and Project Background}

The Republic of Uzbekistan comprises the Republic of Karakalpakstan and 12 provinces (oblasts) as well as 124 cities and 157 rural regions. The country, situated in the central and northern parts of Central Asia, covers a territory of 444,000 square kilometers. With 22.2 million people-60 percent of them in rural areas-Uzbekistan has the largest population of the four Central Asian republics. If the current population growth rate of 3.4 percent continues, Uzbekistan's population can be expected to double in about the next twenty years.

Agriculture is the predominant economic activity in this semi-arid country. Only 10 percent of the land is cultivated, however, and 95 percent of it is irrigated by the two major river systems flowing into the Aral Sea: the Amu Darya and the Syr Darya. Since the 1960s increasing use of these rivers for agriculture, particularly cotton, has greatly reduced the volumes of runoff entering the Aral Sea and resulted in extensive contamination from leached salts and agricultural chemicals.

The policies and systems in Uzbekistan's water supply sector were developed by the central organs of the former Soviet Union. Since independence in 1991 Uzbekistan's government has made reasonable adjustments to suit the new socioeconomic realities. The policies relating to water rights assign priority to domestic water. Emphasis has been placed on drinking water, in line with an April 1994 presidential decree. This decree authorizes a low and unified tariff on the domestic water supply to ensure that drinking water is available to citizens at a reasonable price.

Because of low rainfall (about 110 millimeters a year), water supply in the region depends almost entirely on the Amu Darya River and its system of irrigation canals. The only exception is the deep saline ground water obtained for domestic (after desalination), industrial, and farm use. Communities obtain water from a variety of sources, including piped water supplies to community standpipes and yard and household connections, hand-dug wells, drilled wells with hand pumps, and open bodies of water such as lakes, rivers, and irrigation canals. The poor quality of water supplied by these sources, however, is threatening health and constraining productivity. 


\section{Social Assessments for Better Development}

\section{Aral Sea Crisis}

The Aral Sea Basin is experiencing one of the most serious environmental crises in the world. Since the 1960s the sea has steadily receded as a result of a substantial reduction in the Amu Darya and Syr Darya Rivers, its two tributaries. Cotton and rice production in the rivers' deltas have required increasingly larger quantities of water for irrigation. The small amount of irrigation runoff that reaches the sea is rich in salt and heavily polluted by pesticides, fertilizers, and defoliants. Some of these polluted waters are diverted to adjacent deserts, creating new salt swamps and causing ground water to rise. The rising ground water, in turn, causes waterlogging that damages development and agricultural land and adds to the overall salinization of the region. Once a prime source of potable water, ground water is no longer suitable for drinking.

When it dries, the former sea bottom turns into sand or clay deserts where frequent winds and storms carry salts and dust to nearby fields and settlements, causing additional health problems and salinization of land. The shrinking of the Aral Sea also has affected the climate: the area now has more continental climactic conditions, with longer winters and hotter, drier summers. These changes directly reduce the region's agricultural potential as a cotton-producing area. Moreover, by the early 1980s water salinization and pollution had destroyed the sea's fisheries. In addition, the ecosystems of the deltas of the two tributaries have suffered from spreading desertification, diminishing stream-and groundwater levels, and increasing soil salinity, and traditional reed swamps and tugay forests have almost completely disappeared.

\section{Project Areas}

The Republic of Karakalpakstan and Khorezm Oblast are the two administrative territories in Uzbekistan most severely affected by conditions in the Aral Sea Basin. Karakalpakstan, a de jure autonomous republic, occupies the northwest part of the Kizilkum desert, the southeast part of the Usturt plateau, and the Amu Darya River delta. It encompasses 37 percent (164,900 square kilometers) of Uzbekistan's land area and contains 1.4 million people. Its population density, at 8.5 people per square kilometer, is one of the lowest in Uzbekistan (six times lower than the country average; the most densely populated province, Ankijan, has 452.4 people per square kilometer).

Karakalpakstan's population consists of representatives of three principal nationalities: Karakalpaks (32.3 percent), Uzbeks (32.8 percent), and Kazaks (26.7 percent). Turkmens (5.0 percent) and representatives of other nationalities (3.2 percent) account for the rest. Although the structure of Karakalpakstan's population is similar to that of Uzbekistan as a whole, it contains more young people (less than twenty-five years old) and the birth rate is slightly higher. In addition, the infant mortality rate is much higher in Karakalpakstan than in the rest of the country, ranging from 51.4 per 1,000 live births (according to official figures in 1992) to 92 per 1,000 live births (according to studies undertaken by other demographers), with almost no difference between urban and rural populations. The difference in population growth rates between urban and rural areas is relatively small.

Although officially only 51 percent of Karakalpakstan's population is rural, agricultural activities provide the basic income for a much larger share of the population. Even in the major cities of Nukus and Takhiatash, garden agriculture provides a major source of livelihood to many households. Indeed, a large portion of the water consumed by households connected to the piped water supply system is used to irrigate these gardens. Agriculture is focused on cotton growing and, to a lesser extent, rice growing and cucurbit cultivation. The most developed industrial sectors are those dealing with farm produce processing, construction materials manufacture, and metal working.

Karakalpakstan is one of the poorest regions in Uzbekistan, and the area hardest hit by the Aral Sea crisis. Fishing and related activities, which provided half of the republic's income before the crisis, were abandoned in the late 1980s. Commercial shipping stopped at about the same time. Moreover, agricultural output has dropped 2030 percent, a direct result of soil salinization, climate changes, and reduced labor efficiency associated with health problems. 


\section{Social Assessments for Better Development}

Consequently, an increasingly larger number of chemicals has been needed to maintain output, leading to economic inefficiencies and further deterioration of cultivated lands. Finally, Karakalpakstan's tourist industry along the southern shore of the Aral Sea was abandoned in the mid-1980s.

Khorezm Oblast is located in the northwest part of Uzbekistan, on the left bank of the Amu Darya River in its lower stream. In the north and east it borders Karakalpakstan; in the south and west, Turkmenistan. The province covers 64,000 square kilometers, 60 percent of which contains cultivated and irrigated soils and meadows. The oblast has a population of 1.2 million people and a population density of 190.5 people per square kilometer. The rural population accounts for 74.8 percent of the population.

Ninety-five percent of Khorezm's population are Uzbeks. The age structure of the population is similar to that of Karakalpakstan, except the number of people younger than nineteen years old is slightly higher. In addition, the birth rate in Khorezm is a little lower than in Karakalpakstan (but higher than the national average), average family size is higher, infant mortality is substantially lower (38.9 per 1,000 live births), and population growth is similar. Moreover, differences between urban and rural areas are more pronounced in Khorezm than in Karakalpakstan.

Khorezm's main agricultural activity, cotton growing, is threatened by conditions in the Aral Sea. Economic losses from these conditions are caused primarily by increasing soil salinization, which results in ever-diminishing crop yields. Nearly 40 percent of agricultural land is considered saline and unfit for major crops.

\section{Project Development}

In the late 1980s the government of Uzbekistan launched a program to improve social and physical infrastructure in rural communities. A major focus of this program was the provision of safe piped drinking water. Because of the great need for these services and the adverse effects of the Aral Sea disaster in Karakalpakstan and Khorezm, the government has allocated about 30 percent ( $\$ 130$ million) of its piped water program budget to this region. Good progress has been made in achieving the government's goals, and phase 1 of the three-phase program is almost complete. Nonetheless, concern over widening inequities between urban and rural areas has led the government to seek ways of accelerating rural development through the provision of social and productive infrastructure.

In January 1994 the Council of Ministers passed a resolution creating a special working group, chaired by the first deputy prime minister, to prepare a development program until year 2000. The working group's report, submitted to the Council of Ministers in November 1994, concluded that although Uzbekistan as a whole ranks favorably among comparable middleand lower-middle-income countries, it suffers from large geographical disparities caused by the previous urban bias. Moreover, the report said, in the rush to meet overall targets, planners tend to focus on areas where it is easier and less costly to provide infrastructure. That was particularly the case for water supply and sanitation services in the western part of the country, which includes the Republic of Karakalpakstan as well as the Khorezm, Bukhara, and Navoi oblasts.

At the government's request a World Bank mission visited from September 23 to October 15, 1994, to identify a water supply and sanitation project for the Republic of Karakalpakstan and the Khorezm Oblast. The heads of the governments of the five Aral Sea states agreed to include this project in the Aral Sea Program, which had been presented at an international donors conference in Paris on June 2324,1994. At this meeting it was decided that the World Bank would take the lead in identifying and preparing the project. As part of project identification and preparation, the Bank and local groups undertook a needs assessment to determine what improvements the local population felt were needed. 
Social Assessments for Better Development

Conceptual Framework for Needs Assessments.

The importance of considering the community-felt needs of populations that are directly or indirectly affected by project interventions is increasingly recognized as a general strategy in social development. The basic premise of the

needs approach is that interventions should satisfy the needs and priorities of the project population.

Indeed, putting people first in development projects means perceiving people as intended beneficiaries, rather than as targets of project impacts, and tailoring project design and implementation to their needs and capabilities (Cernea 1991; Uphoff 1991).

The needs assessment strategy recommends taking action according to the expressed needs and desires of the people that will be affected by a project, and not necessarily, or only, according to the aims or needs determined by technical experts or administrative leaders (Hyman, Levine, and Wright 1967).1 The strategy reflects a participatory approach to development because it recognizes that officials and experts do not automatically have a better perspective on people's preferences than the project population, nor are officials and experts necessarily the best advocates of people's real interests (Cernea 1992). 2

In development planning, the needs assessment strategy is extremely helpful as a methodology for designing a plan of social action. Its philosophic foundation reflects an active process in which the recipients of project outputs influence the identification, direction, and sustainability of development projects rather than merely receive a share of the benefits from projects identified by others. The information obtained by the needs assessment, therefore, is integral to a broader social assessment or social impact analysis.

A participatory approach can elicit the expression of many needs and wants, not all of which are relevant or desirable in a project context. Still, in counteracting the paternalistic approach-which sees people as the problem and technicians, bureaucrats, and planners as the solution - the needs approach maintains a confident view. It asserts that people are self-reliant and capable of making substantial contributions in planning changes that will affect their lives.

\section{Conceptual Underpinnings and Antecedents}

Interest in the needs assessment approach has not been limited to the field of development. Moreover, the meaning of the term needs is not identical in all settings. The most common use of the term-where needs denotes a concept and needs assessment is an operational tool used in planning and problem solving - is found in organizational and corporate settings, where the methodology has been clearly delineated. $\underline{3}$ As defined in organizational terms, a needs assessment is a systematic attempt to identify the gaps between existing outputs and outcomes and required or desired outputs and outcomes and, subsequently, to select the most important ones for resolution (Kaufman and English 1979).

Needs assessment surveys are diagnostic processes. They identify important organizational needs, attempt to place a value on a variety of needs that can potentially be satisfied, and identify targets. They are also a means to an end; by enabling organizations to determine what is needed and what to do, they establish with greater precision the most appropriate way to remediate performance weaknesses and deficits (Brinkerhoff 1986).

Within these broad parameters, needs assessments within the context of organizational use vary according to differences in the definition of what constitutes a need and who defines it; whether the gap is defined relative to the perceived or expressed desires of employees, or to preconceived goals, objectives, and policies set up by management; and differences in the scope and selection of stockholders brought into the assessment process. 4 


\section{Social Assessments for Better Development}

Information gathering through a needs assessment relies on inputs from the people who are the object of the study (who provide information based on personal perceptions and observations) and on data derived from measured performance (to reflect objective reality). These two sources combined help the researchers identify the gaps. From this information organizational needs are analyzed, reconciled, and prioritized based on the costs that will be incurred at the organizational and societal levels in either responding to or ignoring the gaps identified. Actions can then be selected on the basis of this ranking, taking into account the views of critical stakeholders (Kaufman and English 1979).

As part of a comprehensive needs assessment methodology, organizations are expected to identify needs through an analysis that identifies the causes of and solutions to the gaps and needs identified (Benjamin 1989). By asking such questions as What good will responding to this need do? and How valuable is a response to this expressed need relative to other needs? it is possible to fulfill the more significant functions of a needs assessment, which are to establish criteria by which the impact of meeting an articulated or prioritized need can be measured and to determine the potential value of meeting a selected need relative to other identified needs (Brinkerhoff 1986).

\section{Needs Assessment in Development Interventions}

Advocates of the needs assessment methods maintain that project success is determined by the involvement of the people a project intends to serve in identifying their interests, needs, and priorities and by the extent to which project action recognizes, accepts, and is responsive to expressed needs. Recognizing that ownership of a project's ideas and responsibility for its ultimate success belong not only to planners and implementers, but also to the intended beneficiaries, distinguishes this process from other planning strategies. Moreover, evidence shows that no matter who initiates a project, its sustainability is greatly enhanced when locally recognized needs are addressed and social groups and structures are mobilized for implementation (Cernea 1991).

As an applied methodology, a needs analysis provides insight into three critical elements of project configuration: project content, mechanisms of implementation, and the policy agenda. Quantifiable information obtained through such surveys can initially be obtained during the early stages of the project cycle (that is, during reconnaissance and identification missions). During the preappraisal and design phases these findings can be drawn on to identify program elements that reflect people's priorities, recommendations that maximize the participation of beneficiaries and other stakeholders throughout the project cycle, and alternative solutions to problems identified by members of the community.

The findings of the needs assessments also support social impact analysis by identifying, locating, and mobilizing the commitment and participation of stakeholders in the project process; identifying expressed needs as criteria for a cost-benefit evaluation of project impact; identifying the roles and functions of stakeholders in project planning and decisionmaking; and establishing clear standards for impact monitoring and mitigation. They also may contribute to the objectives of social impact analysis by identifying the social groups most likely to gain or lose from a specific intervention and, possibly, by recognizing negative project-related impacts that can be eliminated, reduced, altered, or improved.

\section{Benefits of a Needs Assessment Strategy}

The needs assessment approach provides for costeffective alternatives to designing interventions and provides direction for resolving problems. It is less expensive to find out where the sponsoring organization should direct its efforts - and why it should take that direction and tailor interventions to accomplish this - than to fail and then determine what went wrong (Kaufman 1990).

The need to involve clients in decisionmaking has increasingly become a concern of the individuals in donor organizations responsible for making resource allocation and management decisions on development funding 


\section{Social Assessments for Better Development}

(Owen 1994). World Bank operations are often scrutinized by nongovernmental organizations (NGOs) and member governments for indications of efforts to promote participation and ownership, and for evidence of a positive impact on beneficiaries. The adoption of a participatory approach responds to those concerns.

Recognizing how people define their interests and needs and involving them in changes that affect their lives can help ensure their commitment, participation, and investment in projects, and ultimately can help ensure a project's success. Moreover, involving project populations in decisionmaking and resource mobilization and management increases their self-confidence and self-reliance, encouraging them to focus their demands and expectations beyond what governments and donors want to do for them (Cernea 1991).

\section{Uzbekistan Needs Assessment}

During the early preparation of the Uzbekistan Water Supply and Sanitation Project, it was recognized that a needs assessment would help guide the design of investments in the two project regions. Such an assessment would provide the information needed to determine priority project investments and specific recommendations for implementation. The needs assessment would constitute the first phase of a broader social assessment for the project, the purpose of which is to ensure that the project's objectives and interventions are appropriately targeted, acceptable to the users they are intended to benefit, and socially and administratively feasible.

\section{Objectives and Methodology.}

The overall objectives of the needs assessment were to assess how water supply, sanitation, and health fit into the broader needs of Karakalpakstan and Khorezm, as perceived by their populations, and to launch a broader process of social assessment to support the design of the Uzbekistan Water Supply and Sanitation Project. The assessment was initiated by the World Bank in November 1994 and conducted with the help of scientists from the Academy of Sciences of the Republic of Uzbekistan, Karakalpakstan Branch, and from the Expert Sociological Center.

To facilitate the collection and presentation of data, the study area was divided into eight geographical zones based on distance to water resources. Zones 1, 2, and 3 are situated in Khorezm. Zones 4, 5, 6, 7, and 8 are situated in Karakalpakstan. Except for zone 7, each zone includes urban and rural areas, and there is a major city in each region (figure 5.1). The needs assessment consisted of the following:

Household surveys. The sample consisted of 951 households (456 in Karakalpakstan and 495 in Khorezm) in 100 settlements with populations below 20,000. The surveys involved formal visits to families and individual interviews with the adult member of the family using a standard questionnaire. $\underline{5}$ In each settlement one representative of the local administration also was interviewed using the standard questionnaire. All questionnaires were filled in by the interviewers and checked by a supervisor. The data were coded, entered into computers, and processed and analyzed.

Community surveys. Surveys of community infrastructure were conducted in 100 rural state farms and in towns with populations below 20,000 .

Literature review. An extensive review of available literature was carried out. The review focused on a wide range of socioeconomic and environmental conditions in the Aral Sea region.

Community discussions. The needs assessment team visited thirty-nine communities to discuss water supply and sanitation conditions with groups of about fifteen to eighteen people each.

Stakeholder workshop. A stakeholder workshop was convened to review the findings of the household surveys and their implications for project design. Participants included representatives of NGOs, government agencies 
with water supply responsibilities, universities and research institutes, and a network of social scientists from Uzbekistan and neighboring countries.

The findings of the needs assessment have important implications for the project's design and implementation. An additional benefit was the creation of a network of social scientists that includes representatives from Tashkent Univer-

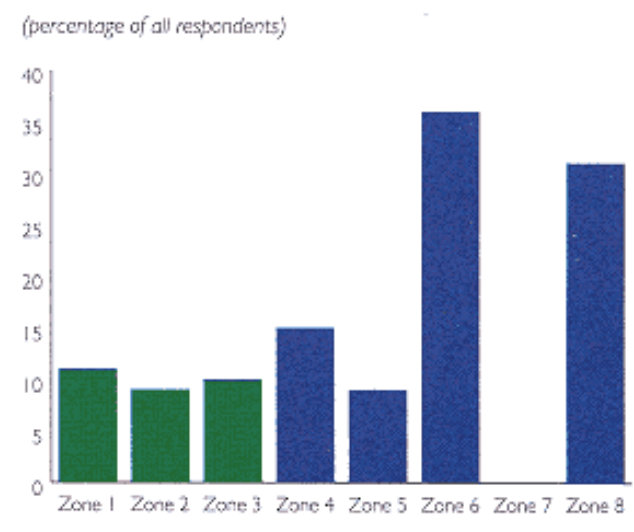

Figure 5.1

Urban population, by zone

Note: Zones

13 are in Khorezm Oblast; zones 48 are in the Republic of

Karakalpakstan. Urban population is the population living in towns with populations of less than 20,000, not the larger urban centers in the areas.

Source: Household surveys.

sity, Karakalpakstan Academy of Sciences, other local universities, local and international NGOs (for example, Union to Save the Aral Sea), and private firms. This network can be instrumental in building capacity for social analysis and designing participatory approaches to planning and implementing critically needed infrastructure projects in the Aral Sea region.

\section{Next Phase: The Broader Social Assessment}

To follow up the needs assessment, ongoing social assessment activities include household, institutional, and industrial surveys to determine water consumption and leakage patterns; surveys of rural and urban institutions and industries to determine their water use patterns; focus group discussions on suggested solutions to the water supply problem and means for preventing leaks and conserving water; willingness-to-pay surveys in eight areas in Karakalpakstan served by private water vendors; and a stakeholder workshop to discuss the latest findings of the needs assessment and to determine how to address water supply problems in the project areas.

The overall objectives of the social assessment for the Uzbekistan Water Supply and Sanitation Project were to identify key stakeholders in specific project areas and propose an appropriate framework for their participation in project design and implementation; predict the social impact of the proposed interventions on households and investigate whether certain social groups may be adversely affected; and help identify the most critical interventions to be undertaken to improve water supply, sanitation, and health. A summary of the main findings of the broader social assessment are presented in annex 5.1. 


\section{Needs Assessment Findings}

The needs assessment generated information that has important implications for the project's design and implementation. This section summarizes the findings of the household and community surveys in three parts. The first part presents the findings relating to socioeconomic conditions in the project areas. 6 The second part presents the findings of the assessment relating to water supply, sanitation, hygiene, and health. The third part presents the results on community-felt needs and willingness to pay.

\section{Socioeconomic Conditions}

Data provided by local officials indicate that the largest portion of settlements within the project areas (28 percent) falls into the group with 1,0013,000 people and that the populations of these settlements have remained relatively stable over the past five years (table 5.1). Additional data reveal that the largest portion of settlements in the project regions (32 percent) have 101300 households. There are only a few smallscale scattered settlements; only 12 percent of settlements have 50 households. Fourteen percent have 51100 households. Only 2 percent have $1,5012,000$ households. According to the needs assessment, most of the families surveyed want to remain in the region, despite the hardships imposed by the Aral Sea crisis. 7

The assessment also provided the following information about household size, income, food consumption, ethnicity and languages, education, and access to community infrastructure.

Family size. The average family size in Khorezm is 7.09 people (table A5.2.1), 5.63 people in urban settlements and 7.23 people in rural settlements. The average family size in Karakalpakstan is 7.56 people, 6.97 people in urban settlements and 7.68 people in rural settlements. In both regions the average number of children less than five years old is 1.19 and the average number of children aged 615 is 2.05 . In both regions an average of 3.24 children are less than fifteen years old.

Table 5.1 Settlement population shares, 1989 and 1994 (percentage of total population ) 1994

301500

5011,000

$1,0013,000$

$3,0015,000$

$5,00110,000$

$10,00115,000$

15,001 and over

Source: Household surveys. 


\section{Social Assessments for Better Development}

Income. Incomes in the project regions are extremely low. Most households (81 percent) depend on wage salaries and pension benefits as their main source of cash income, which at the time of the survey was \$22 a month (table A5.2.2). Most households have multiple wage earners, with men earning an average of 286 sums (\$11) a month, 30 percent more than the average wage of women (199 sums, or \$8). Average monthly incomes are generally higher in Khorezm than in Karakalpakstan (figure 5.2). For many months before the survey, however, families working for the state had not been paid. As a result many rural households relied on earnings obtained from occasional sales of garden crops and livestock. Additional remuneration is received by men, women, and children (ten years old or older) who cut and collect cotton during the cotton-growing season.

Most urban households own livestock kept in the yards of relatives in rural areas. In most cases every adult member of households and all schoolchildren work in the cotton fields for about two months. This is an important source of additional wage income, especially for rural families. In addition, state farms usually distribute earnings at the end of the year, providing additional income. Poor regions and areas with less cotton benefit less, but an average of $\$ 5 \$ 6$ of monthly wage income is derived from these two periodic sources.

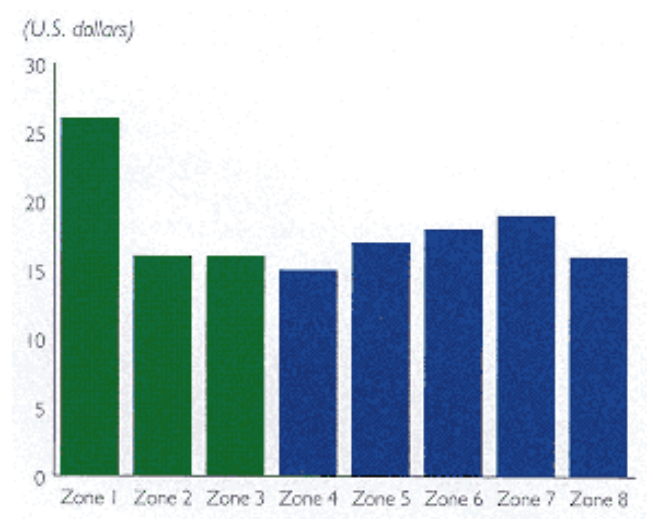

Figure 5.2

Monthly household income from salary and wages, by zone

Note: Zones13 are in Khorezm Oblast; zones 48

are in the Republic of Karakalpakstan.

Source: Household surveys.

In-kind earnings from livestock and garden agriculture can be substantial. Average monthly cash income from garden agriculture is $\$ 1$. Average monthly cash income from livestock is $\$ 2$, with an average in zone 4 earning of $\$ 11$. Without these sources of income, living standards during the transition period would have deteriorated more rapidly. Extensive livestock and land ownership in the two project regions accounts for the population's reliance on livestock and garden agriculture as a source of cash income. In Karakalpakstan 60 percent of households own cows (35 percent among urban populations and 65 percent among rural populations). As discussed earlier, many people in the region rely on livestock for subsistence. In Khorezm 37 percent of households own cows (16 percent among urban populations and 39 percent among rural populations).

Most rural households own enough land to grow crops and maintain livestock - the average plot is about 1 acre. In addition, some families (14 percent) own or rent plots from state farms. A much larger share of families owns land in Khorezm than in Karakalpakstan. Most households use land to grow crops. Only 6 percent of landowners do not grow anything on their plots because they lack the necessary inputs. Among those that do grow crops, 97 percent have their choice of crops ( 1 percent said that the decision is not made by the family), and a large share of these landowners grow orchard crops (55 percent) and vegetables ( 57 percent). Other crops include wheat (23 percent), fodder (11 percent), rice ( 2 percent), and melons ( 0.5 percent $)$. 


\section{Social Assessments for Better Development}

Taking into account cash earnings from livestock and garden agriculture, as well as other sources of informal earnings in rural settlements that increase when people move to cities, the highest average monthly income from all sources is 875 sums, in zone 1 . The lowest, 475 sums, occurs in zones 5 and 8.

Food consumption. A key finding of the needs assessment that has important implications for cost recovery is that food expenditures account for a large portion of household income. In Khorezm 87 percent of the average monthly income is spent on the main food staples.In Karakalpakstan 93percent of the average

monthly income is spent on food. Zones $1,2,6$, and 7 spend at least 80 percent of their income on food. Such high proportions of expenditure on food are indicative of extreme poverty in this ecological disaster area.

Ethnicity and languages. The ethnic composition of the project areas included in the survey is heterogeneous. In Khorezm 94 percent of the population is Uzbeki. By contrast, the sample population of Karakalpakstan encompasses four major ethnic groups: Karakalpaks (32.3 percent), Uzbeks (32.8 percent), Kazaks (26.7 percent), and Turkmens (5 percent). Karakalpaks inhabit mainly the central part of Karakalpakstan (zones 6 and 7), while the Kazaks are located primarily in the northern part (zone 8), and the Uzbeks mainly occupy the southeastern part (4.5 percent). In addition, there is considerable cultural diversity among the many tribal groups in these areas.

The principal language spoken in each household corresponds to the family's ethnic background. In Khorezm practically every family uses the Uzbek language. In Karakalpakstan the largest percentage of families uses Karakalpak (40 percent) and Uzbek. The population also uses Russian sporadically as a means of family communication. The percentage of Russians in the total population, however, is no more than 1 percent.

Education. The survey revealed relatively high levels of education. Currently, practically every child from the age of 6 to 15 attends school. The average education level attained among rural pupils is substantially lower than that among urban pupils. Overall, about 43 percent of women and 37 percent of men have a secondary school education.

Infrastructure. Households in the two project regions have relatively adequate access to community infrastructure. For example, the project areas are well served by electricity and gas. Almost all ( 95.5 percent) of the families are supplied with electricity, and 73 percent of the households in Khorezm (94 percent among urban populations and 72 percent among rural populations) and 58 percent of the households in Karakalpakstan (83 percent among urban populations and 53 percent among rural populations) have a gas supply. In Khorezm 3 percent of households use liquefied natural gas; in Karakalpakstan 10 percent do.

Settlements throughout the project areas have adequate access to most community services and facilities (table 5.2), but the needs assessment also found dramatic differences between rural areas and large towns (such as Nukus and Urgench). Large towns receive substantially better services than rural areas and small towns, particularly in terms of access to water-related services.

Settlements in the project areas communicate by radio relay system ( 8 percent), telegraph (13 percent), telephone (83 percent), and vehicles (20 percent). Overall, access to communication facilities by the settlements in the two project regions is similar, with urban areas enjoying 100 percent access to telephones and vehicles and rural areas having reasonably good access to these services.

The average distance from a settlement to the nearest railway station is 27 kilometers; the maximum distance is 86 kilometers (from Muinaksky region). Road conditions to the provincial center are good. Ninety-three percent of the roads are made of asphalt ( 2 percent are made of crushed stone and 4 percent are unpaved). However, on average only 44 percent of settlements have access to local radio broadcasting, and a much smaller proportion of households have telephone lines in their own 


$\begin{array}{ll}\begin{array}{l}\text { Table 5.2 Infrastructure availability } \\ \text { (percent) }\end{array} & \begin{array}{l}\text { Share of } \\ \text { settlements }\end{array} \\ \begin{array}{l}\text { Type of community } \\ \text { infrastructure }\end{array} & 89 \\ \text { Grocery store } & 79 \\ \text { School } & 64 \\ \text { Hospital } & 63 \\ \text { General goods store } & 60 \\ \text { Medical aid station } & 60 \\ \text { Kindergartens } & 55 \\ \text { Barbershop } & 43 \\ \text { Post office } & 42 \\ \text { Cinema, theater, or cultural } \\ \text { center }\end{array}$

homes (see table A5.2.1). And even where these facilities are available, not all of the population can use them.

Water Supply, Sanitation, and Health

The water supply problem in Karakalpakstan and Khorezm can be characterized as too much water of inadequate quality. Throughout the two regions a large portion of the population uses unsafe water from open sources either as their primary or supplementary source of potable water. This is especially the case in rural areas. Low coverage of piped water, coupled with its unreliable supply and the easy accessibility of unsafe sources of water, account for widespread use of unsafe water.

The excessive use of unsafe water imposes a huge toll on human health. In addition, livestock - an important source of cash and in-kind income-is also affected by the poor quality of water from these open sources. The following presents the findings of the needs assessment that relate to water supply, sanitation, hygiene, and health. 


\section{Social Assessments for Better Development}

Water supply. The findings related to water supply availability are:

More than half the households of the entire population rely on wells and hand pumps as their primary source of drinking water (figure 5.3); piped water is the primary source of potable water for only 38.2 percent of the population.

Because the availability of water from primary sources fluctuates, households rely on multiple sources of water (figure 5.4). The reliance on multiple sources also is induced by the pattern of water use. For example, water from the pipe connected to the house is rarely used to water livestock kept in the yard (table 5.3).

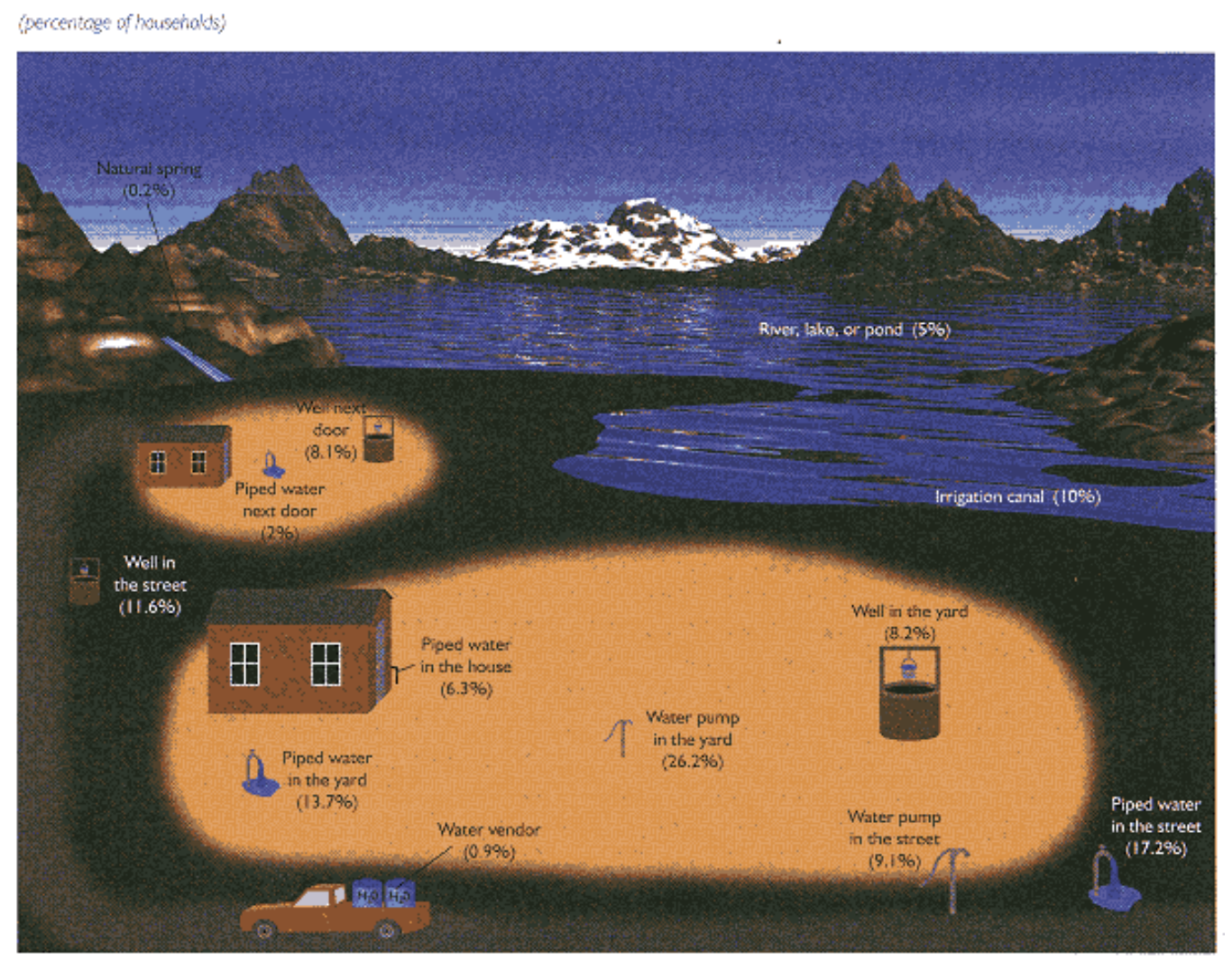

Figure 5.3

Sources of potable water

Almost 57 percent of households of the entire population use hand pumps and open wells to complement other sources of water.

Use of communal sources of water, including unsafe open sources, is widespread. For example, 17.2 percent of households carry piped water to their homes from street standposts. Others (6.3 percent) freely use the piped water connections of their neighbors. The use of communal hand pumps and sharing of hand pumps among neighbors are also common. This practice of sharing and maintaining water facilities among community members is an important social factor on which future community-based operations and maintenance programs can be based.

Households rarely use vendors or purchase bottled water, largely because of their low incomes. 
The use of extremely unsafe sources of water from irrigation canals, rivers, lakes, and ponds is widespread-and children's access to them is difficult to control, even when safer sources are available. Further, the school system provides no education to reduce this risk.

Piped water availability is substantially higher in Khorezm than in Karakalpakstan (figure 5.5; table A5.2.3). Within each region some subregions have much higher availability than others. Especially noteworthy is the extremely low-level availability of piped

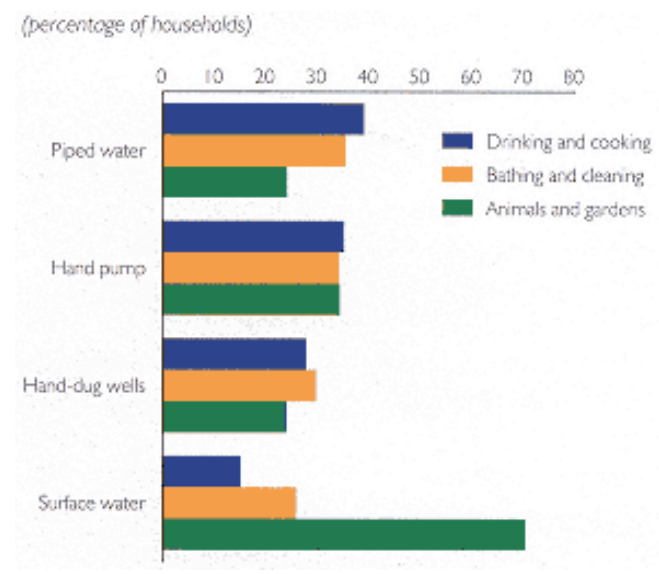

Figure 5.4

Sources and uses of water

Source: Household surveys.

Table 5.3 Sources of water for household needs and for watering crops and livestock

(percent)

\begin{tabular}{|c|c|c|}
\hline Source & $\begin{array}{l}\text { Household } \\
\text { needs }\end{array}$ & $\begin{array}{l}\text { Livestock } \\
\text { and } \\
\text { crops }\end{array}$ \\
\hline Hand pump in yard & 26 & 27 \\
\hline Irrigation canal & 18 & 52 \\
\hline $\begin{array}{l}\text { Common-use piped } \\
\text { water system }\end{array}$ & 18 & 12 \\
\hline Public-use well & 13 & 10 \\
\hline Piped water in yard & 11 & 8 \\
\hline Well in yard & 10 & 8 \\
\hline Hand pump in street & 8 & 8 \\
\hline River, lake, or pond & 8 & 14 \\
\hline Neighbor's well & 7 & 6 \\
\hline
\end{tabular}




$\begin{array}{lll}\begin{array}{l}\text { Piped water in house } \\ \begin{array}{l}\text { Piped water at neighbor's } \\ \text { house }\end{array}\end{array} & 5 & 3 \\ \text { Natural spring } & 1 & 4 \\ \begin{array}{l}\text { Delivered water } \\ \text { Bottled water }\end{array} & 1 & 0.1 \\ \end{array}$

Note: Household needs refer to needs other than drinking and cooking.

Source: Household surveys.

water in zone 3 of Khorezm and zone 5 of Karakalpakstan (figure 5.6; table A5.2.4).

Substantial differences in piped water availability between urban and rural areas persist despite the needs assessment's focus on urban areas with populations of less than 20,000 (table A5.2.5). Even small cities have a much higher piped water coverage (87.2 percent) than rural areas (32.5 percent; figure 5.7). Although expanding urban coverage to 100 percent is desirable, the need for rural coverage is far more pressing.

When piped water is available, the connections are more often to the yard (13.7 percent)

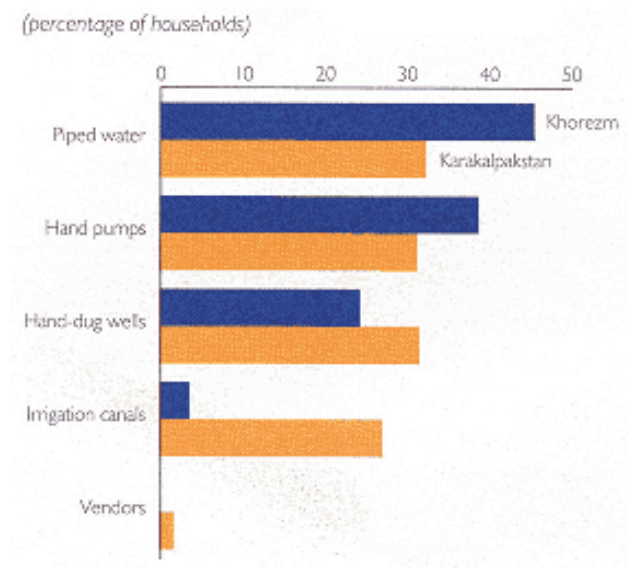

Figure 5.5

Sources of drinking water, by region Source: Household surveys. 


\section{Social Assessments for Better Development}

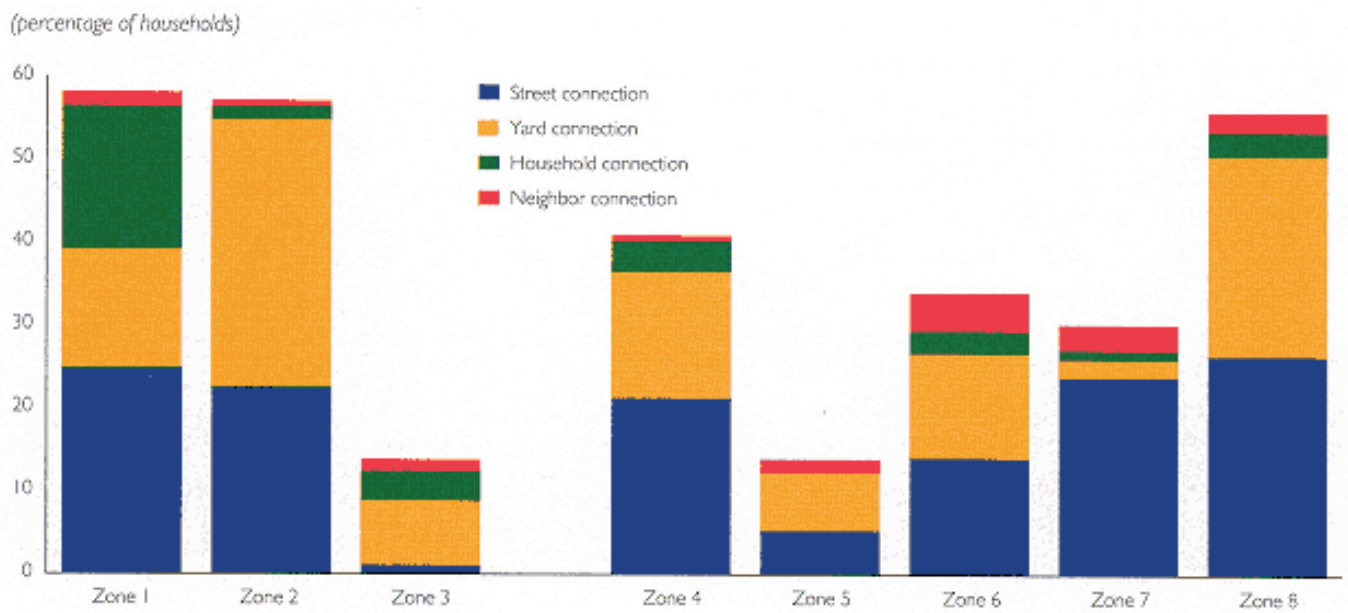

Figure 5.6

Piped water availability, by zone

Note: Zones 13 are in Khorezm Oblast; zones 48 are in the Republic of Karakalpakstan.

Source: Household surveys.

than to the house (6.3 percent; figure 5.8). In rural areas this arrangement is chosen to facilitate the watering of livestock as well as outdoor cooking. The fact that homes do not have waste water facilities is another contributing factor.

When piped water is available, its supply is extremely unreliable. For most households with piped water (70 percent), water is supplied for less than two hours a day. This induces the use of unsafe alternative water sources and the storage of water in open, rusted tanks. Extremely low household incomes make it impossible for families to purchase safer storage facilities.

The unreliability of the water supply shows regional and subregional differences. The more urbanized zone 2 (in Khorezm) distinguishes itself with an average of ten hours of water supplied per day (figure 5.9).

Community-based investigations found that in 64 percent of settlements water pressure is so low that it cannot accommodate new connections. This is especially true in zones 3,5 , and 7 .

When available, piped water is used to water livestock and high-value vegetables (see figure 5.4 and table 5.3).

Despite the high value attached to safe water and the scarcity of piped water connections to yards and homes, a large amount of piped water is wasted. Most connections do not have a tap, and leakage from household pipes is excessive. Although the rationing and limited supply of water limit this waste to some extent, it also degrades water quality. Studies are under way to measure this waste and to facilitate the design of environmental education campaigns on water conservation.

Water quality. Poor water quality is a pervasive problem in the project regions. Because safe piped water is not available to most households, families adopt a variety of strategies to obtain drinking water. About half the households obtain drinking water from sources that are not safe: wells in the yard or next door, irrigation canals, rivers, lakes, ponds, and natural springs. In addition, 34 percent of the families in Khorezm and 14 percent in Karakalpakstan use water storage tanks. In zone 3, 67 percent of the households use water tanks, and in zone 8, 56 percent use them. Drinking water was available in open storage tanks in 70 percent of the households. The average large tank capacity is two tons; the average small tank capacity is four buckets. Little consideration is given to safety in obtaining water from these and other alternative sources. Moreover, storing water further 
deteriorates the quality of already poor-quality water.

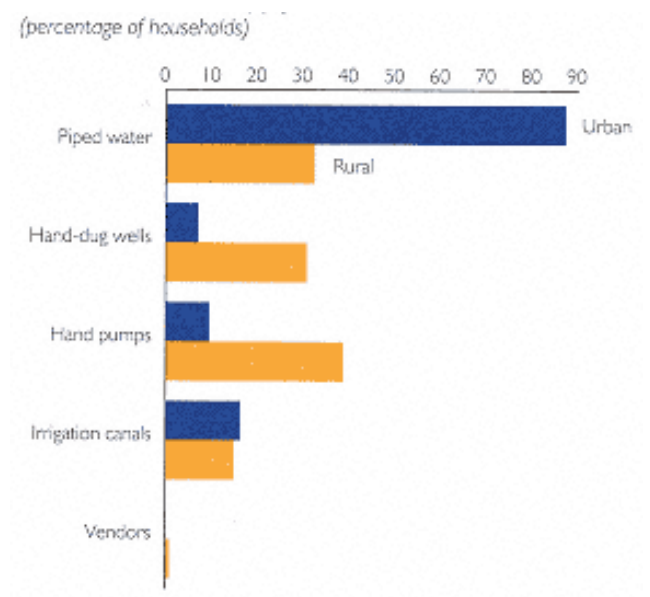

Figure 5.7

Water supply in urban and rural areas

Source: Household surveys.

Perceptions of water quality. The household surveys found the worst water in zones 1, 2, 3, and 6. A large number of households are not satisfied with the quality of the water. Most people (68 percent) are particularly bothered by water's saltiness ( 58 percent in Karakalpakstan and 87 percent in Khorezm) and taste (44 percent in both areas). Other complaints include particles in the water (17 percent), bacteria ( 8 percent), color (5 percent), and smell (4 percent). About 95 percent of households are not fully satisfied with their drinking water (table 5.4). And while households are not satisfied with the quality of

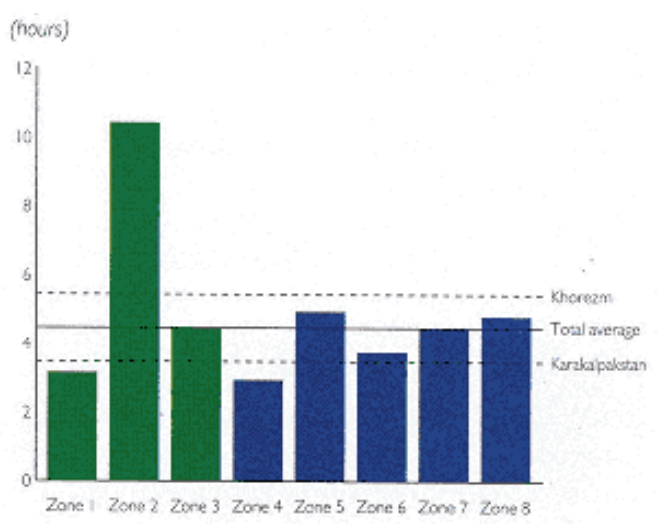

Figure 5.8

Piped water availability, by region Source: Household surveys. 


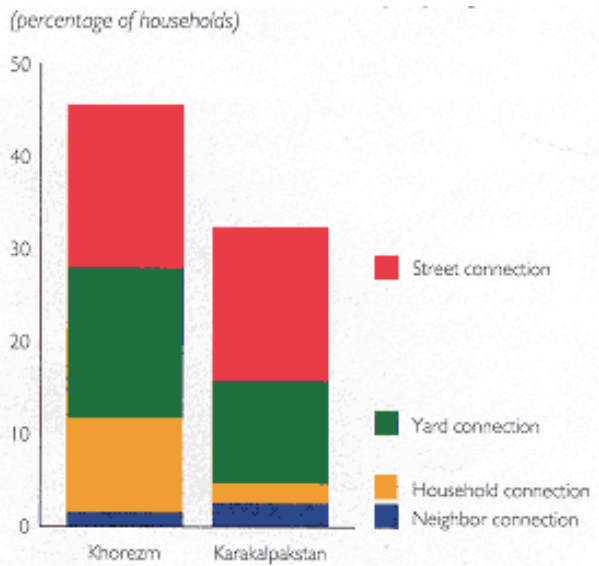

Figure 5.9

Daily piped water availability, by zone

Note: Zones

13 are in Khorezm Oblast; zones 48 are in the Republic of Karakalpakstan.

Source: Houshold surveys.

all water sources, almost all households rate the overall quality of water slightly higher than the quality of drinking water. $\underline{8}$

Water consumption. Actual water consumption in the project areas is not consistent with the amounts supplied. The survey found that a family of seven people uses about 38 liters of water a day for drinking and cooking. In Khorezm consumption per family is 45 liters a day; in Karakalpakstan consumption per family is 30 liters a day. In addition, the average family uses 57 liters a day for such purposes as washing dishes and clothing and cleaning. Thus total household consumption is 95 liters a day, or 14 liters a day per person. Although these domestic consumption rates are low, they are inconsistent with actual piped water supply figures for various cities, towns, and villages in the region. In both Karakalpakstan and Khorezm the piped water supply for households averages 220415 liters a day per person in urban areas The large discrepancy between household water supply

\section{Table 5.4 Household satisfaction evaluation}

(percent)

\section{Rating Share of families}

$5 \quad 5(12$ percent in zone 6$)$

430 (4251 percent in zones 4, 6, 7, and 8)

$3 \quad 44$

213 (1029 percent in zones 1, 2, 3, and 5)

15 (1114 percent in zones 3 and 5)

Source: Household surveys. 


\section{Social Assessments for Better Development}

and consumption figures is due to high water system losses, particularly at standpipes and yard connections where water runs continuously when there is sufficient pressure, and from nondomestic uses such as irrigation and livestock watering.

Cost recovery. Most household water is not paid for by users. The household surveys found that only 26 percent of households pay for water; 53 percent reported that they are not paying for water. Other responses are that the collective farms are paying or neighbors and relatives are paying. Five percent of the households said that they did not know who was paying (figure 5.10). According to a study conducted by the Japanese International Cooperation Agency, water charges are not always calculated based on the consumption measured by water meters. Water charges for most consumers are estimated by inventorying factors such as the number of water taps and the availability of sinks, toilets, and sewerage facilities. 9 Most household water, however, is not paid for by users.

\section{Sanitation.}

Sanitation infrastructure, especially in rural areas, is poor and requires substantial upgrading at both the community and household levels. Improvements are needed in public baths, sanitation facilities in schools and clinics, and household latrines. The most common form of sanitation, used by 75 percent of the population in the project areas, is the hand-dug, unlined, usually unventilated pit latrine, located 1520 meters from the house and more than 20 meters from the water source. When the pit becomes full, about 80 percent of households cover it with

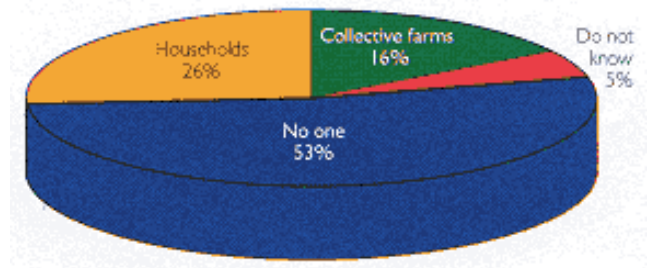

Figure 5.10

Who pays for the water supply?

Source: Household surveys.

soil and construct a new one. The pits are emptied by vacuum trucks in just 10 percent of households. Other means include discharging the waste directly into the street ( 3 percent), cleaning by hand ( 1 percent), and discharging waste water into an irrigation canal (1 percent). Thirty-four percent of the families in Khorezm and 4 percent in Karakalpakstan have cesspools near their houses. A small percentage of households is connected to the central sewerage system (table A5.2.6); only 1.7 percent of the rural population has access to a centralized sewerage system.

Waste water is discharged into a cesspool next to the house in 88 percent of households. In zones 6,7 , and 8 waste water is discharged directly into the street next to the house. In some cases waste water is discharged into the local sewerage system ( 2 percent) or into the centralized sewerage system (1 percent).

Hygiene. Few homes in the project areas have a shower or bath. In Khorezm 9 percent of households have a shower or bath in their homes (40 percent in towns and 6 percent in villages). In Karakalpakstan only 1 percent of households have a bath or shower. About one-third (34 percent) of the population does not have soap to wash their hands; others rarely use soap because supplies are scarce. In Khorezm 10 percent of households have outdoor showers or baths in their yards (18 percent in towns and 9 percent in villages). In Karakalpakstan 13 percent of the households have outdoor showers or baths.10 Many parents wash their children in a large metal pot near the stove, especially during the winter months. Children are washed 3 times a month in Khorezm and 3.4 


\section{Social Assessments for Better Development}

times a month in Karakalpakstan. Homes with yards often install an informal structure for showering. These private washing facilities are especially visible in Khorezm.

Nearly a third of the respondents wash themselves inside the house, either in a household shower or, in rural areas, in a basin. Only 12 percent of urban families wash at home. Most respondents go to public baths to wash (61 percent in urban areas, 46 percent in rural areas), reflecting the social and functional importance of public baths in these areas. The use of public baths is highest in zones 3, 4, and 8 (table A5.2.7). On average, respondents visit public baths 2.6

times a month. Children are taken to public baths 2.4 times a month. In Khorezm respondents visit public baths an average of 2.7 times a month and take their children to them 2.5 times a month. In Karakalpakstan respondents visit public baths 2.6 times a month and take their children to them 2.2 times a month. Urban respondents visit public baths an average of 3.2 times a month; rural respondents visit public baths 2.5 times a month. Children are washed 3.6 times a month in urban areas and 3.1 times a month in rural areas. They are taken to public baths 3 times a month in urban areas and 2.2 times a month in rural areas. A public bath is available and operational (according to an official) in only 45 percent of the settlements in the project area. In 8 percent of the settlements (zones 5 and 7), however, no public baths were available at the time of the survey.

Cleanliness of houses and of the children in each household were evaluated on a scale of 1 to 5 ( 5 being the highest). About half received a rating of 4 , and the findings for both indicators are practically the same. Latrines, however, which are located outside the houses, are not well maintained or sanitary. Similarly, the cleanliness of the cooking areas in homes could be improved.

Health. The poor water, sanitation, and hygiene conditions in Karakalpakstan and Khorezm-as well as a general lack of awareness of the links between sanitation, hygiene, and health - appear to be among the main causes of poor health in the project regions. Although the direct causes of illnesses in the project areas are not clear, official data and the findings from the needs assessment revealed that these environmental conditions, among other causes, are having adverse effects on health. Zone 4 has the highest incidence of intestinal disease (figure 5.11). According to official statistics, the incidence of viral hepatitis, tuberculosis, cancer, and skin disease is rising.

Childhood mortality. Child mortality is high in the Aral Sea region, especially in Karakalpakstan, where there are 45 deaths per 1,000 live births.

Viral hepatitis. The incidence of viral hepatitis in Karakalpakstan increased from 624 to 948 per 1,000 people over the past ten years.

Tuberculosis. During 1985-91 the incidence of tuberculosis in Karakalpakstan increased from 66 to 97 per 100,000 people. In Khorezm the incidence rose from 33 to 44 per 100,000 people. Among children the incidence of tuberculosis increased from 13 to 27 per 100,000 in Karakalpakstan, and in Khorezm, from 14 to 24.

Cancer. During 1985-92 the incidence of cancer in Karakalpakstan increased from 163 to 183 cases per 100,000 people. In Khorezm it rose from 210 to 249. 


\section{Social Assessments for Better Development}

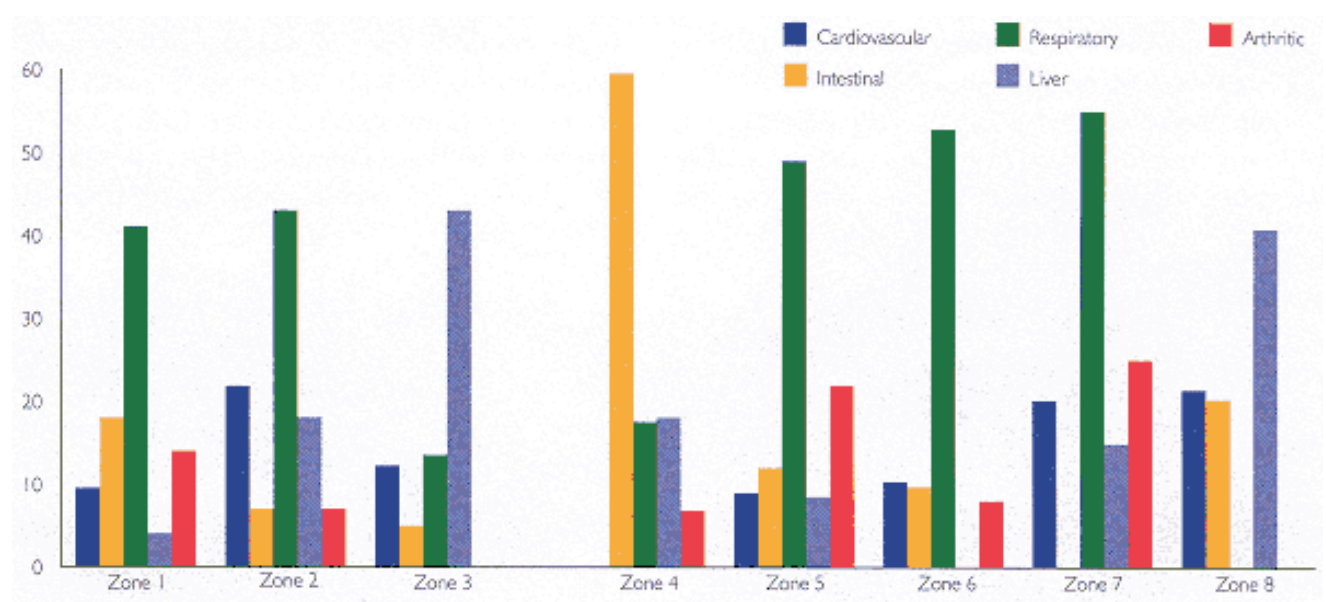

Figure 5.11

Percentage of major diseases, by zone

Note: Zones 13 are in Khorezm Oblast; zones 48 are in the

Republic of Karakalpakstan.

Source: Household surveys.

Skin diseases. In Karakalpakstan there are 983 cases of skin disease per 10,000 people (or twice the rate of the republic as a whole). In Khorezm the incidence rate is 520 cases per 10,000 people. Among children less than fourteen years old there are 649 cases in Karakalpakstan (1.5 times the national rate) and 294 cases in Khorezm.

The survey findings confirm that health conditions in the project areas are poor. For every 100 families interviewed, 23 had at least one member who was sick and had to seek hospital care. On average, every family had at least one member who needed to go to a hospital or seek medical attention twice during the year. Among those who were ill but did not visit a medical facility, three-quarters claimed that the hospital or medical facility is too expensive. The rest reported that the facility is located too far away.

In Khorezm just under one-fifth of respondents reported that they had been ill in the month before the survey. In Karakalpakstan almost 27 percent of respondents reported being ill during this period. Almost as many people visited a medical facility to get treatment in both regions. Of those who were sick but did not visit a medical facility, 78 percent in Khorezm and 73 percent in Karakalpakstan claim that the hospital or medical facility is too expensive; the rest believe that it is too far away (table A5.2.8).

More people were ill within the previous month in urban areas (32 percent) than in rural areas (22 percent) (table A5.2.9). Almost as many people as were sick visited a medical facility to get treatment in rural areas, but nearly 10 percent fewer people visited a hospital in urban areas. Among those who did not visit a medical facility despite being sick, 100 percent in urban areas and 71 percent in rural areas claim that the hospital or medical facility is too expensive; the rest (in rural areas) believe that it is located too far away.

\section{Community-Felt Needs and Willingness to Pay}

Most households - about 65 percent—interviewed mentioned lack of food, particularly flour, as their most important problem (table 5.5). The second most commonly cited problem is the lack of money to purchase flour. And despite their widespread poverty, households reported that their third most pressing problem is the lack of quality water. Their need for quality water is tied to its use as an input for production and livestock management. 


\section{Social Assessments for Better Development}

Urban populations in Khorezm mention water supply problems as their first and second most important problem. Zones 3 and 4 identify water most often among their most important problems. In rural households, however, water problems are most frequently mentioned as the third most important problem and, sometimes, as the second most important problem.

To confirm these findings, the survey team asked the household respondents how they would spend 500 sums (\$20) and 2,000 sums (\$80) if (hypothetically) they were given these amounts. If offered 500 sums-the equivalent of the average monthly wage from state farms at the time of the survey-most households (88 percent) said that they would use the money to buy food (figure 5.12; table A5.2.10). Only 5 percent said that better water would be their first choice. The largest percentage of households (32 percent) said that better water would be their second choice, and the largest percentage of households (21 percent) said that household repairs would be their third

\section{Table 5.5 Main problems in Uzbekistan}

(percentage of households)

Type of problem

Lack of food

Lack of money for flour

Lack of fuel

Water

Lack of construction materials

Lack of opportunities to make a living

Health

Sanitation

\section{Most important problem}

64.7

23.0

3.1

2.7

0.9

0.7

0.4

0.1

Second most
important
problem

16.0

58.9

3.6

9.0

4.0

4.0

1.3

1.0
Third most important problem

8.5

5.3

12.0

25.4

18.0

11.9

6.8

5.8

Source: Household surveys.

choice. If offered 2,000 sums, 81 percent of households said they would use the money to buy food as their first choice; only 5 percent chose an improved water supply. As their second choice, 30 percent cited household repairs or home improvements, and 29 percent cited better water. Twenty percent said that their third choice would be better sanitation, particularly a bathing facility.

The willingness to pay for water improvements is high in both regions. Notwithstanding an inability to pay for water (in Karakalpakstan people spend 93 percent of their incomes on food; in Khorezm they spend 87 percent), 99 percent of households indicated that they want an improved water supply and would be willing to pay an average of 699 sums (\$28) as a one-time installation fee for water connections (house, yard, street) or hand pumps and 16 sums $(\$ 0.64)$ a month for water. This figure indicates the respondents' perceived acute need for water rather than their realistic judgment about ability to pay. Moreover, 52 percent of these households would seek a loan or credit to improve their water supply (figure 5.13). An ever larger percentage in Karakalpakstan is willing to borrow for such an improvement. In addition, most households would pay a higher installation fee for a 
household connection (\$33) than for a yard connection (\$24), street connection (\$10), or hand

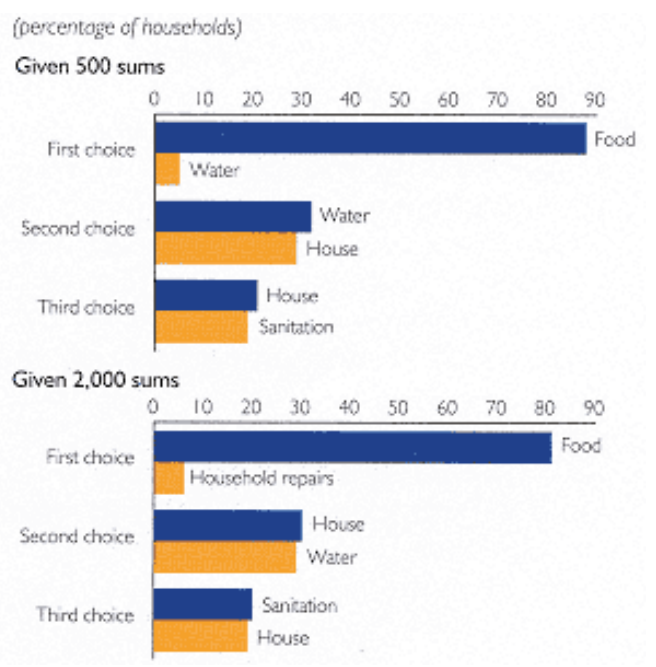

Figure 5.12

Consumption choices

Source: Household surveys.

pump in the yard (\$8; figure 5.14). The monthly fees they would be willing to pay correspond to 13 percent of monthly income in Khorezm and 2 percent in Karakalpakstan (table A5.2.11).

More households want piped water connections in the yard (50 percent) than house connections (39 percent), with the neediest zones (zones 3,4, and 5) having the lowest need for piped connections in the home. The expressed need for house connections is highest in Khorezm (zone 1), in areas where piped water availability through home connections is high, in areas where piped water availability is generally high (zones 1 and 8), and in areas where urbanization is highest (zones 6 and 8; table A5.2.12).

The households were considerably less willing to pay for sanitation improvements; only 78 percent expressed a desire for better sanitation. Ninety-five percent would pay no more than 50 sums (\$2) for a one-time installation. Eight percent of the households in zones 1 and 8 would pay 51100 sums $(\$ 4)$, and .4 percent of the households would pay 101200 sums (\$8). The household surveys found that 71 percent of families would not pay a monthly fee for sanitation. Nineteen percent said that they would pay $\$ 0.44 \$ 0.80$. Four percent of households said that they would pay more than 50 sums $(\$ 2)$.

If offered 500 sums $(\$ 20)$, none of the respondents said that sanitation would be their first choice for its use; only 4 percent said it would be their second choice, and 24 percent said it would be their third choice. If offered 2,000 sums (\$80), only 1 percent of respondents said that sanitation would be their first choice; 6 percent said that sanitation would be their second choice, and 23 percent said it would be their third choice.

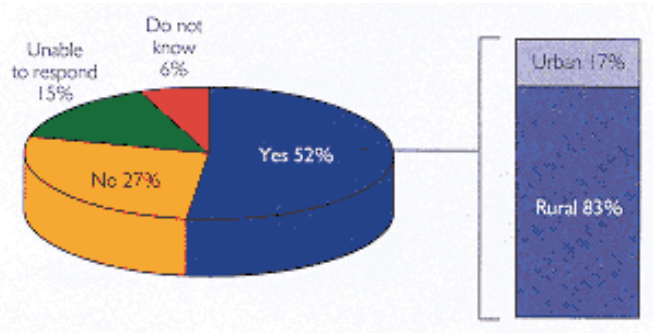




\section{Social Assessments for Better Development}

Figure 5.13

Willingness to borrow to pay for improvements in water

supply

Source: Household surveys.

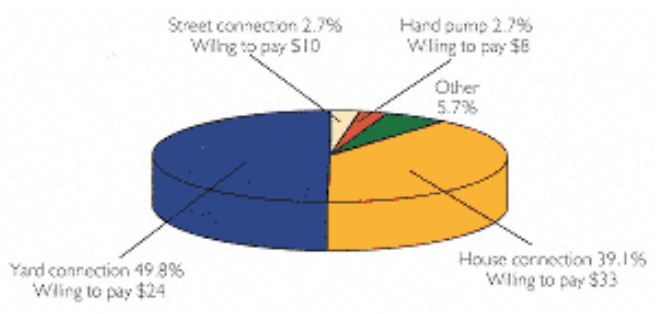

Figure 5.14

Preferences in water supply system improvements

and willingness to pay for installation

Source: Household surveys.

Fifty-two percent of respondents want to reconstruct their latrines; forty-one percent do not want to change them. On average, residents are willing to spend 313 sums (\$13) on their latrines, although 61 percent of households said they would be willing to pay 0100 sums $(\$ 4)$. Among the remaining households, 13 percent would pay 301500 sums $(\$ 12-20), 8$ percent 101200 sums $(\$ 4-8), 8$ percent $201-300$ sums $(\$ 8-12), 5$ percent 5011,000 sums (\$20-40), 3 percent 1,0013,000 sums (\$40-120), and 3 percent 3,0015,000 sums $(\$ 120-200)$.

\section{Project Implications}

The needs assessment revealed that poverty is the most important problem facing the populations of Karakalpakstan and Khorezm. This finding was most clearly expressed in the respondents' overwhelming emphasis on their need for adequate food. For most residents, moreover, good-quality water is viewed as an important input to their productive activities. The availability of good-quality water can improve livestock management, reduce the time spent fetching water that could otherwise be spent in productive activity, and in some cases reduce the costs associated with water-related illness (for example, lost work days due to illness, medical care expenses). In terms of specific project interventions, the following are key implications of the needs assessment.

\section{Water Supply}

The needs assessment highlighted the need for improving water supply and water quality in Karakalpakstan and Khorezm. Moreover, the subregional differences identified highlight the need to address the specific requirements of each zone and even each community in project design and implementation. Not only can these differences help determine the type of water supply improvements appropriate for each community, they can also help establish a system by which the implementation of the project can be monitored at the community level. The following are key implications for improving the water supply:

Increase coverage. The main focus of the project should be expanding the coverage of piped water-especially in rural areas, where only about 30 percent of households have access to a piped water supply. According to the needs assessment, the project should target one zone each in Khorezm and Karakalpakstan where there is low availability of water and a high willingness to pay for piped water, particularly yard connections. House connections should be targeted only in zones that have high levels of urbanization and an existing piped water supply. 


\section{Social Assessments for Better Development}

Improve quality. More than 40 percent of the households in the project regions lack a safe supply of drinking water. Improving the quality of water requires expanding the coverage of the piped water system and ensuring that the water supplied is of good quality. Investments in piped water should be targeted to areas where there are large numbers of households relying on unsafe water sources (that is, irrigation canals, wells, rivers, lakes, ponds).

Conserve water. The high levels of waste and leakage in the water supply system highlight the need for water conservation in the project areas. Where there is a safe and accessible groundwater supply, community-based water supply systems can be established.

The success of such systems, however, will depend on the development of appropriate local institutions, especially during the transition, when the functions of the state collective farms are being reduced. Small, flexible social structures (such as pump committees and water user associations) can be set up to assume responsibility for maintaining or protecting the water facilities from damage, preventing waste, and collecting a minimum

charge from users who do not participate in the physical maintenance of the system. These organizations also can arbitrate conflicts between people who use the water only for drinking and those who abuse the system and use water beyond their entitlement. Such an approach can go a long way toward ensuring the sustainability of the new water network.

One way to determine the most effective arrangements for establishing local water user committees or associations and defining their functions would be to support three or four pilot programs during project preparation.

Generate income. The low income levels in Karakalpakstan and Khorezm and the expressed need for food imply that the investment in water supply should ensure that the public works components of the project generate maximum local employment through the use of local contractors and laborers; include an income-generating component (even as a pilot program) that provides a credit facility to encourage the growth of small businesses, with a particular emphasis on improving women's access to credit; and, where feasible, include a pilot sanitation improvement program, also involving local labor in constructing latrines (or an alternative low-cost technology) and other facilities such as public baths.

Recover costs. Because people in Karakalpakstan and Khorezm spend such a large portion of their incomes on food—93 percent and 87 percent, respectively—any attempt at full cost recovery for improvements in the water supply will require a substantial increase in disposable incomes. And if, as discussed above, the project includes an income-generating component, the region can begin to build the capacity for cost recovery. Until incomes increase, however, continued government subsidies for water will be needed.

Subsidies can be justified on the grounds that improving the water supply will lead to increased labor productivity by improving health. Other possible benefits include enhanced livestock production and time savings. Still, it is important to collect a small water charge (and increase it incrementally), not only to cover a part of supply costs but also to encourage participation, ownership, and conservation. In rural areas there are opportunities for in-kind contributions through household participation in water supply operations and maintenance. In urban areas with piped water supplies, metering should be introduced.

Establish a policy dialogue. Given the high level of poverty in the project areas and the critical need for an improved water supply system, the proposed project does not lend itself to focusing on policy dialogue and institutional reforms. Rather, the principal focus of the project should be on providing the necessary water services in the most expeditious way possible. Still, it will be important to discuss with the government the existing subsidies on large piped water systems that primarily serve large cities, because their continuation would 


\section{Social Assessments for Better Development}

discourage the establishment of communitybased water systems. In addition, it will be necessary to discuss the need to improve sanitation, particularly through the introduction of appropriate alternative technologies.

\section{Sanitation}

Future projects should introduce large-scale sanitation improvements in areas that are already served by piped connections in the home and that have expressed a felt need (primarily urban areas). As part of the first water supply and sanitation investment, however, the project should support pilot sanitation projects that experiment with low-cost alternative technologies (for example, improved pit latrines) in rural areas, where water tables are high and incomes are low. Additional investment will be needed in both urban and rural areas to provide public bathing and school washing facilities. As recommended at the stakeholders workshop, hygiene education also is needed to build public support for improved sanitation facilities. Other investments relating to health improvement should be considered in future investments.

\section{Social or Community Development Fund.}

Introducing a social fund or community development fund in Uzbekistan with financial assis-

tance from the World Bank, could provide the government with a mechanism for rapid and well-targeted assistance to meet the immediate needs of local communities. As indicated by the main findings of the needs assessment, individual zones within the project areas are particularly disadvantaged in terms of water and sanitation. Whether introduced through this or a future project, a social fund or community development fund would provide assistance to rural households by increasing access to essential social infrastructure. Such funds could also be used to ensure the sustainability of water supply improvements by funding the training and technical assistance needed to strengthen project management capabilities in rural communities.

\section{Annex 5.1 Summary Findings of the Uzbekistan Water Supply and Sanitation Social Assessments}

The Uzbekistan Water Supply and Sanitation Social Assessment comprises four separate reports, each focusing on a particular geographical region or issue. These reports include an assessment of water supply and sanitation conditions in major urban centers and of the water supply and sanitation use of the industrial and commercial enterprises operating in these areas; an assessment of water taste and salinity tolerance of communities living in project areas; an assessment of hand pump usage and problems as well as the advantages associated with such pumps in rural project areas; and an assessment of water vendor service in periurban areas of Khorezm and ways to improve the water supply in these areas. The following sections summarize the main findings of these social assessments.

\section{Urban Areas Social Assessment}

The urban areas social assessment survey took place in the major urban centers of Urgench in Khorezm and Nukus in Karakalpakstan. It also examined industrial and commercial water use in these areas. The methodology used to prepare the report included a systematic survey of piped water use focusing mainly on water consumption and leakage patterns at the household level. It also made inquiries into associated socioeconomic implications such as willingness to pay and available sources of income. In addition, an industrial and commercial water use and water conservation survey was conducted. The social assessment aims to describe water supply conditions, identify physical means for achieving water conservation or alternative low-cost supplies, and assess the prospect for increased cost recovery as a means of encouraging water conservation.

The assessment produced the following key findings: 


\section{Social Assessments for Better Development}

Income levels in Nukus and Urgench are high relative to the periurban and rural areas of Khorezm and Karakalpakstan. Average monthly income is about \$51.9 in Nukus and \$59.6 in Urgench. Monthly payments for water supply are low, however, the amounts paid for water supply service are 0.7 percent of the average monthly household income in Nukus and 1 percent in Urgench.

Water supply is intermittent and leakage is high in the cities surveyed. The water supply system in Nukus is in worse shape than the one in Urgench. There are fewer connections to the main pipeline in Nukus, for example. In Nukus 63 percent of households have connections; in Urgench 91 percent of households do. Water availability is also lower in Nukus. In Urgench the main problem with the water supply is its quality. In Nukus availability is the main problem.

Community participation is high, as revealed by the coping strategies used by the population. The methods used to cope with the unreliability, shortages, and low quality of the water supply include repairing leaks themselves, treating the water before using it, storing water, and sharing water sources with neighbors. In most cases, however, the plumbing materials needed for in-house repairs are not readily available. This lack of equipment contributes to the water shortage through leaks.

Food is a priority need; most households report not having sufficient money to buy food. Other problems mentioned include shortages and high cost of flour. When asked about their second most important problem, people remain focused on food. Water supply problems emerged as a third priority.

Willingness to pay for water supply is higher in Nukus. About half of Nukus residents and 22 percent of Urgench residents would be willing to make monthly payments for betterquality water and a more reliable supply. They are willing to pay an average of 35 sums a month (about $\$ 1$, or 2.2 percent of average monthly household income) in Nukus and 60 sums a month (about \$2, or 3.4 percent of average monthly household income) in Urgench.

Sanitary conditions are poor. A significant portion of the population (55 percent in Nukus and 52 percent in Urgench) is not connected to the central sewerage system at all. They either use sewerage pits or discharge their waste water directly into the street. An earth pit is the most common form of sanitation. The sanitation infrastructure in the two urban areas studied is in very poor condition.

Willingness to pay for sanitation system improvements is low. About 24 percent of those surveyed in Nukus and 19 percent in Urgench would be willing to take a noninterest bearing credit for one year to improve their sewerage system. Even though poverty is the priority problem in project areas, people are willing to make sacrifices to have better water supply and sanitation, more so for water than for sanitation.

\section{Salinity Taste Tolerance Assessment}

A survey was conducted to determine people's tolerances for a range of salinity levels in water supplies in affected communities in the urban and rural areas of Karakalpakstan and Khorezm. Other methodologies used in the process included a literature review, community discussions, and a stakeholder workshop.

The taste tolerance survey revealed important information about the main water sources used in different regions, the assessment of water quality in those regions, and the relationship between the quality of the water used and the perceptions of quality. The following summarizes the survey's main findings:

Main water sources vary. Overall, 60.2 percent of the respondents use water from the water pipeline for drinking and cooking. In addition, 24.5 percent use water from hand pumps and 10.3 percent use water from wells, which may not be suitable for drinking and cooking. Other sources include unsafe open water sources such as melioration or irrigation canals and water supplied to the population by water vendors. 


\section{Social Assessments for Better Development}

Household satisfaction levels are low because of the poor quality of water. Only 17.1 percent of respondents are completely satisfied with their main water supply, and 41.1 percent are partially satisfied. The rest (41.3 percent) are unsatisfied. About 34 percent of the rural population is completely satisfied with the quality of water they use which, according to the test results, is of a lower quality than the water used by the urban population. Water quality usually deteriorates during the summer. More than 83 percent of respondents treat their drinking water by boiling and settling.

Laboratory tests indicate that water is of low quality. The average salinity found in the water used for drinking in Uzbekistan is 1.12 grams per liter; there is not a substantial difference between Khorezm and Karakalpakstan. The difference between rural and urban settlements is high, however. The test results show that rural residents have lowerquality water than do urban residents. Households in major cities have access to the best quality water.

Taste tolerance is inversely related to salinity and varies by region. Water samples containing different levels of salinity were evaluated by respondents, and it was found that, after the necessary adjustments, respondents were willing to continuously drink water with a salinity of 1 gram per liter but that they would also tolerate water with a salinity of up to 2.0 grams per liter. Urban residents were slightly more perceptive of taste than rural residents. Most households favored the sample that had an adjusted salinity level of 1.82 grams per liter.

Hand Pump Monitoring Survey and Social Assessment

A large share of the rural population in Karakalpakstan and Khorezm relies on hand

pumps for their primary drinking needs. A far larger percentage uses hand pumps for homebased agricultural and livestock production. Thus household reliance on hand pumps is critically related to rural incomes and family subsistence. The main findings of the hand pump usage survey undertaken in rural areas of Khorezm and Karakalpakstan are as follows:

Hand pumps are a cheap and easy way to maintain water source-99 percent of respondents find hand pumps to be a convenient source of water. Hand pumps are generally not too far from water sources such as irrigation ditches, lakes, and canals. Local drillers usually determine their location and provide parts for installation. In most cases the tools and materials used for hand pump repair-such as welding equipment, welding electrodes, and pipes-are readily and cheaply available in the settlements that use hand pumps.

Water availability from hand pumps is high. On average, hand pumps give water 356 days a year and have an average daily capacity of 907 liters. Hand pumps are used for such purposes as watering animals, washing dishes, doing laundry, cleaning, drinking, and for irrigation. More than one-fifth of respondents do not treat or purify hand pump water before consumption. Nearly half let the water settle before drinking, and 10 percent boil the water in addition to settling.

Water from hand pumps is thought to be satisfactory. The actual quality of water is low, however. Of the 85 percent of respondents who use hand pump water for drinking, 82 percent are satisfied with the quality of the water. Respondents in the northern zones (zones 6, 7,8) are less satisfied. The most commonly cited complaint about hand pump water is its salty taste (36 percent). One-fifth of hand pump users complain of sand and other particles in the water. Chemical analysis of the hand pump water indicates a high salinity ( 2 grams per liter) for water that respondents claim is satisfactory for drinking. The average coli count was 9 , which greatly exceeds the acceptable national index of 3 and the global index of 0 .

Respondents welcome the idea of improving their hand pumps, but only 9 percent can afford such improvements. In addition, an even smaller percentage ( 5 percent) has the means to install an electric pump. No respondent pays for hand pump use, and 82 percent are satisfied with the pump's water quality. Thus, other than repairing broken 


\section{Social Assessments for Better Development}

hand pumps, residents cannot afford to make improvements to existing hand pumps.

Water Vendors and Willingness to Pay Assessment.

The survey area included the settlements of Geophysics, Kos-Kul, Kyzketken, Samanbay, Tausha-Aul, Toyokesh, and Vodnik. These seven settlements were selected as a result of a previous investigation on household water use. Residents of these settlements use vendor water as their sole or combined source of drinking water. The vendor water use survey learned the following:

Periurban areas served by water vendors have lower income levels than urban areas, and asset ownership in households is not high. The reported average household income was about 1,046 sums (\$35), with slight variations among the towns surveyed. Cattle ownership was not high in the areas surveyed; only 23 percent of respondents owned cattle. Among those who did not own cattle, more than half cited the lack of water as the primary reason.

Water vendors are the main source of water for bathing, laundry, and other household purposes, serving more than half of the households surveyed. In addition to the water supplied by vendors, people often use water from open sources such as rivers or streams.

Satisfaction with water vendors' services is low—only about half the respondents are satisfied. There are seasonal changes in the quality and delivery of water; water is delivered more frequently during the spring and summer. Residents, however, would like to see the frequency of delivery increase year-round. The biggest complaint about the water delivered during the spring and summer is its dirtiness, followed by its salinity and smell. There are fewer complaints about dirtiness during the fall and winter.

Residents served by water vendors pay more for their water supply than urban residents.

In a given month the average expenditure for water vendors is 120 sums ( 11.5 percent of monthly income) during the warm season and 90 sums ( 8.5 percent of monthly income) during the cold season. The average amount paid for each delivery is 34.3 sums per household. In light of these high payments, willingness to pay for improvements is also high in these areas. Most respondents (70 percent) agreed to pay more for higher-quality delivered water.

There is a lack of control over water vendors' services, and people pay a lot for low-quality water. In most cases delivered water is taken from open and unsafe sources that are, on average, about 2 kilometers away from households. Lack of transport is an important factor influencing people's dependence on water vendors. Poor-quality water also negatively affects the health of residents. On average, 26 percent of households had at least one ill member during the month before the survey. Most of those who were sick complained about stomach and chronic liver diseases that can be linked to the water supply.

\section{Annex 5.2 Household Survey Data}


Social Assessments for Better Development

Table A5.2.1 Socioeconomic indicators, by zone

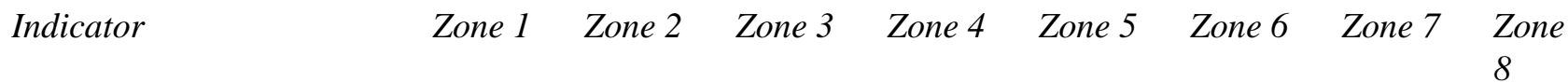

\section{General household \\ indicators}

\begin{tabular}{|c|c|c|c|c|c|c|c|c|}
\hline Percent urban & 11 & 9 & 10 & 15 & 9 & 36 & 0 & 31 \\
\hline Household size & 6 & 7 & 9 & 9 & 5 & 7 & 7 & 8 \\
\hline $\begin{array}{l}\text { Average number of } \\
\text { children ages } 5 \text { and under }\end{array}$ & 1 & 1 & 1 & 2 & 3 & 1 & 1 & 1 \\
\hline $\begin{array}{l}\text { Average number of } \\
\text { children ages } 615\end{array}$ & 2 & 2 & 2 & 2 & 0 & 2 & 2 & 3 \\
\hline $\begin{array}{l}\text { Number of children } 615 \\
\text { who go to school }\end{array}$ & 2 & 2 & 2 & 2 & 0 & 2 & 2 & 2 \\
\hline $\begin{array}{l}\text { Average age of head of } \\
\text { household }\end{array}$ & 45 & 48 & 49 & 51 & 31 & 49 & 47 & 42 \\
\hline Monthly wages (\$US) & 26 & 16 & 16 & 15 & 17 & 18 & 19 & 16 \\
\hline $\begin{array}{l}\text { Total monthly household } \\
\text { income (\$US) }\end{array}$ & 35 & 20 & 21 & 35 & 19 & 23 & 21 & 19 \\
\hline $\begin{array}{l}\text { Percent who speak Uzbek } \\
\text { as primary language }\end{array}$ & 98 & 100 & 100 & 47 & 73 & 3 & 7 & 0 \\
\hline $\begin{array}{l}\text { Percent who speak } \\
\text { Karakalpak as primary } \\
\text { language }\end{array}$ & 1 & 0 & 0 & 8 & 5 & 77 & 63 & 92 \\
\hline $\begin{array}{l}\text { Percent who speak Kazakh } \\
\text { as primary language }\end{array}$ & 1 & 0 & 0 & 8 & 16 & 19 & 12 & 8 \\
\hline \multicolumn{9}{|l|}{$\begin{array}{l}\text { Availability of utilities } \\
\text { (percent) }\end{array}$} \\
\hline Electricity & 90 & 99 & 99 & 99 & 100 & 97 & 99 & 100 \\
\hline Central sewerage system & 2 & 4 & 3 & 2 & 0 & 0 & 2 & 0 \\
\hline Central gas supply & 61 & 86 & 88 & 42 & 55 & 81 & 42 & 80 \\
\hline Piped water supply & 58 & 57 & 14 & 41 & 14 & 34 & 30 & 56 \\
\hline Water storage & 26 & 9 & 67 & 0 & 0 & 38 & 2 & 56 \\
\hline Telephone & 22 & 47 & 21 & 38 & 23 & 24 & 2 & 48 \\
\hline Local radio & 38 & 51 & 44 & 12 & 17 & 9 & 1 & 25 \\
\hline
\end{tabular}




\section{House and land}

Average number of years 17

15

16

17

29

23

23

18

in current house

\begin{tabular}{|c|c|c|c|c|c|c|c|c|}
\hline Average number of rooms & 6 & 6 & 6 & 6 & 6 & 4 & 4 & 5 \\
\hline $\begin{array}{l}\text { Percent who own their } \\
\text { home }\end{array}$ & 97 & 98 & 100 & 100 & 100 & 97 & 95 & 89 \\
\hline Percent who own a plot & 19 & 23 & 4 & 2 & 11 & 44 & 21 & 34 \\
\hline $\begin{array}{l}\text { Average size of plot } \\
\text { (acres) }\end{array}$ & 0.12 & 2.76 & 0.06 & 0.21 & 0.2 & 0.11 & 0.15 & 0.08 \\
\hline $\begin{array}{l}\text { Percent who grow crops } \\
\text { on their land }\end{array}$ & 97 & 100 & 100 & 100 & 100 & 93 & 93 & 92 \\
\hline $\begin{array}{l}\text { Average annual income } \\
\text { from crops (\$US) }\end{array}$ & 19 & 18 & 15 & 38 & 10 & 23 & 1 & 1 \\
\hline $\begin{array}{l}\text { Percent who breed animals } \\
\text { for sale }\end{array}$ & 42 & 15 & 48 & 70 & 8 & 3 & 21 & 24 \\
\hline $\begin{array}{l}\text { Average annual income } \\
\text { from animals (\$US) }\end{array}$ & 30 & 5 & 13 & 137 & 3 & 10 & 123 & 6 \\
\hline $\begin{array}{l}\text { Average number of } \\
\text { cows/bulls }\end{array}$ & 3 & 3 & 3 & 5 & 3 & 5 & 11 & 5 \\
\hline $\begin{array}{l}\text { Average number of } \\
\text { sheep/goats }\end{array}$ & 3 & 2 & 3 & 11 & 2 & 1 & 1 & 0 \\
\hline Average number of horses & 1 & 1 & 1 & 2 & 2 & 8 & 11 & 8 \\
\hline $\begin{array}{l}\text { Average number of } \\
\text { poultry }\end{array}$ & 11 & 9 & 9 & 14 & 9 & 0 & 1 & 0 \\
\hline
\end{tabular}

Note: Zones 13 are in Khorezm Oblast; zones 48 are in the Republic of Karakalpakstan.

Source: Household surveys.

Table A5.2.2 Average income data, by zone

Income data

Zone 1 Zone

Zone

Zone 4

Zone 5

Zone 6

Zone 7

Zone 8 Total

\section{Average income}

(Uzbeki sums)

$\begin{array}{llllllllll}\text { Wage of women } & 271 & 164 & 161 & 138 & 180 & 188 & 174 & 177 & 199 \\ \text { Wage of men } & 376 & 243 & 228 & 235 & 246 & 265 & 297 & 234 & 286 \\ \text { Household wage (M+W) } & 647 & 406 & 389 & 373 & 426 & 453 & 471 & 412 & 485\end{array}$


Social Assessments for Better Development

Of benefits and

$116 \quad 39$

66

133

15

48

37

44

68

additional income

Of wages and benefits

764

446

455

506

441

502

508

455

553

Earnings from livestock 63

$11 \quad 28$

$286 \quad 6$

21

24

13

47

Earnings from crops

40

37

32

80

20

47

3

4

35

Total household income

867

493

514

873

466

570

535

472

634

Average income (US\$)

\begin{tabular}{|c|c|c|c|c|c|c|c|c|c|}
\hline Wage of women & 11 & 7 & 6 & 6 & 7 & 8 & 7 & 7 & 8 \\
\hline Wage of men & 15 & 10 & 9 & 9 & 10 & 11 & 12 & 9 & 11 \\
\hline Household wage $(\mathrm{M}+\mathrm{W})$ & 26 & 16 & 16 & 15 & 17 & 18 & 19 & 16 & 19 \\
\hline $\begin{array}{l}\text { Of benefits and } \\
\text { additional income }\end{array}$ & 5 & 2 & 3 & 5 & 1 & 2 & 1 & 2 & 3 \\
\hline Of wages and benefits & 31 & 18 & 18 & 20 & 18 & 20 & 20 & 18 & 22 \\
\hline Earnings from livestock & 3 & 0 & 1 & 11 & 0 & 1 & 1 & 1 & 2 \\
\hline Earnings from crops & 2 & 1 & 1 & 3 & 1 & 2 & 0 & 0 & 1 \\
\hline Total household income & 35 & 20 & 21 & 35 & 19 & 23 & 21 & 19 & 25 \\
\hline
\end{tabular}

Note: Zones 13 are in Khorezm Oblast; zones 48 are in the Republic of Karakalpakstan.

Source: Household surveys.

Table A5.2.3 Water supply indicators in project

regions

Indicator

Karakalpakstan Khorezm

Sources of drinking

water (percent)

$\begin{array}{lll}\text { Piped water } & 32 & 46 \\ \text { Hand-dug well } & 32 & 24 \\ \text { Hand pump } & 31 & 39 \\ \begin{array}{l}\text { Natural surface water } \\ \text { or irrigation canal }\end{array} & 27 & 4 \\ \begin{array}{l}\text { Vendor } \\ \begin{array}{l}\text { Daily piped water } \\ \text { availability }\end{array}\end{array} & 2 & 0 \\ \end{array}$


Average number of $\quad 4 \quad 5$

hours

\section{Water quality \\ (percent \\ disadvantaged by the \\ following qualities)}

$\begin{array}{lll}\text { Particles } & 12 & 21 \\ \text { Color } & 4 & 5 \\ \text { Smell } & 3 & 5 \\ \text { Taste } & 22 & 46 \\ \text { Saltiness } & 58 & 78 \\ \text { Bacteria } & 3 & 12\end{array}$

Payments for piped

water (percent)

Individuals who do not $\quad 51 \quad 54$

pay

Individuals who pay $\quad 30 \quad 20$

Neighbors who pay 220

Collective farms who $\quad 9 \quad 23$

pay

Source: Household surveys.

Table A5.2.4 Water supply indicators, by zone

Indicator

Zone 1 Zone 2 Zone 3 Zone 4 Zone 5 Zone 6 Zone 7 Zone 8 Total

Sources of drinking

water (percent)

Piped water

$58 \quad 57$

14

41

14

34

30

56

39

Hand-dug well

$12 \quad 18$

52

48

29

17

33

28

Hand pump

37

29

50

35

55

18

26

11

35

Natural surface water or

2

10

7

6

50

50

30

15

irrigation canal

Vendor

0

0

0

0

0

7

0

0

1

Daily piped water availability 
Social Assessments for Better Development

\begin{tabular}{|c|c|c|c|c|c|c|c|c|c|}
\hline Average number of hours & 3 & 10 & 4 & 3 & 5 & 4 & 4 & 5 & 5 \\
\hline \multicolumn{10}{|l|}{$\begin{array}{l}\text { Water quality (percent } \\
\text { disadvantaged by the } \\
\text { following qualities) }\end{array}$} \\
\hline Particles & 15 & 5 & 42 & 0 & 14 & 13 & 26 & 19 & 17 \\
\hline Color & 4 & 3 & 10 & 5 & 7 & 5 & 0 & 3 & 5 \\
\hline Smell & 6 & 5 & 4 & 3 & 1 & 5 & 4 & 0 & 4 \\
\hline Taste & 48 & 15 & 65 & 4 & 26 & 33 & 27 & 27 & 34 \\
\hline Saltiness & 64 & 88 & 97 & 80 & 58 & 51 & 42 & 30 & 68 \\
\hline Bacteria & 1 & 2 & 38 & 0 & 0 & 9 & 3 & 6 & 8 \\
\hline \multicolumn{10}{|l|}{$\begin{array}{l}\text { Payments for piped } \\
\text { water (percent) }\end{array}$} \\
\hline $\begin{array}{l}\text { Individuals who do not } \\
\text { pay }\end{array}$ & 44 & 39 & 82 & 19 & 97 & 41 & 67 & 44 & 53 \\
\hline Individuals who pay & 21 & 34 & 10 & 56 & 1 & 30 & 20 & 37 & 25 \\
\hline Neighbors who pay & 1 & 0 & 0 & 0 & 0 & 5 & 1 & 0 & 1 \\
\hline Collective farms who pay & 31 & 27 & 7 & 4 & 1 & 18 & 11 & 17 & 16 \\
\hline
\end{tabular}

Note: Zones 13 are in Khorezm Oblast; zones 48 are in the Republic of Karakalpakstan.

Source: Household surveys.

Table A5.2.5 Water supply indicators in urban and rural communities

Indicator

Urban Rural Total

$\begin{array}{llll}\begin{array}{l}\text { Sources of drinking } \\ \text { water (percent) }\end{array} & & & \\ \begin{array}{l}\text { Piped water } \\ \text { Hand-dug well }\end{array} & 7 & 33 & 39 \\ \begin{array}{l}\text { Hand pump } \\ \begin{array}{l}\text { Natural surface water } \\ \text { or irrigation canal }\end{array}\end{array} & 16 & 15 & 15 \\ \begin{array}{l}\text { Vendor } \\ \begin{array}{l}\text { Daily piped water } \\ \text { availability }\end{array}\end{array} & 0 & 1 & 1 \\ \end{array}$




$\begin{array}{llll}\begin{array}{l}\text { Average number of } \\ \text { hours }\end{array} & 6 & 4 & 5\end{array}$

\section{Water quality \\ (percent \\ disadvantaged by the \\ following qualities)}

$\begin{array}{llll}\text { Particles } & 15 & 17 & 17 \\ \text { Color } & 12 & 4 & 5 \\ \text { Smell } & 6 & 4 & 4 \\ \text { Taste } & 33 & 35 & 34 \\ \text { Saltiness } & 51 & 71 & 68 \\ \text { Bacteria } & 8 & 8 & 7\end{array}$

Payments for piped

water (percent)

Individuals who do not $25 \quad 57 \quad 53$

pay

Individuals who pay $\quad 65 \quad 19 \quad 25$

Neighbors who pay $\quad 6 \quad 1$

Collective farms who $2 \quad 18 \quad 16$

pay

Note: Zones 13 are in Khorezm Oblast; zones 48

are in the Republic of Karakalpakstan.

Source: Household surveys.

Table A5.2.6 Sanitation indicators, by zone

Indicator $\quad$ Zone 1 Zone 2 Zone $3 \quad$ Zone $4 \quad$ Zone $5 \quad$ Zone $6 \quad$ Zone $7 \quad \begin{aligned} & \text { Zone } \\ & 8\end{aligned}$

\section{Connection (percent)}

$\begin{array}{lllllllll}\text { Connected to central sewerage } & 1.6 & 4.0 & 2.5 & 2.1 & 0 & 0 & 2.1 & 0\end{array}$

system

With sewer hole or well

$\begin{array}{llll}31.9 & 10.6 & 54.3 & 6.3\end{array}$

$6.3 \quad 0.8$

6.6

0

8.6

Construction of latrine (percent)

$\begin{array}{lllllllll}\text { Concrete } & 22.8 & 21.0 & 2.5 & 0 & 0 & 1.4 & 4.3 & 2.9\end{array}$


Social Assessments for Better Development

\begin{tabular}{|c|c|c|c|c|c|c|c|c|}
\hline Brick & 8.5 & 26.4 & 54.4 & 0 & 0 & 0 & 2.3 & 2.7 \\
\hline Mud or sand & 68.1 & 46.8 & 37.8 & 100 & 100 & 97.2 & 79.9 & 94.4 \\
\hline Other materials & 0.6 & 5.8 & 5.3 & 0 & 0 & 1.4 & 13.5 & 0 \\
\hline \multicolumn{9}{|l|}{ Willingness to pay } \\
\hline $\begin{array}{l}\text { Percent willing to make } \\
\text { improvements to current } \\
\text { latrine }\end{array}$ & 59.3 & 56.8 & 52.1 & 73.5 & 64.1 & 22.2 & 20.2 & 60.9 \\
\hline $\begin{array}{l}\text { Average one-time } \\
\text { improvement expenditure } \\
\text { (sums) }\end{array}$ & 733.0 & 86.0 & 298.0 & 35.0 & 120.0 & 124.0 & 292.0 & 148.0 \\
\hline $\begin{array}{l}\text { Average monthly operations } \\
\text { cost (sums) }\end{array}$ & 10.0 & 10.0 & 9.0 & 15.0 & 9.0 & 8.0 & 6.0 & 41.0 \\
\hline
\end{tabular}

Note: Zones 13 are in Khorezm Oblast; zones 48 are in the Republic of Karakalpakstan.

Source: Household surveys.

Table A5.2.7 Health and hygiene indicators, by zone

Indicator

Zone 1 Zone

Zone 3 Zone 4 Zone 5 Zone 6 Zone 7 Zone

\section{Health (percent, within the past month)}

Families with member who became 23

ill

Families with member who visited 22

a hospital

Families who believe a hospital is 14 too expensive

Families who believe a hospital is 3 too far

$$
22
$$

11

31

28

28

21

\section{Hygiene}

Percent who wash in a shower in $\quad 27$

15

17

15

8

28

28

16

the yard

Percent who wash at the public $\quad 39$

46

64

63

37

46

38

64

bath

Average number of visits to the

3

3

3

2

3

4

3

4 
Social Assessments for Better Development

Average number of times children

34

3

32

5

5

4

are washed per month

Average number of children who 2

3

2

4

4

are taken to the public bath per

month

Note: Zones 13 are in Khorezm Oblast; zones 48 are in the Republic of Karakalpakstan.

Source: Household surveys.

\section{Table A5.2.8 Health and hygiene indicators in project regions}

Indicator

Karakalpakstan

Khorezm

Health (percent, within the past month)

Families with member who became ill 27

Families with member who visited a hospital

Families who believe a hospital is too expensive

Families who believe a hospital is too far

\section{Hygiene}

Percent who wash in a shower in the yard

Percent who wash at the public bath

Average number of visits to the public bath per

month

Average number of times children are washed per 3

month

Average number of children who are taken to the public bath per month

Source: Household surveys.

Table A5.2.9 Health and hygiene indicators in urban versus rural areas

Indicator

Urban

Rural

Total

\section{Health (percent within the past month)}

Families with member who became ill 32

Families with member who visited a

24

21

21

hospital 
Families who believe a hospital is too 17

expensive

Families who believe a hospital is too

0

4

3

far

\section{Hygiene}

Percent who wash in a shower in the $\quad 26$ yard

Percent who wash at the public bath 61

Average number of visits to the public 3

$46 \quad 48$

bath per month

Average number of times children are 4

$3 \quad 3$

washed per month

Average number of children who are 3

32

$2 \quad 2$

taken to the public bath per month

Source: Household surveys.

Table A5.2.10 Consumption choices

(percent)

Type of expenditure

First choice

Second choice

Third choice

\section{If given 500 sums, what would be your top three consumption choices?}

Food products

Install water pipe in yard

4

14

4

Install water pipe in house

1

15

7

Install hand pump in yard

0

3

2

Install gas or buy firewood or coal

1

7

3

Repairs or extensions to house

2

29

21

Purchase better lavatory

Build bathroom or shower

Start a small business

Purchase everyday manufactured goods

Purchase long-term manufactured goods

Purchase animals 
Cover health expenses

Rites and rituals

0

1

Pay off debts

0

1

Do not know

1

3

No answer

0

6

13

Total

100

100

100

\section{If given 2,000 sums, what would be your top three} consumption choices?

Food products

Install water pipe in yard 2

$\begin{array}{lll}81 & 9 & 2\end{array}$

Install water pope in house

Install hand pump in yard

0

15

7

Install gas or buy firewood or coal

Repairs or extensions to house

Purchase better lavatory

0

30

19

Build bathroom or shower

1

3

Start a small business

Purchase everyday manufactured goods

Purchase long-term manufactured goods

Purchase animals

Cover health expenses

Rites and rituals

Pay off debts

0

0

2

Do not know

1

0

0

No answer

0

1

3

Total

100

3

11

100

Source: Household surveys. 
Table A5.2.11 Willingness to pay for water supply, by zone

Zone Expenditure
Willingness to pay for installation and
operation of preferred water supply
system (average expenditure, Uzbeki
sum)

Pipeline in

the house
Pipeline in
the yard
Pipeline in

the street
Hand pump

in the yard
Total

\begin{tabular}{|c|c|c|c|c|c|c|}
\hline \multirow{2}{*}{1} & One-time & 862 & 775 & 450 & 200 & 824 \\
\hline & Monthly & 14 & 21 & 14 & 18 & 16 \\
\hline \multirow[t]{2}{*}{2} & One-time & 115 & 176 & 50 & 300 & 166 \\
\hline & Monthly & 24 & 19 & 5 & 8 & 19 \\
\hline \multirow[t]{2}{*}{3} & One-time & 688 & 776 & & 400 & 758 \\
\hline & Monthly & 19 & 13 & & 10 & 14 \\
\hline \multirow[t]{2}{*}{4} & One-time & & 264 & 133 & & 258 \\
\hline & Monthly & & 14 & 15 & & 14 \\
\hline \multirow[t]{2}{*}{5} & One-time & 518 & 692 & 400 & 50 & 619 \\
\hline & Monthly & 21 & 15 & 18 & 10 & 16 \\
\hline \multirow[t]{2}{*}{6} & One-time & 942 & 1098 & & 35 & 958 \\
\hline & Monthly & 11 & 13 & & 20 & 12 \\
\hline \multirow[t]{2}{*}{7} & One-time & 1145 & 894 & & & 1030 \\
\hline & Monthly & 23 & 14 & & & 19 \\
\hline \multirow[t]{2}{*}{8} & One-time & 718 & 450 & & & 671 \\
\hline & Monthly & 21 & 8 & & & 19 \\
\hline \multicolumn{2}{|c|}{ Total average one-time expenditure } & 830 & 610 & 258 & 190 & 699 \\
\hline & 16 & 16 & 16 & 13 & 14 & 16 \\
\hline
\end{tabular}

Willingness to pay for installation and operation of preferred water supply system (average expenditure, US\$ )

1

One-time

34

31

18

8 


\begin{tabular}{|c|c|c|c|c|c|c|}
\hline & Monthly & 1 & 1 & 1 & 1 & 1 \\
\hline \multirow[t]{2}{*}{2} & One-time & 5 & 7 & 2 & 12 & 7 \\
\hline & Monthly & 1 & 1 & 0 & 0 & 1 \\
\hline \multirow[t]{2}{*}{3} & One-time & 28 & 31 & & 16 & 30 \\
\hline & Monthly & 1 & 1 & & 0 & 1 \\
\hline \multirow[t]{2}{*}{4} & One-time & & 11 & 5 & & 10 \\
\hline & Monthly & & 1 & 1 & & 1 \\
\hline \multirow[t]{2}{*}{5} & One-time & 21 & 28 & 16 & 2 & 25 \\
\hline & Monthly & 1 & 1 & 1 & 0 & 1 \\
\hline \multirow[t]{2}{*}{6} & One-time & 38 & 44 & & 1 & 38 \\
\hline & Monthly & 0 & 1 & & 1 & 0 \\
\hline \multirow[t]{2}{*}{7} & One-time & 46 & 36 & & & 41 \\
\hline & Monthly & 1 & 1 & & & 1 \\
\hline \multirow[t]{2}{*}{8} & One-time & 29 & 18 & & & 27 \\
\hline & Monthly & 1 & 0 & & & 1 \\
\hline \multicolumn{2}{|c|}{ Total average one-time expenditure } & 33 & 24 & 10 & 8 & 28 \\
\hline \multicolumn{2}{|c|}{ Total average monthly expenditure } & 1 & 1 & 1 & 1 & 1 \\
\hline
\end{tabular}

Table A5.2.12 Water system preferences, by zone

\begin{tabular}{|c|c|c|c|c|c|c|c|}
\hline Zone & $\begin{array}{l}\text { Pipeline in } \\
\text { the house }\end{array}$ & $\begin{array}{l}\text { Pipeline } \\
\text { in the } \\
\text { yard }\end{array}$ & $\begin{array}{l}\text { Pipeline in } \\
\text { the street }\end{array}$ & $\begin{array}{l}\text { Hand pump } \\
\text { in the yard }\end{array}$ & $\begin{array}{l}\text { Hand pump } \\
\text { in the street }\end{array}$ & $\begin{array}{l}\text { Other } \\
\text { system }\end{array}$ & $\begin{array}{l}\text { Do not } \\
\text { know }\end{array}$ \\
\hline
\end{tabular}

Which water system would you like to have? (number)

$\begin{array}{lllllllll}1 & 144 & 71 & 2 & 5 & 1 & 14 & 25 & 262 \\ 2 & 20 & 57 & 8 & 4 & 3 & 13 & 19 & 124 \\ 3 & 9 & 74 & 1 & 1 & 0 & 7 & 17 & 109 \\ 4 & 1 & 49 & 8 & 0 & 0 & 0 & 1 & 59 \\ 5 & 40 & 71 & 3 & 2 & 0 & 2 & 0 & 118 \\ 6 & 69 & 50 & 1 & 6 & 0 & 9 & 14 & 149\end{array}$




\begin{tabular}{|c|c|c|c|c|c|c|c|c|}
\hline 7 & 24 & 40 & 0 & 1 & 0 & 3 & 26 & 94 \\
\hline 8 & 23 & 8 & 0 & 0 & 0 & 0 & 5 & 36 \\
\hline Total & 330 & 420 & 23 & 19 & 4 & 48 & 107 & 951 \\
\hline \multicolumn{9}{|c|}{$\begin{array}{l}\text { Which water system would you like to } \\
\text { have? (percent) }\end{array}$} \\
\hline 1 & 55 & 27 & 0 & 2 & 0 & 5 & 10 & 262 \\
\hline 2 & 16 & 46 & 6 & 3 & 2 & 10 & 15 & 124 \\
\hline 3 & 8 & 68 & 0 & 0 & 0 & 6 & 16 & 109 \\
\hline 4 & 2 & 83 & 14 & 0 & 0 & 0 & 2 & 59 \\
\hline 5 & 34 & 60 & 3 & 2 & 0 & 2 & 0 & 118 \\
\hline 6 & 46 & 34 & 0 & 4 & 0 & 6 & 9 & 149 \\
\hline 7 & 26 & 43 & 0 & 1 & 0 & 3 & 28 & 94 \\
\hline 8 & 64 & 22 & 0 & 0 & 0 & 0 & 14 & 36 \\
\hline Total & 35 & 44 & 2 & 2 & 0 & 5 & 11 & 951 \\
\hline
\end{tabular}

Source: Household surveys.

\section{Notes}

The task manager of the needs assessment and main author of this chapter is Ayse Kudat. The field work for the assessment was carried out by Arustan Zholdasov, with support from Alisher Ilkhamov, both from the Expert Sociological Center. The Network of Social Scientists from the Aral Sea Region-consisting of Ibragim Iskenderov of the Uzbekistan Academy of Sciences, Sabir Kamalov of the Karakalpakstan Branch of the Uzbekistan Academy of Sciences, Alisher Ilkhamov, Arustan Zholdasov, and Yusuf Kamalov of the Union of Aral and Amudarya Protection, a nongovernmental organization-provided significant inputs. Shavkat Mukhamedov of the Expert Sociological Center coordinated the statistical sampling and performed the initial data analysis. Nezahat Ozmen participated in the field work, performed the final data analysis, and created the graphics. Janis Bernstein prepared the final report.

Roger Batstone, task manager of the proposed Uzbekistan Water Supply and Sanitation Project, supported the social assessment throughout the project preparation process. Financial assistance for carrying out the assessment was provided by the Fund for Innovative Approaches in Human and Social Development and the Dutch Consultant Trust Fund.

1. It is not dogma that projects should only be carried out where there is a community-felt need. Nor can the design and implementation of development projects always or fully respond to the expressed needs of the people they are supposed to benefit (Hyman, Levine, and Wright 1967). 


\section{Social Assessments for Better Development}

2. However, the populist contention that the people affected by a project always know better than technical personnel and have sufficient skills is as erroneous as the paternalistic fallacy that a bureaucracy alone can initiate or guide all that is needed for development (Cernea 1992).

3. In the United States initial interest in needs assessment was generated by federal and state laws such as the Elementary and Secondary Education Act and the Community Mental Health Act, both of which tied the disbursement of federal funds to the completion of needs assessments (Benjamin 1989).

4. Needs in organizational usage are usually based on the following criteria: discrepancy, measured by the difference between the ideal or expected level of performance and the actual level; democratic, reflecting the perception of the majority of people; diagnostic, defined through research and causal analysis; and analytic, discovered through intuition, insight, and expert observation (Kaufman 1990).

5. The interviews were conducted by teams of interviewers, who received specialized training in Nukus and Urgench, and their supervisors. To facilitate the field work throughout the study period, each group of interviewers (three to four people) and a supervisor were provided with a car. Each group was responsible for interviewing fifty to eighty people. To establish positive contacts with the respondents, each survey team brought gifts (candy, cookies) on each visit to every household. Although the respondents were receptive and highly cooperative in answering the survey questions, the field visits occasionally were hampered by adverse weather conditions and icy roads.

6. These conditions are somewhat different from those outlined in the introduction because urban areas with more than 20,000 people were excluded from the sample.

7. Most families (94 percent) do not want to relocate. Among those that do want to relocate, the largest percentage (31 percent) cited environmental problems as the reason. Other reasons include availability of job opportunities (21 percent), family problems (18 percent), need to expand living space or housing (13 percent), and purchase of land or a house (10 percent).

8. An ongoing NGO effort sponsored by the Uzbekistan Water Supply and Sanitation Project is measuring the quality of piped water.

9. A Japanese team is conducting a study on water metering. The study team, together with Vodokanal officials in Karakalpakstan and Khorezm, surveyed the area to select households for installing the water meters (brought from Japan). Sample households were chosen to reflect a balanced representation of different consumers classified according to the availability of sewerage, toilets, baths, and hot water. Vodokanal staff in various areas will record the meter readings at specified intervals.

10. Most of these households have outdoor showers or baths because the houses are made primarily out of clay, and many feel that water lost from the water supply system might cause extensive damage inside the homes. 


\section{Social Assessments for Better Development}

\section{References}

Benjamin, Steve. 1989. A Closer Look at Needs Analysis and Needs Assessment: Whatever Happened to the Systems Approach? Performance and Instruction 28(9):1216.

Brinkerhoff, Robert 0. 1986. Expanding Needs Analysis. Training and Development Journal 40(2):6465.

Cernea, Michael M. 1991. Knowledge from Social Science for Development Policies and Projects. In Michael M. Cernea, ed., Putting People First: Sociological Variables in Rural Development, 2nd ed. New York: Oxford University Press.

1992. The Building Blocks of Participation: Testing Bottom-Up Planning. World Bank Discussion Paper 166. Washington, D.C.

Davis, Gloria. 1994. Methods and Tools for Social Assessment/Social Impact Assessment. World Bank, Environment Department, Social Policy and Resettlement Division, Washington, D.C.

Giddens, Anthony. 1990. The Consequences of Modernity. Stanford, Calif.: Stanford University Press.

Hentschel, Jeske. 1994. The Costs of Participation to the World Bank: Emerging Evidence. Human Resources Development and Operations Policy Working Paper 31. World Bank, Washington, D.C.

Hyman, Herbert, G. Levine, and C. Wright. 1967. Inducing Social Change in Developing Communities. Geneva, Switzerland: United Nations Research Institute for Social Development.

Kaufman, Roger. 1990. A Needs Assessment Primer. In Edith L. Allen, ed., Needs Assessment Instruments. Washington, D.C.: American Society for Training and Development.

Kaufman, Roger, and F. W. English. 1979. Needs Assessment: Concept and Application. Educational Technology, Englewood Cliffs, N.J.

Miner, Horace. 1960. Culture Change under Pressure. Human Organization 19(3):164-67.

Owen, D. 1994. A Review of Techniques for Systematic Client Consultation. World Bank, Africa Regional Office, Southern Africa Department, Washington, D.C.

Salmen, Lawrence. 1987. Listen to People: Participant-Observer Evaluation of Development Projects. New York: Oxford University Press.

Tollison, Peggy. 1988. Can Participation Improve Needs Analysis? Journal for Quality and Participation 11(4):2627.

Ulshak, Francis, L. 1983. Human Resource Development:

The Theory and Practice of Needs Assessment. Reston, Va.: Reston Publishing Company.

Uphoff, Norman. 1991. Fitting Projects to People. In Michael M. Cernea, ed., Putting People First: Sociological Variables in Rural Development, 2nd ed. New York: Oxford University Press. 


\title{
6- \\ Improving Lives through Kazakstan's Water, Sanitation, and Health Project
}

\author{
Stan Peabody, Janis Bernstein, Leonid Gurevich, Irina Malkova, S. I. Ospanov, Rita Cestti, and Ayse Kudat
}

The Republic of Kazakstan is preparing a water supply, sanitation, and health project to alleviate the harsh living conditions resulting from the ecological crisis in the Aral Sea Basin. $*_{\text {T }}$ The project, as originally conceived, focuses on Aralsk and Kazalinsk, the two districts of the country most affected by the Aral Sea crisis. These two districts are isolated from the rest of the country and are the most economically depressed and socially vulnerable areas in Kazakstan. Because of the extreme poverty and lack of employment opportunities in these areas, many of the districts' inhabitants—-particularly the more skilled—have either already moved or are planning to do so.

\section{Why a Social Assessment?}

Because water supply, sanitation, and health systems must accommodate the needs of the population they are designed to serve, a social assessment was carried out to ensure that the proposed Kazakstan Water Supply, Sanitation, and Health Project responds to the needs of its intended beneficiaries, particularly the poor. This report presents the findings of the social assessment and discusses their implications for the design and implementation of the project. This section provides a brief background on the origin of the project and the proposed project areas. Subsequent sections present the objectives and methodology for carrying out the social assessment, the key findings of the assessment, and the implications of these findings for project design and implementation.

\section{Aral Sea Crisis}

The Aral Sea Basin covers 690,000 square kilometers, with borders on Kazakstan, the Kyrgyz Republic, Tajikistan, Turkmenistan, and Uzbekistan. The Aral Sea lies between Kazakstan and Uzbekistan in a vast depression in the Kyzyl Kum and Kara Kum Deserts. In 1960 the sea was the fourth largest inland lake in the world. Since then, however, the sea has steadily receded as a result of a substantial reduction in the flows of the Amu Darya and Syr Darya Rivers, its two tributaries, caused by the increasingly large quantities of water diverted for irrigation.

Today the Aral Sea Basin is about half its original size and is one of the most serious environmental crises in the world. The many environmental and economic problems associated with the shrinking of the Aral Sea include a loss of many potable water sources and the pollution of others as well as negative impacts on health and productivity. When Kazakstan became independent, it was severely affected by the environmental problems of the region, particularly the water supply crisis.

To respond to these problems, Kazakstan, along with the four other Aral Sea Basin countries, requested assistance from the international community. The five countries subsequently worked in cooperation with the United Nations Development Programme (UNDP), United Nations Environment Programme (UNEP), and the World Bank to develop a program to address the crisis. The Aral Sea Program now includes actions to mitigate the impacts of environmental degradation, develop sustainable water and

land management strategies, and equip regional institutions with the capacity to implement the program.

\section{Proposed Project Areas}

The Aralsk and Kazalinsk districts (rayons) located within the Kzyl-Orda Region (oblast), are the poorest and most economically weak and socially insecure territories in Kazakstan. Aralsk, which encompasses 56,300 square kilometers, is situated in the northwest part of the Kzyl-Orda Region, bordering the Aral Sea. Kazalinsk, which 


\section{Social Assessments for Better Development}

encompasses 39,600 square kilometers, is situated in the western part of the region. The combined population of the two districts is about 150,000, or 1 percent of the country's population. The region ranks lowest in per capita income, with industrial production representing only 1.1 percent of the country's total production. The principal industry in both districts is agriculture, specifically the breeding of sheep, horses, camel, and astrakans. State rice farms are also located in Kazalinsk. In both districts, however, the Aral Sea disaster has intensified social and economic problems.

Aralsk was originally settled near an old fishing village during the construction of the Orenberg-Tashkent Railway (1903-05), a principal trunkline to the East. It later became the administrative center of the district and eventually flourished as a local industrial center and minor tourist attraction. Kazalinsk, situated to the south of Aralsk, was originally settled as a fort town near the Syr Darya River. It was superseded by the creation of Novo-Kazalinsk during the construction of the railway. Novo-Kazalinsk eventually became a regional administrative center as well, and is now the largest settlement in the district.

Since independence the economies of both districts have been in severe turmoil. Many of the problems are similar to those faced in other parts of Kazakstan: the collapse of previous trading structures and sources of raw materials and inputs; the absence of alternative markets; and the substantial reduction of budgetary allocations from the center and regional governments. The combined effect has been an increase in unemployment, delayed or unpaid salaries, and disguised unemployment (when employees are put on indeterminate, unpaid leave). These problems have been exacerbated by the great distance of the two districts from potential markets or sources of materials, as well as by their dependence on three local industries: fish processing, wood working, and ship repair. Of the three, only the ship repair factory has adapted to the new circumstances; it now repairs railroad cars. Moreover, the steadily worsening ecological situation (declining water quality, increased water scarcity, and salt-infused winds, especially in Aralsk) has taken its toll on the population, prompting many to migrate. Although some migrants return - primarily because of the lack of employment opportunities and access to housing elsewhere — there continues to be a net outflow of people, especially skilled labor.

\section{Social Assessment Objectives and Methodology}

The importance of considering the perceived needs of the populations directly or indirectly affected by project interventions is recognized as a general strategy in social development. The basic premise of this approach is that interventions should satisfy the needs and priorities of the populations they are intended to benefit in ways that are culturally acceptable. Putting people first when investing in development, therefore, means perceiving people as intended beneficiaries rather than as targets of project impacts, and tailoring a project's design and implementation to their needs and capabilities. 1 To determine the perceived needs and other social aspects of the water supply and sanitation situation in Aralsk and Kazalinsk, the World Bank, working with local groups, carried out a social assessment for the proposed Kazakstan Water Supply, Sanitation, and Health Project.

\section{Objectives}

The social assessment in Aralsk and Kazalinsk was undertaken to determine the socioeconomic effects and health implications of current water supply and sanitation systems. Taking into account the characteristics of the area (that is, outmigration of skilled labor, isolation, and widespread poverty), the principal objectives of

the social assessment were to determine the actual extent of the outmigration from Aralsk and Kazalinsk and anticipated trends; identify prospects (including improvements in water supply or sanitation) that would encourage people to remain in the area; determine the extent to which the population considers improved water supply to be a major need; and assess people's willingness to pay for improvements. 


\section{Social Assessments for Better Development}

\section{Activities}

To achieve these objectives, the social assessment consisted of several activities that involved substantial participation by the intended beneficiaries as well as by government agencies, local research institutes, and private firms. These activities included:

Demographic and ethnographic studies. Various studies of the area were conducted to determine its demographic profile, the physical hardships of local residents, and whether the area was in a permanent decline. These studies were followed by ethnographic studies of Aralsk and Kazalinsk that focused on the response of people to limited, irregular, and poor-quality water supplies. These studies were complemented by a detailed socioeconomic inventory of a number of communities that covered major institutions, community infrastructure, population and employment, and the impact of the water system and tariffs on behavior.

Household survey. A socioeconomic survey of 500 households focused on income, employment, household assets, migration patterns, access to water and sanitation, perceptions of water availability and quality, current water costs, water system preferences, ability and willingness to pay for improved water supplies, and assessments of changes over the past decade. The survey also was designed to define opportunities for community participation in water system improvements and in solving other problems.

Complementary studies. In addition to the household survey, the social assessment relied on an appraisal of the economic prospects of the two districts, supplemented by in-depth interviews with managers of twenty-three enterprises and state or collective farms concentrating on their economic status, labor structure, water use, constraints, and opportunities. A rapid assessment of water delivery institutions in the area was also carried out.

Focus group discussions. Finally, a series of focus group discussions was conducted at seven sites in the project area. These discussions centered on perceptions of the links between improved water supplies and economic opportunities, participation, health, and migration. They were designed to provide additional input from key stakeholders to interpret the results of the household surveys and to generate information that could not be obtained in the survey. Throughout this chapter, comments from the participants at these meetings illustrate some of the key findings of the social assessment.

\section{Subsequent Steps.}

On November 28, 1995, the Committee for Water Resources, the World Bank, the Kzyl-Orda Pedagogical Institute, and the Giller Institute sponsored a stakeholder workshop to discuss the findings of the social assessment and their implications for project design and implementation. The workshop was attended by more than sixty people representing a wide spectrum of stakeholders, including community, district, regional and central administrations; water agencies; nongovernmental organizations (NGOs); Kzyl-Orda University, the Kazak Academy of Sciences; the Committee for Water Resources; the International Fund for the Aral Sea; the UNDP, the U.S. Agency for International Development; and the World Bank.

Workshop participants expressed a keen interest in the proposed project and a strong desire to ensure rapid implementation and broad impact. They endorsed the proposed project approach emphasizing certain goals and means: water investments that maximize local health, income, and employment impact; active community participation and local responsibility for operations and maintenance followup; and income-generating initiatives (especially those that also address priority ecological problems).

Because of the active participation of the regional and district water authorities, workshop participants were able to identify priority water investments. Despite strong interest in income-generating initiatives, however, few specific recommendations emerged from workshop discussions. The project preparation team thus plans to 


\section{Social Assessments for Better Development}

conduct additional workshops in Aralsk and Novo-Kazalinsk to engage the participation of a broader range of community leaders, residents, and local NGOs. The workshops will discuss the program of income-generating ideas gathered and elaborated by United Nations volunteers and use it to develop a program approach for the project, as well as to identify priority pilot activities that can be started in the near term.

\section{Key Findings}

The social assessment covered a wide range of issues and generated data that have important implications for the design and implementation of the water, sanitation, and health project. This section describes the findings in three parts. The first part summarizes the general socioeconomic conditions in the project area, including demographic conditions, employment, income, nutrition, housing and related assets, and enterprises. The second part presents the findings related to water supply, sanitation, hygiene, and health as they relate to different stakeholder groups, particularly households and enterprises, and discusses the status of water supply and sanitation institutions. The third part presents the findings on priority needs and willingness to pay.

\section{Socioeconomic Conditions}

The socioeconomic conditions of the proposed project area are generally very poor. Throughout the area there is widespread poverty and high rates of unemployment. People working at the state enterprises have not received salaries for several years. The desire to leave is strong because many people perceive their condition to be worsening. To further complicate their situation, households must deal with severe natural conditions imposed by the ecological crisis.

Population. In January 1995 the total population of the two proposed project districts was 152,350 people. Aralsk had 78,450 inhabitants, 62 percent of whom were urban and 38 percent of whom were rural (figure 6.1). Although the total population of the Aralsk district increased by 7 percent between 1991 and 1994, the population in Aralsk City increased by only 2 percent, from 34,890 to 35,510. The main increase took place in rural areas (about 15 percent) and the two working settlements of Aralsulfat and Saksaul (6 percent and 8 percent). In 1992 about 3,160 people migrated into the district. During the past two years, however, more people have been leaving than coming in. In 1994 the ratio of people migrating in to those leaving the district was 1:2.4.

In January 1995 Kazalinsk had 74,120 inhabitants, 58 percent of whom were urban and 42 percent of whom were rural (see figure 6.1). Although the total population of the Kazalinsk district increased 0.3 percent between 1989 and 1995, the urban population increased 2.2 percent, from 42,040 to 42,960. Most of the urban growth occurred in Novo-Kazalinsk settlement. In the past several years, however, the population in Kazalinsk City has declined, from 8,140 inhabitants in 1992 to 7,915 in 1995. There has been almost no growth in the rural areas (31,110 in 1989 compared with 31,160 in 1994). The population of Kzyl-Orda Region has declined since 1991, with a slight increase in 1994 over 1993 (figure 6.2).

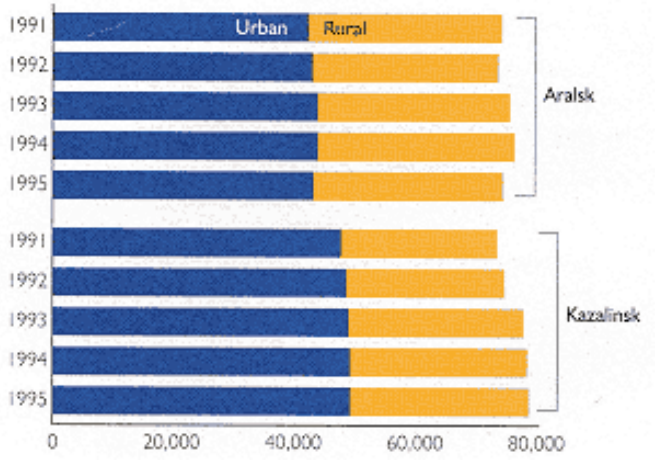


Figure 6.1

Urban and rural population, Aralsk

and Kazalinsk districts, 1991-95

Source: District Statistical Offices.

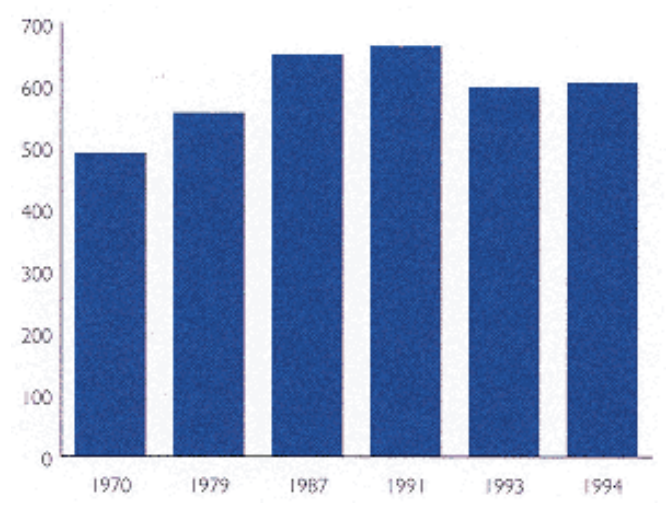

Figure

6.2 Population, Kzyl-Orda Region, 1970-94

Source: Region statistical data.

At the end of 1994 there were 14,800 households in the Kazalinsk district and 13,680 households in the Aralsk district. Household size averages 5.0 people in Kazalinsk and 5.7 people in Aralsk. During 1989-95 household size fell in both districts (except in the rural households of Kazalinsk, where household size increased from 5.9 to 6.0 people; figure 6.3). Households in the survey sample average 6.2 people per household (5.8 in district centers, 5.7 in working settlements, and 6.9 in rural settlements). Although this is larger than the average for the district, households in the Kazakstan sample are smaller than those reported in similar surveys in the Tashauz region of Turkmenistan (7.0 total; 6.9 in urban areas and 7.1 in rural settlements) and Khorezm (7.1 total; 5.6 in urban settlements and 7.2 in rural

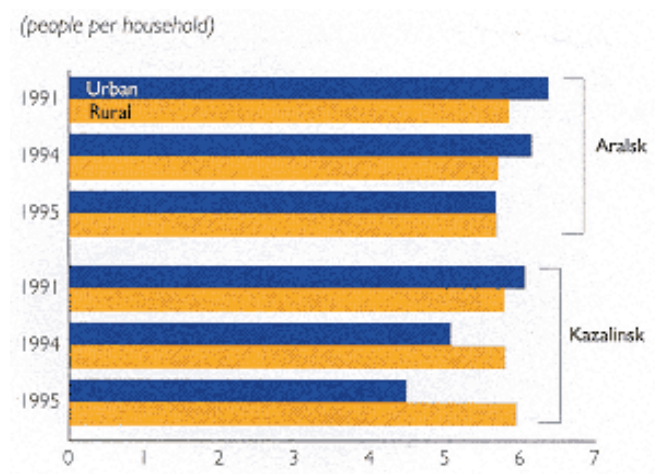

Figure 6.3

Household size, Aralsk and Kazalinsk

districts, 1991-95

Source: District Statistical Offices.

settlements) and Karakalpakstan (7.6 total; 7.0 in urban settlements and 7.7 in rural settlements) in Uzbekistan. Households in the Kazalinsk and Aralsk surveys had an average of 1.2 children less than 6 years old and 1.4 children from 615 years old, 0.9 pensioners, and 1.2 unemployed. 


\section{Social Assessments for Better Development}

Kazalinsk and Aralsk are ethnically homogeneous, especially because of the exodus of many Russians following independence. In 1994 the population in both districts was 97.8 percent Kazak and 1.5 percent Russian. In 1989 Aralsk was 92.6 percent Kazak and 5.4 percent Russian; Kazalinsk was 96.2 percent Kazak and 2.7 percent Russian. The exodus of non-Kazak also changed the gender ratio and age distribution in Kazalinsk, but not Aralsk. The population in Aralsk remained 50.2 percent female and 49.7 percent male between 1989 and 1995, but the population of Kazalinsk went from being 49.5 percent female and 50.5 percent male in 1989 to 55 percent female and 45 percent male in 1995.

According to local data, the population profile of Kazalinsk has changed significantly since independence. In Aralsk, by contrast, the profile has remained relatively stable. For example, the age distribution of the population has changed very little in Aralsk; the only noticeable change between 1989 and 1995 was an increase in the 1429 age group from 28 percent to 29 percent (and a corresponding drop from 40 percent to 39 percent in the under-14 age group). In Kazalinsk, however, there has been a drop in every age category except among those 60 and older, which has increased significantly (figure 6.4). This outcome

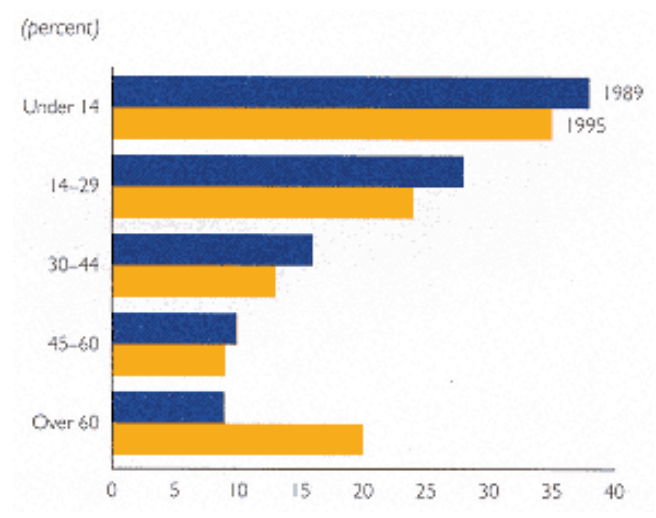

Figure 6.4

Age distribution, Kazalinsk district

Source: District Statistical Office.

reflects the exodus of working-age people and a concomitant decline in the number of births.

Migration. Migration has had a considerable impact on the population of the two districts. In 1970, 1979, 1991, 1992, and 1993 (the years for which there are comparable data) Kazalinsk had a net population loss due to migration (except in 1992). Aralsk lost population in three of those five years (figure 6.5). Of the respondents to the household surveys, 37 percent indicated that they would like to relocate. In Kazalinsk district the percentage was 46 percent; in Aralsk, 29 percent. Nonetheless, the number of respondents in both districts that is actually ready to move is much smaller (11 percent of the total, or 30 percent of those wanting to move). The percentages are very high compared with other countries in the region. In Uzbekistan, for example, only 4 percent of the population in the proposed water supply and sanitation project area indicated a desire to move.

Among the respondents wanting to move, 84 percent cited the ecological situation in the Aral Sea zone as the main factor influencing this desire. This situation refers to the overall economic and physical deterioration in the area caused by the shrinking of the Aral Sea. Other reasons relate to job opportunities (18 percent) and family relations (10 percent). The household survey found that the main reasons preventing departure are lack of money for moving (83 percent) and lack of transport (11 


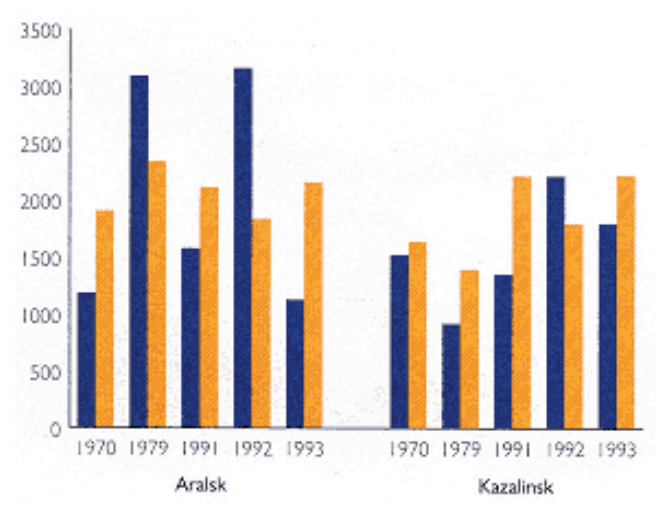

Figure 6.5

Population movement, Aralsk and Kazalinsk

districts, 1970-93

Source: District Statistical Offices.

percent; figure 6.6). People said that they would be less inclined to move if wages were higher (62 percent), the environment were bet-

If we are given money and help to move, then for the sake of our children we will agree to leave for a better place.

If I get money I would go to another place. We have dirty air. I do not believe that we will ever have clear air and Aral Sea restored.

We should move to another place. The conditions here do not allow good health and a normal life.

-Focus group discussions

ter (40 percent), employment opportunities were greater (35 percent), living conditions were improved (34 percent), children had greater opportunities ( 8 percent), and water were in greater supply (8 percent).

Those wanting to relocate can be distinguished from the rest in several ways. First, they are among the best educated: 64 percent of those who completed higher education and 67 percent of those who started higher education said they want to move, but no more than 20 percent of those in the lowest education categories (primary or incomplete secondary) expressed this desire. If the sample is divided into three income groups, 50 percent of those in the highest income group want to emigrate, compared with 30 percent of the people in the lowest income group. Fifty-one percent of the respondents in NovoKazalinsk and 48 percent of those in Kazalinsk want to emigrate, but only 30 percent of the Aralsk respondents want to move. Overall, 44

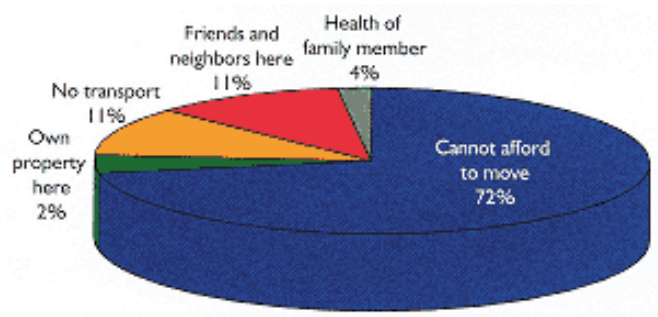

Figure 6.6

What keeps people from moving?

Source: Household surveys. 


\section{Social Assessments for Better Development}

percent of the respondents in working settlements, 33 percent of those in the district center,

Staff reductions have influenced everyone. Most regrettable are the young specialists who came, did not find good conditions, and left.

—Focus group discussions

and 34 percent of those in rural settlements want to emigrate. The highest incidence of desire to emigrate is in four rural settlements: 75 percent of the respondents in Abay, Berlik, Karakum, and Tokabay said they want to move. These settlements are among the most remote and have the worst economic position. In short, emigration is taking away the people who could likely play the most important roles in rebuilding the local economy.

Employment. Among the households surveyed in the two project districts, most (71 percent) reported that one or two family members were employed. In Aralsk, however, a significantly smaller share of households had two workers (27 percent compared with 38 percent in Kazalinsk). There was also a higher percentage of families without any employed members ( 22 percent compared with 15 percent in Kazalinsk). Most employees are qualified workers and specialists. Among the households surveyed, only 23 percent of family members are employed by the state farms.

According to the survey, 57 percent of the families interviewed have one or two unemployed family members, and 11 percent have three or more. The average number of unemployed family members is $1.2 ; 1.4$ in Aralsk and 1.0 in Kazalinsk. In-depth interviews with the managers of industrial and agricultural enterprises in the region found that this high rate of unemployment can be attributed to reductions in overall production (figure 6.7). For example, a shoe factory in Novo-Kazalinsk has almost ceased production. In the agricultural sector, pasture land and crop areas are being reduced. This situation, typical for the republic as a whole, is intensified by conditions in the project area, particularly the shortage of water.

Employees do not get paid for months. At farms and many enterprises women are the first to be laid off.

Since 1990 the total number of employees in the two districts has fallen 27 percent. In Aralsk District the number of workers fell 30 percent and in Kazalinsk, 24 percent. In Aralsk the number of male workers fell 29 percent; in Kazalinsk the drop was 25 percent. The number of female workers fell a total of 30 percent; in Aralsk the drop was 37 percent and in Kazalinsk, 23 percent. The number of skilled workers also fell during this time, 22 percent in Aralsk and 30 percent in Kazalinsk. Unemployed workers usually do not get any benefits; only five respondents said that their unemployed family members receive 500 tenge (\$7.94) a month. One respondent said that their unemployed family members receive up to 1,000 tenge a month, and one respondent said that the amount was more than 1,000 tenge. In addition to the officially unemployed, a large cadre of people is on unpaid leave from enterprises. The actual number could not be assessed accurately through the social assessment.

Income. In May 1995 the average monthly wage in Kazakstan was estimated to be 4,612 tenge (\$73.20). In Kzyl Orda the average monthly wage was 3,595 tenge (\$57.06). The household survey reported average wages for the principal employees of 1,844 tenge (\$29.26); 


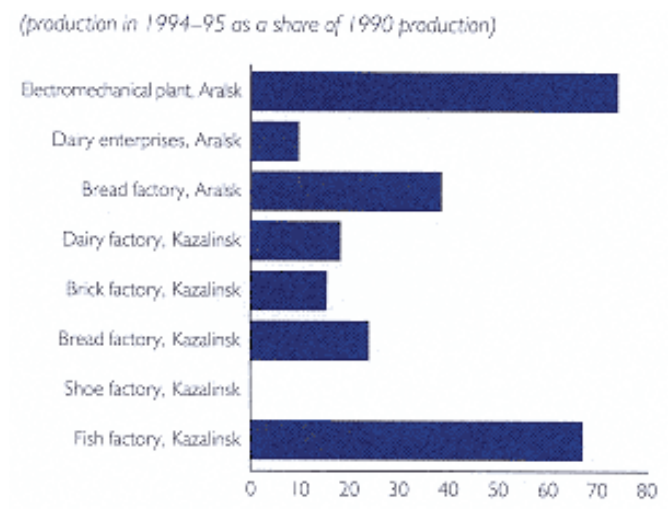

Figure 6.7

Decline in nonagricultural output, Aralsk and Kazalinsk

districts, 1990/1994-95

Note: City-based enterprises for which data

were provided.

Source: Household surveys.

1,961 tenge (\$31.13) in Aralsk and 1,737 tenge (\$27.57) in Kazalinsk. Incomes in the project area are dramatically lower than the average for the country because of the ecological disaster. These figures are deceptive, however, because few people actually receive their wages. In 1995, 48 percent of the sample received wages; 63 percent of the respondents living in district centers received wages, 56 percent in working settlements, and 32 percent in rural areas. Increasingly, employees are paid in kind; that is, either in the products produced by their firm or in foodstuffs that their managers obtain through barter. In most cases people living on farms receive in-kind payments.

Attempts to obtain detailed income data through the household survey were only partially successful. When asked to estimate their annual income, respondents reported an average family income of 12,722 tenge (\$211), with the highest incomes reported in district centers and the lowest ones in rural areas (figure 6.8). Taking into account all income sources, including sales of animals and crops, respondents reported annual incomes of 17,585 tenge (\$279), with the highest incomes reported in rural settlements and the lowest in working settlements. Comparing the two sets of figures reveals a considerably higher dependency on nonsalary sources of income in rural areas. Total income from all sources appears to be highest in the rural areas, net rural incomes would be lower if transport costs were factored in. Finally, all

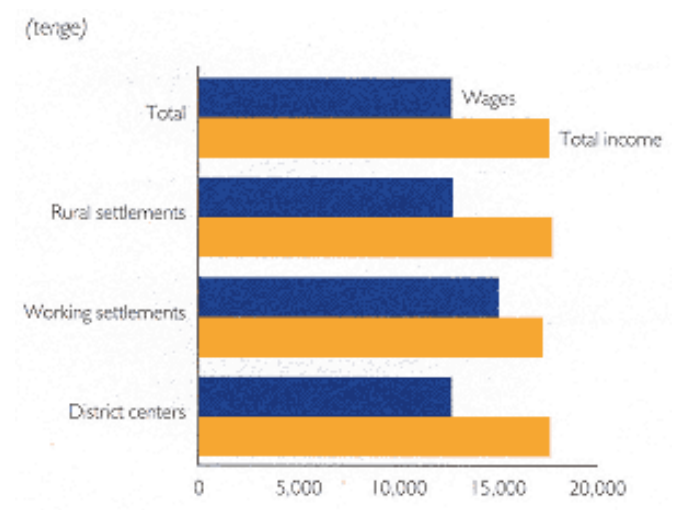

Figure 6.8

Self-reported annual household income, by 


\section{Social Assessments for Better Development}

settlement type

Source: Household surveys.

income levels would be considerably lower if calculations were based on actual salary received.

In addition to estimating their total incomes, respondents provided detailed information on their income from each source: wages, pensions, farm profits, sale of agricultural production, and animal sales (figure 6.9). Although the data yielded total income levels that are unrealistic in aggregate, the relative contribution to household income from different sources is considered reliable as an overall indicator. According to these data, wages account for 48 percent of the average total household income. In Aralsk wages account for 52 percent and in Kazalinsk, 44 percent. Pensions account for 39 percent of household income, and farm profits, the third largest category, account for 9 percent of total household income.

In addition to traditional sources of income, new, informal sources are emerging. For example, a prominent source of income, whose extent is hard to determine, is petty commerce based on shopping tours to Almaty, Turkestan, and elsewhere. People who engage in this activity amass capital, travel to large cities, and transport goods back home to sell door-to-door or in the market. Most people buy clothes and other items through this informal commercial network. The barter and one-time sale of family assets provide another source of cash or in-kind income to much of the population, making it impossible to assess income levels with certainty.

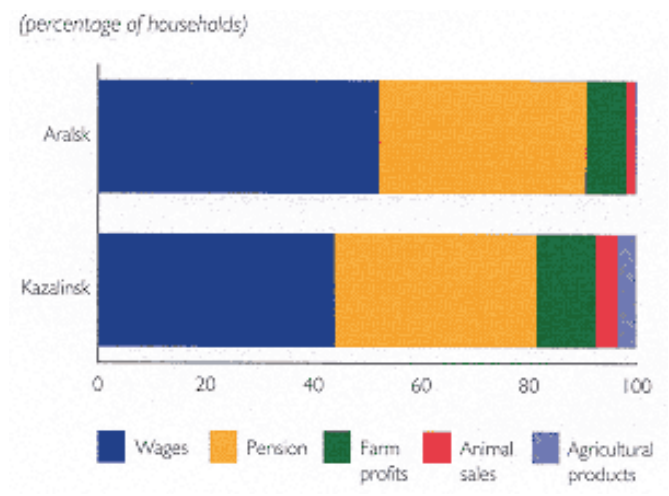

Figure 6.9

Self-reported estimated income sources, Aralsk

and Kazalinsk districts

Source: Household surveys.

The population perceives economic conditions to be extremely difficult and uncertain. When respondents were asked to compare their economic status with others in their communities, 65 percent said their incomes were below average, 29 percent reported average incomes, and 2 percent reported higher than average incomes.

These perceptions are supported by estimates of the amount families spend on food. On average, respondents indicated that they spend over three-fourths of their family income on food, much higher than the Kazakstan average of 47 percent. The average varied from 87 percent for people living in working settlements to 90 percent for district centers, to 93 percent for rural settlements. Of these, the rural populations are the most likely to receive in-kind food payments in lieu of salary; thus the effective share of income spent on food is likely to be even higher than indicated.

Nutrition. Inadequate nutrition is a major problem. According to the households surveyed, poor nutrition is caused by high prices for food ( 94 percent), lack of the necessary products for trade ( 25 percent), and the poor quality of 


\section{Social Assessments for Better Development}

products (21 percent). Most households ( 88 percent) buy food in the market and in state shops (4 percent). Traditionally, meat and dairy products were the staples of the Kazak diet. At the time of the survey, however, just over half of the families surveyed ate meat regularly. The most commonly available products are bread and tea.

The local population provides itself with milk and eggs from the cows and poultry in their community. The correlation between having cows and having meat, however, is not so direct because it depends on the seasonal slaughtering of cattle and their distribution among relatives. Vegetables traditionally do not play a big role in the Kazak diet; potatoes are the most commonly consumed vegetable. In earlier times home gardening was common, even in urban areas, using shallow groundwater sources. Now that groundwater salinity levels are high, gardening has almost been abandoned in Kazalinsk, and production has declined in areas where people continue to garden. Although fishing and fish breeding have traditionally been widely practiced in Kazakstan, fish products are not an essential component of local residents' diets. At the time of the interview only 6 percent of families had fish in their refrigerators. This pattern of consumption means that the population might be getting insufficient amounts of protein, carbohydrates, and vitamins. Flour products account for the main part of the population's diet.

Housing and related assets. Most residents (92 percent) in both districts live in single-family houses, with an average of 4.9 rooms per house. Only 8 percent live in apartment buildings. Most dwellings (93 percent) are privately owned by the residents. According to the survey, these dwellings are well served by electricity, lavatories in the yard, radio, gas tanks, electrical appliances and other assets (figure 6.10). As discussed in the next section, however, they are not well served by water and sanitation facilities.

The average area of a home garden attached to a house is 165.6 square meters, although 17 percent of the respondents have no such plot. Only 15 percent of the respondents own land, the average size of which is 0.46 hectares. Two percent of the respondents rent the plots they occupy. The average size of a rented plot is also 0.46 hectares. The rental charge is paid partially with crops; only one respondent said that he paid cash. These payments usually go to the

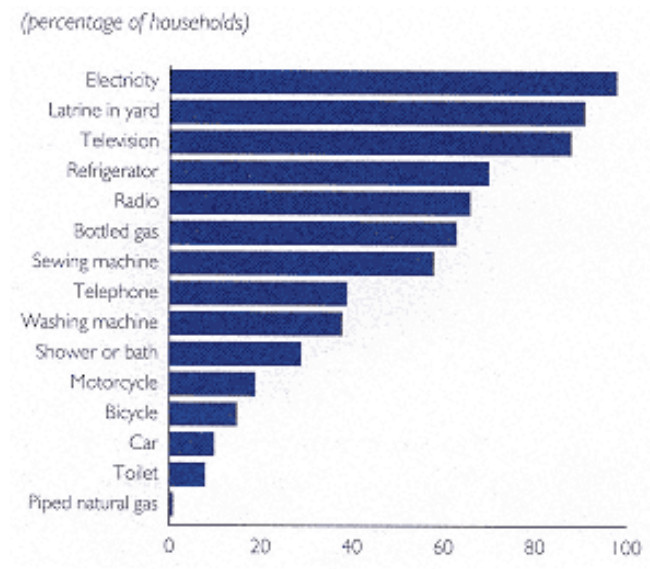

Figure 6.10

Household assets

Source: Household surveys.

local administration. It is up to the leaseholder to decide what to cultivate on the rented land. Generally, however, the plot attached to a house is used to cultivate vegetables (for example, tomatoes, potatoes, carrots), and the crops are usually consumed by household members ( 78 percent of those who cultivate vegetables near the house do not sell them). 
Rented land is used to cultivate potatoes (an average of 412 kilograms per family), wheat (183 kilograms), vegetables (72 kilograms), and rice (69 kilograms). Such low productivity in home agriculture can be explained by several factors. First, unlike cattle breeding, garden agriculture is not a traditional way of life for the local population. Second, there is a shortage of water for irrigation, especially in Aralsk. In fact, families cultivate plants on the plot attached to their house only if they have a supply of water in the yard or can obtain water from irrigation channels. Third, in Kazalinsk production has declined as a result of saline groundwater.

\section{Table 6.1 Livestock ownership}

$\begin{array}{lll}\text { Animal } & \begin{array}{l}\text { Proportion of } \\ \text { families who } \\ \text { own (percent) }\end{array} & \begin{array}{l}\text { Average } \\ \text { number in } \\ \text { families } \\ \text { that own } \\ \text { this } \\ \text { species }\end{array} \\ \text { Cows } & 57 & 1.8 \\ \text { Sheep } & 41 & 5.3 \\ \text { Camels } & 12 & 1.6 \\ \text { Horses } & 10 & 1.7 \\ \text { Poultry } & 19 & 6.3\end{array}$

Source: Household surveys.
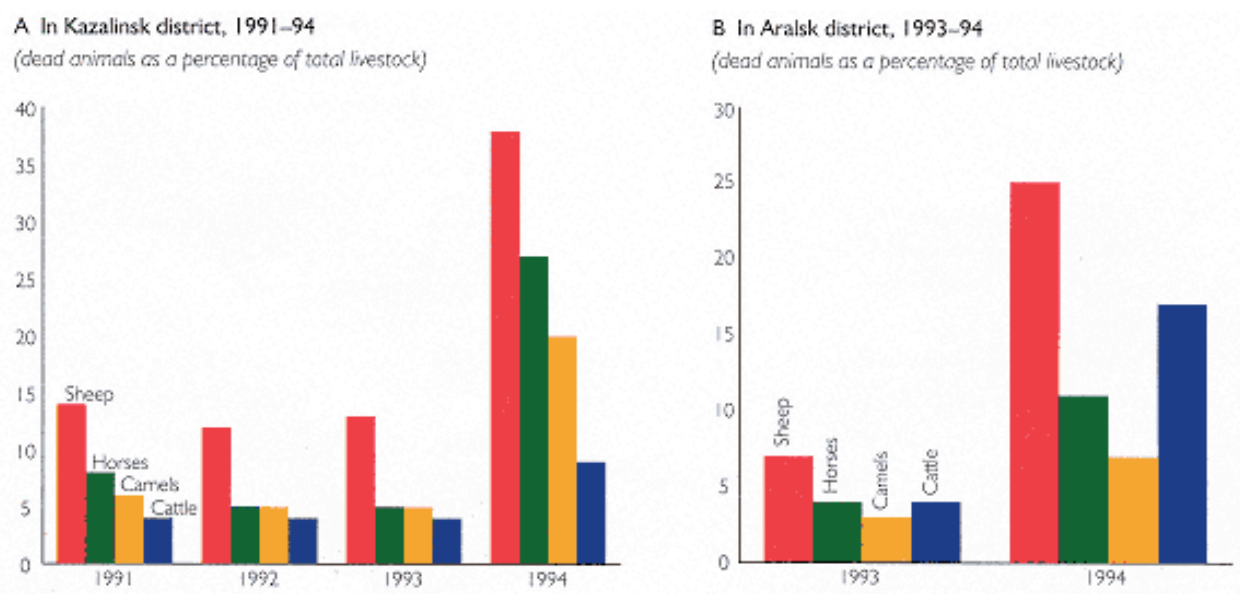

Figure 6.11

Livestock losses

Source: Household surveys.

Stock breeding is the traditional form of Kazak farming. In the project area, however, 34 percent of families do not own any animals; 39 percent of the families in Aralsk do not own animals, and 29 percent of Kazalinsk families do not own animals. Among families that own animals, the largest percentage owns cows and sheep (table 6.1). 


\section{Social Assessments for Better Development}

Animals have both symbolic and economic value in rural Kazakstan. Cattle, and especially sheep, were fundamental to the traditional Kazak livelihood and way of life, a measure of prosperity, guarantee of well being, and protection from famine. Thus the current state of home stock-breeding is serious. In recent years the number of cattle has declined for two main reasons. First, animals are slaughtered to add to family income and to pay off debt, particularly where state farm livestock were distributed to families as part of the privatization process. Second, the cattle plague associated with salt contamination is on the rise (figures 6.11a and 6.11b).

Another reason for the decline in the number of cattle is that Aralsk Water, the local water supply and sewerage system administration, launched a campaign in the summer of 1994 to register household livestock in order to collect water fees. According to the tariffs in effect in 1994, owners were expected to pay an annual fee of 1,542 tenge (\$24.48) for each cow and 547 tenge (\$8.68) for each sheep. Because these fees are essentially the market price of the animals at

the end of the year, this level is intolerably high for local residents.

The Kazalinsk water administration has fixed prices for watering livestock for six months of the year (during the summer people water their cattle, sheep, and goats using other sources). The charges are very low; higher charges would have disastrous consequences for households. According to the survey, however, 71 percent of the respondents said that if they had more water (no matter what quality), they would like to raise more animals.

On state and collective farms, some of which were reorganized into joint-stock ventures, cattleholding also declined, partly because of disease and partly because of in-kind payments to employees. According to in-depth interviews, the cattle population fell an average of 20 percent over the past five years. In addition, cattle productivity fell for several reasons: insufficient roughage in the diet (due to high cost), pasture land damaged by salinization, and insufficient water for watering cattle. Moreover, land once used to grow fodder grass is going out of crop rotation for the same reasons: worsening soil conditions and insufficient water for irrigation.

The average amount of milk per family owning a cow is 3.3 liters a day. Nonetheless, it should be noted that the household surveys were conducted in May, during the calving period, when most of the milk had to be used to feed calves. On average, however, the decline in cattle productivity is similar to the national average. Egg production in families with poultry is 3.9 a day, or 0.7 per person on average. Families who raise animals get about 200 kilograms of meat a year, or 98 kilograms per family on average. Families generally use meat for their own needs, although a portion may be sold. Exchange in kind is also widely practiced (for example, meat is exchanged for other edible goods and for clothes).

Enterprises. Irrigated agriculture and livestock breeding are the main economic activities in Kazalinsk. Aralsk depends primarily on livestock-breeding. Both districts, however, have experienced a sharp decline in output in both agricultural and nonagricultural activities. Moreover, the pace of output decline appears to be more acute in the nonagricultural sector than in the agricultural one. Data from selected citybased enterprises in both districts reveal that production output in 1994/95 ranged from 0-75 percent of 1990 production levels (see figure 6.7).

The financial status of agricultural and nonagricultural enterprises has deteriorated over the past five years. Twenty-two enterprises reported profits in 1990. Of these, the number reporting losses began to increase in 1993, and in 1994 almost three-quarters reported losses and none of the agricultural enterprises was profitable. City-based nonagricultural enterprises, as well as agricultural enterprises, have encountered numerous problems as they continue to carry out their operations. These problems are related to:

Lack of liquidity. Despite the liberalization of prices, barter remains the most common form of commercial transaction for almost all enterprises. The lack of liquidity has left enterprises without cash for purchasing needed inputs and paying salaries. Instead of being paid salaries, employees are given consumer goods obtained through 


\section{Social Assessments for Better Development}

barter.

Limited access to credit. Access to commercial banking is limited, either because interest rates are very high (about 300 percent in April 1995) or the offered repayment term is very short (one year).

Removal of subsidies. The phasing out of price distortions in infrastructure services has caused fundamental changes in the relative prices of electricity, heating, and water. Unless enterprises in the region obtain technical support to increase their efficiency in the use of energy and water, they will not achieve economic viability in the new business environment.

Shortage of basic inputs. Gas and fuel shortages are a powerful constraint to free and open entry to the energy market. Moreover, gasoline prices in Aralsk and Kazalinsk are higher than in Almaty (about 67 percent more in Aralsk, 25 percent more in Kazalinsk). It is not clear, however, if this disparity is the result of transport costs or the monopoly structure of the energy system.

Excessive taxation. The tax system is complex, cumbersome, and induces noncompliance. The central government imposes almost 100 different taxes, which for some enterprises

can add up to 100 percent of production costs. Consequently, informal trading and avoidance of record-keeping are common-place in both districts.

Decline in human capital. Enterprises are not able to pay salaries, let alone offer better working conditions (or better salaries) to their employees. As a result specialists and skilled workers are leaving the area and looking for new opportunities in Almaty, Chimkent, Jambul, and Kzyl-Orda.

Lack of financial markets. Privatization has been slow, and financial markets have not developed to provide credit to promote entrepreneurialism.

\section{Water Supply}

Inadequate water supplies have a negative effect on health and productivity in both Aralsk and Kazalinsk, with the most adverse effects occurring in the rural areas of Kazalinsk. This section assesses the sector's institutional stakeholders and presents the social assessment's findings on the social aspects of the water supply system. The next section assesses sanitation services and the consequences they have for hygiene practices and health.

Institutional framework. Besides households and enterprises, the other major stakeholders in the water supply and sanitation sector in the project area include the district and region administrations, the State Committee for Water Resources, the Ministry of Housing and Communal Services, and the Ministry of Health. The State Committee for Water Resources plays both a policymaking role and an operational role for the water supply sector. Through one of its affiliates, the Project and Construction Enterprise Kzyl-Orda Agricultural Water Supply, the committee exercises responsibility for the construction and operation of the Aralsk-Serbulak Pipeline and for Repair and Maintenance Organizations 1 (Aralsk) and 2 (Kazalinsk). 2

The Ministry of Housing and Communal Services, through the Kzyl-Orda Committee on Housing and Communal Services and the local administrations of the Kazalinsk and Aralsk districts, has primary responsibility for water supply and sanitation policies and programs in the cities of Aralsk and Kazalinsk, including citybased working settlements. Local administrations supervise the Aralsk and Kazalinsk Water Canalization and Sewage Companies. 


\section{Social Assessments for Better Development}

Finally, the Ministry of Health, through sanitary and epidemiology stations in Aralsk and Kazalinsk districts, is responsible for monitoring drinking water quality standards, ensuring sanitary conditions of water supply systems, controlling epidemics, and developing sanitation and hygiene education programs.

The following assessment and characterization of the water supply situation in Aralsk and Kazalinsk is based on informal interviews with the administrators of different agencies. Subsequent parts of this section concentrate on the conditions, perceptions, and opportunities of water users.

Water service delivery agencies are just beginning to achieve some measure of autonomy from local administrations, which own the water supply assets. The local administrations are gaining some experience in being accountable to their constituents and representing the interests of the population. But operation agencies still face strong disincentives for maintaining facilities, preserving their value, and reducing production costs.

Updated long-term development plans for the sector are lacking. Old plans, based on the operating and subsidizing principles of the old regime, are still in effect. Operating entities are concerned with their immediate survival, coping with reduced budget allocations for capital investments and recurrent expenditures.

The entities responsible for providing water services act without apparent concern for the concept of providing water services of good quality at a reasonable cost.

Current cost recovery policies that attempt to cross-subsidize are self-defeating. Policies favor the domestic sector, attempting to offset low domestic tariffs with high industrial tariffs. Actual payment levels are very low. If continued, this approach is likely to lead to severe consequences for the water sector. For example, piped water supply for industrial users in Kazalinsk is

priced at 600 tenge (\$9.50) per cubic meter-300 times the domestic rate. Several major industrial units have switched from piped water supplies to delivery of water by trucks to avoid such high prices for piped water, causing significant revenue losses to the water agencies.

Water rate structures are highly distorted. For example, in December 1994 domestic users in Aralsk accounted for 50 percent of consumption and were responsible for only 1 percent of total revenues. At the same time industrial enterprises accounted for 14 percent of consumption but were responsible for 39 percent of revenues. During the first quarter of 1995 domestic users in Kazalinsk accounted for 78 percent of consumption and contributed only 3 percent of revenues, while industrial enterprises accounted for 1 percent of consumption and contributed 12 percent of revenues.

The labor productivity of operating agencies is very low. In Aralsk one staff member serves 160 people, there are 20 house connections per staff member, and 6,100 cubic meters of water are sold per staff year. In Kazalinsk one staff member serves 260 people, there are 21 house connections per staff member, and 5,400 cubic meters of water are sold per staff year.

Operational efficiency is low. For example, water losses in the Aralsk-Serbulak system range from 45-70 percent of total production. A full assessment of losses is precluded by the lack of meters at both production and intake points, as well as in most distribution channels. Similar losses reported in the distribution network range from $40-50$ percent.

Water quality laboratories are being equipped with modern equipment provided by donors. Because of the lack of chemical reactives and spare parts, however, there is a considerable risk that these labs will soon be nonoperational. 


\section{Social Assessments for Better Development}

Although several local entities are responsible for sampling and analyzing water quality, the information collected is not used for day-to-day monitoring. Instead, it is used for statistical purposes at the regional level. In the event of severe contamination of a ground-water well, for example, the population directly affected is not advised immediately. Instead, the responsible agency waits for an order from its line authority at the regional level before responding to the emergency.

In short, major restructuring of the water sector is needed in the project area.

Overview. Aralsk and Kazalinsk's desert locations make water a critical factor for survival. Except for early fishing settlements on the Aral Sea and the fort settlement at Kazalinsk near the Syr Darya, population growth in the two districts has been predicated on the development of water sources. The initial investments in water supply were related to railroad construction and operations, for which a pipeline was constructed to Aralsk district from the Syr Darya. Novo-Kazalinsk is also connected to a pipeline from the Syr Darya that was replaced by increasingly larger pipes in 1930, 1950, and 1983.

Because Syr Darya water levels and quality dropped in the 1970s and 1980s, a treatment plant was built in Kazalinsk in 1987. Several remote settlements also were outfitted with small desalinization plants. Finally, in 1992 the Aralsk-Serbulak Pipeline was constructed to bring high-quality groundwater to Aralsk and Kazalinsk from a pumping field located near Aralsk. The pipeline has been problematic from the start, however. Interruptions are frequent, water pressure is low, and many proposed connections were never installed. In addition, many parts have gone out of service because of the failure of tapstands and lack of replacement parts in Aralsk and other locations.

Theoretically, 73 percent of the population of Aralsk has access to water from the Aralsk-Serbulak pipeline, 13 percent has access from the Syr Darya, and 15 percent from groundwater or tank deliveries. A much smaller percentage of the population, however, actually receives water from the pipeline. In Kazalinsk part of the city of Novo-Kazalinsk and three rural settlements are connected, although not all connections function. For example, from Kazalinsk the pipe connection goes south to Basykara (Zhalantos Batyr) to serve the settlement associated with the major diversion weir as well as the neighboring settlement of Kumzhiyek. Although

Zhalantos is the next settlement in the direction of Novo-Kazalinsk, and is nominally connected to the line, its underground pipeline in the settlement has been only partially installed and cannot be used because of its many leaks. Instead, water is trucked from the connection point to houses. Novo-Kazalinsk is also nominally connected to the pipeline, but the connection only serves parts of the city. The parts of the city that are connected receive Aralsk-Serbulak water when it is available; otherwise, Syr Darya water is diverted to them.

Sources and availability of water. The household survey found that people obtain water from a variety of water sources (figure 6.12). The most prevalent are tapstands in the street (37 percent), taps in the yard (29 percent), taps in a neighbor's yard (22 percent), a spring (14 percent), and from water truck deliveries (14 percent). Sources vary considerably by district and location, however. 


\section{Social Assessments for Better Development}

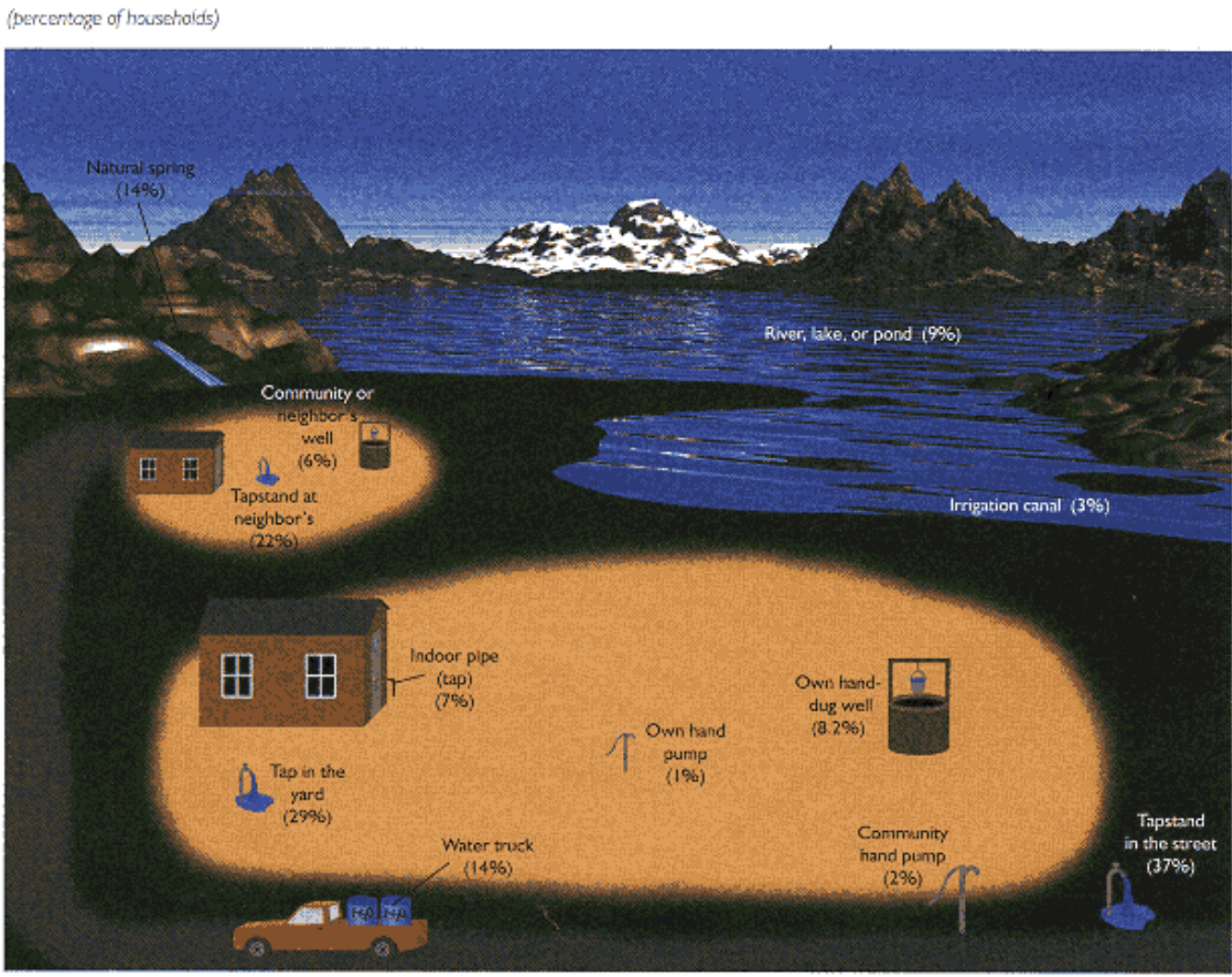

Figure 6.12

Sources of potable water

For example, 54 percent of the sample in working settlements has access to tapstands in the street, but only 20 percent of the respondents in the rural settlements have access to them (figure 6.13). In Aralsk 47 percent of the respondents have access to tapstands in the street, but only 27 percent of those in Kazalinsk do (figure 6.14). Similarly, 32 percent of the rural sample obtains water from springs, but only 4 percent of those in working settlements and 2 percent in the district centers obtain water from springs. Moreover, 1 percent of Aralsk respondents and 28 percent of Kazalinsk respondents get water from springs. And water trucks serve 14 percent of the total sample, but 32 percent of those in district centers, 2 percent of those in working settlements, and 14 percent of those in rural settlements.

The survey also found that people use water from different sources for different purposes, and that consumption varies by season (figure 6.15). Of the respondents with access to water 


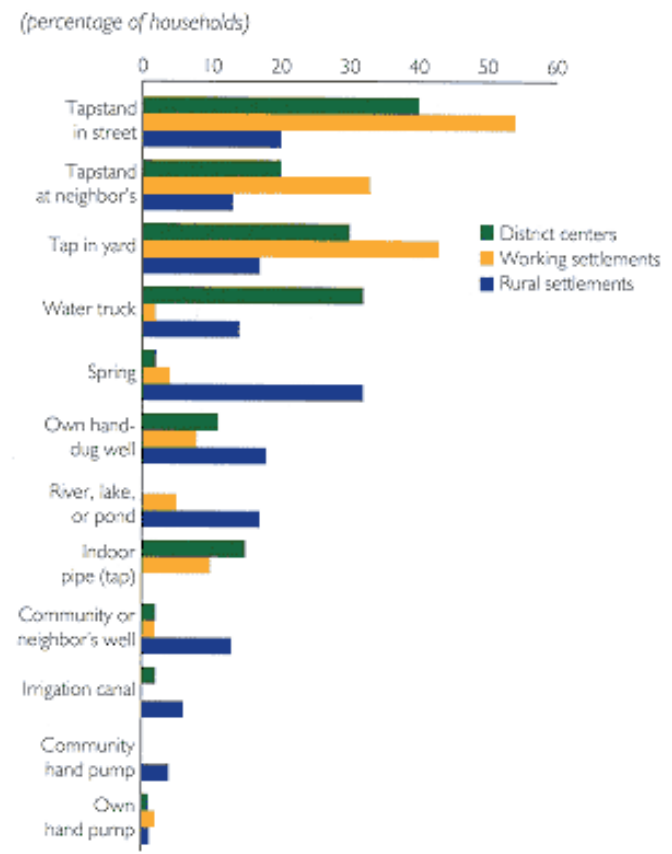

Figure 6.13

Household water sources, by settlement type Source: Household surveys.

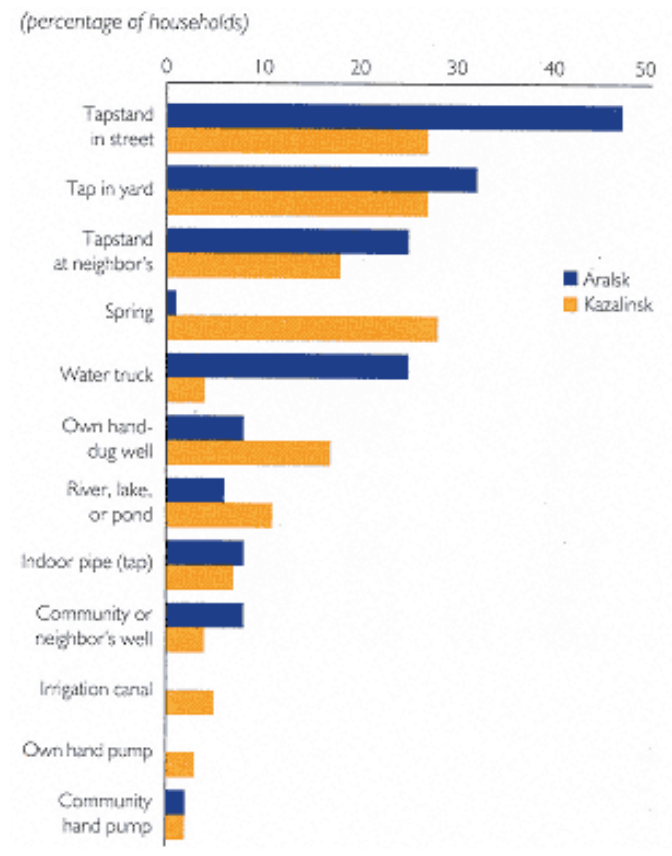

Figure 6.14

Household water sources, by district

Source: Household surveys.

taps, 39 percent use tap water for cattle (23 percent of the total). Twelve percent of those with tap water use it for irrigation (21 percent of the total). 
The average distance between a respondent's residence and a primary water source was 29.25 meters. The average distance to a secondary source was 55.25 meters. Although the range of distances was similar in district centers, working settlements, and rural settlements, there is a clear difference between the two districts. People in Aralsk live closer to their water sources than people in Kazalinsk (figures 6.16a and 6.16b).

When asked if they have enough water for different purposes, most respondents rated their situation as adequate or marginally adequate (figure 6.17). An adequate water source is not necessarily reliable, however. When asked to rate the reliability of their primary water source on a scale of 1 to 5 , with 1 being the lowest, half of the respondents rated their water sources in the top two categories. People in Aralsk and in the district centers reported the highest levels of

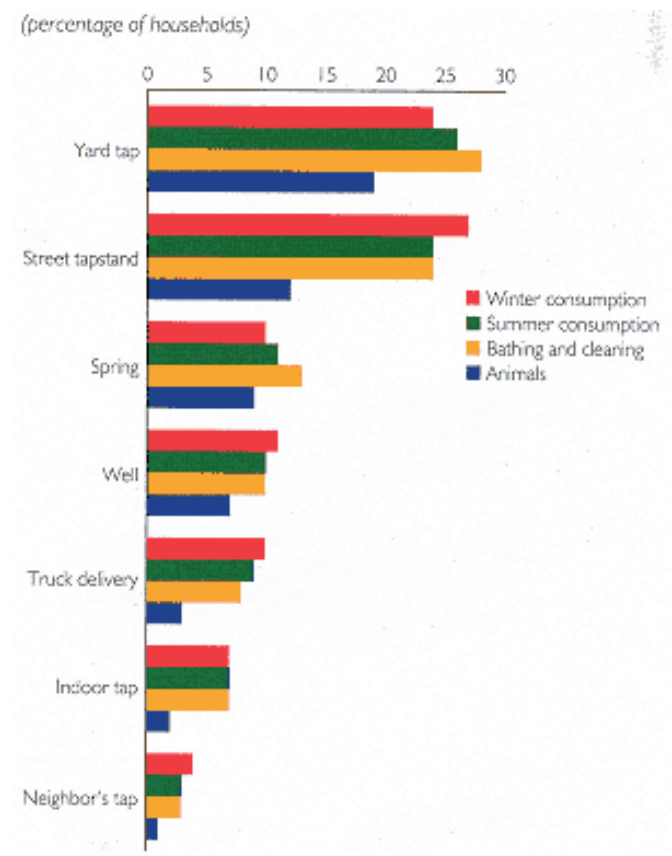

Figure 6.15

Primary water source for main uses

Source: Household surveys.
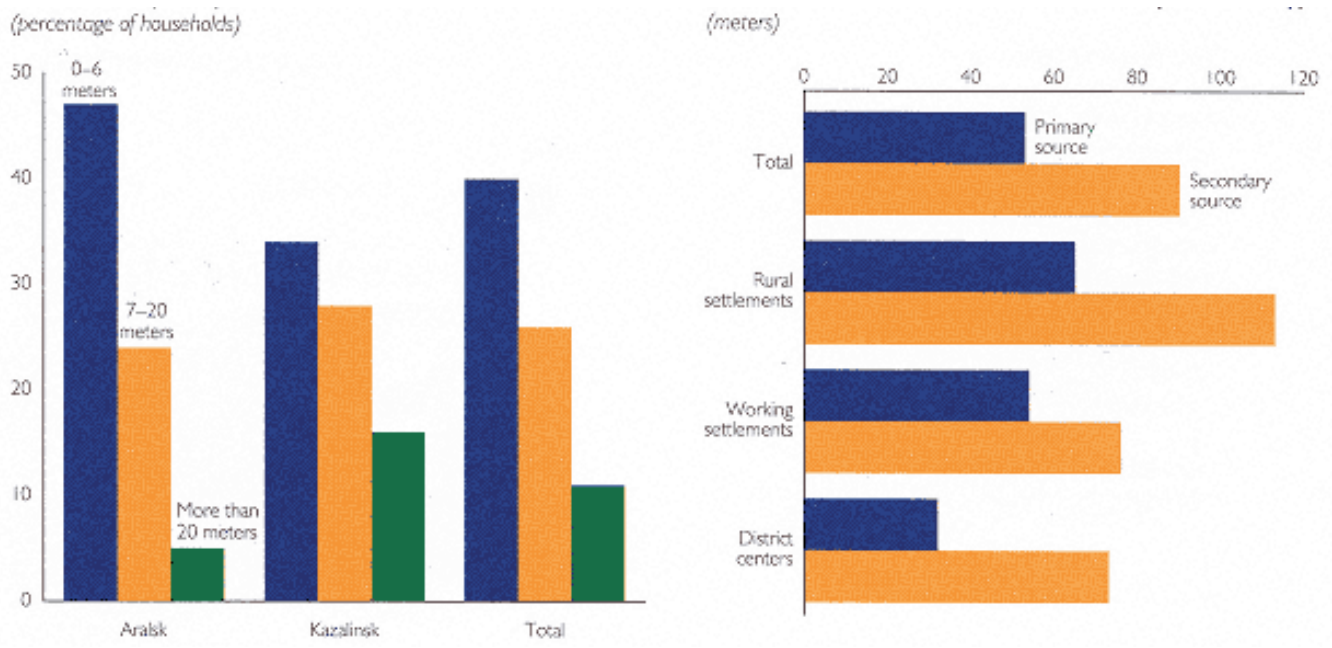
Figure 6.16

Distance to water source

Source: Household surveys.

reliability, with primary sources rated slightly higher than secondary sources (figures 6.18a and 6.18b). At the time of the survey, moreover, 60 percent of those who used tap water as their primary source had well-functioning taps. Of the remaining users of tap water, 19 percent had leaking taps, 9 percent had taps that were missing, and 3 percent had leaking pipes and no taps.

The costs of coping with inadequate water supplies are high and getting higher, with sys-

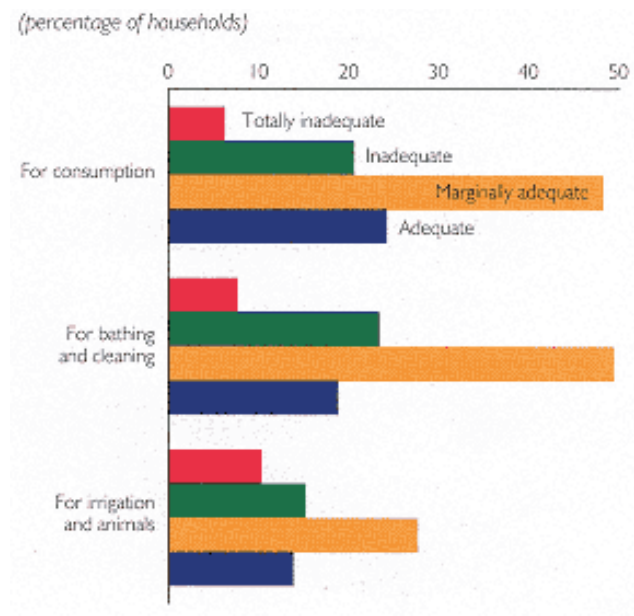

Figure 6.17

Adequacy of water source

Source: Household surveys.

tem breakdowns becoming more common and water quality deteriorating. Where piped water systems are unavailable or inoperable, people generally obtain and then store water delivered

It is possible to produce everything locally. But water is needed for this. If we grow wheat, we will supply ourselves with flour and bread.

-Focus group discussions

by tank trucks. Although the official tariff for domestic water is 2 tenge per cubic meter, water deliveries arranged by the urban or farm administration cost about 40 tenge a tank (about 1.5 cubic meters), and transport (petrol) costs an additional 60 tenge. Families that make their own arrangements pay as much as 280 tenge a truck, which may come once or twice a month. A family that depends on a water truck pays almost $\$ 85$ a year for delivered water, which is equivalent to about 3.5 months' income.

Dissatisfaction with the water supply is high. Only 16 percent of the households in the sample had no complaints about their water supply. Among the complaints, poor water quality was the most common (31 percent), followed by high price ( 23 percent) and distance from the house 


\section{Social Assessments for Better Development}
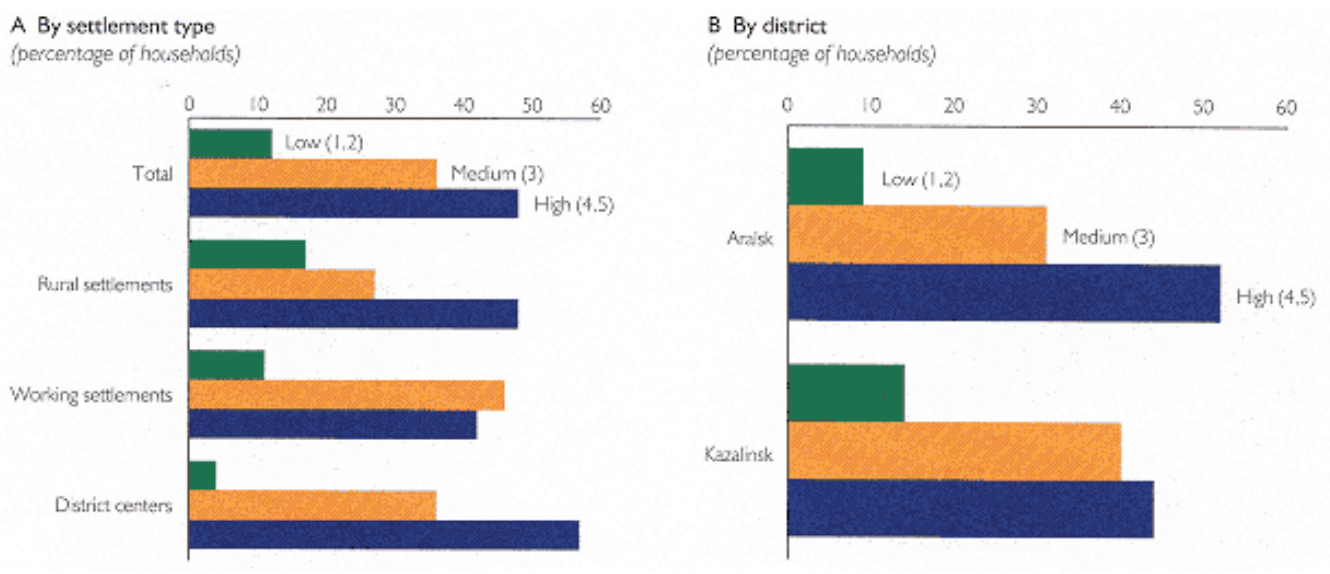

Figure 6.18

Perceived reliability of water source

Source: Household surveys.

(22 percent). Satisfaction was highest in the district centers (19 percent compared with 13 percent in rural areas; figure 6.19) and in Aralsk (21 percent compared with 11 percent in Kazalinsk).

Water quality. Water quality has deteriorated significantly during the past two decades, particularly in rural areas, as a result of the increased pollution of the Syr Darya and the declining quality (Kazalinsk) and quantity (Aralsk) of groundwater. Most settlements that are not connected to the Syr Darya pipelines or the AralskSerbulak pipeline have some sort of local piped system, frequently consisting of a few tapstands. Most settlements obtain water from the Syr Darya, although a few tap underground sources. A few communities have desalinization plants, which essentially do not function, and most chlorination facilities are out of commission because of a lack of chlorine. In addition, all groundwater sources are thought to be of poor quality. Consequently, rural areas have uniformly poor-quality water, except those with active connections to the Aralsk-Serbulak pipeline.

As noted above, 31 percent of households expressed dissatisfaction with the quality of their water. Dissatisfaction is highest in rural settlements (41 percent compared with 10 percent in district centers) and higher in Kazalinsk (39 percent) than in Aralsk (23 percent). When asked about water quality, 11 percent of households classified it as poor and 57 percent classified it as good. Location has a big effect on these responses. In Aralsk 75 percent of respondents said the water quality was good, compared with 39 percent in Kazalinsk (figure 6.20). People living in district centers generally rated the water quality as good (85 percent), but residents of working settlements and rural settlements had a much lower level of satisfaction (50 percent and 45 percent, respec- 


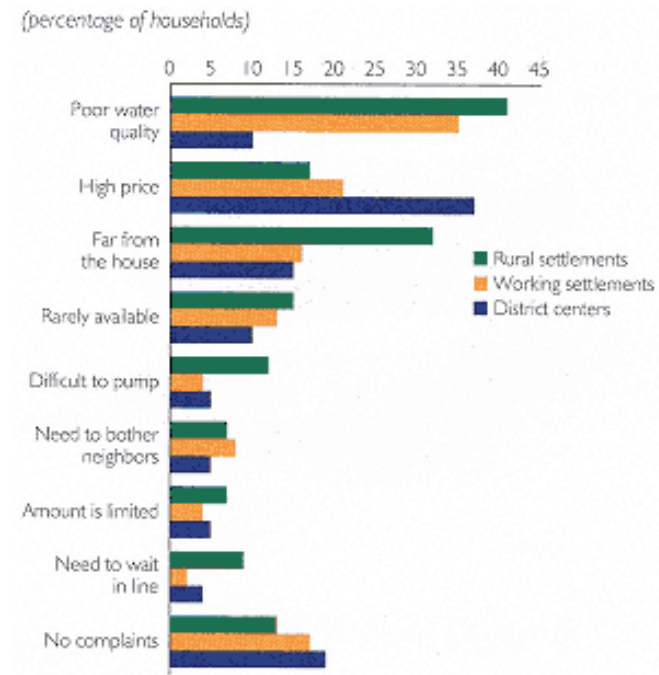

Figure 6.19

Complaints about water supply, by settlement type Source: Household surveys.

tively). Nineteen percent of rural residents classified their water as poor, compared with 2 percent in district centers, 15 percent in Kazalinsk, and 8 percent in Aralsk (figure 6.21).

Complaints about water quality also vary with location. People in working settlements complained about saltiness ( 28 percent) and particles in the water ( 7 percent). Rural respondents complained about saltiness (42 percent), muddiness ( 28 percent), bad taste ( 21 percent), and bacterial contamination (17 percent). The most frequent complaint of residents living in district centers was muddiness ( 8 percent). Thus people who receive Aralsk-Serbulak water are relatively satisfied with water quality, and those who do not are justifiably dissatisfied (figure 6.22). In some parts of Kazalinsk, residents receive water alternatively from the Syr Darya and the Aralsk-Serbulak Pipeline, depending on the availability of the pipeline. Informal discussions with residents in these areas indicate that they can immediately tell which source the water is being delivered from because the quality of the two sources is so different.

As a further indication of poor water quality, 76 percent of the household respondents boil their water before consuming it, and 46 percent only drink water in tea. The incidence of drinking fresh water is highest in the district centers (43 percent) and lowest in working settlements ( 20 percent). In Aralsk 35 percent of respondents

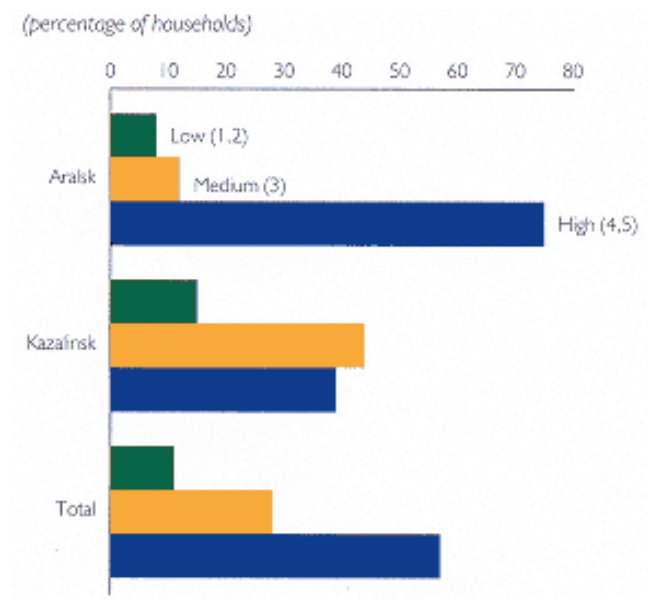




\section{Social Assessments for Better Development}

Figure 6.20

Water quality ranking, by district

Source: Household surveys.

drink fresh water, but only 13 percent do so in Kazalinsk. Boiling water is most common in rural areas (84 percent) and Kazalinsk (80 percent; figure 6.23).

\section{Sanitation and Hygiene}

Throughout the proposed project area, neither sanitation nor hygiene practices conform to modern standards. They are generally acceptable, however, particularly given such limited access to water in homes or even yards. Most respondents (52 percent) admitted that they simply pour waste water directly on the ground; 41 percent discharge their waste water into a cesspit in the yard near the house. Only 5 percent of households are connected to a central sewerage system, and 2 percent are connected to a local sewerage system. Increased availability of water will make better sanitation imperative.

The household survey found that hygiene practices on the whole are satisfactory; improvements will depend on better water supplies. This is particularly true for personal cleanliness. Although the survey did not include specific questions regarding handwashing facilities, household visits suggest that simple water dispensers for handwashing are common in yards, and virtually every home has a washstand inside the main entrance. Bathing facilities vary from buckets in a utility room to more tradi-

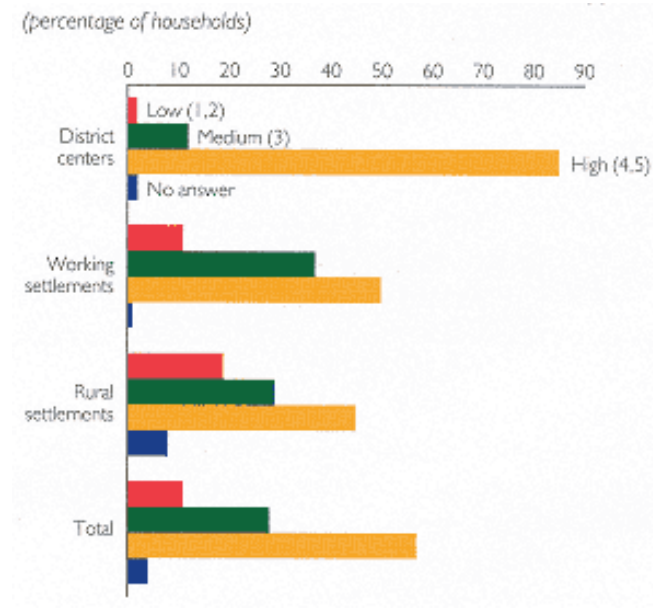

Figure 6.21

Water quality ranking, by settlement type Source: Household surveys. 


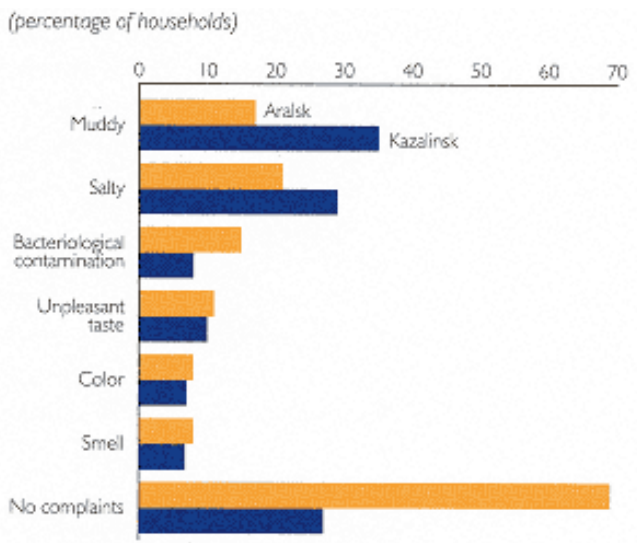

Figure 6.22

Complaints about water quality, by district

Source: Household surveys.

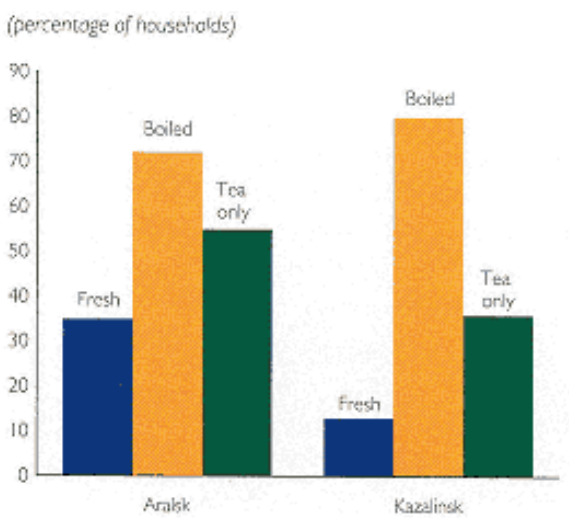

Figure 6.23

Fresh and boiled water consumption, by district

Source: Household surveys.

tional bathing facilities in an outside room. On average, the largest percentage of the population took a bath 3.8 times a month in their own home and 2.8 times a month in public bathhouses. Moreover, most children (69 percent) are bathed about once a week during the winter. During the summer they are bathed more frequently. In the thirty-day period preceding the survey, 37 percent of respondents took their children with them to the bathhouses.

The use of soap is often limited, especially in large families. Children wash their hands with soap an average of 2.1 times a day. In 79 percent of respondents' houses there was soap near a washstand. In 19 percent, however, there was no soap at all. Taking into account that the average family size is about six people, there is only 0.4 pieces of soap per person in each family per week.

\section{Health}

The environmental conditions associated with the Aral Sea crisis, as well as poor nutrition and the shortage of safe water, have had a negative impact on health in the project areas. Only 26 percent of the respondents reported that members of their families were healthy; 40 percent said that their health was good enough, 37 percent complained that the health of their family members was not good, and 6 percent said that the health of their relatives was poor. 


\section{Social Assessments for Better Development}

Among those reporting health problems, 91 percent said that both the adults and children of their families suffered from various diseases. The most common illnesses cited were diarrheal diseases (15 percent) and tuberculosis (13 percent). Among children, flu and other respiratory illnesses accounted for 40 percent of the illnesses. Other common diseases include blood diseases (10 percent) as well as rheumatism, other bone structure diseases, and hepatitis ( 7 percent). Although these responses are consistent with data provided by the director of Kazalinsk's Regional Hospital, they do not reflect the high rates of anemia (the reduction of hemoglobin in the blood), which is water-related. Given the poor quality of the water, the high incidence of boiling water undoubtedly accounts for the relatively low incidence of diarrhea and hepatitis.

According to the regional hospital in Kazalinsk, children less than a year old have a mortality rate that was constant at 29 cases per 1,000 live births during 1991-94. The morbidity rate during this period, however, almost doubled, from 790 per 1,000 to 1,600 per 1,000 (1.6 illnesses per child in the first year of life; figure 6.24). In addition, the number of cases with umbilical cord-related bleeding after birth increased from 32 cases in 1991 to 79 cases in 1994. This condition appears to be associated with the high salinity and nitrate content of drinking water. In addition, the morbidity rate

for anemia of women of reproductive age went from 29 percent in 1989 to more than 50 percent in 1993. Anemia is also linked to a high concentration of nitrate in drinking water.

In addition to its impact on human health, poor water quality in the project area threatens the health of livestock and, among other factors (such as inaccessible markets, low prices relative to production costs), constrains the production of livestock and related products. The main effects of the poor water supply are:

The high salinity content (510 grams per liter) of shallow groundwater wells, which are the main source of drinking water for livestock (particularly sheep, horses, and camels), appears to be causing them to suffer from diseases with unusual symptoms. Veterinarians from Moscow and St. Petersburg have visited various farms in Aralsk and diagnosed animals as having salt poisoning and kidney disease. For most livestock, water with a salinity level above 7 grams per liter can reduce growth and productivity or increase mortality. The sheep mortality rate, for example, has increased almost threefold, from 136 per 1,000 cases in 1993 to 382 per 1,000 cases in 1994.

In addition to salt, the high nitrate content of the water from the Syr Darya River (about 20 milligrams per liter) is causing anemia. Consequently, the immune system of animals is weakened, and death may follow. The high nitrate content also causes a lower rate

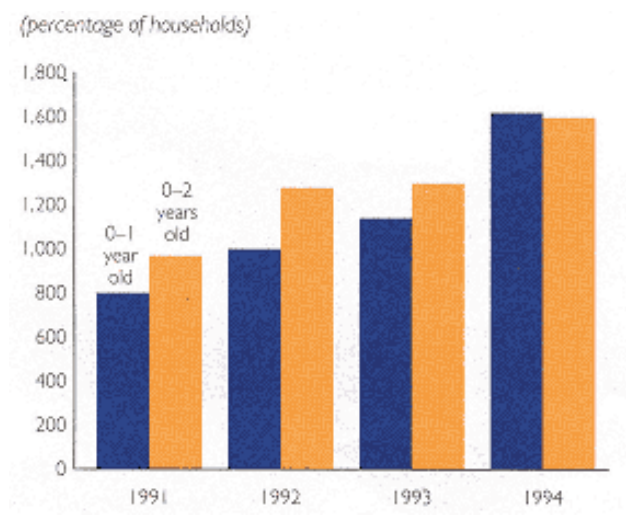

Figure 6.24

Infant morbidity rate, Kazalinsk district, 1991-94

Source: Household surveys. 


\section{Social Assessments for Better Development}

of weight gain, thyroid dysfunction, arthritic conditions, and miscarriages. Statistics provided by the veterinarian in Aralsk show that the number of deaths related to metabolic malfunctioning increased from 6,000 to 14,000 between 1993 and 1994.

Water shortages appear to be a severe constraint to livestock productivity. Directors of several state farms reported that only half of the area available for pasture is being used because of the high cost of water (water from the Aralsk-Serbulak pipeline costs 17 tenge per cubic meter for livestock purposes).

The cattle are ill because of the reduction in pastures, salty soil, and the poor quality of the water.

The most dangerous thing for the cattle is the excess salt in their feed.

—Focus group discussions

\section{Changing Conditions.}

Respondents were asked to compare living conditions today with those one year ago, five years ago, and ten years ago. Overall, they said that conditions are worse now than in the past, but that things are improving (figure 6.25). Aralsk respondents were less optimistic about future prospects than those in Kazalinsk (figure 6.26).

The high cost of living was the most frequently cited cause of worsened living conditions. The second most common response was irregular payment of wages and pensions compared with one year ago and five years ago. But ecological problems were the second most common response when comparing conditions between today and ten years ago (figure 6.27). The pattern of response was similar between districts and district centers as well as between working and rural settlements, with people in Aralsk and in district centers citing living expenses and irregular wages and pensions more frequently than people in Kazalinsk and rural areas, respectively. People in rural areas cited ecological problems more frequently than the other two groups.

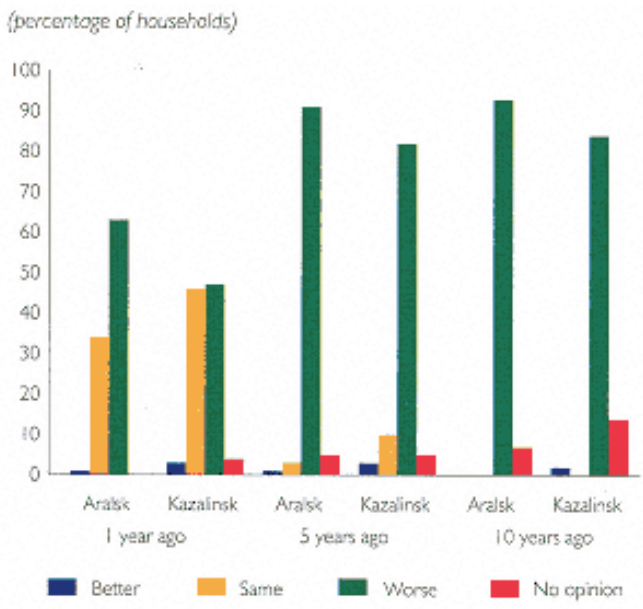

Figure 6.25

Household comparisons of living conditions, by district

Source: Household surveys. 


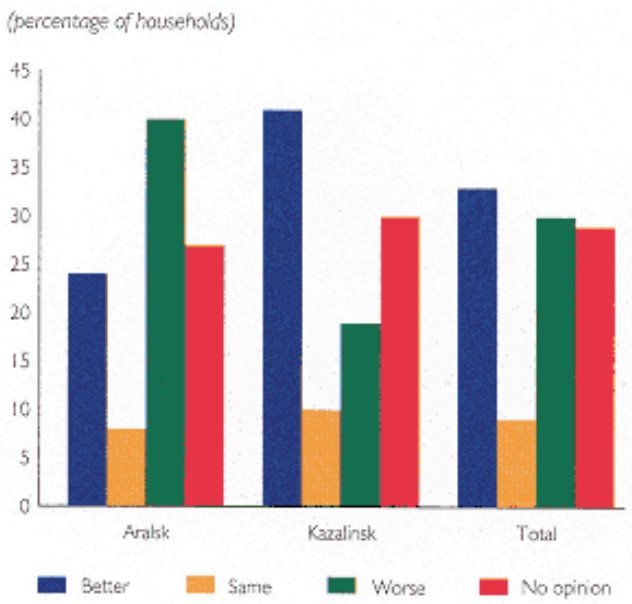

Figure 6.26

Household expectations of future prospects, by district

Source: Household surveys.

People are clearly most worried about their economic situation, especially the new challenges they face with economic restructuring: high cost of living, irregular wages, and unemployment. These are relatively new problems for most people, who are struggling to find solutions while still expecting the state to solve their problems.

\section{Priority Problems and Willingness to Pay}

Despite the water problems discussed above, water is not the most important problem people in Aralsk and Kazalinsk face. When asked to identify their main problems, respondents mentioned water less often than four other problems (table 6.2). Although water quality was mentioned by 19 percent of respondents (and water shortages by 9 percent), 75 percent mentioned income to buy food, 41 percent mentioned the lack of gas, coal, or wood, and 51 percent mentioned wages not being paid. Given the extremely weak local economy, however, these results should not be interpreted to mean that water is not a problem. Rather, they indicate a reasonable set of priorities and the fact that the people have developed strategies for coping with water shortages, but not for managing other major new challenges.

The responses indicate that water conditions are more severe in Kazalinsk than in Aralsk-poor water quality was mentioned twice as often in Kazalinsk as in Aralsk. This difference can be explained by the fact that the residents of Aralsk use water the from the Aralsk-Serbulak water

We don't even get our salaries on time. During 1994, we have received only 10 percent of our salary in cash.

Today it is difficult to find a good job. Many skilled young people are leaving the region. Some give up working.

It's necessary to solve the problem of drinking water and salary. When you don't get paid, you don't want to work.

-Focus group discussions

system, while residents of Kazalinsk consume mainly unpurified Syr Darya River water. Flour shortages also were mentioned more often in Kazalinsk, where most families bake their own bread, than in Aralsk, where a mechanical bakery is subsidized by the regional administration. Retail bread prices in Aralsk are half the price as in Kazalinsk, and bread quality is considerably better. 
The secondary importance of water problems for the population in both project districts was confirmed by respondents' answers to

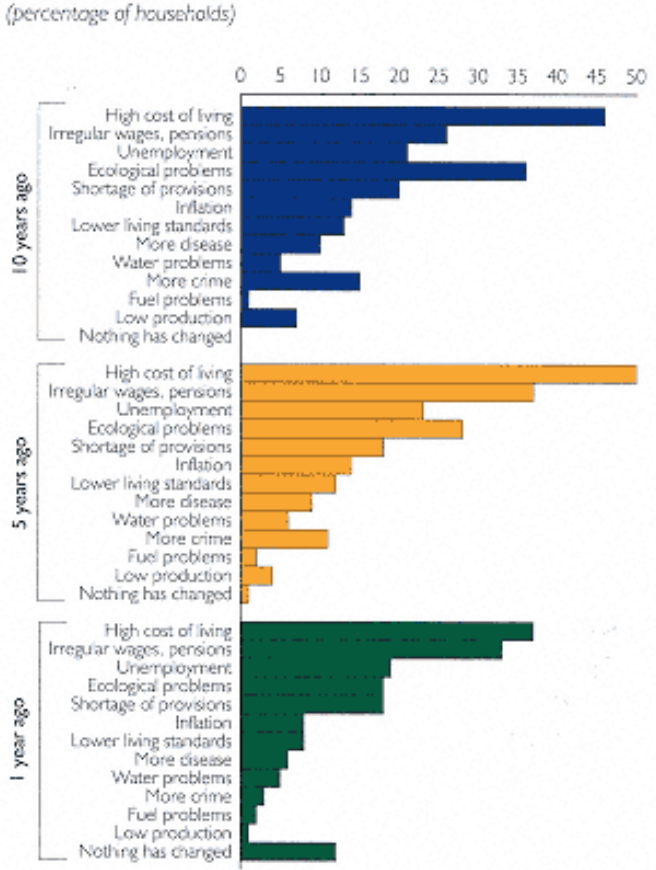

Figure 6.27

Household views on what has gotten worse Source: Household surveys.

Table 6.2 Main problems for households (percent)

\begin{tabular}{|c|c|c|c|}
\hline Problem & Total & Aralsk & Kazalinsk \\
\hline No money for food & 75 & 77 & 73 \\
\hline Unpaid wages & 51 & 53 & 49 \\
\hline $\begin{array}{l}\text { No money for gas and } \\
\text { coal }\end{array}$ & 41 & 50 & 32 \\
\hline No flour & 25 & 14 & 36 \\
\hline $\begin{array}{l}\text { Water (poor quality } \\
\text { and inadequate supply) }\end{array}$ & 23 & 19 & 28 \\
\hline No employment & 21 & 19 & 21 \\
\hline Poor water quality & 14 & 10 & 19 \\
\hline $\begin{array}{l}\text { Poor state of the } \\
\text { environment }\end{array}$ & 14 & 16 & 13 \\
\hline
\end{tabular}




\section{Social Assessments for Better Development}

$\begin{array}{llll}\text { Poor health } & 13 & 11 & 13 \\ \text { No building materials } & 9 & 14 & 10 \\ \begin{array}{l}\text { Inadequate water } \\ \text { Criminal activity }\end{array} & 9 & 9 & 9 \\ \text { No drainage } & 1 & 1 & 2 \\ \begin{array}{l}\text { No business } \\ \text { opportunities }\end{array} & 1 & 1 & 3\end{array}$

Source: Household surveys.

hypothetical questions about how they would spend 1,500 tenge $(\$ 23.80$; figure 6.28$)$. As their first choice, 82 percent said that they would use the money to buy food. As their second choice, 47 percent said that they spend the money on clothes and shoes, while 11 percent said that their second choice would be to buy livestock, poultry, and animal feed. The third choices were to buy livestock, poultry, and animal feed ( 20 percent), to visit a doctor or buy medicine ( 20 percent), and to buy wood or coal (14 percent). The fact that a substantial portion of respondents would use the money to visit a doctor or purchase medicine confirms the low quality of free medical service and high levels of morbidity.

When asked how they would spend 15,000 tenge (\$238), respondents also mentioned buying food most frequently (55 percent), followed by buying clothes and shoes ( 8 percent) and moving elsewhere ( 7 percent).

Although water did not emerge as their most important problem, households are ready to pay

2,865 tenge ( $\$ 45.48$ ) for improvement in their water supply. Twenty-eight percent of respondents indicated a willingness to pay a one-time charge of 2,500 tenge (\$39.70) for a twenty-fourhour water supply, and an average monthly fee of 241 tenge (\$3.83). As it stands, people with limited access already pay high prices for water delivered by tank truck, and very little of these

My friend has two children: one studies at school in the morning, the other in the afternoon. The one that studies in the afternoon is waiting for the brother to get his clothes. What will happen to our children if these conditions continue.

-Focus group discussions

funds go toward maintaining the water supply systems. Tariffs could be increased somewhat if high-quality water were made available, but they could not be raised as high as the current cost of delivered water.

The household surveys also found that 62 percent of respondents ( 60 percent in Aralsk and 65 percent in Kazalinsk) want piped water in their homes on a twenty-four-hour basis. The second most prevalent response (10 percent) was for piped water in the yard, followed by piped water in the house for a fixed number of hours ( 8 percent). Respondents indicated a willingness to pay a one-time fee averaging 2,965 tenge $(\$ 45.50)$ for the improvement of their 


\section{Social Assessments for Better Development}

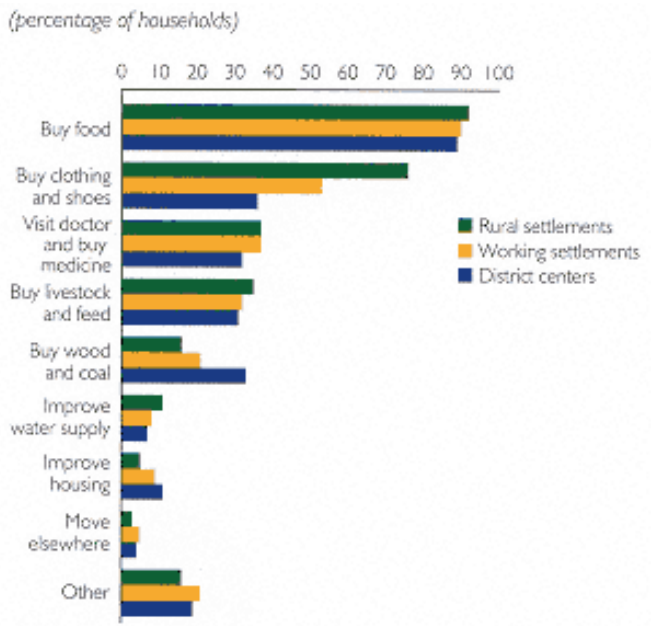

Figure 6.28

Household uses for 1,500 tenge, by settlement type

Source: Household surveys.

choice. To obtain a tap in their yard, respondents indicated a willingness to pay an average of 2,381 tenge (\$37.80) per household, with 34 percent willing to pay 2,500 tenge (\$39.70) and 43 percent willing to pay 1,000 tenge $(\$ 15.90)$ to be hooked up to an adequate water supply. In total, 59 percent indicated a willingness to pay for a connection to a good water supply (figure 6.29).

When asked about their willingness to pay for improved water supply and sewerage, 25 percent of respondents said that they would pay 4,000 tenge (\$63.50) (figure 6.30). In total, some 57 percent were willing to pay for water supply and sewerage. Rural households were slightly less inclined to pay than households in district centers, and households in Kazalinsk were less inclined to pay than households in Aralsk. When asked why they did not make improvements themselves, 71 percent of respondents said they could not afford to, and 19 percent said they did not have the necessary materials. This monthly payment level is lower than the estimated monthly cost of water delivery (450 tenge a month). This estimated cost represents a large share of income (16 percent of the average high income from all sources and 22 percent of the average lower income) and exceeds generally accepted water and sanitation fee standards of 5 percent of poverty-level income.

\section{Project Implications}

Improving water supply and sanitation in Aralsk and Kazalinsk is important but is not the highest priority for the residents of these districts. Although households and enterprises identify the lack of adequate water as a problem, both groups are more concerned about reviving the economy and improving general environmental conditions in the area. Focus groups confirm these conclusions. Thus any water supply investment in the area should be complemented by income-generating activities.

Although water may not be a major problem relative to the other challenges confronting the region, a better water supply system would help improve the productivity of agricultural enterprises, increasing incomes and expanding food supply - both priority concerns for the population. Achieving these goals will also require restructuring the institutions that manage the water supply. In addition, further improvements will require increasing the supply of animal feed.

The high prices that households pay for water demonstrate that people with limited access already pay high prices for water, very little of which goes to maintaining or improving the systems. Coping strategies are expensive, and most of the costs of tank deliveries - the main coping strategy - go to fuel end delivery. Thus little of the costs 
return to the system. Even if high-quality water were available, it is unlikely that tariffs could be increased to completely cover costs. Consequently, the World Bank may have to consider cost recovery as an objective to be achieved progressively, following institutional reform and greatly improved service.

To help raise income levels in the area, improvements in the water supply system should be labor intensive to maximize local employment. Although the social assessment did not reveal a critical sanitation problem, consideration should also be given to financing a labor-intensive sanitation component to improve sanitation facilities and generate income.

The social assessment concluded that traditional ties between neighbors and extended family members are strong, as demonstrated by

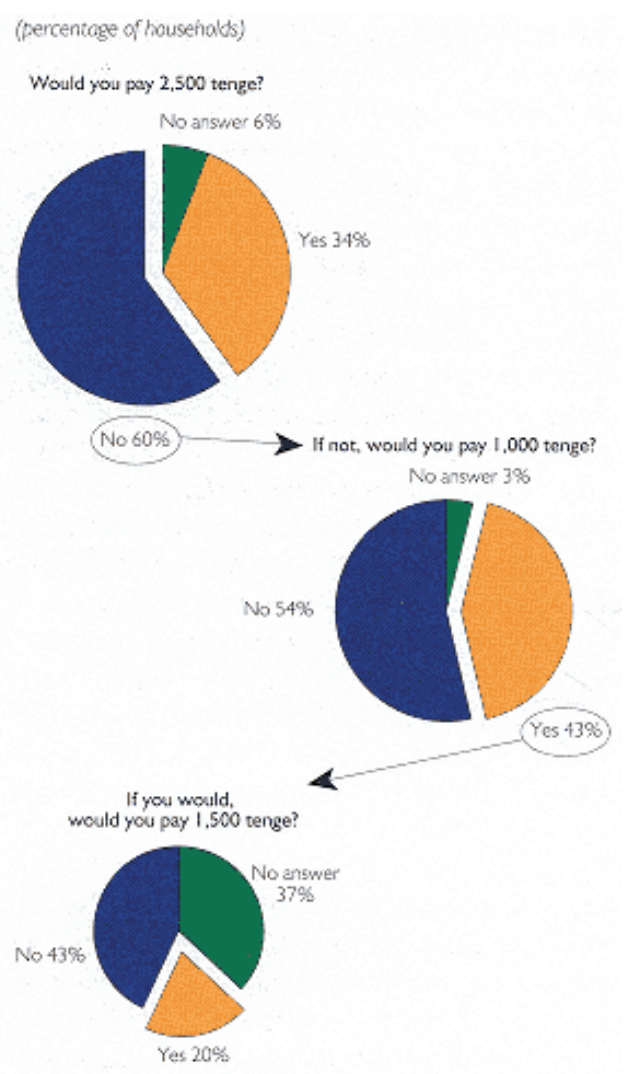

Figure 6.29

Household willingness to pay for improvement in the water supply and sewerage

Source: Household surveys. 


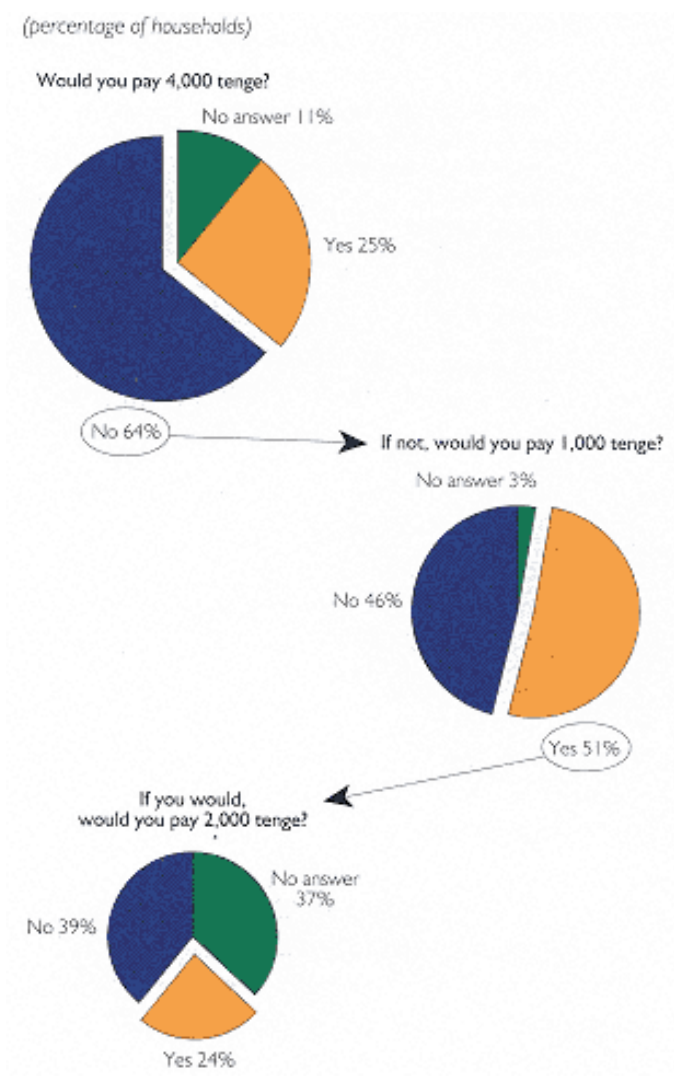

Figure 6.30

Household willingness to pay for improvement in the water supply and sewerage

Source: Household surveys.

patterns of sharing and mutual assistance, particularly in rural areas. This tradition should be incorporated into the project design and implementation. Indeed, the project should include investments that involve community participation in designing, implementing, and carrying out operation and maintenance responsibilities for the new water systems as well as for the sanitation improvements. This process should be developed within communities, enabling community leaders to assume responsibility for organizing and building consensus. In addition, these approaches should be implemented through pilot projects as soon as possible. Doing so will not only allow communities to test new approaches and obtain their immediate benefits, it will also demonstrate that the government is committed to improving conditions in the area.

Finally, the project preparation process should include an analysis of additional potential investments in the area that could improve the quality of life and help mitigate the environmental effects of the Aral Sea crisis. For example, the project might support investments in desert forestry (that is, Saksaul trees) and assistance to help migrants establish themselves in other locations.

\section{Notes}

This chapter is based on the efforts of many people and institutions in Kazakstan and Washington, D.C., and a number of associated reports. The task managers of the social assessment are Stan Peabody and Ayse Kudat.

Rita Cestti conducted the economic analysis of enterprises and farms and the analysis of water institu- 


\title{
Social Assessments for Better Development
}

tions. The field implementation of the household survey was assisted by Alima Kainekeevna Zharnagambetova of the Kazak Academy of Sciences.

S. I. Ospanov, sociologist in the Kazak Academy of Sciences, prepared ethnographic studies of the water systems and water use in Aralsk, Kazalinsk, and Novo-Kazalinsk, and compiled a socioeconomic profile of communities in the project area. Barberghen S. Dosmanbetov, rector of the Korkuta Kzyl-Orda Pedagogical Institute, prepared a demographic profile of the area. Leonid Gurevich and Irina O. Malkova of the Giller Institute prepared the household survey and analyzed the household data. The Kzyl-Orda Pedagogical Institute managed field implementation of the household survey and hosted the stakeholder workshop. The Institute of Economics of the Kazak Academy of Sciences prepared an economic assessment of development prospects in the two target districts. Nataly Beisenova of the World Bank resident mission in Kazakstan prepared proceedings of the stakeholder workshop.

Bulent Ozbilgin and Ilya Lipkovich provided data analyses.

The Fund for Innovative Approaches in Human and Social Development and the Dutch Consultant Trust Fund provided financial support.

1. See chapters 1 and 2 of this volume for a full discussion of the conceptual framework for a needs and social assessment.

2. Repair and Maintenance Organization 1 is responsible for operating and maintaining the pipeline, monitoring water quality along the pipeline, and distributing water to Aralsk City (Aralsk Vodokanal), Saksaul train station, rural settlements outside the city borders (Jambul, Kulundi, and Zhizhaga). Repair and Maintenance Organization 2 is responsible for operating and maintaining the 70-kilometer pipeline from Kambash (Akbai) to Novo-Kazalinsk, monitoring water quality along the pipeline, and distributing water to Kazalinsk Vodokanal and four rural settlements outside the city borders (Basikara, Kumzhiek, Muratbayev, and Zhalantos Batyr).

\section{7 - \\ Strengthening Ashgabat's Urban Transport System}

\author{
Ayse Kudat, Stan Peabody, Ovezdurdy B. Muhammetberdiev, and Klaus Moeltner
}

This chapter analyzes social aspects of urban passenger transport problems in the city of Ashgabat, capital of Turkmenistan.* To the World Bank's proposed Turkmenistan Urban Transport Project this study contributes a focused social analysis-findings on the behavior, views, and interests of the users and suppliers of public and private transportation. The report concentrates on passenger transport use patterns and needs. In particular, it analyzes the extent to which public demand for transport is being satisfied and how willing and able users are to pay more for better services. The answers to these questions have not only helped design project components; they have also facilitated a useful policy dialogue with the government of Turkmenistan and enabled public transport managers to introduce a number of small but extremely effective reforms that raised levels of public satisfaction with what had been a service in steady decline. 


\section{Social Assessments for Better Development}

Ashgabat, located at the southern edge of the Kara Kum Desert, contains more than 500,000 people. Its working population of 220,000 accounts for 42 percent of the total population.1 Over the past few years the city's population has grown by an average of 8 percent a year. Public investment to maintain and expand infrastructure and urban services has lagged behind the rapidly growing demand, however. The gap between demand and service provision is particularly evident in the public and private transport sector. The city's public transportation consists of a trolley bus system operated by the municipality and bus, minibus, and taxi services operated by the Ministry of Transport. The core of the bus fleet consists of large buses produced in other states of the former Soviet Union and new minibuses from Iran. Many enterprises, ranging from private firms to state industries and government departments, also operate buses or vehicles rented from the ministry to serve the needs of their employees; yet the drivers also use them to supplement public buses, particularly on lucrative routes.

The public transport system is complemented by a growing fleet of private cars used for taxi services. Despite taxi licensing laws in place since January 1995, informal transportation activities are still mostly unregulated. Nevertheless, the law makes it difficult for the informal fleet to provide services at affordable prices.

The public transport system is plagued by low vehicle use (only 60 percent of the fleet is operable), a short operational life of vehicles (buses, for example, last only six to seven years, half as long as in Western economies), weak institutional structure and management, poor cost recovery, and an inadequate road infrastructure. These problems bear particularly heavily on the poorest segments of the population, where households spend a disproportionately large share of their incomes on transportation. These households express widespread dissatisfaction with transport services, as found by the social assessment, and remedial actions have been taken to address their needs.

The purpose of the proposed project is to improve transportation in Ashgabat so that it operates efficiently, effectively, and sustainably. This chapter presents the results of empirical

research conducted in February 1995 as part of the World Bank's project identification process. The social assessment focused on the potential beneficiaries of the proposed project - transport users and enterprise transport suppliers - to better understand transport use patterns and needs. An attempt was made to understand the sources of widespread dissatisfaction with transport services and to incorporate beneficiary views into the project design. Because cost recovery is critical to the sustainability of public transport, the social assessment also paid special attention to the cost of transport to individuals and families and to users' ability and willingness to pay higher fares.

In addition, the social assessment aimed to help identify the most critical interventions that could be undertaken immediately_changes that could be implemented locally without additional external capital investment to improve public transport in Ashgabat. This objective was fulfilled. Within a month of the assessment's completion, and on the basis of a verbal presentation of its findings, local transport officials had already begun to respond and to use the findings to make operational reforms. By September 1995, when officials and academics met to discuss the findings of the social assessment, the results of the reform process were already visible, and public levels of dissatisfaction had been reduced. That joint discussion identified additional ways in which the results of the social assessment could be used, and proposed significant further modifications to transport policy and practice. Thus this report represents a record at one point in time of the urban transportation situation in Ashgabat - a situation that is in a process of significant change and evolution.

The social assessment was conducted by two teams from the Magtymguly State University, Ashgabat, and the Turkmen Academy of Sciences, Ashgabat, both led by prominent Turkmen sociologists. Eighty-one local social scientists and computer specialists conducted about 2,000 structured interviews and analyzed the data. The research efforts were supported by a team of social scientists from the World Bank. The social assessment investigation consisted of the following activities: 


\section{Social Assessments for Better Development}

A household survey was administered to 590 households randomly selected from the city's sixteen districts (called micro rayons) in proportion to the district's population. The survey's purpose was to gain basic household information, assess household behavior, and analyze the actual and potential needs of transport users. Interviews covered family size, labor force participation, income, schooling, and family food budgets; access to, use, and costs of public and private transport; and satisfaction with Ashgabat public transportation. 2

A transport user survey was conducted at bus stops throughout the city at various times of the day. $\underline{3}$ More than 1,000 interviews were held with people waiting at bus stops. Questions referred to the time spent waiting and journeying; the uses, costs, and purposes of transport; satisfaction and needs; income; and willingness to pay for improvements. 4

Observations of vehicle frequency and passenger demand were made at 301 sites, with survey supervisors counting the number of men, women, and children waiting at the bus stop and recording the results, three times at each site, at five-minute intervals (for a total of 903 observations). At each site the supervisors also counted the number of buses, trolleys, minibuses, and enterprise and private carriers—excluding taxis—-that stopped at the bus stop or passed by (301 observations of transport traffic from early morning to late at night).

An enterprise survey was conducted to obtain information on the status and importance of enterprise transport and on prospects for changes in its status. The survey covered ninety-two enterprises and institutions (industrial, commercial, governmental, non-governmental) $\underline{5}$ that together employ more than 20,000 people and operate 1,763 vehicles, 48 percent of which are passenger vehicles.

In addition to surveys, the research team conducted informal interviews and meetings with household members, transport users, enterprise representatives, and transport suppliers.

A semistructured survey of thirty drivers (bus, trolley, and minibus) on work conditions and

job satisfaction and a rapid survey of the monthly transport pass system from twelve users and eighteen nonusers were performed in June 1995.

A stakeholder workshop, held shortly after field work was completed, brought together the researchers, the representatives of the Ministry of Transport and the municipality, and World Bank mission members to share preliminary survey results and to exchange concerns and ideas. In September 1995 a World Bank mission visited Ashgabat to review the social assessment findings and agree to further actions, including proposed policy reforms and an operations improvement plan.

Thus the social assessment was a mechanism that, by gathering the views of the urban population, enabled this group to make known its views with regard to the kinds of changes needed in public transport and the consequences - for the people and the economy — of the current public transport situation. Particular attention was paid to gender and ethnic issues and to ensuring that low-income groups were included in the assessment. To these were added the views of other stakeholders, particularly those—such as drivers and managers—without whom change would be difficult to implement. Through the work process triggered by the preparation of a World Bank-financed project, the social assessment was able to ensure that transport users' concerns were heard by and had an effect on management. A process of consultation has been set in motion that shows every sign of continuing.

This introduction closes with a brief summary of some of the main household characteristics derived from the survey (box 7.1, table 7.1). The next section of the chapter presents and interprets the findings of the social assessment by topic, integrating the findings of the different surveys. The concluding section sets out implications for project design and identifies the positive effects the social assessment has on transport policy and operations 


\section{Social Assessments for Better Development}

and in providing a framework for stakeholder participation.

\section{Main Findings}

The most important conclusion that can be gained from the surveys undertaken in February

\section{Box 7.1 Characteristics of the households surveyed}

On average, there are 4.5 people in a household, with 2 of them working. Almost 79 percent of families are Turkmen, 17 percent are Russian, and 4 percent belong to other ethnic groups. The ethnic percentages of workers are similar.

Most households (86 percent) live in apartments, while 14 percent own or rent single houses. Privatization in the housing sector has permitted a high level of de facto home ownership, with some citizens owning several housing units. Households' average monthly income from official and informal sources is about 7,500 manats, of which almost 80 percent goes toward food (see table 7.1).

There are slightly more working men than working women in a household— 55 percent compared with 45 percent—with male workers earning an average of 22 percent more than female workers.

1995 is that the residents of Ashgabat were deeply unhappy with urban transportation. 6 No matter how the questions were phrased, to whom they were addressed, or how the results were disaggregated, nearly 90 percent of the respondents expressed dissatisfaction with the public transport system. Without exception, these views were expressed by every social group: workers ( 89 percent of respondents not satisfied), workers by district (82-100 percent), public transport users (90 percent), and those who walked to work (87 percent), with comparable levels for Turkmen (88 percent), Russians (94 percent), women (90 percent of households and 93 percent of users) and schoolchildren. This dissatisfaction results from the poor availability, operation, and maintenance of vehicular services as well as from inadequate road network and transport support infrastructure.

\section{Table 7.1 Average characteristics of the households surveyed}

\section{Characteristic}

Household size

Total number of working people

Number of working men

Number of working women

Number of children under 15

Number of schoolchildren

Retired persons

Share of households living in an apartment(percent)

\section{Response}

1.1

0.9

1.3

1.3

0.5

85.9

14.1 


\section{Social Assessments for Better Development}

Share of households living in a single

house (percent)

Total monthly family income

(manats)

Share of household income spent on

79.3

food (percent)

a. At the time of the survey, February 1995, wages had increased 2.8 times. Source:

Household survey.

Dissatisfaction with bus and minibus services was especially pronounced and was directly related to the high and unpredictable prices paid for low-quality services. As this report shows, poor workers are particularly dependent on the public transport system. Poor workers also pay a larger share of their incomes for these services than do better-off workers. This section details the main reasons for high levels of dissatisfaction and the way in which the findings were used to introduce a series of internal reforms.

Urban passenger transport in Ashgabat is mainly used for commuting to work, shopping, visiting friends and relatives, attending school, and engaging in leisure activities. The following modes are available:

Personal transport — bicycle, motorcycle, private car

Taxi —official Ministry of Transport taxi or unofficial private car

- Enterprise bus - transport provided for employees by some industries and organizations

Public transport — trolley bus (operated by the

municipality) or bus or minibus (Ministry of

Transport).

In this chapter the term users, unless otherwise qualified, refers to all public transport users, whether exclusive or not. People who rely exclusively on walking to commute to work and who do not take transport are referred to as walkers. Thus workers who are walkers on weekdays may become weekend users, for example, to visit a friend or relative.

\section{Who Depends on Public Transport?}

Commuting workers, shoppers, and others depend on public transport.

Commuting workers. Public transport is by far the most important sector of urban passenger transport, particularly for commuting to and from work. Public transport is also the area that the public is most dependent on and most dissatisfied with.

The dependence on public transport - as well as its cost, unreliability, and burden on the poor-is illustrated by the means chosen to commute to work. More than 60 percent of workers commute at least partly by public transport (bus, trolley 
bus, or minibus), and more than half depend exclusively on some form of public transport (table 7.2) $\underline{7}$ Almost half the users of public transport are commuting to work (figure 7.1).

Workers also use other, nonpublic modes to commute to work:

Twenty percent of workers walk for their entire commute to work

Almost 20 percent of households reported at least one working member using a privately owned car to commute, exclusively or in combination with other means. Fourteen percent of workers use cars to get to work at least part of the way.

About 15 percent of workers rely on enterprise transport to some extent, and 9 percent use this mode exclusively. About 27 percent of households contain workers that use enterprise transportation. The role of enterprise transport is discussed in a later section.

Shoppers and others. Shoppers also depend on public transportation: 54 percent of shoppers use buses, trolleys, or minibuses to shop, with 48 percent relying on buses and trolleys alone. Among household respondents 30 percent walk to shops without using public or private transportation.

Most schoolchildren walk to school. Only 8 percent claim that their journey involves a bus, trolley, or minibus. Most children are in preschool and elementary school (the average age of observed schoolchildren was 8.7 years),

Table 7.2 Modes of transport used by workers

(percent)

$\begin{array}{ll}\text { Mode } & \begin{array}{l}\text { Used, not } \\ \text { exclusively }\end{array} \\ \text { exclusively }\end{array}$

\section{Nonpublic}

$\begin{array}{lll}\text { Walk } & 20.2 & -\mathrm{a} \\ \text { Car } & 10.2 & 13.8 \\ \text { Enterprise bus } & 9.3 & 15.2 \\ \begin{array}{l}\text { Any nonpublic } \\ \text { mode }\end{array} & 39.7 & 45.0 \mathrm{~b}\end{array}$

\section{Public}

$\begin{array}{lll}\text { Bus } & 11.1 & 43.9 \\ \text { Minibus } & 2.8 & 29.3 \\ \text { Trolley } & 2.3 & 24.1 \\ \text { Bus and minibus } & 8.2 & 21.0 \\ \text { Bus or trolley } & 19.3 & 49.8 \\ \text { Bus, trolley, or } & 55.0 \mathrm{~b} & 60.3\end{array}$


minibus

Note: Taxis were not included because they are considered insignificant for commuting.

a. Because most people walk part of their commute, this figure was not calculated.

b. These figures were not calculated but are estimates that are roughly the midpoint of the range of what is possible, given other data.

Source: Household survey.

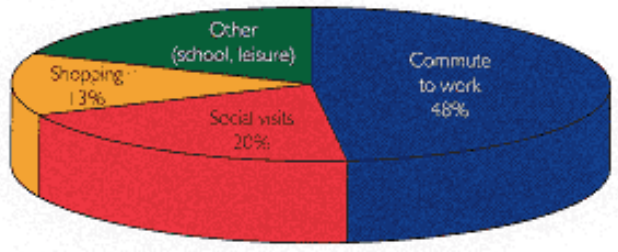

Figure 7.1

Uses of public transport

Source: Household survey.

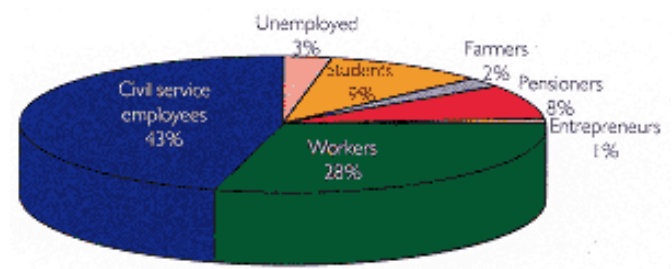

Figure 7.2

Users of public transport

Source:Household survey.

and the distances between homes and primary schools are usually short.

Various categories of workers-civil service employees, workers, and a small number of other professions and occupations-constitute about 75 percent of the users of public transport (as measured by those waiting for it). Thus about a quarter of public transport users are in categories that are sometimes termed not economically active-students, housewives, pensioners, the unemployed, and so on (figure 7.2). Similarly, almost 40 percent of public transport trips are made not for strictly economic reasons but for social purposes, led by education and leisure (19 percent) and family and social visits (20 percent; see figure 7.1).

\section{User Profiles: Poverty, Gender, and Ethnicity}

Figure 7.3a compares the incomes of public transport users (those waiting at bus stops for 


\section{Social Assessments for Better Development}

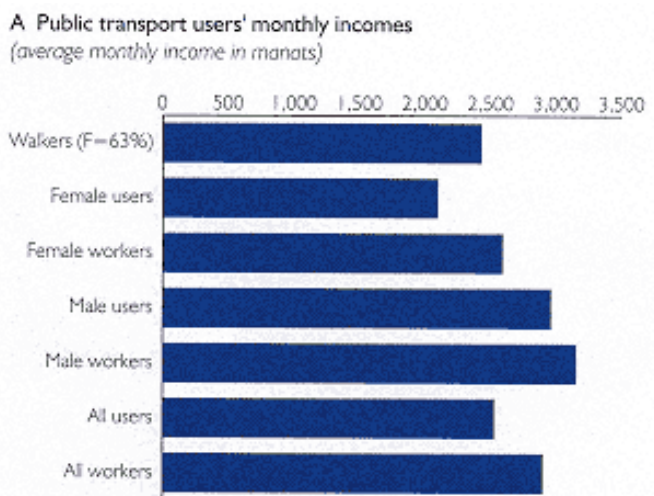

$B$ Vehicle being waited for

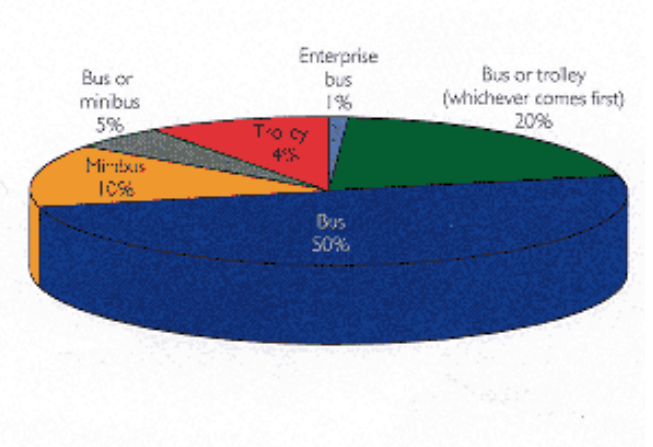

Figure 7.3

Influence of income on commuting

Note:Walker=only walks to work; user=uses public transport to work.

Source:Household survey and surveys of users waiting at bus stops (taxis omitted).

public vehicles) with those of working people in general $\underline{8}$ Public transport users have substantially lower monthly incomes than workers in general:2,533 manats compared with 2,903 manats. Gender comparisons show that female users are substantially poorer than male users: the women's monthly earnings are 30 percent lower than those of the men (2,101 manats compared with 2,965 manats).

The finding that public transport users are poorer than workers in general is supported by the choice of mode of public transport relative to the cost of travel by that mode. As noted above, commuters rely much more on buses than on minibuses and trolleys. Nearly 50 percent of workers depend on buses or trolleys for at least part of their commute, but only 30 percent use minibuses, and only 3 percent rely on minibuses exclusively. The user survey confirmed this finding. When people waiting at a bus stop were asked which mode of transport

they were waiting for, more people (50 percent) said they were waiting for a bus than for any other mode of transport (figure 7.3b). Three categories - waiting for a bus, for a trolley, or for either-accounted for the vast majority of users. This exclusive waiting for a cheaper vehicle is called dependency in this chapter. Only 15 percent of users claimed to be waiting for minibuses exclusively or as an alternative to buses. $\underline{9}$ This preference is based significantly on cost. Even when unofficial tariffs were applied, buses and trolleys still cost half as much as minibuses. Also, larger vehicles are safer and less crowded. These findings once again show the wide use and importance of publicly owned transport - especially regular buses - to Ashgabat's population, and the need to make improving these vehicles a priority.

The social assessment clearly demonstrates that the improvements to the public transport system, and particularly improvements in bus and trolley services, would directly serve the needs and interests of low-income groups, especially women. This conclusion is amplified in the comparison of districts below.

Female workers are likely to be slightly older than their male counterparts, work closer to home, pay less for commuting, earn less, and be somewhat more dissatisfied with transport arrangements (table 7.3). Women are also much more likely to walk to work than men, much less likely to take a car or enterprise bus, and slightly more reliant on buses and trolleys for commuting (table 7.4 and figure 7.4). Men and women display similar preferences in their choice of vehicle.

Workers who walk the entire way to work are here termed walkers. (Most schoolchildren and 30 percent of shoppers also journey by walking all 


\begin{tabular}{|c|c|c|c|}
\hline Characteristic & $\begin{array}{l}\text { All } \\
\text { workers }\end{array}$ & Male & Female \\
\hline Age (years) & 37.4 & 37.1 & 37.7 \\
\hline $\begin{array}{l}\text { Monthly income } \\
\text { (manats) }\end{array}$ & 2,903 & 3,158 & 2,595 \\
\hline $\begin{array}{l}\text { Number of days at } \\
\text { work per week }\end{array}$ & 5.4 & 5.4 & 5.3 \\
\hline $\begin{array}{l}\text { Nominal walking } \\
\text { time from home to } \\
\text { work (minutes) }\end{array}$ & 55.8 & 59.9 & 50.8 \\
\hline $\begin{array}{l}\text { One-way } \\
\text { commuting cost } \\
\text { (manats) }\end{array}$ & 6.2 & 6.9 & 5.5 \\
\hline $\begin{array}{l}\text { Share not satisfied } \\
\text { with transport } \\
\text { arrangements } \\
\text { (percent) }\end{array}$ & 89.0 & 87.8 & 90.5 \\
\hline
\end{tabular}

the way, but are not included here). Twenty percent of workers are walkers. Table 7.5 compares some of the characteristics of walkers with those of public transport users (many of whom walk for part of their commute). Walkers are more likely to be female, to work close to home, and to spend less time commuting. They also earn a good deal less than nonwalkers, mainly because many of them are low-paid women and because women earn less in general (see table 7.3 and figure 7.3a). The level of dissatisfaction with public transport was almost as high among walkers as among users, since walkers use public transport for other purposes such as shopping, school transport, or visiting friends and relatives.

Three main factors influence a commuter's decision to walk to work: $\underline{10}$

A short distance to the workplace

Insufficient funds for regular use of public or private transport

Unavailability or low frequency of public transport between home and work. Some walkers, especially those constrained by cost or transport availability, will probably become users once the system improves and prices stabilize. They are clearly not indifferent to the public transport situation, as the data show.

\section{Experience of Public Transport}

For users, five factors are paramount in determining satisfaction with transport services: 
time, cost, dependability or predictability, comfort, and safety. Of these, time and cost are examined in more detail, and the adverse influence of unpredictability on both will be seen. Only anecdotal or superficial information was obtained on comfort and safety. In examining these five fac-

Table 7.4 Transport modes of the average worker, by gender

(percent)

\begin{tabular}{|c|c|c|}
\hline Mode & Male & Female \\
\hline Walking only & 13.6 & 28.3 \\
\hline Commute includes car & 19.7 & 6.5 \\
\hline $\begin{array}{l}\text { Commute includes enterprise } \\
\text { bus }\end{array}$ & 19.7 & 9.6 \\
\hline $\begin{array}{l}\text { Commute includes bus, } \\
\text { trolley, or minibus }\end{array}$ & 53.7 & $57.0 \mathrm{a}$ \\
\hline $\begin{array}{l}\text { Commute includes bus or } \\
\text { trolley }\end{array}$ & 48.4 & $51.5 \mathrm{a}$ \\
\hline $\begin{array}{l}\text { Commute depends on bus or } \\
\text { trolley only }\end{array}$ & 17.6 & $21.4 \mathrm{a}$ \\
\hline
\end{tabular}

a. Difference is not statistically significant.

Source: Household surveys.
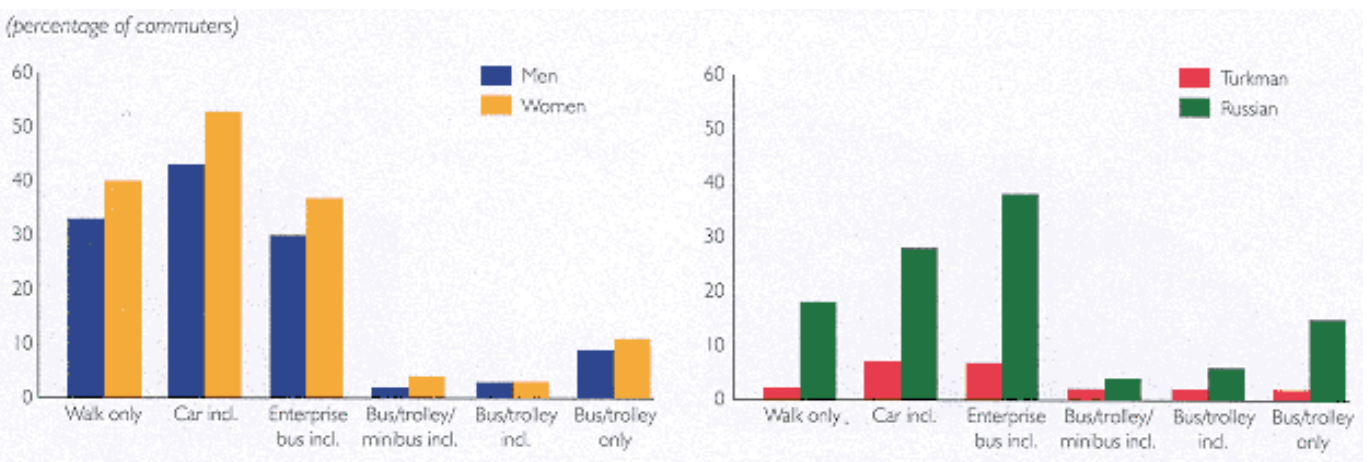

Figure 7.4

Gender, ethnicity, and workers' mode of transport

Note: The columns show the extent to which different groups vary in the proportions of their use of different modes of transport from the average proportions of their participation in the labor force.

Thus, for example, women are $40 \%$ more likely to walk to work than the composition of the labor force would suggest. Russians are nearly $30 \%$ less likely to use a car. Source:Household survey.

tors, many of the causes of dissatisfaction with public transport become apparent. 


\section{Social Assessments for Better Development}

Time. The total time spent on a journey involves the walk to the bus stop, the wait at the bus stop, and travel time in the vehicle.11 Depending on the destination, the user may have to take more than one vehicle (a vehicle ride is referred to as a trip). Most transport users (65 percent) only need to take one vehicle to complete a journey.

Around 26 percent of riders take two vehicles, and slightly less than 10 percent take more than two vehicles. On average, people use 1.5 vehicles a journey. The number of vehicles used has a major effect on the duration, cost, and predictability of the journey.

For most Ashgabat residents a journey to get to work, the market, or other destinations starts with a walk to a bus stop. The average duration of this first walk is nine minutes, with 81 percent of users walking ten minutes or less. Only 5 percent walk more than twenty minutes (figure 7.5 ).

\section{Table 7.5 Characteristics of walkers and transport users}

\begin{tabular}{|c|c|c|}
\hline Characteristic & Walkers & $\begin{array}{l}\text { Transport } \\
\text { users }\end{array}$ \\
\hline Monthly income (manats) & 2,430 & 3,050 \\
\hline $\begin{array}{l}\text { Duration of commute } \\
\text { (minutes) }\end{array}$ & 18.6 & 40.8 \\
\hline $\begin{array}{l}\text { Nominal walking time from } \\
\text { home to work (minutes) }\end{array}$ & 18.6 & 65.6 \\
\hline $\begin{array}{l}\text { Share working in home } \\
\text { district (percent) }\end{array}$ & 54.3 & 11.3 \\
\hline $\begin{array}{l}\text { Share who are female } \\
\text { (percent) }\end{array}$ & 62.9 & 40.3 \\
\hline $\begin{array}{l}\text { Share who are dissatisfied } \\
\text { with public transport } \\
\text { (percent) }\end{array}$ & 86.9 & 89.8 \\
\hline \multicolumn{3}{|c|}{$\begin{array}{l}\text { Note: Walkers are workers who walk the entire } \\
\text { distance to work. Transport users are workers who } \\
\text { use public or private transport at least for part of } \\
\text { their commute. }\end{array}$} \\
\hline
\end{tabular}

This time is quite predictable and is not a problem for most.

The problems begin at the bus stop, where about 30 percent of users wait five minutes or less (figure 7.6). A large portion of users (47 percent) wait between ten and twenty minutes for their ride. The average waiting time is about seventeen minutes, but passengers changing vehicles to arrive at their final destination will wait an additional average seventeen minutes.

These average waiting times do not seem unacceptable, and taken at face value the figures hardly seem to explain widespread dissatisfaction. But waiting times show wide variance, particularly by time of day and on weekends. Variations in waiting times are lowest in the early morning, rising at off-peak times, rising higher at peak evening 
times, and rising highest on week-

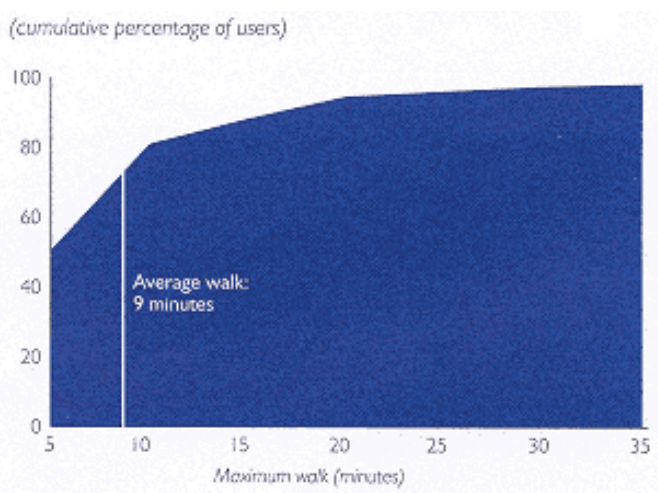

Figure 7.5

Length of time to walk to nearest bus stop Source: User survey.

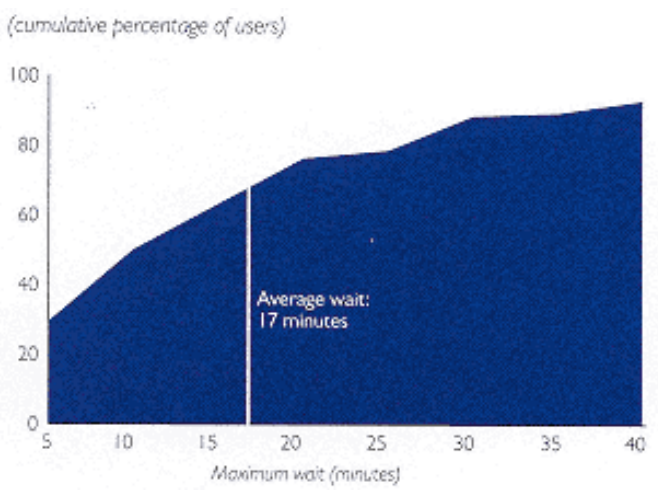

Figure 7.6

Length of time to wait for public transport Source: User survey.

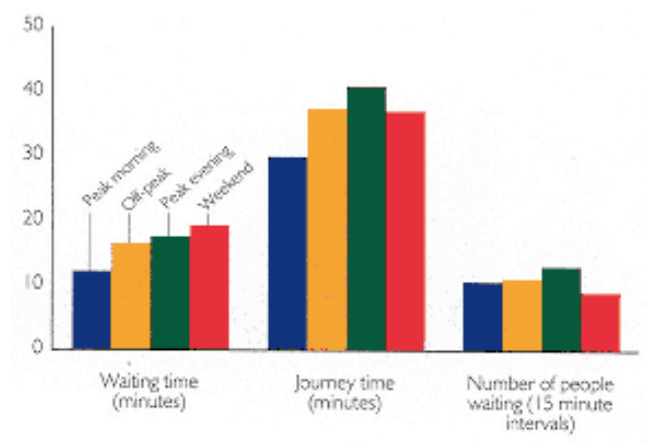

Figure 7.7

Waiting times, journey times, and vehicle congestion, by time of day

Source: User survey.

ends (figure 7.7). It is not statistically possible to differentiate waiting times by type of vehicle. The variations in 


\section{Social Assessments for Better Development}

waiting times are too great, and many people, after waiting a long time in vain for a bus or trolley, end up taking a minibus at twice the cost. Average waiting times are shortest for taxis (about eight minutes) and longest for enterprise buses (twenty-five minutes).

The longer the waiting time, the more crowded the vehicle is likely to be. Using the number of people waiting at a bus stop as a proxy measure of the extent to which vehicles were crowded, bus stops and vehicles are most crowded at peak evening hours (an average of thirteen people waiting).

More important, however, was the unreliability of the services and the uncertainty about transport service schedules. Commuting workers are also affected by the need to get to work on time and by the longer waits and greater unpredictability at the end of the day. 12 Unpredictability causes employees to arrive late for work. Moreover, job turnover rates are high because people are constantly trying to find work near their home to avoid long commutes. Employees who work late often must be taken home by enterprise or rented vehicles because no public transport is available after hours. Also, inadequate public transport during non-peak hours hinders shift work. According to personal observations and comments made by field supervisors, buses often do not stop at designated stops. The variation in waiting time results from the imbalance between the demand and supply of urban transport, and particularly from the infrequency and unpredictability of the arrival of vehicles at bus stops. Although the public transport system shows a fairly satisfactory frequency at the beginning of the day, it slacks off as the day goes on, and can hardly satisfy demand during the peak evening hours. This situation causes enormous hardship to commuting workers and leads to many complaints. Moreover, public transport comes to almost a complete standstill during weekends. The frequency of different types of vehicles stopping at bus stops was observed during various periods. $\underline{13}$ Vehicle frequency is not a measure of the number of passengers traveling by that means, because different vehicles have very different carrying capacities. The results of the analysis are shown in figures $7.8 \mathrm{a}$ and $7.8 \mathrm{~b}$. In particular, these patterns can be seen:

Buses and trolleys. Taken together, there are 50 percent more buses and trolleys in the peak morning hours ( 3 vehicles every fifteen minutes; 64 percent of all vehicles stopping) than in the peak evening hours (2.1 vehicles; 50 percent). During off-peak hours the frequency is even lower (1.6 vehicles; 48 percent) and drops further ( 0.7 vehicles; 24 percent) during the weekend.

Minibuses show an opposite trend. Their lowest frequency is during the morning peak hours (1.4 vehicles; 30 percent) and they rise in frequency during the day, with the greatest frequency at times of peak demand in the evening ( 2 vehicles). Over the weekend they
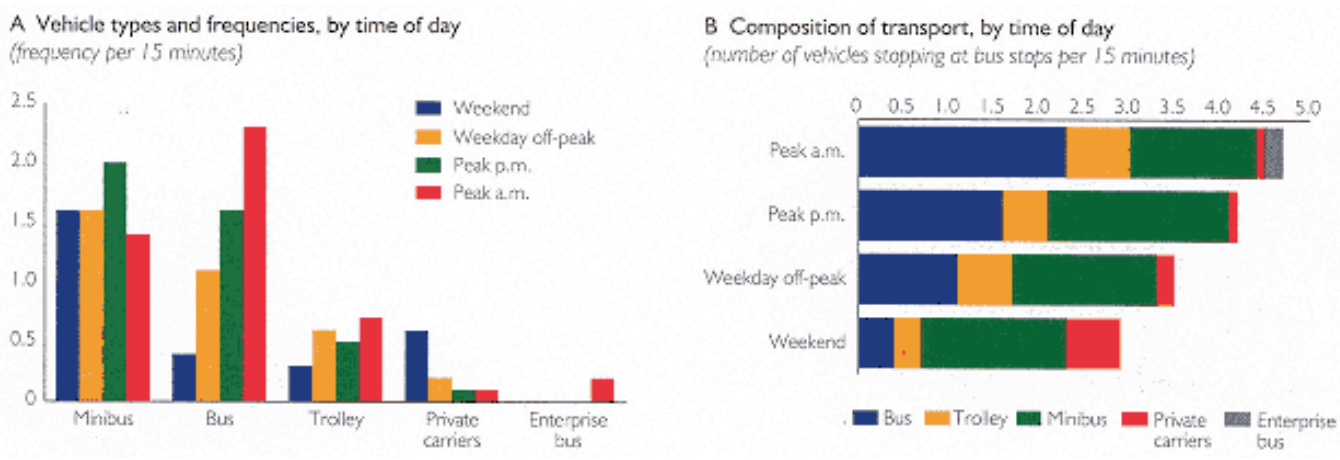

Figure 7.8

Results of vehicle frequency analysis

Source: Supervisor survey.

maintain an average frequency of 1.6 vehicles every fifteen minutes. 
Private carriers also show a contrary trend. They are more available at off-peak daytime hours (0.15 vehicles) and especially on weekends, when their frequency is four times as great ( 0.6 vehicles). This supply helps alleviate public transport shortages at these times, and is partly a function of the use of private cars as unofficial taxis.

Enterprise buses stop to take people to work.

Thus Ashgabat residents are more likely to use private vehicles on the weekend than on weekdays, partly because of the lack of public transport services and partly because of the greater availability of private carriers during that time.

The pattern of journey duration, including walking to and waiting at a bus stop, is shown in figure 7.9. The average journey lasts thirty-seven minutes, with the actual time spent in vehicles accounting for about eleven minutes. About 60 percent of journeys last thirty minutes or less, and 75 percent of journeys are shorter than forty minutes. Just more than 10 percent of users face journeys of one hour or more. The longest average journey time was observed during peak evening hours (forty-one minutes). Morning peak journeys are about eleven minutes shorter, and off-peak and weekend journey times (thirty-seven minutes) are close to the average (see figure 7.7). Although the variation among these numbers is not dramatic, there is a large potential to shorten waiting and journey times for many transport users.

There are no significant differences in journey time by gender, except perhaps that women's average journey is 1015 percent longer (table 7.6). Women are more likely to travel at off-peak times for purposes other than commuting, and thus at times when public transport services are slow. Thus women would particularly benefit from improvements in public transport.

Travel costs: why the poor pay more. The social assessment findings, especially on actual travel costs, opened the way to a policy dialogue and management and pricing reforms (see below). At the time of the survey (February 1995) many residents were paying far more than the official tariff, especially for buses and trolleys. To understand what users paid, a brief description of the fare system is useful. The official bus or trolley

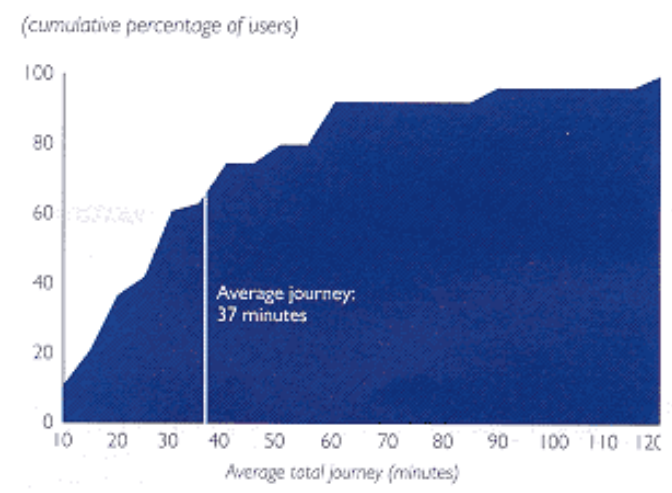

Figure 7.9

Total duration of journey using public transport Source: User survey. 
Table 7.6 Journey details, by gender

$\begin{array}{lcc}\text { Characteristic } & \text { Male } & \text { Female } \\ \begin{array}{l}\text { Waiting time at bus stop } \\ \text { (minutes) }\end{array} & 16.5 & 17.3 \\ \begin{array}{l}\text { Number of vehicles needed to } \\ \text { reach destination }\end{array} & 1.4 & 1.5 \\ \begin{array}{l}\text { Duration of journey (minutes) } \\ \text { Source: } \text { User survey. }\end{array} & 34.5 & 38.9\end{array}$

tariff was 5 tenge (100 tenge=1 manat). Each payment was good for only one trip, without transfers. For 30 manats users could buy monthly passes, supposedly good for buses and trolleys (not minibuses). Without a pass, fares had to be paid in cash; no single tickets were sold in advance. Because virtually no coinage is in circulation, 1 manat is in effect the smallest available denomination for cash transactions. Thus people paid a cash fare of 1 manat a trip and received no change, effectively paying twenty times the official tariff.

The official minibus fare in February 1995 was 2 manats. People could pay cash or buy a ticket for one trip, whatever the route or journey length. People normally paid cash. But minibus drivers often changed the fare arbitrarily, particularly if they decided to follow an unscheduled route and embark on detours. In this case passengers had to choose between paying special fares and getting off. Some drivers also charged more depending on the time of day. Official taxi charges were 2 manats a kilometer, but actual fares were on average five times higher.

Against this background the following patterns emerge of payments for trips and costs of journeys. Most users responding to the survey - 70 percent—-paid cash for their trips. Monthly bus and trolley passes and prepurchased minibus tickets each accounted for 15 percent of respondents. Passes were preferred by low-income residents: the mean monthly income of pass users was 2,118 manats, compared with the overall user average income of 2,533 manats. High-income groups were more likely to use minibus tickets (mean monthly income of 2,374 manats) or to pay cash (2,666 manats). Most cash riders (79 percent) paid the official 2 manats for each minibus trip, twice the official bus and trolley fare. The average trip cost for cash payers was 3.2 manats (table 7.7). A minority paid much more - up to 50 manats per trip.

Table 7.7 Trip and journey characteristics

\begin{tabular}{|c|c|c|}
\hline Characteristic & Mean & Majority \\
\hline $\begin{array}{l}\text { Cost of a trip } \\
\text { (manats) }\end{array}$ & 3.2 & $\begin{array}{l}79 \text { percent pay } 2 \\
\text { manats }\end{array}$ \\
\hline $\begin{array}{l}\text { Number of vehicles } \\
\text { needed to complete } \\
\text { journey }\end{array}$ & 1.46 & $\begin{array}{l}65 \text { percent need } \\
\text { I vehicle }\end{array}$ \\
\hline $\begin{array}{l}\text { Total cost of journey } \\
\text { (manats) }\end{array}$ & 5.12 & $\begin{array}{l}45 \text { percent pay } \\
\text { less than } 2 \\
\text { manats; } 73 \\
\text { percent pay less } \\
\text { than } 4 \text { manats }\end{array}$ \\
\hline
\end{tabular}




\section{Social Assessments for Better Development}

\section{Source: User survey.}

These data and information gained through informal interviews revealed that people were in constant uncertainty as to how much they would end up paying for trips and journeys as well as how long journeys would take. Price gouging by drivers was the main cause of this uncertainty, and the main result was extensive and widespread dissatisfaction.

At the time of the household surveys lowincome groups were spending a substantially larger portion of their income on public transport than higher-incomes households. The poorest quarter of households spent 12.8 percent of their income on public transport; the richest quarter spent 6.11 percent.14 Because lower income travelers are more likely to ride buses or trolleys and to use monthly passes, their higher relative expenditure may have resulted from their being forced to use non-pass vehicles, owing to the unavailability of buses or trolleys. Sometimes bus and trolley drivers may not honor passes or may demand surcharges. This would help explain why only 15 percent of transport users use monthly passes despite the theoretical potential for savings on fares.

These questions led in June 1995 to a brief survey of thirty respondents to investigate why more people did not avail themselves of the cost-effective pass system. Twelve of the thirty respondents used passes; eighteen did not. By that time passes cost 30 manats (raised in the second week of April 1995) and were sold in buses and trolleys, as well as at kiosks at the final stops of major bus lines in the city center. All respondents knew about the passes and where to buy them. Only a few knew how much they cost, or that they were valid for both buses and trolleys.

Pass users. Users with passes found them convenient because of scarcity of the coins needed

to pay the exact fare and because it was often impossible to buy an individual ticket in overcrowded vehicles. Non-users of passes were allowed to give up to three reasons for their choice. The most frequently cited response was that they mainly used minibuses. Other reasons were that buses were too crowded and infrequent (79 percent of responses) and too expensive (36 percent), that respondents did not usually use buses or trolleys (29 percent), and that drivers did not honor passes (14 percent). Thus passengers confirmed that drivers asked pass-holders for surcharges.

All respondents thought the introduction of special, lower-priced passes for disadvantaged groups was a good idea that would find widespread support among the city's populace. The findings supported the conclusion that passes would only be useful to a larger group of users if bus and trolley services were improved first. The price of a pass is now more than some residents are willing or able to pay. The idea of special passes for low-income groups, the elderly, and other vulnerable social groups is discussed later in this chapter.

What the drivers said. This picture of transport costs indicates that drivers are important stakeholders in the transport system, for they make decisions on taking unscheduled routes or charging passengers extra fares. Accordingly, a short, semistructured survey of thirty drivers was conducted in June 1995. The sample included ten each of bus drivers, trolley drivers, and minibus drivers. Interviews were held in the work situation, in vehicles, or in garages during breaks between shifts. Given the management changes implemented as a result of the social assessment, particularly as they relate to drivers' earnings, motivation, and behavior (see below), the findings reported here relate strictly to the situation at the time of survey, and may or may not reflect the current situation.

Drivers are usually hired and paid by local transport enterprises that, in turn, are contracted by the Ministry of Transport to provide transport services to the population. Bus and trolley drivers work eight hours a day, six days a week. Minibus drivers work ten- to twelve-hour shifts for three or four days a week. Bus and trolley drivers had no opportunity to earn overtime pay, but minibus drivers frequently provide transport services after fulfilling 


\section{Social Assessments for Better Development}

their official workload, keeping the money earned during that time. It was not clear whether employers encouraged or tolerated this behavior, or whether the overtime use of public buses indicated a severe lack of control and supervision by enterprise management. Minibus drivers claimed that the additional earnings could range from 5003,000 manats per month-16100 percent of their official salary.

Depending on seniority, bus drivers earned from 2,5008,500 manats a month, trolley drivers earned 4,0006,000 manats, and minibus drivers earned 3,0005,000 manats. None of the respondents was satisfied with his salary. An acceptable monthly salary was considered to be 20,00040,000 manats (bus drivers), 10,00025,000 manats (trolley drivers), and 5,00010,000 manats (minibus drivers, apparently expecting continued overtime earnings).

When asked if they collected extra charges from passengers, only one driver admitted that it was sometimes done. But twelve of the thirty drivers gave reasons for overcharging, including The current salary is not enough to make a living or to support a family; We have to pay for spare parts out of our own pocket; and Our management encourages us to overcharge. No respondent admitted taking additional payments from pass holders.

Drivers were asked what they liked about their job. Only about half the respondents could think of job features that they actually liked, such as their work environment and their colleagues. About 70 percent of drivers supplied information on what they did not like about their job. The three most common complaints were the low salary, the inadequate supply of spare parts, and the rudeness and bad behavior of passengers.

Because bus drivers were generally dissatisfied with their salaries and many other aspects of their job, they had a strong incentive to earn extra income by overcharging passengers or, in the case of minibus drivers, by providing transport services using public vehicles. This conclusion supported the recommendation to recognize the need to create appropriate incentives for drivers,

to foster discipline, and to ensure adequate performance through enhanced supervision by transport management units.

Safety and comfort. Passengers, especially the elderly and children, are more likely to get injured trying to board a vehicle at bus stops at peak times.15 The extremes of summer heat and winter cold, and the lack of benches or shelter at many bus stops, also particularly affect the elderly and infirm.

Drivers were asked to grade the technical condition and safety of their vehicle on a scale of 1 to 5 , with 5 being the best. Minibus drivers gave the best grades (average 3.3), followed by trolley drivers (2.8) and bus drivers (2.3). This result was expected because minibuses, a recent addition to Ashgabat's transport fleet, are usually no more than two to three years old. Buses and trolleys tend to be two to three times older. Minibus drivers said that the most important technical improvement to the vehicle was an additional door and a wider aisle. Bus and trolley drivers voted for air conditioning and more seats.

Bus and minibus drivers believed that the most important steps to improve road safety were wider roads, better street lighting, and, most of all, a better control mechanism to ensure an acceptable technical condition of other, nonpublic transport vehicles.

\section{Identifying Priority (Problem) Districts}

The social assessment sought to determine which of Ashgabat's sixteen districts should be viewed as a priority for public transport improvements. The three key criteria used were high commuting volume (flows into and out of the district), high level of dependence on public transport for commuting, and great dissatisfaction with public transport. 
Although most work is done in the commercial central districts, most workers live in peripheral residential areas, especially to the south and east (figure 7.10). Twenty percent of workers work in their home district. Of these, half walk all the way to work and half use some means of transport. Most workers ( 80 percent) commute between districts.

The total commuting flow or volume into and out of each district is shown in figure 7.11a.16 The busiest district by far is the city center (district 7), with 44.1 percent of the total commuting flow. Six other districts also have a high commuting level: 11, 16, 6, 5, 3, and 13. Districts are also distinguished by the extent of their residents' dependence on public transport, effectively meaning dependence on buses and trolleys, the cheapest and most widely used transport modes (figure 7.11b). More than 60 percent of the residents of districts 11, 15, and 4 depend on public transport. Another six districts $(10,3,13,16,14$ and 5) show dependency rates of 4060 percent. Levels of dissatisfaction with public transport at the time of survey were universally high, ranging from 83100, with only six districts below 90 percent (figure 7.11c).

Putting together the seven districts with high commuting rates, the nine districts with high dependency, and the ten districts with highest dissatisfaction, three districts emerge with high scores across the board: districts 3, 13, and 16 (table 7.8). In addition, three more districts had particularly high scores on two criteria, making a total of six priority districts. Districts 4 and 15 both score high on dependence and dissatisfaction, and district 11 ranks

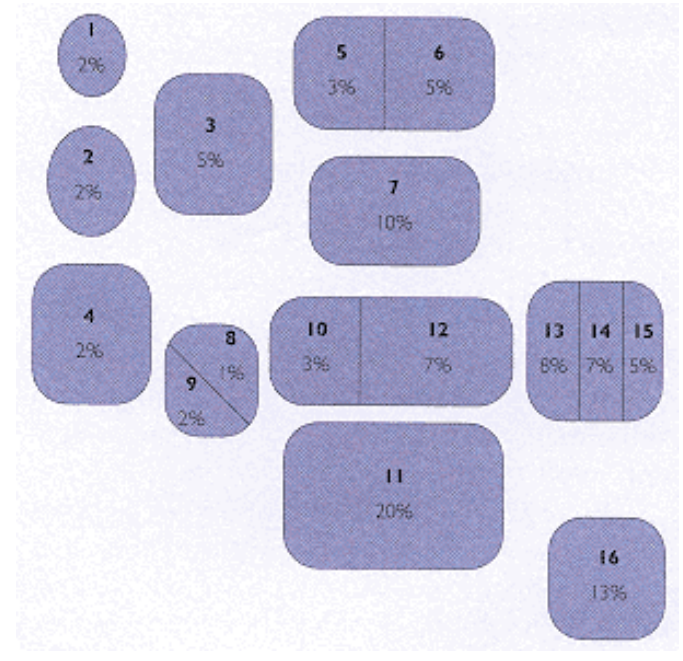

Figure 7.10

Ashgabat population distribution, by district

Note: The schematic shows the approximate geographical positions of each of the 16 districts, together with its share of city population. The percentages do not add to 100 because some of the city's population is not included within these districts.

Source: Science Network of Turkmenistan. 


\section{Social Assessments for Better Development}

\section{(percerin)}

A Commuting level

(overoge percentoge of commuters in and comimuters out)

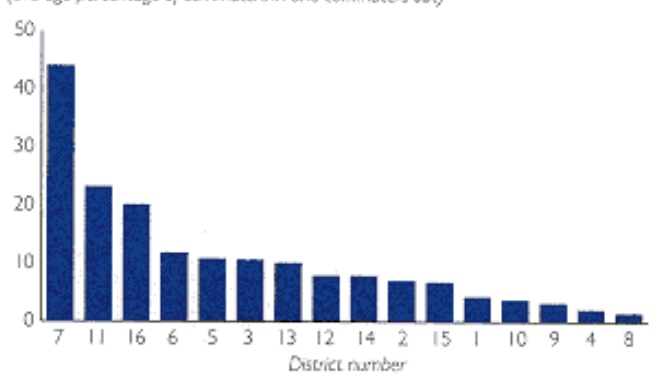

District number

C Dissatisfaction level

(ivercentoge of comviuters who are dissotisfied with fublic trowatport?

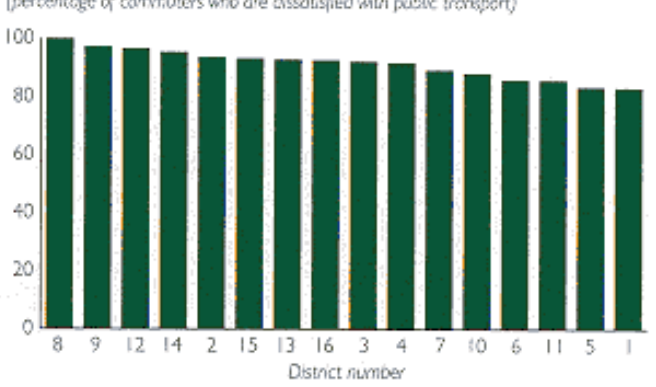

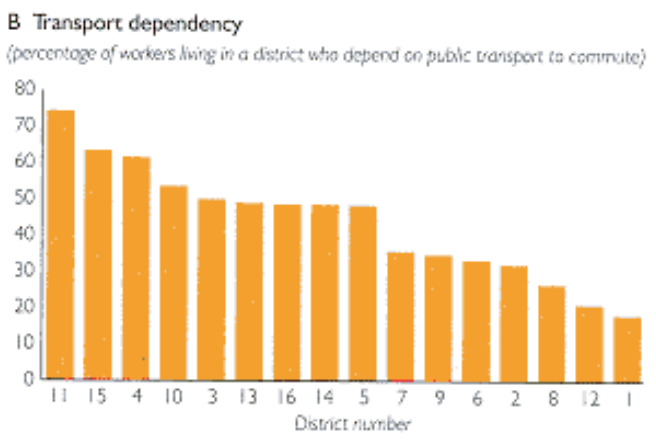

D Share of city population

(percentege of tity tropatation total $=958$;

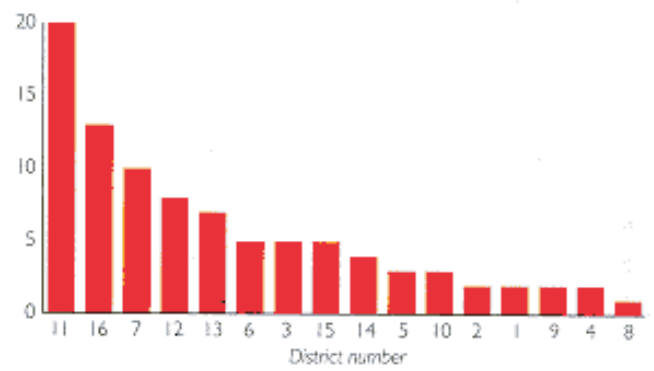

Figure 7.11

Ashghabat district characteristics

a. Expressed as the average of two percentages:

commuters out of this district as a share of all commuters'

districts of origin and commuters into this district as a share

of all commuters' destinations.

Source: Household survey.

first in dependence and second in traffic level. The peripheral districts, especially in the south and southeast, particularly suffer from transportation problems.

These six problem districts account for more than half of the city's population (figure 7.11d). How do income levels in these districts compare with other districts and with the citywide average? Of the problem districts, only districts 13 and 16 exceed the city income average (7,500 manats a month), and by very little (figure 7.12). District 15 is average, and the other three (3,4, and 11) have household incomes below the city average. Overall, the problem districts show a combined average household income of 6,800 manats (10 percent below the city average), and the three lower-income problem districts account for 27 percent of the city's population. Thus transport improvements in these peripheral areas would mainly benefit low-income residents.

\section{Willingness to Pay for Improvements}

Given their high levels of dissatisfaction, what kinds of improvements do households and users wish to see to urban transport, particularly public transport? Households and users show a substantial preference for more frequent buses, followed by bigger buses. These preferences suggest a desire for both greater comfort (more seats, less crowding) and greater safety. Together with more reliable services, these three choices account for more than 80 percent of the first preferences of households and users. Other frequent suggestions were additional routes and cleaner buses. These survey findings were complemented by informal interviews with users that also generated suggestions, including suggestions for more frequent buses and trolleys, shorter intervals, more large buses, control of prices charged by drivers, opportunity to buy bus tickets in advance, new routes, better service to outside regions, and better service 


\begin{tabular}{|c|c|c|c|c|c|}
\hline District & Commuting level & $\begin{array}{l}\text { Transport } \\
\text { dependence }\end{array}$ & $\begin{array}{l}\text { Share } \\
\text { dissatisfied }\end{array}$ & $\begin{array}{l}\text { Share of city } \\
\text { population }\end{array}$ & Type \\
\hline 1 & 4.4 & 18.2 & 83.3 & 2 & \\
\hline 2 & 7.1 & 32.1 & 93.6 & 2 & \\
\hline 3 & 10.7 & 50.0 & 92.2 & 5 & A \\
\hline 4 & 2.2 & 61.5 & 91.7 & 2 & $\mathrm{~B}$ \\
\hline 5 & 10.9 & 48.4 & 83.5 & 3 & \\
\hline 6 & 11.9 & 33.3 & 86.0 & 5 & \\
\hline 7 & 44.1 & 35.8 & 89.3 & 10 & \\
\hline 8 & 1.6 & 26.7 & 100.0 & 1 & \\
\hline 9 & 3.3 & 34.8 & 97.2 & 2 & \\
\hline 10 & 3.8 & 53.6 & 88.1 & 3 & \\
\hline 11 & 23.3 & 74.4 & 85.8 & 20 & $\mathrm{C}$ \\
\hline 12 & 8.0 & 21.1 & 96.6 & 8 & \\
\hline 13 & 10.2 & 49.0 & 92.9 & 7 & A \\
\hline 14 & 8.0 & 48.6 & 95.4 & 4 & \\
\hline 15 & 6.9 & 63.3 & 93.3 & 5 & B \\
\hline 16 & 20.2 & 48.6 & 92.7 & 13 & A \\
\hline
\end{tabular}

Note: Boldface denotes a severe problem, bold italics denote a significant problem. A=high commuting, high dissatisfaction, moderate dependence on public transport: $\mathrm{B}=$ high dependence on transport, high dissatisfaction; $\mathrm{C}=$ high commuting, high dependence on transport, moderately high dissatisfaction.

Source: Household survey.

to local markets. The overall message from these findings is clear: people want urban transport vehicles, especially buses, to serve bus stops more frequently; to follow predetermined, official schedules and itineraries; and to charge fixed, predictable fares. Additional routes are especially important to residents of outlying districts and commuters to the periphery, because these groups experience more severe transportation problems than those who live and work more centrally.

When asked what they would be willing to pay for better service, respondents were almost evenly split between those who were willing to pay more per trip (34 percent), those who were willing to pay the same amount (32 percent) and those who wanted to pay less (35 percent; table 


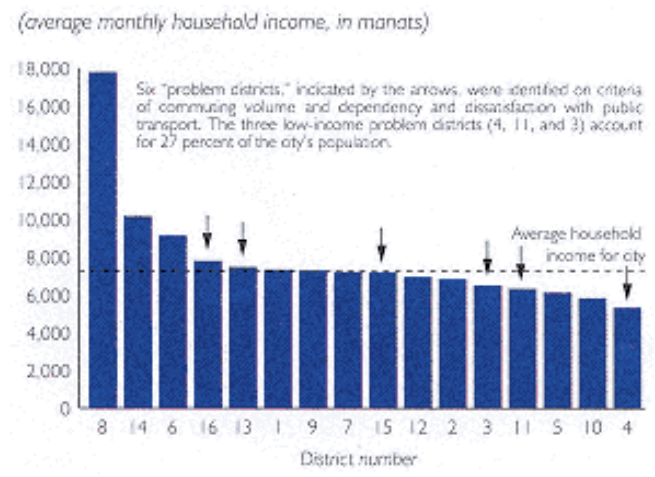

Figure 7.12

Average household income, by district

Source: User survey

7.9). Of course, at the time of the survey, passengers had to pay far more than the official fare. Almost 94 percent of users accepted a fare of 1 manat, twenty times the prevailing official fare; less than 6.5 percent were unwilling to pay that amount. Willingness to pay therefore reveals the local, normative concept of a just or fair price, rather than observed behavior. Unwillingness to pay is just as important a finding, however.17 In many cases people paid fares resentfully, and over the longer term changed their behavior by changing jobs or moving to reduce commuting distance, or by walking to work.

Significantly, willingness to pay per trip was sensitive to the amounts people actually paid. About 79 percent of public transport users paid 2 manats a trip, while 14 percent paid 3 manats or more, 4 percent paid 1 manat, and 3 percent less than 1 manat (table 7.9).

The results of the willingness to pay survey not only gave a rough guide as to what tariff levels the public would accept, they also helped incorporate users' views into the process of economic reforms, cost recovery, and price setting. The findings also drew attention to the poorest users, for whom some kind of safety net had to be considered.

\section{Enterprise Transport}

The estimated 6,000 enterprises and institutions in Ashgabat range from business organizations

Table 7.9 Willingness to pay for transport improvements, by actual trip cost

$\begin{array}{lllllll}\text { Trip cost } & \begin{array}{l}\text { Share of } \\ \text { respondents } \\ \text { (percent) }\end{array} & \begin{array}{l}\text { Average } \\ \text { trip cost } \\ \text { (manats) }\end{array} & \begin{array}{l}\text { Average } \\ \text { amount for } \\ \text { improved } \\ \text { transport that a } \\ \text { group is willing } \\ \text { to pay (manats) }\end{array} & \begin{array}{l}\text { Share of } \\ \text { respondents willing } \\ \text { to pay more } \\ \text { (percent) }\end{array} & \begin{array}{l}\text { Share of } \\ \text { respondents willing } \\ \text { to pay same } \\ \text { (percent) }\end{array} & \begin{array}{l}\text { Share of } \\ \text { respondents } \\ \text { willing to pa } \\ \text { less (percent }\end{array} \\ \begin{array}{l}\text { Less than } 1 \\ \text { manat }\end{array} & 3 & 0.16 & 2.00 & 100 & 0 & 0 \\ 1 \text { manat } & 4 & 1.00 & 4.00 & 70 & 26 & 4\end{array}$


Social Assessments for Better Development

$\begin{array}{lcccccc}2 \text { manats } & 79 & 2.00 & 3.00 & 33 & 36 & 31 \\ \begin{array}{l}3 \text { manats or } \\ \text { more }\end{array} & 14 & 13.58 & 4.00 & 14 & 12 & 74 \\ \begin{array}{l}\text { All } \\ \text { respondents } \\ (803)\end{array} & 100 & 3.47 & 3.00 & 34 & 32 & 35 \\ & & & & & \end{array}$

Source: Household survey.

and government departments to public and private factories and farms. Official figures indicate that about 280 of these enterprises offer transport services to some or all of their employees. According to informal interviews with many households and workers, however, enterprise transport services had deteriorated in the months before the survey. The ninety-two enterprises surveyed during the social assessment represented a wide range of activities and owned or operated nearly 1,800 vehicles. Almost 90 percent of enterprises own cars (an average of 4.2 vehicles for enterprises that own them), 52 percent own buses (average of 1.9), and 7 percent own minibuses (average of 2.4). More than 88 percent of the enterprises surveyed say that they own these vehicles because of the nature of their work. Provision of transport service to workers is significant: of the 20,000 workers employed by the ninety-two enterprises, 24 percent use enterprise buses to go to work, 55 percent use public transport, and 5 percent use their own car.

The unsatisfactory urban transport situation adversely affects the productivity of enterprises. Employees sometimes arrive late for work because of transport problems. Employment instability results when employees switch jobs every time they move to keep commuting distances short. Evening and early-morning work in enterprises is only possible through self provisioning of transport, because publicly owned vehicles rarely operate between 9 p.m. and 6 a.m. Many employees, especially those working in restaurants and hotels, must be taken home by enterprise-owned or rented vehicles after work, because no public transport is available after hours. More than 48 percent of the firms and institutions surveyed said that transport problems adversely affected productivity, while 32 percent said that this might be the case. Only 20 percent saw no connection between the quality of public transport and their productivity.

Enterprises are unwilling to strengthen their role as providers of transport to their employees. Many enterprises complained about high operating and maintenance costs for their vehicle fleet, the lack of spare parts, and the fact that drivers of enterprise buses often use the vehicles off-hours for private commercial activities. About 40 percent of enterprises that own transport vehicles would prefer to stop offering this service but are reluctant to do so because alternative urban transport arrangements do not exist. As a result most enterprises have a great interest in an improved urban transport system.

\section{Private Cars}

Almost 14 percent of workers use a private car to go to work, although this does not necessarily indicate vehicle ownership because commuters may share transport.18 The vast majority ( 79 percent) of car users are men, most of whom use their private cars mainly for their own commuting needs. In most cases only one household member uses the household car to go to work; other household members either walk or use other transport modes. For this reason the income difference between car users and others is not statistically significant.

Low household income does not necessarily prevent car ownership. Many enterprises sell their old vehicle stocks to employees at low prices or allow employees to use enterprise cars in exchange for repair and maintenance. Although car owners may pay for vehicle upkeep and even make extra income by provid- 


\begin{tabular}{|c|c|}
\hline Characteristic & Response \\
\hline Use car as taxi regularly & 4.5 \\
\hline $\begin{array}{l}\text { Number of times a week these } \\
\text { households take passengers }\end{array}$ & 21.3 \\
\hline Average charge per life (manats) & 46.2 \\
\hline Would like to use car as taxi & 12.9 \\
\hline $\begin{array}{l}\text { Would not consider using car as } \\
\text { taxi }\end{array}$ & 77.4 \\
\hline $\begin{array}{l}\text { Did not respond to the taxi } \\
\text { question }\end{array}$ & 5.2 \\
\hline $\begin{array}{l}\text { Think that roads in neighborhood } \\
\text { are bad }\end{array}$ & 88.4 \\
\hline Have problems finding spare parts & 45.8 \\
\hline Think fuel is too expensive & 20.6 \\
\hline Have trouble finding repairman & 10.3 \\
\hline $\begin{array}{l}\text { Have other problems with regard } \\
\text { to car }\end{array}$ & 28.4 \\
\hline $\begin{array}{l}\text { Average expenditure on repairs } \\
\text { and fuel per month (manats) }\end{array}$ & 3,482 \\
\hline
\end{tabular}

Note: Of households surveyed, 27 percent claim to own a car.

Source: Household survey.

ing unofficial taxi services, only a small minority do so. Car-owning households had an average monthly income of about 9,500 manats, compared with 6,600 for households without a car. This difference is close to the cost of maintaining a private car (table 7.10).

Official municipal figures reported 6,500 private cars in 1994, an 8 percent increase from 1993, but the actual number is hard to determine. The social assessment data indicated about 30,000 private cars-almost five times the official figure. The larger figure is based on the claim by 27 percent of the households surveyed to own a car, and there are about 111,000 households in the city. This large discrepancy between official data and the social assessment may have occurred because some households acquired a vehicle after the official figures were compiled. But even correcting for an assumed annual growth of 810 percent and a time lag in official figures only brings the number to 7,0008,000. One factor that would deflate the high survey figure is the use of enterprise vehicles as personal vehicles by employees, which may have led their users to claim ownership of them during the survey.19 Still, the official figure appears to be a severe underestimate, and the actual figure is probably three to 


\section{Social Assessments for Better Development}

four times higher (that is, 20,00025,000).

Whatever the figure, an increasing fleet of private cars serves as informal taxis throughout the city. According to interview respondents, people resort to private carriers when they need to bring along cargo, such as merchandise for the market, and for journeys over longer distances. The driver usually charges 50 manats for a passenger with cargo. Without cargo the fees range from 1020 manats, depending on the length of the ride. Despite the potential for considerable extra earnings from taxi services, only 4.5 percent of households use their car regularly as a taxi, with an average of twenty-one lifts a week. Another 13 percent of households is seriously considering using their car as taxi. According to the respondents, the main deterrents to a more widespread supply of informal taxi services are the perceived high price of fuel, the lack of available spare parts, and, most of all, the bad condition of roads (table 7.10). Because the potential earnings from the provision of transport services could be well over 4,000 manats a month-more than enough to cover fuel and standard maintenance and repair expenses $(3,500$ manats) - the unavailability of spare parts and the bad condition of roads remain the only real barriers to wider use of private cars for taxis for those willing to do so.

This finding is reinforced by the fact that 72 percent of households, car owners or not, consider their neighborhood road infrastructure to be unsatisfactory. Only in district 11 is the satisfaction rate above 50 percent. Ten districts have satisfaction rates between 10 and 40 percent, and in five districts $(1,2,3,8,12)$ more than 90 percent of residents are unsatisfied. When the data are weighed by district population, the highest number of unsatisfied households is found in districts 11,16, 7, 13, and 14 (figure 7.13). The problem, once again, is more acute in peripheral

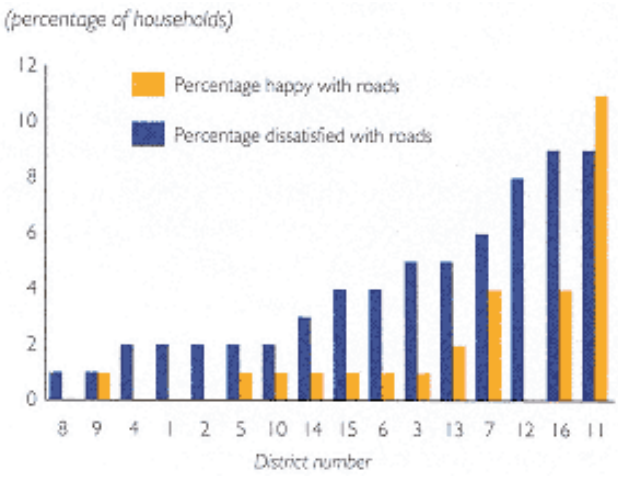

Figure 7.13

Satisfaction with road infrastructure, by district Source: Household survey.

areas, especially in the north and northwest (districts 6,1,2,3) and in the southeast (districts 11, 13, 14, and 16). These are also the zones in which road infrastructure improvements are most needed.

Despite the reluctance of most households to use their cars for commercial purposes, the informal taxi fleet has grown rapidly. About 1,350 private units-about 1 for every 100 workers-ply Ashgabat's streets offering transport services to the public.20 If barriers to market entry are lowered (for example, through improvements in roads and road infrastructure) and the 13 percent of interested households begin offering taxi services, this number may rise to 5,100 vehicles (or 1 per 30 workers). Such a development could have profound implications for the restructuring of the urban transport system, especially the taxi sector. 


\section{Social Assessments for Better Development}

\section{Summary and Analysis of Findings.}

An overwhelming majority of public transport users are unhappy with public transport services.

Roots of dissatisfaction. The social assessment clearly shows that people in Ashgabat rely heavily on public transportation. Every day about 160,000 citizens - nearly a third of the population-use public vehicles for a variety of activities. Buses and trolleys are in especially high demand, with 50 percent of the city's workforce and 84 percent of transport users relying on these two modes of transportation. Bus and trolley users usually belong to low-income groups. This is especially true for female riders, who are more likely to use buses and trolleys than minibuses, taxis, or enterprise transport. Residents and users are as dissatisfied with the current public transport situation as they are dependent on it. Ninety percent of interviewed users and 85 percent of surveyed households are unhappy with public transportation services.

Dissatisfaction is rooted in four main problems:

Vehicle frequency. Vehicle frequency, especially of buses and trolleys, is greatest in the morning and decreases as the day goes on, with little improvement during evening rush hours. Transport slows down even more on weekends, while demand falls only slightly.

Costs and willingness to pay for improvements. Eighty percent of cash-paying passengers were paying 2 manats or more for a single bus or trolley trip - at least forty times the official tariff in February 1995 and four to five times the tariff after the April upward revisions. Many transport users were reluctant to invest in the theoretically cheaper monthly bus-trolley passes (currently 30 manats) because unreliable bus and trolley schedules could force them to revert to minibuses or taxis, depriving them of an acceptable return on their outlay. Users also avoided passes because fares sometimes changed depending on the time of day or the itinerary determined by the driver. A third of the users interviewed were unwilling to pay more for an improved system, but 93.5 percent would accept a 1 manat increase in bus and trolley fares.

Service to the urban periphery. Although users throughout the city suffer from the transport system's shortcomings, outlying districts—particularly those in the south and southeast—seem to be the worst off and seem to require a much tighter, more reliable transport network.

Road infrastructure. Poor roads deter many private car owners from using their vehicles as informal taxis, a move that would provide an important supplement to public transportation. More than 70 percent of households are unhappy with their local road infrastructure. Bad road conditions are a particular concern in northwestern and southern peripheral districts.

Private taxis. The official taxi service is complemented by a fleet of about 1,350 private taxis. This informal transport resource could grow rapidly if car maintenance tools and spare parts were more widely available and road conditions improved. Informal taxis play an important role during periods when public transport is infrequent, especially during weekends. At the same time these taxis could be serious competitors to official taxis, especially once the official taxis are privatized and government subsidies are

stopped, as suggested in the proposed project. There is currently no mechanism to ensure that informal taxis follow road safety procedures and pursue environmentally sound operations.

The labor market and the role of enterprise transport. Confronted with the current unsatisfactory transport system, many Ashgabat workers end up looking for employment near their homes, as documented by the high number of walkers (20 percent of all workers). If they have to move, they are likely to look for another job in their new neighborhood. Many enterprise managers report that labor allocation is inefficient (transport concerns 


\section{Social Assessments for Better Development}

outweigh comparative skill advantages) and moving-related job turnover rates are high. Enterprises also suffer from having to operate and maintain an expensive transport vehicle fleet to complement inadequate public transport services.

Importance of urban public transport for the poor and women. Improvements in public transport (whether publicly or privately managed) - particularly improvements in bus and trolley services — will directly serve the needs and interests of low-income groups, especially women.

\section{Project Implications}

The social assessment consulted Ashgabat's urban transport stakeholders widely in its surveys. It revealed the breadth and depth of popular dissatisfaction with urban transport, especially with the public transport system, informal fare structures, and reduced transport availability during evening rush hours. These findings led Ashgabat's public transport management to embark on a process of internal reform. Managers identified changes that could be made to policies and procedures under their control, in contrast to policies and procedures requiring national government action or external financing. These internal reforms were initiated within a month of the social assessment, even before the formal written social assessment report was transmitted. By the time of the follow-up mission (September 1995) an impressive array of changes had been instituted, and public dissatisfaction had been reduced markedly.

\section{Policy Dialogue}

The social assessment identified two specific measures to be considered by the transport authorities to improve cost recovery:

Raising current official bus and trolley tariffs from 0.5 to 1 manat, while leaving the minibus fare of 2 manats unchanged. As a safety net for the 6.5 percent of users who cannot afford these tariffs, monthly passes could continue to be sold for 30 manats. 21 Once fares stabilized, the price for regular monthly passes could be raised to cost recovery levels, and special low-price passes could be made available to the poorest segments of the population. $\underline{22}$

Creating incentives for drivers to stop overcharging riders and collecting itinerary-specific fare adjustments to stabilize official tariffs and prevent revenue leakage. Such incentives could take the form of salary increases, special benefits and rewards for adequate job performance, tighter supervision, and strictly enforced disciplinary measures if regulations are violated.

The social assessment also pointed to measures that would restore and maintain public confidence in the public transport system. It indicated that the improvements suggested above must be accompanied by a strong community outreach and public information program. Official itineraries and fares should be announced through the media. Schedule and itinerary information should be clearly posted at bus stops and inside vehicles. Buses should carry numbers and destination signs. Finally, tickets and monthly passes should be widely available throughout the city at sales offices known to the public. These relatively low-cost measures would help users make more informed choices about transport modes while demonstrating to the public that a clear effort was being made to provide better transport services.

Urban public transport management has become more aware that additional financial resources are important, both from external financing and from improved cash generation by operations. At the same time urban transport services could be improved significantly 


\section{Social Assessments for Better Development}

through structural and operational changes. Reforms instituted by management in the wake of the social assessment included:

Substantially raising bus drivers' salaries, thus reducing the incentives for them to supplement their incomes by exploiting the public, and increasing the differential between the salaries of drivers and those of other occupational groups. At the same time transport supervisors were designated to ride on buses to monitor the behavior of drivers, and drivers who appropriated money given as fares faced dismissal. Other disciplinary measures were instituted to control poor performance, including a more systematic approach to the lunch break problem (that is, the problem of workers not returning to work after the lunch break). These carrot and stick reforms resulted in a marked improvement in driver performance and hence in service to the public.

Increasing the nominal fare of 5 tenge a trip by a factor of ten, to 50 tenge. Because the social assessment revealed that, in practice, people had been paying twice the new amount, the burden on the poor was halved, yet management had begun a process of cost recovery. Moreover, the liquidity situation of various transport modes improved substantially. Because coins were in short supply, books of twenty tickets were made available to the public so that passengers were able to pay the actual nominal fare.

Keeping more vehicles in service as a result of improved liquidity. This, together with improved driver performance, allowed management to improve bus scheduling. As a result buses began displaying routes and fares.

Strengthening of internal management and personnel.

Legalization and regulation of private taxis. Given the important role private taxis can play in filling the transport gap, this segment of the market should be regularized to some degree-say, through annually renewable licenses and flat license fees - but not to the point of a severe crowding out of the existing stock. Once the efficiency and capacity of urban transport is restored, more elaborate measures and regulations can be implemented. Little seemed to have changed in this area by September 1995.

Transport and the labor market. The quality and efficiency of urban transport has direct economic implications for the city's labor market and enterprise productivity. Because inflexible public housing policies and legal barriers restrict people from choosing the location of their residence, their job choices are heavily influenced by the quality and efficiency of public transport. An improved urban transport system would allow for better, more efficient functioning of the labor market (especially important during the ongoing period of economic transformation and privatization) and help enhance enterprise productivity.

The September 1995 review of the social assessment discussed the following policy and procedural steps: $\underline{23}$

Publicizing the results of the social assessment. This step would acknowledge the widespread dissatisfaction that had existed among users of urban public transport.

Proposing possible solutions to transport problems and discussing them with stakeholders. These stakeholders include both those involved in the solutions-the users-and those involved in implementing the solutions-management and workers, including drivers and mechanics.

Pointing out that tariff increases, in conjunction with other reforms, would reduce the real costs of urban transport. Low fares did not mean cheap transport, especially for the poor. The social assessment showed that people were paying up to six times the official tariff because of very high informal tariffs, or had on many occasions effectively been denied the transport they needed. Poor cost recovery, in turn, exacerbated a vicious cycle of problems: transport companies could not afford vehicle maintenance or adequate salaries for drivers, leading to a large number of vehicles off the road as well as abuses and inefficiencies. 


\section{Social Assessments for Better Development}

Improving the quality of service. Consumers needed to be convinced that tariff increases would result in better service. Early tariff

increases, essential to fund transport operations, could come from service improvements that did not require major investment, such as further operational, maintenance, and institutional reforms. Later tariff increases might have to await more costly capital investment, such as in the rehabilitation and replacement of vehicles. $\underline{24}$

Ensuring a social safety net. Users in special categories who truly cannot afford the full tariff-such as students, the very poor, or pensioners-need to be assured continued access to public transport, while transport companies require a transparent and timely mechanism to compensate them for carrying passengers at reduced tariffs.

By contributing a stakeholder analysis to the project preparation phase and by researching and presenting the behavior and views of the public and other stakeholders, the social assessment has set a precedent for the continued involvement and consultation of stakeholders and for ensuring that the urban transport system serves the needs of the public. Thus the findings of the social assessment are very much part of an active and ongoing policy dialogue with the government of Turkmenistan.

\section{Implications of the Social Assessment}

The findings of the social assessment provide guidance on alleviating such problems in Ashgabat's urban transport system as vehicle frequency, cost recovery, poor service in peripheral areas, and bad road infrastructure. The results of the assessment also show that such technical and physical improvements alone will not solve Ashgabat's problems.

Vehicle frequency. This problem can be addressed partly through the purchase of more vehicles (especially the large buses preferred by most users), the rehabilitation of existing vehicles, and-most of all—better schedule and itinerary planning. Users may receive substantial benefits from a step as small as the better timing of drivers' lunch breaks, a problem reported by most survey supervisors. The greatest need for higher vehicle frequency is during the evening rush hours and on weekends. To address the issue of vehicle frequency, the social assessment supports including components to purchase new buses, to rehabilitate and selectively replace existing vehicles, and to provide technical assistance for management and transport planning in the proposed project.

Cost recovery. The case for cost recovery and its relation to improved service and value for money was made in the preceding section. The social assessment supports a progressive move to cost recovery in the public transport system, in conjunction with improved service and the abolition of unofficial fares.

Improved service to the urban periphery. Given the lower income levels in the southeastern peripheral zones, where the greatest need for transport service has been identified, a reinforced urban transportation fleet for the city outskirts should be considered based on technically feasible and cost-effective solutions.

Selective improvement to road infrastructure. As a parallel measure to the provision of more vehicles to outlying districts, possible improvements in access roads could be considered after technical and economic assessments. Such improvements could include relatively inexpensive elements of traffic infrastructure (lighting, traffic lights, and clearly marked bus stops).

Importance of institutional reform. The results of the social assessment show that physical and technical improvements alone — such as the purchase of additional vehicles and better vehicle maintenance-will not solve Ashgabat's urban transport problems. It became obvious from the surveys that people want and need a bettermanaged transport system. Thus institutional reform measures must be an integral component of the proposed World Bank project. 


\section{Social Assessments for Better Development}

The longer term: road infrastructure and people's needs. The social assessment provides strong support for the proposed project to focus on improvements to public service vehicles, thus enhancing transport quality to match the price paid by transport users. In the longer term, investment in the urban road network and infra-

structure will be essential to make transport improvements sustainable. Such future investment should also take into account the perspective of all stakeholders, including the majority of low-income residents who do not travel by private car and the proportion of workers (currently 20 percent) who walk. Thus such improvement efforts should include already identified needs, such as street lighting, adequately designed sidewalks, and sheltered bus stops with seating. More important, such efforts may help influence which areas get served and what types of roads are priorities. Urban road infrastructure, like public transportation, is a social need that requires a social assessment.

\section{Notes}

The task manager of the social assessment and main author of this chapter is Ayse Kudat. Professor Vincy Fon of the George Washington University contributed substantially to data analyses and prepared the first draft of the social assessment. Klaus Moeltner helped with additional analyses and graphical work. J. Keith Rennie edited the manuscript, with the assistance of Yvonne Dobbelmann. Stan Peabody designed and supervised the user survey. The field work for the assessment was carried out by Ovezdurdi B. Muhammetberdiev, professor of sociology at the Turkmen State University and general director at the Education and Spirituality Renaissance Fund (Galkynysh Fund), and by Maya Atabalovna Atajanova, professor at the Academy of Sciences in Ashgabat. They were assisted by eighty-one interviewers, coders, and supervisors. Computer analysis was undertaken by Gavril M. Bulgakov of Turkmen State University, Eugeny Stroganov, and Alexandre Shikhberdievich.

Task Manager Yusupha Crookes supported the social assessment throughout the project preparation process. Financial assistance to carry out the assessment was provided by the Fund for Innovative Approaches in Human and Social Development.

1. Officially, Ashgabat's work force is 176,000 people. However, the social assessment estimated that about 220,000 people work in the city. The difference between these two figures can be explained partly by outdated official statistics and partly by the growing informal sector participation of the labor force. Unfortunately, no official or other reliable sources of data are available to verify this finding.

2. Four teams of five interviewers were managed by a field supervisor who reviewed and completed interview schedules and conducted verification visits to selected interviewed households. Interview schedules were coded almost simultaneously, which facilitated feedback and quality control, sometimes resulting in revisits to households to clarify ambiguous responses. Interviews were conducted over two weekend days and one work day (Saturday, Sunday, and Monday) to maximize the possibility of finding people at home. The questionnaire is reproduced in annex 2 of the original draft of the report.

3. Throughout this document the term bus stop is used in a broad sense and refers to all locations in town where public or private transport vehicles stop regularly. 


\section{Social Assessments for Better Development}

4. The user survey of 1,084 respondents at bus stops was conducted by three teams of three people over four days (Friday evening, Sunday, Monday, and Tuesday morning). The two 7.5-hour shifts, from 6:30 a.m. to 2 p.m. and from 2 p.m. to 9:30 p.m., included both rush hours and slack times. Each team covered approximately one-third of the city, sampling both primary and secondary bus stops. During the first night shift it became clear that the roving approach was unproductive after about 7:30 p.m. because too many bus stops were unlighted and unpopulated. On subsequent nights each team moved between three or four designated intersections to catch people moving in and out of the city center.

5. The sample is believed to be adequate for a general understanding of the situation and for making rough estimates but is inadequate for more rigorous analysis.

6. With respect to public satisfaction and specific transport practices, the findings of the social assessment are reported in the past tense because of the changes introduced as a result of the assessment. More enduring social characteristics, such as household composition and income, are reported in the present tense.

7. Exclusively as used in this text refers to a situation in which a worker uses one specific mode of transport to get to work, with or without additional walking. In the 566 households surveyed, 1,094 workers (of 1,121) provided information on their modes of transport. Working household members could mention up to three modes, including walking, that they use regularly for their commute.

8. That is, comparing the incomes of users from the user survey with those of working people in households, from the household survey.

9. Because these figures come from the user survey, they exclude walkers and users of private transport (car, taxi, enterprise transport).

10. Walkers, as well as users of taxis and private cars and, to a large extent, users of enterprise transport, are not captured by the user survey, which was conducted at public bus stops. Accordingly, the household survey gave a lot of attention to these groups.

11. Throughout this chapter, the term journey is used to describe the entire commute from home to

work. Trip refers to individual segments of this commute. Thus a journey can consist of more than one trip.

12. Ashgabat citizens work an average of 5.3 days a week, and do not work most of the weekend.

13. A vehicle frequency analysis was conducted as part of the supervisor survey. The number and type of vehicles arriving at or passing a bus stop were captured in fifteen-minute intervals during three periods of the day: peak morning (6:30 a.m.-9:30 a.m.), peak evening (3:30 p.m.-6:30 p.m.), and off-peak hours (between morning and evening peaks and late evening), and on the weekend. 


\section{Social Assessments for Better Development}

14. The quartile ranges were $0-40,000,40,001-60,000,60,001-95,000$, and more than 95,000 manats a month.

15. Comfort and safety were not major topics of investigation, but the February 1995 social assessment generated information on these topics from various sources, including questionnaire data and informal observation. The driver survey in June contained specific questions on these topics.

16. A district's commuting volume is measured by its share of all commuters' destinations and its share of all commuters' starting points. Figure 5.11 a shows each district's average of the two numbers. This number may be compared with each district's share of the city's population (figure 7.11d).

17. For tabular survey results of priorities for improvement and willingness to pay for improvements, see annex tables A.9 and A.10 in the original draft of the report.

18. Car is used here to mean private vehicle, including cars, trucks, and small buses.

19. The survey did not ask respondents in whose name the vehicle was legally registered. The interpretation of misleading claims to private ownership of enterprise vehicles is supported by the fact that the enterprise survey found that 5 percent of workers were using their own vehicles to commute, while the household survey showed almost 14 percent doing so. Yet the two surveys agreed on the total percentage of workers using either a private car or an enterprise vehicle (29 percent). Ride sharing was not investigated in detail by the two surveys, so projections from the commuters' use of private cars to private ownership is uncertain.

20. This calculation is based on an estimate of 110,000 households, of which 27 percent own cars, of which 4.5 percent use these cars as taxis on a regular basis.

21. Additional consideration should be given to the 36 percent of respondents who recently reported that they find 30 manats too expensive. Since this figure is based on a rather small sample of observations, affordability issues could be considered based on the most recent income figures available for vulnerable groups such as pensioners and the disabled. Adjustments have been made to salaries and wages, but information concerning the implications of these changes for pensions was not available when this report was written.

22. If subsidies are needed, they should be provided by the government, not by the suppliers of transport services.

23. Two meetings were held in September 1995. The first was with transport and Ashgabat city officials; the second was a subregional social science meeting attended by transport officials, complemented by discussions with senior government and city officials.

24. Data on family incomes and transport tariffs suggest that workers pay 0.5 percent of their salaries for urban transport—a very low figure by international comparison. 


\title{
8- \\ Rehabilitating the Kyrgyz Republic's Power and District Heating Services
}

\author{
Eugen Finkel and Helen Garcia
}

Asocial assessment was carried out as part of the preparation of the Kyrgyz Republic's Power and District Heating Rehabilitation Project. ${ }^{*}, 1$ The objectives of this assessment were to analyze patterns of fuel use for distinct groups of rural and urban households, evaluate implications of higher energy costs for residential consumers, outline elements of an energy strategy for different types of households, and design a social safety net to protect the lowest-income households from increased energy costs.

The assessment, undertaken in collaboration with local experts, consisted of the following activities: in-depth interviews and focus group discussions with low-income consumers, representatives of nongovernmental organizations (NGOs), and government officials; data analysis of the Kyrgyz Republic Household Energy Survey; and a survey of 150 households using district heat in the city of Bishkek undertaken in June 1995 to appraise residents' capacity and willingness to pay for heating and hot water. $\underline{2}$

The combined effect of the recent increases in coal and liquified petroleum gas prices and the proposed higher tariffs for heat, hot water, electricity, and gas will have a major impact on household energy users in the Kyrgyz Republic, particularly among the poor. To mitigate the adverse social effects of these price increases on vulnerable groups, the government should put in place a suitable social safety net. The social assessment found that such a safety net would require the provision of subsidies to the lowest-income consumers, particularly urban households using district heating and natural gas for heating, and on urban and rural households using coal, firewood, and dung for heating.

\section{Patterns of Household Energy Use}

The social assessment found that differences in fuel use patterns in the Kyrgyz Republic are associated with three factors: in urban areas, access to district heat and access to the natural gas network; and in rural areas, availability of an outside stove for cooking. Based on these factors, households can be classified into groups and subgroups of energy users beyond the broad distinction of rural and urban households, providing a more precise picture of fuel use patterns among different types of households (figure 8.1). Urban households can be divided into households with access to the district heating network (core urban households) and households without access to this network (semiurban households). These two groups can be subdivided into subgroups with access to the natural gas supply network and subgroups without access to this network. The resulting four subgroups of urban households have distinct patterns of fuel use (figures 8.2 and 8.3).

Rural households can be divided into households owning a stove for cooking in their yards and households not owning such a stove. $\underline{3}$ These two subgroups of rural households also show distinct patterns of fuel use (figure 8.4). The identified patterns of fuel use of the different households were a key frame of reference for data analysis. 


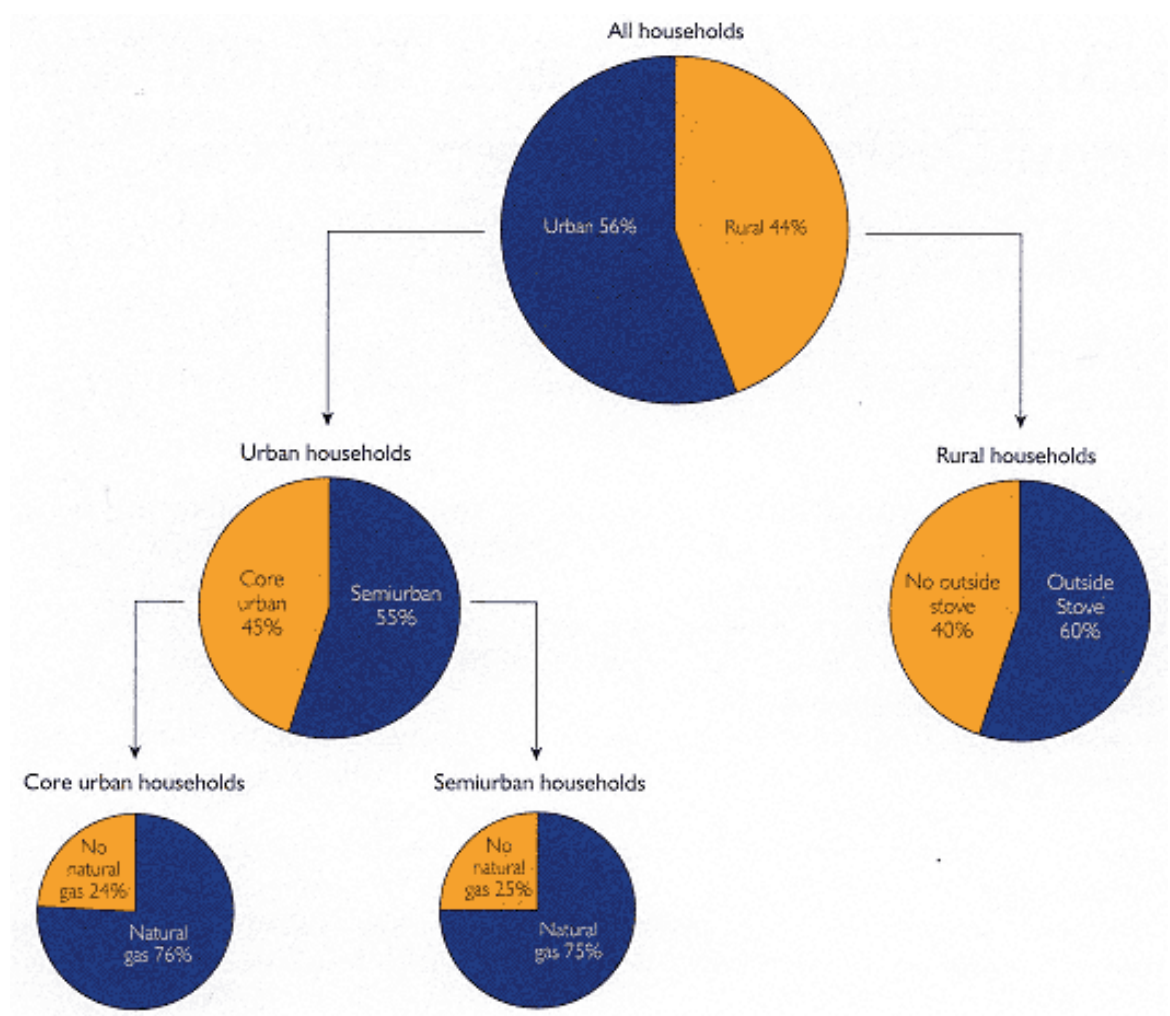

Figure 8.1

Overview of households in the Kyrgyz Republic, by pattern of fuel use Source: Kyrgyz Republic Household Energy Survey 1994.

\section{Core Urban Households.}

Core urban households - the group of urban households with access to the district heating network—constitute 25 percent of the households in the Kyrgyz Republic. The vast majority of these households live in apartment buildings located in the central parts of cities. Eight of ten core urban households are in Bishkek, which has the largest district heating network. Other households are in cities that are also connected to the district heating network, namely Karakol, Karakul, Kyzil Kiya, and Osh.

Although all core urban households use district heating as their principal means of space heating, their access to the natural gas network determines their fuel use patterns for cooking and water heating (table 8.1). 4 Households with access to the natural gas network use natural gas year-round almost exclusively to cook their main meals, breakfast, and snacks as well as to heat water (mostly for hot beverages such as tea and coffee). Natural gas is also used to supplement district heating. Focus group discussions with district heat customers found that households often use their gas-fired cooking stove to supplement district heating. By contrast, households without access to the natural gas network use electricity to cook and to heat water (again, mostly for tea and coffee). Liquified petroleum gas and firewood are also used to some extent.

\section{Semiurban Households}

Semiurban households have no access to district heating. Most of these households are freestanding, private houses located in the outskirts of cities. The fuel use patterns of these house- 


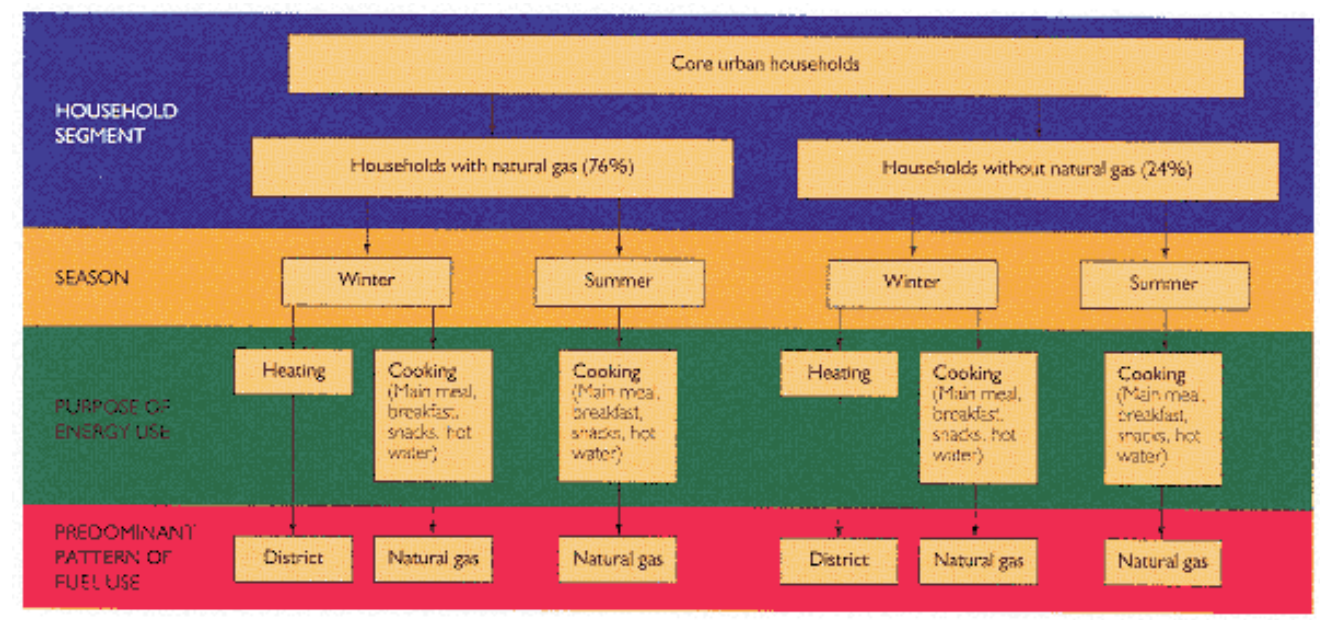

Figure 8.2

Fuel use patterns in core urban households

Note: District heating includes the provision of hot water.

Source: Kyrgyz Republic Household Energy Survey 1994.

Table 8.1 Household fuel use, by subgroup

(percentage of households)

\begin{tabular}{|c|c|c|c|c|c|}
\hline & Core urban & & Semiurban & & \\
\hline $\begin{array}{l}\text { Type of fuel and } \\
\text { use }\end{array}$ & $\begin{array}{l}\text { With } \\
\text { natural gas }\end{array}$ & $\begin{array}{l}\text { Without natural } \\
\text { gas }\end{array}$ & $\begin{array}{l}\text { With } \\
\text { natural gas }\end{array}$ & Without natural gas & Rural \\
\hline \multicolumn{6}{|l|}{ District heating } \\
\hline Space heating & 100.0 & 100.0 & n.a. & n.a. & n.a. \\
\hline Water heating & $100.0 \mathrm{a}$ & $100.0 \mathrm{a}$ & n.a. & n.a. & n.a. \\
\hline \multicolumn{6}{|l|}{ Natural gas } \\
\hline Space heating & 13.1 & n.a. & 96.2 & n.a. & n.a. \\
\hline Cooking & 100.0 & n.a. & 100.0 & n.a. & n.a. \\
\hline Water heating & 93.1 & n.a. & 98.1 & n.a. & n.a. \\
\hline \multicolumn{6}{|l|}{ Electricity } \\
\hline Space heating & 8.5 & 29.3 & 3.8 & 21.1 & 11.6 \\
\hline Cooking & 6.9 & 90.2 & 7.7 & 65.2 & 49.7 \\
\hline Water heating & 6.2 & 85.4 & 1.9 & 55.3 & 40.7 \\
\hline
\end{tabular}


Social Assessments for Better Development

\begin{tabular}{|c|c|c|c|c|c|}
\hline Space heating & 0 & 0 & 0 & 0 & 0 \\
\hline Cooking & 0 & $24.4,17.0 \mathrm{~b}$ & 0 & $57.8,45.3 b$ & $27.8,16.6 b$ \\
\hline Water heating & 0 & 9.8 & 0 & $26.7,16.8 b$ & $8.3,5.3 b$ \\
\hline \multicolumn{6}{|l|}{ Coal } \\
\hline Space heating & 0 & 0 & 7.7 & 92.5 & 65.9 \\
\hline Cooking & 0 & 0 & 0 & 71.4 & 54.3 \\
\hline Water heating & 0 & 0 & 0 & 73.3 & 54.3 \\
\hline \multicolumn{6}{|l|}{ Firewood } \\
\hline Space heating & 0 & 2.4 & 3.8 & 64.6 & 86.4 \\
\hline Cooking & 0 & 12.2 & 1.9 & 39.8 & 86.8 \\
\hline Water heating & 0 & 12.2 & 1.9 & 38.5 & 84.1 \\
\hline \multicolumn{6}{|l|}{ Dung } \\
\hline Space heating & 0 & 0 & 1.9 & 8.7 & 74.5 \\
\hline Cooking & 0 & 0 & 0 & 15.5 & 77.2 \\
\hline Water heating & 0 & 0 & 0 & 17.4 & 77.5 \\
\hline \multicolumn{6}{|c|}{ n.a. Not applicable. } \\
\hline \multicolumn{6}{|c|}{ a. The district heating system includes provision of hot water. } \\
\hline
\end{tabular}

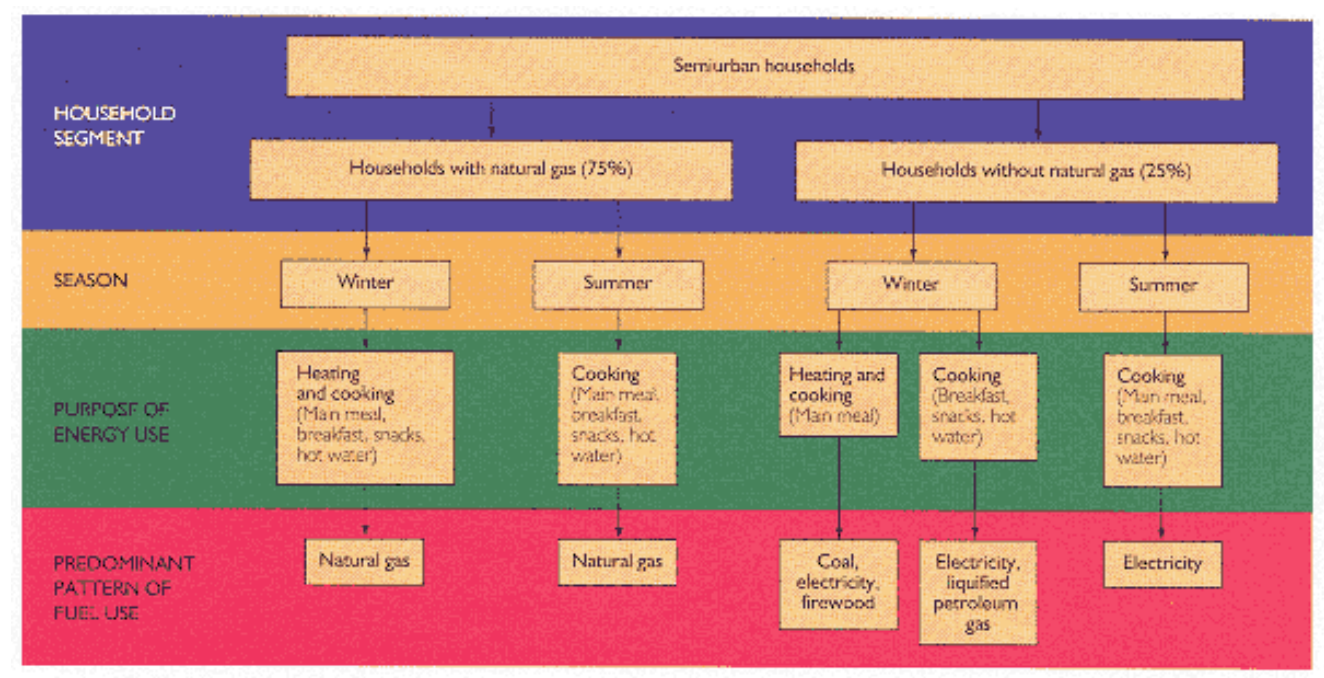




\section{Social Assessments for Better Development}

Figure 8.3

Fuel use patterns in semiurban households

Source: Kyrgyz Republic Household Energy Survey 1994.

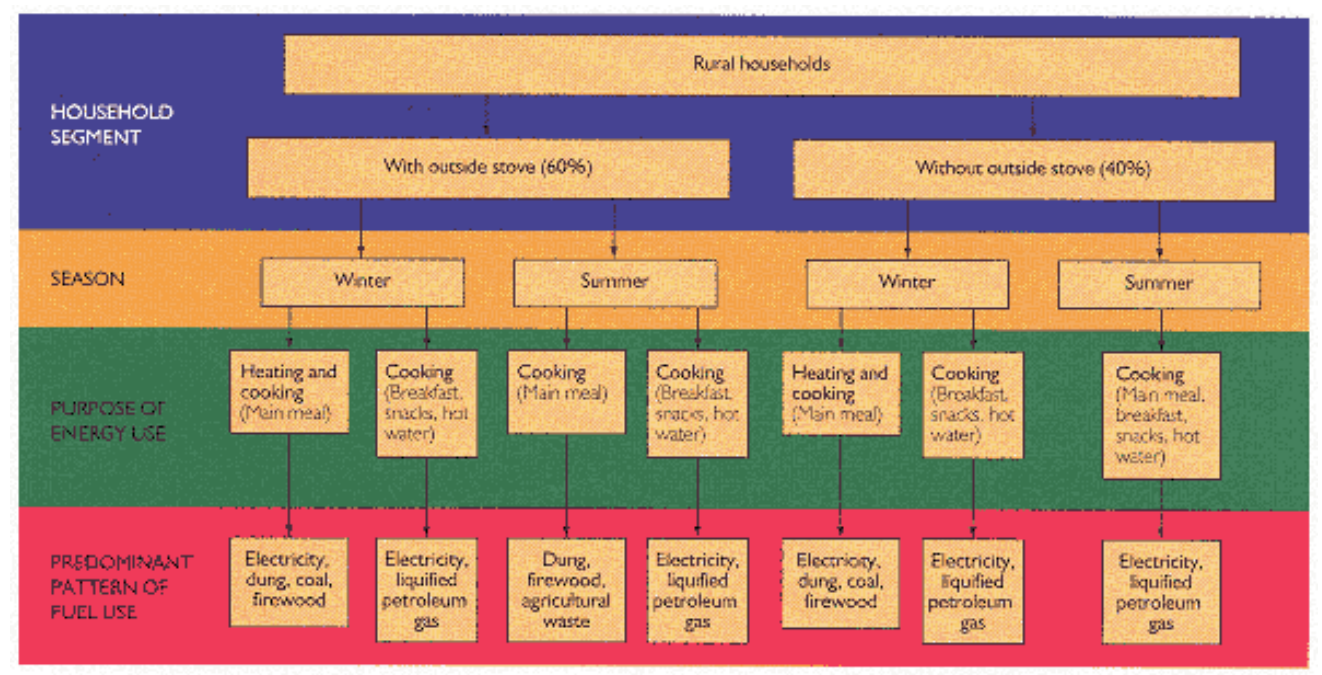

Figure 8.4

Fuel use patterns in rural households

Source: Kyrgyz Republic Household Energy Survey 1994.

holds are also largely determined by access to the natural gas network. Those with access to the natural gas network use natural gas for space heating, cooking, and water heating-almost exclusively in both winter and summer. Other fuels like electricity, coal, firewood, and dung are less frequently used. Households without access to the natural gas network have a much more diversified fuel use pattern, characterized by distinct seasonal variations. During the winter these households use coal and electricity primarily for space heating and to cook main meals, with firewood used as an important complementary fuel, in combination with coal.

Moreover, households use electricity or liquified petroleum gas to cook breakfast and snacks and to heat water for coffee and tea. During the summer electricity is primarily used to cook the main meals, breakfast, and snacks and to heat water.

\section{Rural Households}

Rural households have more complex patterns of fuel use than core urban and semiurban households. They rely on a wider range of fuels because they do not have access to district heating or to the natural gas network. Coal, firewood, dung, electricity, and liquified petroleum gas are the fuels rural households use most (see table 8.1). Qualitative information from the field further revealed that households owning a stove for cooking in their yards - about 60 percent of rural households - follow a different seasonal pattern of fuel use than households that do not own a stove. $\underline{5}$ During the summer households with stoves cook their main meals on those stoves burning firewood, agricultural waste, and dung, while households that do not own stoves mainly use electricity and liquified petroleum gas (see figure 8.4).

According to local experts, there has been a massive shift to dung, electricity, and firewood use for heating and cooking because of the recent increases in coal and liquified petroleum gas prices. Similarly, the household energy survey found that more than one-third of rural households now use dung as their main heating fuel (table 8.2). In addition, nearly three-quarters of households are using more dung for space heating and cooking than 
before the increase in coal prices and two-thirds are using

Table 8.2 Main heating fuel used by semiurban households (without natural gas) and rural households

(percentage of households)

$\begin{array}{lll}\text { Fuel } & \text { Semiurban } & \text { Rural } \\ \text { Coal } & 88.8 & 59.6 \\ \text { Electricity } & 5.6 & 2.6 \\ \text { Firewood } & 1.9 & 4.0 \\ \text { Dung } & 1.2 & 33.3 \\ \begin{array}{l}\text { Liquified } \\ \text { petroleum gas }\end{array} & 0.6 & \text { n.a. }\end{array}$

n.a. Not applicable.

Source: Household Energy Survey, Kyrgyzstan, 1994.

more electricity for the same purposes (table 8.3). Despite the reported increase in the use of electricity, local experts believe that electricity consumption in rural areas is underreported because of the large number of illegal connections.

\section{Implications for the Design of a Social Safety Net}

This section analyzes the implications and potential effects of increased energy tariffs on

Table 8.3 Trends in fuel use by semiurban households (without natural gas) and rural households

(percentage of households)

Fuel use and response Semiurban Rural

Electricity for space

heating

Not used before

Use more now

41.2

65.7

Use same as before

5.9

Use less now

17.6

8.6

Electricity for cooking 


\begin{tabular}{|c|c|c|}
\hline Not used before & 3.8 & 19.3 \\
\hline Use more now & 81.9 & 58.0 \\
\hline Use same as before & 11.4 & 6.0 \\
\hline Use less now & 2.9 & 16.7 \\
\hline \multicolumn{3}{|c|}{$\begin{array}{l}\text { Liquified petroleum gas } \\
\text { for cooking }\end{array}$} \\
\hline Not used before & 22.9 & 44.8 \\
\hline Use more now & 2.1 & 2.3 \\
\hline Use same as before & 10.4 & 4.6 \\
\hline Use less now & 62.5 & 48.3 \\
\hline \multicolumn{3}{|l|}{ Coal for space heating } \\
\hline Not used before & - & 2.0 \\
\hline Use more now & 13.3 & 2.6 \\
\hline Use same as before & 39.3 & 27.0 \\
\hline Use less now & 47.3 & 68.4 \\
\hline \multicolumn{3}{|l|}{$\begin{array}{l}\text { Firewood for space } \\
\text { heating }\end{array}$} \\
\hline Not used before & - & 3.0 \\
\hline Use more now & 12.5 & 34.5 \\
\hline Use same as before & 31.7 & 29.9 \\
\hline Use less now & 55.8 & 32.2 \\
\hline \multicolumn{3}{|l|}{ Firewood for cooking } \\
\hline Not used before & 4.7 & 3.1 \\
\hline Use more now & 35.9 & 33.6 \\
\hline Use same as before & 20.3 & 35.1 \\
\hline Use less now & 39.1 & 28.1 \\
\hline \multicolumn{3}{|c|}{ Dung for space heating } \\
\hline Not used before & 7.1 & 14.2 \\
\hline Use more now & 57.1 & 75.1 \\
\hline
\end{tabular}


Use same as before

28.6

9.8

Use less now

7.1

0.9

Dung for cooking

Not used before

Use more now

76.0

Use same as before

Use less now

8.0

1.3

— Not available.

Source: Household Energy Survey, Kyrgyzstan, 1994.

Table 8.4 Kyrgyz Republic household energy policy matrix

\begin{tabular}{|c|c|c|c|c|c|}
\hline \multirow[b]{2}{*}{$\begin{array}{l}\text { Household } \\
\text { segments }\end{array}$} & \multirow[b]{2}{*}{$\begin{array}{l}\text { Household } \\
\text { subsegments }\end{array}$} & \multicolumn{2}{|c|}{$\begin{array}{l}\text { Monthly energy } \\
\text { expenditure } \\
\text { (som) }\end{array}$} & \multicolumn{2}{|c|}{$\begin{array}{l}\text { Potential impact of tariff } \\
\text { increases }\end{array}$} \\
\hline & & Current & Future & Recent & Future \\
\hline \multirow[t]{2}{*}{$\begin{array}{l}\text { Core urban } \\
\text { households }\end{array}$} & $\begin{array}{l}\text { With natural } \\
\text { gas }\end{array}$ & 58 & 238 & $\begin{array}{l}\text { Moderate } \\
\text { direct } \\
\text { financial } \\
\text { impact due to } \\
\text { gas for } \\
\text { cooking }\end{array}$ & $\begin{array}{l}\text { Strong } \\
\text { financial } \\
\text { impact } \\
\text { Limited scope } \\
\text { for switching } \\
\text { to cheaper } \\
\text { alternative } \\
\text { fuels }\end{array}$ \\
\hline & $\begin{array}{l}\text { Without } \\
\text { natural gas }\end{array}$ & 31 & 219 & $\begin{array}{l}\text { Minimal } \\
\text { direct } \\
\text { financial } \\
\text { impact due to } \\
\text { liquified } \\
\text { petroleum gas } \\
\text { for cooking }\end{array}$ & $\begin{array}{l}\text { Low-income } \\
\text { consumers } \\
\text { may not be } \\
\text { able to afford } \\
\text { their } \\
\text { apartments } \\
\text { any longer }\end{array}$ \\
\hline
\end{tabular}

Project and policy responses

Short term Long term

Subsidy to Reduce hot water

low-income costs by installing consumers for paying heat hot water meters in and hot water introduce apartments; consumption-based billing; promote Lifeline tariff conservation of hot water

Reduce heat losses and save heat costs by improving insulation in buildings and apartments; reduce excessive ventilatio in buildings and apartments

Reduce costs for ga by installing gas meters in apartment 
Semiurban With natural 251

households gas

Without

natural gas
153

175

Second

highest

financial impact due to highest use of coal and liquified petroleum gas

Rural With outside 104 households stove

Highest
financial
impact due to
predominant
use of gas

Moderate impact of higher electricity tariff due to relatively low consumption levels

Strong impact of higher electricity tariff due to high consumption levels

Limited margin for switching to cheaper fuels (dung, firewood)

131

Without $\quad 104 \quad 131$ outside stove

introduce

consumption-based billing; promote conservation of gas

Subsidy to low-income consumers for paying gas bill

Lifeline tariff

Reduce costs for ga by installing gas meters in apartment introduce consumption-based billing; promote conservation of gas

Subsidy to low-income

(Outside project context) consumers for purchase of coal

Strong impact of higher electricity tariff due to second highest level of electricity consumption

Broad margin

Shrinking for switch to margin for cheaper fuels switching to (dung, cheaper fuels firewood) (dung, firewood)

Advantage of outside cooking stove

Third highest financial
Subsidy to low-income consumers for purchase of coal

Lifeline tariff
(Outside project context)
Subsidy to low-income
(Outside project context) 


$\begin{array}{lll}\begin{array}{l}\text { impact due to } \\ \text { elevated use } \\ \text { of coal and } \\ \text { liquified } \\ \text { petroleum gas }\end{array} & \begin{array}{l}\text { electricity } \\ \text { tariff due to } \\ \text { highest level } \\ \text { of electricity } \\ \text { consumption }\end{array} & \begin{array}{l}\text { consumers for } \\ \text { purchase of } \\ \text { coal }\end{array} \\ \begin{array}{l}\text { Broad margin } \\ \text { switch to } \\ \text { cheaper fuels } \\ \text { (dung, }\end{array} & \begin{array}{l}\text { Shrinking } \\ \text { margin for }\end{array} & \begin{array}{l}\text { switching to } \\ \text { cheaper fuels } \\ \text { firewood) }\end{array} \\ & \begin{array}{l}\text { (dung, } \\ \text { firewood) }\end{array} & \end{array}$

Source: Household Energy Survey, Kyrgyzstan, 1994.

various population groups. It also makes specific recommendations for a social safety net to protect the poor households that will be hurt the most by increased tariffs. As a short-to mediumterm measure, energy subsidies, in the form of coupons, will be provided to eligible low-income households using district heating, natural gas, and coal. Over the long term a cost-effective program on household energy efficiency and conservation is proposed as a follow-up measure to ensure that reforms in the district heating sector are sustainable. Table 8.4 summarizes these policies and programs.

\section{District Heating and Hot Water}

About half the urban population in the Kyrgyz Republic is provided with heating and hot water from the district heating network, the main source of heating for this population. Other fuels-like coal, gas, heating oil, liquified petroleum gas, kerosene, and dung — are not used for heating.

Households connected to the district heating network are the urban group most affected by an increase in tariffs. These households spend an average of 20 som a month on district heating (table 8.5). With the proposed tariff increases, core urban households will experience a staggering increase in their district heating bill, to about nine times its current level.

In addition, households will have to pay more for electricity under the proposed tariff structure. Although the impact of higher electricity tariffs will be low for households with gas and moderate for those without gas, the combined increase in fuel prices will have a major impact on households, particularly those in the lowest income group.

The Bishkek survey of district heat customers provided information on household capacity to pay for utilities. On average, 70 percent of

Table 8.5 Average household expenditure on fuel, current and after tariff increase (som per month)

$$
\text { Core urban }
$$

Fuel

With natural

gas
Semiurban

With natural Without natural gas Rural
gas

District heating 


\begin{tabular}{|c|c|c|c|c|c|}
\hline Current & 20.2 & 19.4 & n.a. & n.a. & n.a. \\
\hline After tariff increase & 187.8 & 187.8 & n.a. & n.a. & n.a. \\
\hline \multicolumn{6}{|l|}{ Natural gas } \\
\hline Current & 31.4 & n.a. & 236.5 & n.a. & n.a. \\
\hline After tariff increase & 31.4 & n.a. & 236.5 & n.a. & n.a. \\
\hline \multicolumn{6}{|l|}{ Coal } \\
\hline Current & n.a. & n.a. & 6.6 & 123.3 & 73.3 \\
\hline After tariff increase & n.a. & n.a. & 6.6 & 123.3 & 73.3 \\
\hline \multicolumn{6}{|l|}{ Electricity } \\
\hline Current & 6.8 & 10.0 & 7.5 & 19.6 & 22.7 \\
\hline After tariff increase & 18.4 & 29.1 & 20.6 & 41.9 & 50.3 \\
\hline \multicolumn{6}{|l|}{$\begin{array}{l}\text { Liquified petroleum } \\
\text { gas }\end{array}$} \\
\hline Current & n.a. & 2.0 & n.a. & 7.2 & 5.1 \\
\hline After tariff increase & n.a. & 2.0 & n.a. & 7.2 & 5.1 \\
\hline \multicolumn{6}{|l|}{ Firewood } \\
\hline Current & n.a. & n.a. & 0.5 & 2.4 & 2.0 \\
\hline After tariff increase & n.a. & n.a. & 0.5 & 2.4 & 2.0 \\
\hline \multicolumn{6}{|l|}{ Dung } \\
\hline Current & n.a. & n.a. & - & - & - \\
\hline After tariff increase & n.a. & n.a. & - & - & - \\
\hline \multicolumn{6}{|l|}{ Total } \\
\hline Current & 58.4 & 31.4 & 251.1 & 152.5 & 103.1 \\
\hline After tariff increase & 237.6 & 218.9 & 264.2 & 174.8 & 130.7 \\
\hline
\end{tabular}

n.a. Not applicable (does not use fuel or has no access to fuel).

Source: Household Energy Survey, Kyrgyzstan, 1994.

household spending goes toward food and about 10 percent goes toward energy. Not surprisingly, however, the poorest households spend more on food and energy—about 78 percent and 22 percent, respectively—with nothing 


\section{Social Assessments for Better Development}

left for other subsistence needs (figure 8.5). This finding implies that these households must resort to borrowing money to pay for other essential requirements such as transport, housing, education, and health care. With the ongoing institutionalization of economic reforms in the Kyrgyz Republic, some of which involve cost recovery schemes, households are having to assume increased financial responsibility for the use of basic social services. Clearly, low-income households suffer disproportionately in this scenario.

Low-income customers could be cushioned from higher tariffs for heating and hot water if a subsidy program were developed that protects the poor and the vulnerable while ensuring that they pay what they can afford and that requires high-income groups to pay the real cost of supply. The subsidy design has been guided by the principle of keeping the Kyrgyz National Energy Holding Company (KNEHC) from performing social functions that constrain business performance and of assigning social responsibilities to agencies that are in charge of and qualified to assume them.

The subsidy level is based on the assumption that households should spend no more than 30

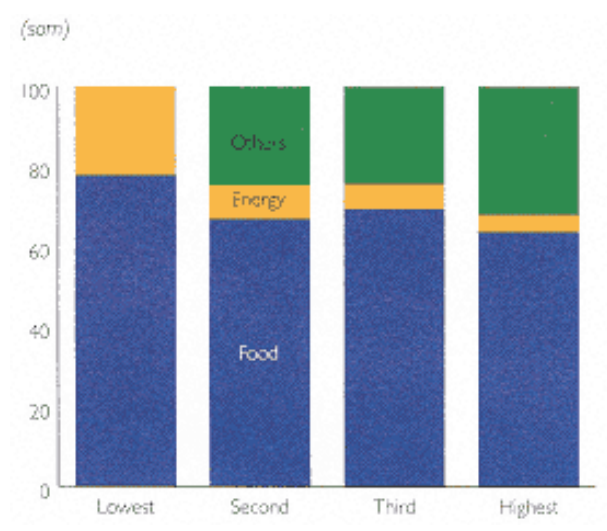

Figure 8.5

Composition of household expenditure, by expenditure group Source: Bishkek subsample survey 1995.

percent of their monthly income on heating and hot water. Thus the portion of the heating and hot water bill above 30 percent will be subsidized.

Although this level is high, even for those with adequate income, it represents a midpoint benchmark based on recent empirical data: the reported fuel expenditure share of 22 percent for low-income households in the Bishkek survey and the expenditure share of about 40 percent for non-food items for poor urban households estimated in the recent Kyrgyz Republic Poverty Assessment. In light of the 40 percent figure, the 30 percent limit for the heating and hot water charge would ensure that the food budget of the poorest households is not jeopardized, although these households will have to make significant adjustments in terms of other non-food requirements. The energy price shocks will be extremely difficult for the poorest households to absorb, particularly because low-cost fuel substitutes are not available.

Considering that some 200,000 households use district heating, and calculating based on income data collected through this social assessment, about 70,000 households will be eligible for the subsidy. This subsidy will amount to about 56 million som a year.

Since the subsidy is envisioned to be phased out over the short to medium term, a more sustainable development program for the district heating sector will have to be considered. This will require the implementation of a follow-up project to help households reduce their heating and hot water costs. Such a project will need to have 


\section{Social Assessments for Better Development}

two major components to increase water and energy efficiency:

1. Modest investments to rationalize the consumption of hot water by installing hot water meters in apartments, introducing consumption-based billing, and promoting the conservation of hot water

2. Modest investments to reduce heat loss by improving insulation in buildings (attic, basement) and apartments (caulking, weatherstripping) levels, and by reducing excessive ventilation in buildings and apartments.

The Bishkek survey found that these approaches could be successful: 82 percent of

district heat and hot water customers would welcome consumption-based billing for hot water, 77 percent would be willing and able to conserve hot water, and 45 percent would be willing to install a meter and pay for it in monthly installments. Of those willing to conserve hot water, 40 percent would be able to cut their consumption by up to 25 percent and 35 percent would be able to save 2550 percent. Differences in the households' willingness to pay for additional heating and hot water costs and for the installation of hot water meters for consumption-based billing are shown in figure 8.6.

\section{Natural Gas}

The subgroup of semiurban households with access to the natural gas network suffers the most from recent fuel price and related tariff increases, particularly for natural gas. These households rely on natural gas year-round as their principal fuel for space heating, cooking, and water heating. They are mostly private houses that are not connected to the district heating network. They have limited means of coping with high natural gas prices because cheaper alternative fuels (like dung) are not available. This segment of the population pays the highest energy bill—an average of 250 som a month, of which gas accounts for 95 percent (see table 8.5).

Gas consumption is not metered. Consumers pay a flat rate based on usage, area of the home, and number of people in the household. This

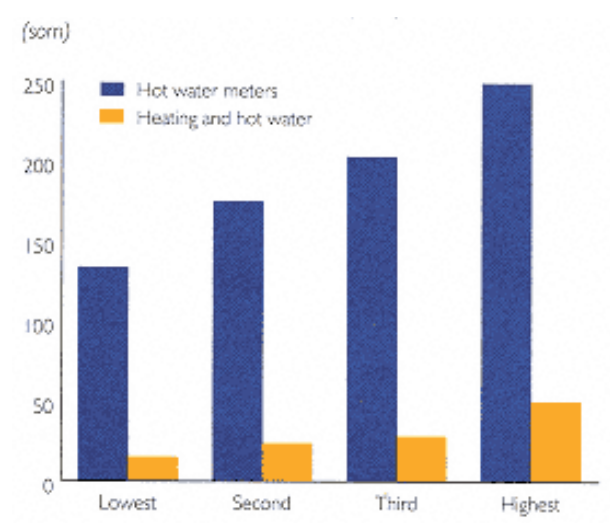

Figure 8.6

Willingness to pay, by expenditure group

Source: Bishkek subsample survey 1995.

system provides no incentive for households to conserve energy, and it puts a higher, often unfair, payment burden on families with more children. The household energy bill of this subgroup could be reduced through the installation of gas meters, introduction of consumption-based billing, and promotion of gas conservation. 


\section{Social Assessments for Better Development}

Low-income semiurban households connected to the natural gas network would be the beneficiaries of the natural gas subsidy. Of the 70,000 households using natural gas for heating and cooking, about 20,000 households would benefit from the subsidy. The subsidy would be provided as coupons to be used against the payment of natural gas bills. The total cost of the subsidy would be about 16 million som a year.

\section{Coal}

Some population groups have been seriously affected by the recent increase in coal prices. The most vulnerable are semiurban households without access to the natural gas network, as well as those rural households for which coal is the main heating and cooking fuel. The survey data found that nine of ten semiurban households without access to natural gas use coal as their main heating fuel. Fewer households (60 percent) depend on coal in rural areas because more than one-third use dung as their main heating fuel.

The coal subsidy for urban and rural households would be targeted primarily to households below the poverty line, comprising 175,000 households in rural areas and 21,000 households in urban areas (that is, semiurban households without natural gas). The subsidy would be given in the form of a voucher to be used against the purchase of coal, equivalent to the cost of 1 ton per household per year. Based on an average retail price of 400 som per ton of coal, the subsidy would amount to 78 million som.

\section{Electricity.}

All households rely on electricity for lighting and household appliances, and some use it as a supplementary heating fuel. The impact of

higher electricity tariffs on core urban households with access to natural gas will be low. For core urban households without gas the impact will be moderate. However, there is limited scope for fuel substitution among core urban households because cheaper, alternative fuels are not available in urban areas. The impact of higher electricity tariffs on semiurban households with access to natural gas will be moderate given these households' relatively low level of electricity consumption. Semiurban households without access to natural gas are the most vulnerable subgroup; their electricity consumption is highest (212 kilowatt hours a month) among urban households—-nearly twice as high as semiurban households with gas.

Many semiurban households access electricity through illegal network connections. As a result use of this fuel has risen significantly. These households also have limited scope for fuel substitution, and their capacity to adopt adequate coping strategies in an environment of increasing fuel prices is seriously constrained by limited access to cheaper, alternative fuel sources.

Rural households will also be significantly affected by higher electricity tariffs because of their high level of electricity consumption. They have a broader scope for fuel substitution than urban and semiurban households given the relative availability of free or low-cost fuel sources such as firewood and dung. But these sources too are coming under increasing demand. Among the households surveyed, 78 percent said that firewood was in great shortage. Firewood is becoming increasingly scarce due to the limited forest cover. Similarly, the dung supply is likely to fall because cattle production in the country has decreased in recent years.

To cushion the impact of higher electricity tariffs on low-income households, a lifeline tariff of 15 tyins (100 tyins=1 som) per kilowatt hour for the first 100 kilowatt hours consumed each month should be subsidized. 


\section{Social Assessments for Better Development}

\section{Targeting Subsidies}

The Ministry of Labor and Social Protection, which administers subsidies targeted to low-income households, will be responsible for implementing the proposed subsidy scheme and social safety net. The technical assistance provided under the Social Safety Net Project will help strengthen the ministry's operational capacity and refine current approaches to targeting.

Eligible residential customers will be required to submit an application for energy subsidy to the ministry's field offices. Applications will be reviewed based on the income test procedures applied in the common monthly subsidy scheme, which targets households with per capita incomes of less than 68 som a month. Approved applications will be reviewed every twelve to eighteen months to ensure that households continue to meet eligibility requirements. These procedures will apply to both the district heating and natural gas subsidy scheme.

Subsidies for low-income district heating and natural gas consumers will be in the form of coupons. Beneficiaries will give the coupons directly to the appropriate utility providers to ensure that subsidies are used only for heating and gas bills. The distribution of vouchers for the purchase of coal will be handled by the Ministry of Labor and Social Protection through its social assistance offices.

\section{Participation}

Public participation is essential for the success of the proposed social safety net and subsidy scheme. The objectives of a participatory approach are to inform the public appropriately, to consult beneficiaries and other stakeholders in order to facilitate qualified contributions from the grassroots level and specialized independent entities, and to enable supervision, monitoring, and control by the public.

To achieve those objectives, the Ministry of Labor and Social Protection will conduct public hearings on the safety net prior to its implementation. The hearings should be carried out both at the central level and at the ministry's field offices in charge of social assistance. Follow-up hearings should be undertaken, preferably after three to four months, to monitor implementation and gather feedback from the public. Invited participants at the hearings, particularly

at the central level, would include NGO representatives and independent specialists. In addition to the public hearings, the public will be periodically informed through the media on payments carried out, number of beneficiaries targeted, and effectiveness of administrative procedures adopted.

This approach will facilitate appropriate information flow, two-way communication with beneficiaries, and contributions, supervision, and monitoring by a wide range of stakeholders.

\section{Cost, Financing, and Implementation of the Subsidy Program}

Direct subsidies for consumers of district heating, natural gas, and coal will total about 150 million som a year (56 million som for district heating and hot water customers, 16 million som for natural gas customers, and 78 million som for coal, firewood, and dung users). Financing for this subsidy could come from an additional tax on gasoline. Considering that 300,000 tons (375 million liters) of gasoline were consumed in 1994, the additional tax would be 0.4 som a liter over the current retail price of 3.2 som a liter.

\section{Notes}


* The fieldwork for this social assessment was undertaken by Eugen Finkel with assistance from local consultants Sagyn Ismailova and Medet Sultanbaev. Statistical analysis was done by Helen Garcia in collaboration with Eugen Finkel. Klaus Moeltner assisted in the preparation of earlier charts and graphs. The paper benefited from helpful comments by Salem Ouahes and Ayse Kudat. Special thanks are extended to the European Union for the use of data from their Kyrgyzstan Household Energy Survey.

1. District heating is a central system of providing heating to a community or a set of communities, managed by the district administration.

2. This Household Energy Survey, undertaken in October 1994 by the Energy Advisory Group and financed by the European Union, generated a sample comprising 686 urban and rural households. The June 1995 user survey provided data on income and on household expenditures on food and energy. The average income of a household with access to district heat is 920 som a month. The average monthly income of a one-person household is 397 som; a two-person household, 713 som; a three-person household, 822 som; a four-person household, 1,212 som; and households with five or more people, 1413 som. It is remarkable to see that 22 percent of the households using district heat in Bishkek earn 1,200 som a month.

3. These breakdowns are based on qualitative information provided by local experts.

4. Hot water is also provided as part of district heating. The survey results showed, however, that 93 percent of core urban households with a gas connection use natural gas to heat water, mainly for making hot beverages such as coffee and tea. Among households without natural gas, 85 percent use electricity for this purpose.

5. The 1994 Kyrgyz Republic Household Energy Survey used in this social assessment did not have data on ownership of stoves for use in yards among rural households.

\section{9- \\ Overcoming the Ravages of Tajikistan's Civil War}

John S. Schoerberlein-Engel

The violence that shredded the fabric of Tajikistan society during the 1992 civil war was the result of the long-term breakdown of the social structures that sustained social order.* Of vital importance to Tajikistan's reconstruction is rebuilding its physical infrastructure as well as rebuilding the social network by which society sustains itself under normal circumstances. Without social reconstruction, the population will be unable to facilitate and implement other forms of reconstruction in Tajikistan. Unless the problems that sparked the civil war are addressed, further conflict will ensue.

\section{Historical Background}

The civil war began in southwestern Tajikistan in May 1992. It reached its height in November and December with the storming of the capital, Dushanbe. By February 1993 the conflict was reduced to scattered fighting and extreme tension throughout the country. The specific event that led up to the war may be traced to rioting in Dushanbe in February 1990. However, the roots of the conflict extend further back in the Soviet period-a period 


\section{Social Assessments for Better Development}

that imposed on Tajikistan society a series of oppressive social disruptions. Community organization was severely disrupted, particularly under Stalin when the country underwent a rapid transformation to state-run agricultural production. This is especially true in the southwestern region of Tajikistan, where the civil war began and was most severe.

Southwestern Tajikistan, comprising the former provinces of Kölab and Qörghanteppa, 1 was sparsely populated at the start of the Soviet era. In 1924 Qörghanteppa-about 1.5 percent of what was to become Tajikistan-contained 15,450 people. By 1981 the province's population had reached 799,000, about 20 percent of the republic's total population (the population of the republic as a whole tripled during this time). Such growth is common in areas undergoing rapid urbanization, but in Qörghanteppa in 1981 rural residents outnumbered urban residents by nearly $5: 1$.

Dramatic population growth was accompanied by a marked shift in ethnic composition. In 1924 the province was mainly populated by various Turkic-speaking groups (including Uzbeks, Turkmens, and Laqays). Tajiks accounted for less than one-fifth of the province's population. Although recent demographic data for the province are highly unreliable, it is clear that Tajiks now make up well over half of the population.

These extraordinary demographic changes were the result of massive, involuntary migration within Tajikistan during the two decades following World War II. Southwestern Tajikistan is characterized by low hills and the valleys of tributaries to the Amu-Darya river. In Tajikistan the Amu-Darya, one of Central Asia's three major rivers, constitutes the boundary between Tajikistan and Afghanistan. During the postwar period the Soviet government sought to expand cotton production throughout Central Asia by expanding the amount of land under irrigation. Between 1940 and 1960 the land sown with cotton in Tajikistan increased by 115 percent, from $1,061,000$ hectares to $2,280,000$ hectares.

To support this expansion, it was necessary to import labor into newly irrigated areas. In southwestern Tajikistan most of this labor was brought in from mountainous areas in the east and southeast of Tajikistan-in particular, from Gharm, Qarategin, and Badakhshan. Most mountain populations did not want to abandon their home villages, as the state pressed them to do, but they were told that it would be impossible to develop the economy of the mountain regions. Moreover, the authorities promised that the cotton economy would raise their living standards. Since the labor imported from mountain regions was almost entirely Tajik, the ethnic composition of Qörghanteppa changed considerably.

Although the province's population flourished because of migration and a high fertility rate, living standards remained extremely poor. Cotton production methods were very chemical-intensive, including not just fertilizers and pesticides but also defoliants that were used to increase the efficiency of hand-pickers. These chemicals, as well as the high fertility rates and general poverty, had an extremely detrimental effect on the health of the region's population. Malnutrition among children was widespread, infant mortality rates were very high, and life expectancy, especially for women, was very low.

By the 1970s rapid population growth had intensified pressure on resources. Land was no longer plentiful and unemployment began to rise. Pressures on resources were exacerbated by the severe inefficiency of the state in providing goods and services in the predominantly staterun economy. The population depended on the state distribution network for many essential goods, including flour and cooking oil. By the 1980s the state was proving increasingly incapable of meeting these needs. Economic reforms under Gorbachev brought additional economic hardship in the late 1980s. Finally, with the collapse of the Soviet Union in late 1991, the longdeteriorating economic situation became a full-scale crisis.

This crisis intensified tensions in Qörghanteppa and elsewhere in Tajikistan. Groups that had been displaced by Gharmi and other Tajiks as the majority population—including Özbeks, Laqays, and Uzbek-speaking 


\section{Social Assessments for Better Development}

Arabs-resented the involuntary immigrants for several reasons. As predominantly sheepherding people, indigenous Uzbek-speakers had enjoyed a fair degree of independence from the Soviet system because they derived a significant portion of their livelihood from selling sheep on the private market. Moreover, the expansion of cotton production encroached on valley bottomlands where there had once been rich fodder. In addition, the immigrant population had assumed most of the positions in the expanding Soviet bureaucracy-both on the collective farms on which the new communities were based and in the local government administration. The tensions between these groups manifested themselves, for example, in Gharmi functionaries excluding Özbeks and Arabs from access to positions, resources, and privileges. Yet the overt manifestation of antagonisms that were later expressed during the civil war could scarcely have been anticipated on the basis of this kind of limited rivalry.

\section{Political Context.}

Bureaucratic rivalries also existed between the local administrations in Qörghanteppa and, in particular, neighboring Kölab. Both provinces had had an uneasy relationship with the central administration and had at various times been altered or eliminated as separate administrative units. Qörghanteppa was made subordinate to the capital in 1947, while Kölab persisted as a province until 1955, indicating the greater influence of local government officials there. When these provinces were reestablished in the 1970s as part of a trend toward greater regional autonomy throughout Central Asia, Kölabi was reestablished in 1973, while Qörghanteppa had to wait until 1977. Since then there have been repeated efforts to administratively incorporate Qörghanteppa into Kölab-most recently in 1988. It was an attempt to achieve this end militarily that sparked civil war in Tajikistan in 1992.

The combination of resource stresses, intercommunal tensions, and bureaucratic aspirations that led to the outbreak of warfare in Qörghanteppa quickly spread to other parts of the country. However, a larger political context was also decisive in setting the stage for conflict.

Two political developments were particularly important: challenges to the traditional ruling groups, which were initiated by the democratization movement throughout the Soviet Union; and adjustments in the regional geopolitical order, which followed the demise of the Soviet Union and assertions of independence by the various Central Asian republics.

\section{Opposition Movements}

The development of opposition movements in Tajikistan was closely tied to rising popular dissatisfaction with the economic, health, and other social problems already mentioned, as well as to the old grievances associated with the suppression of native culture, language, and religion under Soviet rule and inequities in political representation and access to resources. Although the development of opposition movements in Central Asia lagged behind similar movements elsewhere in the Soviet Union, by 1989 a number of organizations had appeared - the most important being Rastokhez — that took a critical stance toward government policies.

Rastokhez (meaning renaissance in Tajik) was founded by intellectuals who sought to revive Tajik culture and, in particular, Tajik language, in the face of the severe russianization and sovietization that Tajikistan society had undergone. Specifically, Rastokhez sought to establish Tajik as the republic's national language (in place of Russian) and to increase the language's visibility in higher education, the media, and the culture. In addition, Rastokhez made a number of other political demands at this time, including sovereignty for Tajikistan (though not independence), an end to the Communist Party's monopoly on power, and other economic and social reforms. As a concession to this reformist mood, parliamentary elections were to take place in March 1990, and reformers both within and outside the party appeared likely to win significant support. 


\section{Social Assessments for Better Development}

In February 1990, however, an event occurred that set back reform in the republic for the next year and a half. Rumors circulating in Dushanbe claiming that Armenian refugees from Azerbaijan were being given priority housing led several hundred protesters to the headquarters of the Communist Party to demand an explanation. Housing was a particularly sensitive issue in Dushanbe because many residents had been on waiting lists for more than a decade and it was common for extended families to live in single dormitory rooms. The crowd was told that the first secretary of the party would address their questions, but he failed to appear at the appointed time and contradictory explanations were given for his absence, which enraged the crowd. Conflicting accounts attribute the first incidence of violence to either protesters wielding bricks or militia snipers placed atop surrounding buildings. In any event the militia began shooting on the crowd below, producing a number of casualties.

This event sparked popular rage and mob violence that quickly escalated into three days of general mayhem in the capital. Government and party officials retreated to their protected residential neighborhoods, leaving the rest of the city to be destroyed by mobs. The rioters were reportedly augmented by rural youths. The chaos was eventually quelled by Soviet troops, who in the process killed numerous citizens, many of whom were not participants in the violence.

A state of emergency was declared in an effort to restore order. A curfew remained in effect for well over a year. There was a crackdown on opposition groups, whom the government blamed for the violence, even though Rastokhez and the Islamic leadership played an important role in calming the situation. The elections went ahead in this climate of extreme tension. With the crackdown on opposition groups and a government monopoly on the media, the resulting Parliament was totally dominated by old-guard communists. Little reform took place in the subsequent year and a half, though the opposition gradually became more vocal, bolstered by Gorbachev's glasnost policies. The Democratic Party of Tajikistan was founded in August 1990 by reformers, including many participants in the Rastokhez movement and a significant contingent of former communists. Such defections caused a few members of Parliament to represent this party, but otherwise reform groups had little access to or effect on the running of the country.

\section{Presidential Election}

The turning point for political events in Tajikistan was spurred by the attempted coup against Gorbachev in August 1991. Tajikistan's president and Communist Party had supported the coup and were preparing to crack down on local political opposition. This inspired a massive outpouring of popular opposition to the government, manifested in tens of thousands of demonstrators filling the streets of Dushanbe. As a result the president resigned in September and an agreement was reached to hold the first presidential election in November. Widespread opposition also resulted in a temporary suspension of the Communist Party, though it was promptly recreated under a new name. Large-scale demonstrations, conducted in an extraordinarily orderly and peaceful manner, continued to voice a number of demands, including a call for new parliamentary elections, but no further significant concessions were given.

During the presidential campaign the old guard had a near-complete monopoly on the media. The media described the opposition candidate as a fundamentalist and chauvinist nationalist, though in fact he was a well-known figure with a solidly secular attitude and strong ties to Russian and European culture. The elections were carried out in an atmosphere of intimidation directed at opposition supporters, in some cases even resulting in violence, and there were significant balloting irregularities. As a result the governing party's candidate won the election with two-thirds of the vote.

Demonstrations were called off in the wake of the elections, but government efforts to restrict the opposition led them to start anew within a few months. Opposition demands focused on the resignation of the conservative chairman of Parliament and renewed calls for parliamentary elections. After a series of concessions that were quickly retracted, the demonstrators turned to more desperate measures, including an unarmed attempt to 


\section{Social Assessments for Better Development}

blockade the Parliament in its building until it addressed their concerns.

Meanwhile, the government orchestrated rival demonstrations in support of itself for which collective farmers were bused into Dushanbe from Kölab. Then the president pushed an already tense situation over the brink: He used emergency powers to create a Presidential Guard by arming the Kölabi demonstrators. In the ensuing struggle, the opposition attempted to seize the president and took over television broadcasting. The interior minister and one of the most powerful generals joined the opposition. The president then agreed to form a coalition government in which 30 percent of ministerial positions would be held by opposition figures-the same share of the vote the opposition had won in the presidential elections. Meanwhile, the president retained his post, Parliament retained its composition, and the Communists continued to preside over twothirds of the ministries. Though this new arrangement was achieved by force and the old guard was left largely in place, it might have served as a workable solution until new elections could be organized.

The Kölabi Communist Party leadership, however, took this opportunity to deal militarily with their rivals in Qörghanteppa. In addition, a dimension of outside intervention was decisive in both initiating the civil war and determining its outcome.

\section{New Geopolitical Situation}

Following the collapse of the Soviet Union in late 1991, each of the Central Asian republics gained the status of an independent country. Actual independence, however, remained very much in doubt. For the most part local Soviet military installations and troops remained under central control—especially in Tajikistan. The military remained in Tajikistan for the ostensible purpose of guarding borders with Afghanistan and China, and it declared its neutrality with regard to internal disputes. But when the Kölabi began their offensive against Qörghanteppa, significant amounts of military hardware fell into Kölabi hands. (The claim that it was stolen is implausible, though it might have been sold by local commanders or given over by a directive from higher up.) The Russian military subsequently began to openly support the Kölabi side.

Russia was clearly interested in ensuring a friendly and dependent regime in Tajikistan. Uzbekistan's intervention-which also may have been covert in the earlier stages of the conflict but later become overt - undoubtedly had a similar motivation. Thus when the coalition government was established in Dushanbe in May 1992, the leadership of Kölab refused to recognize it. Leninabad Province, the leaders of which traditionally had dominated Tajikistan politics, also refused to accept the rule of the Dushanbe government. The coalition did, however, find strong support in other regions, notably Pamir (Mountain Badakhshan Autonomous Province), Gharm (the administration of which was directly under Dushanbe), and, most important, Qörghanteppa.

Kölab first declared an economic blockade of the capital, and then initiated a struggle against the coalition government supporters in neighboring Qörghanteppa. The Presidential Guard of Kölabis, though officially disbanded, retained its arms and formed the core of a Popular Front whose goal was to reestablish Communist rule-or more precisely, Kölabi Communist rule. This struggle rapidly became bloody and, furthermore, took on an ethnic dimension. The chief targets of Kölabi military action were the immigrant communities from Gharm, Qarategin, and Pamir regions. They enlisted the support of the local Uzbek, Arab, and other groups, who saw this as an opportunity to redress their secondary status in their home territory. The Özbeks previously had tended to support the Communists because the opposition had been identified with an effort to promote Tajik culture, though such Tajik chauvinism was largely an unsubstantiated accusation made by the Communists.

In any case, all substantive issues in the political debate were clouded by rumor and fear once the bloodshed began. As communities were burned, people were chased from their homes, women were raped, and the death toll mounted into the thousands, retaliations became inevitable. The stresses that had existed from the deteriorating 


\section{Social Assessments for Better Development}

economy and shortages of jobs and resources were augmented by outrage and fear, making virtually every citizen ready to fight for simple survival. Thus communities that had lived in peace came to be mortally opposed. The presence of substantial heavy arms, particularly on the Kölabi side, intensified the rapid escalation of violence.

The first phase of the civil war resulted in a Kölabi victory in Qörghanteppa, which was won at the cost of the nearly total destruction of numerous Gharmi and Qarategini communities and tens of thousands of refugees. The Kölabi forces then turned to capturing Dushanbe. By late October 1992 they had secured the support of the Russian and Uzbekistan militaries, and with the help of air power and heavy weapons the Kölabi Popular Front gained control over much of the country by the end of the year. The early months of 1993 were marked by massive retribution campaigns-including house-to-house searches, summary killings, and the bombing and burning of communities - directed against presumed supporters of the opposition. Skirmishes continued throughout 1993 in the mountains and regions bordering Afghanistan, where many of the opposition had fled. Large numbers of refugees remain in Afghanistan and in states of the former Soviet Union, and others are displaced within Tajikistan. A significant portion of the Gharmis and Pamiris who had been settled in Qörghanteppa fled to the Pamir and Gharm regions, and remain wary of returning for fear of retribution.

Meanwhile, the Badakhshan Autonomous Province (in the Pamir region) and Leninabad Province continue to resist control by the new government. Badakhshan, where the local government favored the opposition movements, has severed most links to the republic. The economic crisis produced by this isolation, combined with the burden of large numbers of refuges, is only alleviated by aid organizations that supply the region with essentials through the Kyrgyz Republic. Leninabad, which initially supported the move to restore conservatives to power, has since shown reluctance to accept domination by a government that has supported the installation of Kölabi officials in every branch of the government and the still overwhelmingly state-run economy.

In sum, the civil war resulted in about 50,000 deaths, or 1 percent of Tajikistan's population.

Some 15 percent of the population was forced to flee their homes, with 10 percent becoming refugees abroad (mainly in Afghanistan, Russia, Uzbekistan, and other parts of the former Soviet Union). Most of these effects were felt in a single region (Qörghanteppa Province) that accounts for less than one-quarter of the country.

Economic production in most of Tajikistan has largely come to a halt, and the state-run distribution network has ceased to function. As a result, the country's inhabitants have severely limited access to basic needs such as building materials, simple medications, and basic foodstuffs. The climate of uncertainty makes entrepreneurs reluctant to risk any private enterprise. The lack of economic output has resulted in a severe shortage of foreign exchange, without which Tajikistan cannot obtain the energy resources needed to bring goods to market or enable production of any kind.

\section{Social Mechanisms for Overcoming the Effects of Civil War}

Tajikistan remains in a state of severe social tension, divided by regional, political, and ethnic loyalties. For reconstruction to succeed, it will be necessary to overcome these rifts and restore the social fabric that enables disparate groups to live together in peace.

For this to happen, there must be high-level initiatives aimed at political accommodation and economic reform. Of equal importance, however, are lower-level, local mechanisms that contribute to social reconstruction. There are four types of such mechanisms: intracommunal and family-based self-help mechanisms, traditional social integration mechanisms connecting various communities; local, community-level interventions (customarily organized by the Soviet state); and mechanisms employed by nongovernmental organizations (NGOs) or private enterprises. 


\section{Social Assessments for Better Development}

\section{Community and Family Networks}

The most immediate social participatory mechanisms available to families and communities are those that exist within families and communities themselves. Such mechanisms accounted for the largest portion of the reconstruction effort that had been completed by October 1993, when World Bank staff undertook a Tajikistan Reconstruction Mission.

Mechanisms of this type include the mobilization of financial, labor, and material resources. Many of the tasks of reconstruction at the family and community level require significant financial resources. Because of severe shortages, the costs of building supplies, transport, and even sustenance have risen sharply. However, communities in Tajikistan are traditionally oriented toward saving. Under normal circumstances families build up their financial and other resources in preparation for the resource-intensive events that punctuate their lives, including weddings, circumcisions, and other community-oriented rituals in which the family incurs great expense hosting an event to which the community is invited. When a son is married, for example, families often make considerable investments, sometimes including the purchase of a car and, with few exceptions, the construction of a new house or acquisition of an apartment. Accumulated resources include cash, building materials, and other materials intended as gifts for the newlyweds.

Although the period of prolonged hardship preceding the civil war diminished the capacity of families to accumulate such resources, there were still considerable reserves available in the community. Only in communities where every home was destroyed was this not the case.

After the civil war the redistribution of these reserves began almost immediately, in the form of informal loans within the family or more formal loans at the community level. In some cases people who had accumulated resources were reluctant to make loans, not only because it potentially interfered with, for example, wedding plans, but also because it is not customary to charge interest on loans between family and friends. But, given the extremely inflationary economy, it had become impossible to recover any significant amount of loaned money. For many people the principle of generalized reciprocity was overriding; that is, they expected, in a generalized way, that the community would provide needed assistance sometime in the future in exchange for any resources they pro-

vided. Others sought to conceal their resources. For people with immediate needs the availability of such resources could be greatly improved if a mechanism were developed in which borrowing is not done face-to-face between relatives or neighbors, but rather through more impersonal arrangements where the payment of interest would be acceptable.

One of the most difficult challenges of social reconstruction is that within communities the atmosphere of generalized reciprocity has been considerably diminished. Many communities were severely traumatized by the many violations of community trust that accompanied the civil war. Moreover, because of the crisis many people reasonably fear that their prospects for survival have been severely diminished. The only way that such problems can be addressed is by restoring the basis for trust within communities by, for example, organizing forums for collective problem solving. Meanwhile, it is of vital importance for long-term security that local officials and community leaders act in a responsible and equitable manner.

Besides financial resources, the reserves that are available in communities include material goods such as food supplies and building materials. Most families are in a more or less perpetual process of construction, adding onto their homes or building new homes for their children. Because building materials are difficult to obtain even under normal circumstances, families often acquire a supply well before an anticipated need. Such supplies were commonly shared with the needy in the aftermath of the civil war. In addition, needs become temporarily redefined under crisis circumstances. A destroyed house often retains some amount of usable building materials. 


\section{Social Assessments for Better Development}

Since it is considered normal for a single household to include two or more nuclear families (including parents and siblings), several families often choose to reside in one house and to use the building materials from other, destroyed houses to reconstruct that house.

Reconstruction tasks of all kinds require considerable labor. In many communities this is not a problem-the economic shutdown resulting from the war made available a large pool of labor. In other communities labor needs must be met in a different manner because many young men have died or because young men remain the targets of retributions and therefore are reluctant to return to their communities. In those cases trust must be reestablished to encourage people to return. Where labor shortages persist, other mechanisms must be used to bring in labor from other areas.

\section{Traditional Cross-Community Social Integration}

Even though the Soviet system was oriented toward making the individual dependent on the state and thus toward diminishing the importance of other support networks — such as the Islamic community, the extended family, the village, traditional professional organizations, and so on—such alternative support networks persisted to a large degree.

One immediately evident form of support provided by Islamic institutions in war-affected areas was in the shelter provided by mosques. Even in communities where all other structures were destroyed, the community mosque often remained intact because it was built from durable materials-usually baked bricks rather than the sun-dried bricks and stucco of most rural domestic construction. More important, mosques were often spared from destruction because they were sacred symbols of a culture common to the warring parties. This in itself indicates the potential for promoting reconciliation between communities.

More concretely, Islamic institutions possess wealth that is pooled on a scale larger than particular communities. These funds could be used for reconstruction. In the period before the civil war Islamic institutions grew rapidly because the government began tolerating greater religious activity. In addition, resources are channeled to the Islamic institutions from abroad. The Central Asian Islamic organizations receive considerable assistance from countries like Iran, Saudi Arabia, and Turkey to expand their infrastructure and religious activities. Thus the Islamic organizations can provide not only resources but also an institutional framework for providing assistance.

Another broad framework for intercommunity assistance derives from the geographical

dislocations imposed during the Soviet era. For instance, the Gharmi communities in Qörghanteppa have sought refuge among their relatives and compatriots in the Gharm region. But since Gharm suffered considerable losses during the civil war and the period of retributions that followed it, other regions are in a better position to assist the Gharmi communities in Qörghanteppa. Pamir, for example, suffered from economic isolation in the period following the war but was spared the direct effects of warfare. Many people fled Qörghanteppa and other regions for Pamir because they or their parents had been relocated from there under Stalin (or later). Now, as they begin returning to their homes, they will have a certain amount of support from the communities that temporarily harbored them.

Other communities in Qörghanteppa severely affected by the civil war include Russians, Ukrainians, Germans, and Kyrgyz. In many cases the assistance that these groups have received from their home communities in Russia, the Kyrgyz Republic, or Germany has amounted to the provision of refuge. It would be of more long-term value, however, for these home communities to provide assistance to these communities to rebuild in Tajikistan. 


\section{Social Assessments for Better Development}

\section{Local Government Mechanisms.}

Some of the local state structures that were put in place under the Soviet system have been among the most effective at rebuilding war-torn communities. The first focus of their efforts was the reconstruction of school houses, clinics, and other public infrastructure. The scarcity of building materials has often made it impossible to complete such reconstruction, and buildings typically have had windows without glass, or have lacked other fixtures, such as doors and electrical lighting. Nevertheless, in many communities such schools were the only habitable structures during the first year following the war, and they were used to house many returning refugees. As of late 1993 it was still impossible to conduct classes in many schools for this reason.

Local government organizational efforts have been the key factor in reconstruction of schools and other public buildings. Also instrumental in getting the job done has been the volunteer labor provided by the communities. These communities have faced severe unemployment because of the depressed economy-a problem in no way alleviated by the use of volunteer labor in the reconstruction of public buildings. Still, local governments could play a similar organizational role in other reconstruction tasks, such as the rebuilding of private housing.

Emergency relief mechanisms developed under the Soviet system involved local governments and large state enterprises organizing work brigades to send to the disaster area. Such initiatives also followed the civil war, though the scope is no longer as broad-work brigades for disaster relief used to come from throughout the Soviet Union, but now they are drawn from other parts of Tajikistan.

The government sending the brigade seeks volunteers, who are paid their normal wages plus a stipend for travel and time away from home. Such brigades not only bring labor but also (in principle) are supplied by their home governments with the materials needed to carry out their designated tasks. Because supplies are scarce and there have been organizational problems in arranging the transport of material inputs over long distances, many of these efforts are considerably less effective than they could be. Experienced development organizations could play an important role in improving the organization of reconstruction efforts of this kind.

Local governments in war-affected areas also have played an important role in general organization, oversight, and implementation of reconstruction assistance. Local governments are well positioned to identify areas and cases of greatest need. The high level of integration and oversight built into the Soviet system of governance means that local governments have extensive records on each household under their jurisdiction. Local governments function on several levels, ranging from provincial and district governments to neighborhood committees. Records for each household are kept in the district government offices, and the neighborhood committees know each constituent household personally. This information network (where it

has not been destroyed by the war) could be a valuable tool for assessing households' needs. These needs include materials and possibly reconstruction loans. Local governments have already played a key role in this capacity, supporting the emergency loan, relief, and reconstruction supplies programs the central government has implemented since the war.

In addition, local governments can play an important role in assessing social tensions in communities and in initiating efforts to overcome them. To play this role effectively, however, local institutions must be seen as even-handed and sincerely concerned about the interests of the community. Many such institutions have a mixed history in this regard - and indeed many individual officials played an active partisan role in the war. The potential for these kinds of problems is increased in the many cases-especially in Qörghanteppa but also elsewhere in Tajikistan - where officials who were sympathetic to opposition forces were dismissed (or fled) and replaced by nonlocal officials based on political criteria. 


\section{Social Assessments for Better Development}

\section{Mechanisms for Involvement of Nongovernmental Organizations}

By overseeing the activities of government institutions, NGOs could play an important role in increasing confidence in these institutions. In recent years there has been growing consensus on the necessity of building the institutions of a civil society. Most of this work has yet to be done, and indeed in many ways the context of general reconstruction is an ideal one for establishing new institutions of this kind.

The basis for such institutions was established during the final years of the Soviet period, when the Children's Fund of Tajikistan, the Women's Association of Tajikistan, the Culture Fund of Tajikistan, and a number of other such institutions were founded. Although initially they were subordinate to Soviet umbrella organizations and were not fully independent from the state, the potential existed for new realms of activity.

To some degree such activity has been taken up in the aftermath of the civil war. The Women's Association, for instance, has played an active role in identifying cases of need and coordinating government assistance. Such activities need to be expanded.

Another important area where independent organizations can play a crucial role in reconstruction is in the provision of essential relief aid and reconstruction materials. Organizations such as the Children's Fund have attempted to provide such assistance, but their resources are extremely limited and their organizational experience is inadequate. Private, forprofit organizations also have played an important (if limited) role in this area. For example, an organization called Tajikistan-Russia has coordinated the import of critically needed raw materials and machinery that are essential to getting key industries back in operation. These organizations have also engaged in purely humanitarian work, for example, providing support to orphanages that care for the children of war victims. The business climate must be improved to enable the success of such enterprises.

\section{Conclusion}

Tajikistan's reconstruction will depend strongly on the efforts of institutions to reweave the country's social fabric. Whether these institutions are traditional, family- or community-based organizations; institutions surviving from the Soviet era; or new, independent nonprofit or for-profit enterprises-it is through such mechanisms that the practical tasks of reconstruction can be accomplished so that the country may be able to avoid such civil strife in the future.

\section{Notes}

* This chapter is based on the author's many years of field work in Tajikistan, for which thanks are owed to innumerable social scientists and members of the communities discussed. The work benefited from a close collaboration with Ayse Kudat.

1. Since the civil war these two provinces have been united and renamed Khatlan Province. The unification and division of these provinces has been repeated several times in the course of Tajikistan's history, representing efforts to consolidate bureaucratic control. These provinces are often cited in Western literature by the Russian corruption of their names-for example, Kulyab for Kölab and Kurgan-Tyube for Qörghanteppa.

10 Enabling the Safe Use of Biotechnology: Principles and Practice

11 Biodiversity and Agricultural Intensification: Partners for Development and Conservation 


\section{Social Assessments for Better Development}

12 Rural Development: From Vision to Action (forthcoming)

13 Integrated Pest Management: Strategies and Policies for Effective Implementation

14 Rural Finance: Issues, Design, and Best Practices (forthcoming)

15 The Economics of Involuntary Resettlement (forthcoming)

16 Social Assessments for Better Development: Case Studies in Russia and Central Asia

17 Expanding the Measure of Wealth: Indicators of Environmentally Sustainable Development

18 Five Years After Rio: Innovations in Environmental Policy

19 Advancing Sustainable Development: The World Bank and Agenda 21

\section{Related ESD Publications}

Monitoring Environmental Progress: A Report on Work in Progress

Nurturing Development: Aid and Cooperation in Today's Changing World

Toward Sustainable Management of Water Resources

Water Supply, Sanitation, and Environmental Sustainability: The Financing Challenge

The World Bank Participation Sourcebook 